\title{
The economics of accounting regulation : effects of Dutch accounting regulation for public accountants and firms
}

Citation for published version (APA):

Maijoor, S. J. (1991). The economics of accounting regulation : effects of Dutch accounting regulation for public accountants and firms. [Doctoral Thesis, Maastricht University]. Maastricht University.

https://doi.org/10.26481/dis.19910517sm

Document status and date:

Published: 01/01/1991

DOI:

10.26481/dis.19910517sm

Document Version:

Publisher's PDF, also known as Version of record

Please check the document version of this publication:

- A submitted manuscript is the version of the article upon submission and before peer-review. There can be important differences between the submitted version and the official published version of record.

People interested in the research are advised to contact the author for the final version of the publication, or visit the DOI to the publisher's website.

- The final author version and the galley proof are versions of the publication after peer review.

- The final published version features the final layout of the paper including the volume, issue and page numbers.

Link to publication

\footnotetext{
General rights rights.

- You may freely distribute the URL identifying the publication in the public portal. please follow below link for the End User Agreement:

www.umlib.nl/taverne-license

Take down policy

If you believe that this document breaches copyright please contact us at:

repository@maastrichtuniversity.nl

providing details and we will investigate your claim.
}

Copyright and moral rights for the publications made accessible in the public portal are retained by the authors and/or other copyright owners and it is a condition of accessing publications that users recognise and abide by the legal requirements associated with these

- Users may download and print one copy of any publication from the public portal for the purpose of private study or research.

- You may not further distribute the material or use it for any profit-making activity or commercial gain

If the publication is distributed under the terms of Article $25 \mathrm{fa}$ of the Dutch Copyright Act, indicated by the "Taverne" license above, 


\section{The Economics of Accounting Regulation}

Effects of Dutch Accounting Regulation

for Public Accountants and Firms 


\title{
The Economics of Accounting Regulation
}

\author{
Effects of Dutch Accounting Regulation
}

for Public Accountants and Firms

\section{PROEFSCHRIFT}

ter verkrijging van de graad van doctor aan de Rijksuniversiteit Limburg te Maastricht, op gezag van de Rector Magnificus, Prof. Mr. M.J. Cohen, volgens het besluit van het College van Dekanen, in het openbaar te verdedigen op vrijdag, 17 mei 1991 om 16.00 uur

door

Steven Jacobus Maijoor

geboren te Hong Kong 
Promotor:

Beoordelingscommissie:
Prof. dr. J.H.R. van de Poel

Prof. dr. J.G. Backhaus (voorzitter)

Prof. H.L. Brink RA

Prof. dr. D.W. Feenstra RA

Prof. dr. C.C.P. Wolff

CIP-DATA KONINKLIJKE BIBLIOTHEEK, DEN HAAG

Maijoor, Steven Jacobus

The economics of accounting regulation : effects of Dutch accounting regulation for public accountants and firms / Steven Jacobus Maijoor. - Maastricht : Datawyse. - Ill. Thesis Maastricht. - With ref.

ISBN 90-5291-050-2

NUGI 683

Subject heading: accounting ; regulation.

Layout: Karin Scheele, A Point, Maastricht

Production: Datawyse, Maastricht / Krips Repro Meppel 


\section{Acknowledgements}

This thesis has benefited from the ideas, criticisms, and data provided by many. It is therefore impossible to identify all who have contributed, and I apologize to those who are inevitably but unintentionally omitted here.

This thesis strongly reflects my discussions with, and training by, Willem Buijink and Jan van de Poel. I am especially indebted to the latter for persuading me to start an academic career and for being a thesis advisor and mentor whose support and encouragement were invaluable. Willem Buijink is especially thanked for the many detailed suggestions and criticisms he gave at all stages of the manuscript, and for teaching me the appreciation of empirical accounting research.

I would like to thank Jürgen Backhaus, Henk Brink, Dick Feenstra, and Christian Wolff for judging the final version of the manuscript and providing useful comments.

I am indebted to a number of people who either commented on (very) early versions of the manuscript or provided perceptive discussions on some of the topics. I would like to thank several collegues at the University of Limburg: Laury Bollen, Tjeu Blommaert, Denis de Crombrugghe, Piet Eichholtz, René Olie, Arnold Schilder, Hein Schreuder, Art Selender, and Eddy Vaassen. I also wish to extend special appreciation to: Ray Ball (University of Rochester), Michael Bromwich (London School of Economics), Kees Cools (University of Brabant), Peter Geilen (Chamber of Commerce Maastricht), Rick Hayes (California State University), Rien van Hoepen (Erasmus University), Frank Stephen (University of Strathclyde), and Stephen Zeff (Rice University).

In addition, a number of institutions gave me valuable data, including the Netherlands Central Bureau of Statistics (CBS), the Dutch Institute of Registered Accountants (NIVRA), the Dutch Chambers of Commerce, and the Ministry of Justice. Financial assistance to print the dissertation was provided by the Staal Stichting 1966.

The editorial comments of Sen McGlinn have greatly increased the readability of the text, and the generous help of Karin Scheele significantly improved the layout.

Most of all, I wish to thank those who contributed to this thesis although they are not experts in the field of accounting research. The support of my friends, family, and especially Mariëlle made completion of this thesis possible. Of course, the usual disclaimer applies.

Steven Maijoor

April 1991 Maastricht 



\section{Contents}

1 Introduction

2 Economic Consequences and Accounting Policy Making

2.1 Introduction to the Economic Consequences Issue

2.1.1 The Economic Consequences Concept

2.1.2 Normative and Positive Analyses of the Consequences of Accounting Regulation

2.2. The Economic Consequences Approach to Accounting Policy Making

2.2.1 Arguments for an Economic Consequences Approach to Accounting Policy Making

2.2.2 Regulators and the Economic Consequences Approach

2.2.3 Arguments against an Economic Consequences Approach to Accounting Policy Making

2.3 Evaluating the Desirability of the Economic Consequences of Accounting Regulation

2.3.1 Evaluating the Efficiency Consequences of Accounting Regulation

2.3.2 Evaluating the Distributional Consequences of Accounting Regulation

2.4 Summary and Conclusions

3.1 Public Interest Theory

3.1.1 Arguments For Accounting Regulation

3.1.2 Arguments Against Accounting Regulation

3.1.3 Empirical Evidence Supporting Arguments For and Against Regulation 
3.2 Private Interest Theory

3.2.1 Private Interest Theory: an Introduction

3.2.2 Application of the Private Interest Theory to Accounting Regulation

3.2.3 Empirical Evidence Regarding the Application of Private Interest Theory to Accounting Regulation

3.2.4 Criticisms and Alternatives

3.3 Comparing the Public and Private Interest Theory

4 Economic Effects of Dutch Accounting Legislation for Registered Accountants in Public Accounting

4.1 Economic Effects of Accounting Regulation for Public Accountants

4.2 Previous Research

4.3 Effects of Dutch Accounting Legislation on the Market for Public Accounting

4.3.1 Effects of Dutch Accounting Legislation on the Size of the Market for Public Accounting

4.3.2 Developments on the Supply Side of the Market for Public Accounting

4.3.3 The Results of Demand and Supply: Income Data

4.4 Other Factors Affecting the Market for Public Accounting

4.4.1 Voluntary Demand for Public Accounting

4.4.2 Concentration of Suppliers

4.4.3 Technological Changes

4.5 Summary and Conclusions

5 Economic Effects of Accounting Regulation for Contracts of the Firm: Dutch Accounting Legislation and Legal Form Choice

5.1 Economic Effects of Accounting Regulation for Firms:

a Contracting Perspective

5.2 Previous Research

5.2.1 Empirical Literature on Financial Accounting and Agency Problems

5.2.2 Dutch Literature on Legal Form Choice

5.3 Effects of Dutch Accounting Legislation on Legal Form Choice

5.3.1 Effects of the 1970 Change on Legal Form Choice 
6.1 Summary

6.2 Strengths and Weaknesses of the Study

6.3 Application of Economic Analyses to Dutch Accounting Regulation

6.4 Suggestions for Further Research

6.4.1 Research on Economic Consequences

6.4.2 Research on the Political Process

Appendix 2.1

References

Nederlandse Samenvatting

(Summary in Dutch) 



\section{Chapter 1 \\ Introduction}

This study will address two main questions: why does financial accounting regulation exist, and how can it be evaluated? Both questions will be approached from an economic point of view. Evidence of the economic effects of accounting regulation can contribute to its explanation and evaluation. This study will provide evidence of the economic effects of Dutch regulations on public accountants and firms.

Before 1970, the financial accounting practice of Dutch firms was still more or less unregulated. For example, no requirement existed for companies to audit their annual accounts, while only a small fraction of them had to disclose. Existing disclosure requirements at the time contained only minimal specifications for the asset side of the balance sheet. In the past 20 years, however, Dutch accounting regulations have expanded rapidly. Today, firms' financial accounting practices are substantially determined by regulation.

Various characteristics of financial accounting practice are now affected by regulation. The number of information items to be disclosed in annual accounts is regulated. There is for example a requirement to disclose a geographical breakdown of sales (section 380-2, Title 9). The measurement of items is to a large extent affected by regulation. An example is the measurement rule which requires that capitalized $R \& D$ costs should be amortized within a maximum period of five years (section 386-3, Title 9). The auditing of financial information is also heavily influenced by regulation. Large private companies are, for example, required to have their annual accounts audited. Regulations also determine which firms are required to disclose. General and limited partnerships are for example not required to disclose. Finally, the frequency of disclosure is affected by regulations. Public companies listed on the Amsterdam Stock Exchange are required to disclose half-yearly reports (sections 28-c and 29 of the Rules Relating to Securities of the Amsterdam Stock Exchange ${ }^{1}$ ).

The current Dutch accounting regulation is only one of many alternative institutional arrangements of the market for accounting information. The

"Fondsenreglement van de Amsterdamse Effectenbeurs. 
number of options is in fact rather large. This becomes apparent when national regulations are compared. For example, in the United States regulation is mainly focused on listed firms. In the Netherlands, these firms constitute just a small fraction of all the firms which are subjected to accounting regulation. A second example is German accounting regulation, which differs significantly from the Dutch regulation despite the European Directives. The German regulation is heavily influenced by tax laws while in the Netherlands this is not the case. The difficulties which have been encountered in harmonizing national accounting regulations show that the differences between the various institutional arrangements are not trivial (see e.g. [Brink, 1989]).

The regulation of Dutch accounting practice has various origins. The main sources are: company law, jurisprudence of the Enterprise Chamber ${ }^{2}$, Guidelines of the Council for Annual Reporting ${ }^{3}$, the Rules Relating to Securities of the Amsterdam Stock Exchange, and instructions of international bodies such as the International Accounting Standards Committee (IASC) and the Organization for Economic Cooperation and Development (OECD). In this study "accounting regulation" is defined as including all the regulations from these various sources which affect the previously mentioned characteristics of financial accounting practice (i.e. the number of information items, measurement of information items, auditing, which firms are subject to regulation, and the frequency of disclosure). By convention, regulation of the competence to audit (i.e. the sole right of registered accountants to audit) falls outside the term "accounting regulation", but it will nevertheless be considered in this study (see chapter four).

The substantial impact of accounting regulation on accounting practice, and the large number of alternative regulatory models are important motives for undertaking this study. A specific accounting regulation can be chosen from a wide variety of institutional arrangements, all with their specific effects on financial accounting practice. This implies a choice problem. Which regulation is the "better" or the "best"? In other words, how can we evaluate accounting regulation? The question is whether current Dutch accounting regulation is "optimal". Serious doubts have been expressed both by academics and regulators. Van der Grinten [1981], for example, raised the matter of the heavy burden of the regulation for firms. He also doubts whether the regulation would meet the cost-benefit criterion. Similarly, Bouma [1988] suggests that Dutch accounting regulation might have passed the "social optimum". Regulators have criticized Dutch accounting regulation in similar terms. During the parliamenta-

${ }^{2}$ Jurisprudentie van de Ondernemingskamer.

${ }^{3}$ Richtlijnen van de Raad voor de Jaarverslaggeving. 
ry discussions of the last main change in Dutch accounting regulation (i.e Title 8 , Book 2 of the Dutch Civil Code), some members of parliament questioned whether this regulation was not going "too far" analysis of the regulation was denounced.

However, the doubt about the "optimality" of Dutch accounting regulation evokes another, more fundamental, question. If it is not clear whether the "best" or "better" regulation has been established, why is it enforced? The policy making process can have many different outcomes. Which outcome is chosen and why? In other words, the issue is how we can explain accounting regulation.

In Dutch accounting literature, the subject of evaluating and explaining accounting regulation is hardly developed [Van de Poel, 1988, p.20]. Dutch financial accounting textbooks are mainly concerned with the interpretation of existing accounting regulation. The latter is treated as a given. According to Traas [1980, pp.208-209], traditional business economic theory is not adequate for supporting the policy making process. He concludes that there is an urgent need for the development of a theory which can contribute to accounting policy making. Klaassen [1978, p.589] advocates more concern with the objectives of accounting regulation. Finally, Bouma [1988, p.285], like Van der Grinten [1981], states that the evaluation of the costs and benefits of accounting regulation deserves more attention.

In the American and British literature, the evaluation and explanation of accounting regulation has received more attention. The analyses are based on all relevant disciplines: economics, law, psychology, history, and sociology. This study will take an economic point of view. Economic analyses consider accounting information and its regulation as economic commodities. Using this view implies that the standard economic analyses of economic goods are applicable. This study will draw heavily on the literature on the economics of accounting regulation. Hence, it is related to the field of public finance, in which there is a long tradition of applying economic analysis to regulation. A major advantage of applying economic analysis is that this discipline has studied regulatory problems for a long time. Problems which seem to be unique and new to the field of accounting, appear to have been dealt with many years ago in economic theory. The achievements of the economic analysis of regulation can be used for the analysis of accounting regulation.

\footnotetext{
${ }^{4}$ See reports of the parliamentary debates of the Second Chamber, 1982-1983, pp.44644480 and pp. $4537-4555$.
} 
Finally, before proceeding with the outline and purpose of this study, some key terms should be defined. The term "financial accounting practice" refers explicitly to the actual decisions and activities of firms, as well as to products of these decisions and activities, in so far as they are concerned with the provision of financial information. The term "accounting legislation" refers to the specific part of accounting regulation which stems from legislation. The term "accounting regulation" has been described earlier in this section. Finally, the term "accounting policy making" refers to the process of designing, establishing and upholding accounting regulation.

\section{Purpose and Outline of the Study}

The initial proposal for this research project, formulated some four years ago, was for a cost-benefit analysis of Dutch accounting regulation to determine its desirability. As the project proceeded, it became evident that employing a costbenefit analysis was not feasible. First, due to information problems, a costbenefit analysis of accounting regulation appeared to be very difficult if not impossible, to implement (see chapter two). Second, more recent developments in the positive economic analysis of the policy making process suggest that we should not be surprised if accounting regulation does not meet the cost-benefit criterion (see Watts and Zimmerman [1986, chapters seven and ten], and chapter three of this study). Hence, the research questions of the project were changed.

The two main questions this thesis attempts to answer are: (1) How can accounting regulation be evaluated?, and (2) How can accounting regulation be explained? In chapters two and three we will see that empirical evidence on the economic effects of accounting regulation can contribute to both the evaluation and explanation of accounting regulation. Therefore, this thesis will make some initial steps towards providing this evidence (chapters four and five).

This study can be viewed as an integration of two fields. One is the BritishAmerican literature on the economics of accounting regulation. The other is the collection of pragmatic knowledge on Dutch accounting practice and its regulation. The specific Dutch institutions require an adjustment of the analyses found in the British-American literature, and also allow the testing of hypotheses that cannot be tested in Anglo-Saxon countries. For example, Dutch financial accounting practice was, until recently, relatively unregulated, and some recent changes in Dutch accounting regulation are very dramatic, in contrast to the frequent but relatively minor regulation changes produced by a "standard by standard" revision process. 
The outline of this thesis is as follows. Chapter two is concerned with the contribution of economics to the evaluation of accounting regulation. It includes a literature review and an empirical study of the extent to which Dutch regulators considered economic consequences when making accounting policy.

Chapter three will review economic explanations of accounting regulation. Both the public and private interest theory of accounting regulation will be discussed extensively. The debate on the efficiency of accounting regulation will be part of the discussion of public interest theory.

Chapters four and five are concerned with the economic consequences of two Dutch laws for two different groups. The two laws are the Act on Annual Accounts of 1970 and Title 8, Book 2 of the Dutch Civil Code of 1983. The two groups are public accountants and firms.

Chapter four will investigate the economic consequences of these laws for public accountants. To generate hypotheses on these effects, a supply and demand framework of the market for public accounting services will be used. Evidence will be provided of the effects of the laws on (1) the actual amount of services supplied and demanded in the market for public accounting, and (2) on the development of the number of suppliers in this market. Finally, some other data on the market for public accounting services will be discussed.

Chapter five will investigate the economic consequences of the two Dutch laws for firms. Both acts make changes affecting the legal form categories (e.g. the public limited liability company and the private limited liability company) which are subject to accounting regulation. An agency framework will be used to generate hypotheses on these effects. Evidence will be presented of the effects of the two Dutch laws on the choice of legal form by firms. The data used are time series based on the total number of firms in various categories of legal forms and the number of firms switching between categories of legal forms.

Chapter six will give a review of this study, including a summary, conclusions, a discussion of the strengths and weaknesses of the study, proposals for future research, and some suggestions for accounting policy making. 


\section{Chapter 2 \\ Economic Consequences and Accounting Policy Making}

The central theme of this chapter will be the contribution of analyses of the economic consequences of accounting regulation to accounting policy making. It will discuss the relevance of empirical evidence on economic consequences, as provided in chapters four and five for Dutch accounting legislation, for designing, establishing, and upholding accounting regulation. Before starting discussing the central theme of economic consequences and accounting policy making, a general introduction to the economic consequences concept will be given. After this introduction, the second part of this chapter will discuss views in the literature and regulators' opinions as to the function of analyses of economic consequences for accounting policy making. The third and last part of this chapter will deal with the evaluation of the economic consequences of accounting regulation.

The chapter proceeds as follows. Section 2.1 , the general introduction to the economic consequences concept, contains the following elements: (1) description, origin and classification of the economic consequences concept, and (2) a discussion of the distinction between normative and positive analyses of economic consequences. Section 2.2 will summarize and discuss views in the literature and regulators' opinions on the function of economic consequences in accounting policy making. An important aspect to consider will be the debate on whether regulators should take economic consequences of accounting regulation into account in the policy making process. In addition, the consideration of economic consequences by Dutch legislators, in relation to the two major changes in Dutch accounting legislation in 1970 and 1983, will be discussed. The parliamentary working papers and reports of debates of both acts were reviewed to determine whether economic consequences were considered by Dutch accounting policy makers. Section 2.3 will discuss the analysis of the economic desirability of the effects of accounting regulation. A distinction will be made between the efficiency effects and the distributional effects of accounting regulation. It will be concluded that it is impossible to assess the desirability of either effect from an economic point of view. The role of the researcher is restricted to

1 This chapter is a revised version of Maijoor [1988]. 
providing evidence of the economic consequences of accounting regulation. It is up to accounting policy makers, or researchers from other disciplines, to judge the desirability of these consequences. Finally, section 2.4 will give a summary and provide conclusions.

\subsection{Introduction to the Economic Consequences Issue}

\subsubsection{The Economic Consequences Concept}

The term "the economic consequences of accounting" has been described as "the impact of accounting reports on the decision making behavior of business, government, unions, investors, and creditors" [Zeff, 1978a, p.56]. Applying this to the regulation of accounting implies that 'economic consequences' are the effects of accounting regulation on the decision making behavior of various parties [Zeff, 1978b, p.19]. In other words, the economic consequences of accounting regulation concern all the differences in decision making between a situation with regulation and a situation without regulation [Bromwich, 1985, p.78]. Other terms for "economic consequences" are "economic impacts" or "economic effects" [Chow, 1983a, pp.73-74]. To illustrate the term "the economic consequences of accounting regulation", examples are given below for the following groups: users of accounting information, producers of accounting information, auditors of accounting information, and accounting policy makers (i.e. regulators).

An example of the economic consequences of accounting regulation for users would be the investor who has made up a portfolio of the stocks of various firms based on his expectations of future cash flows. A regulation is passed which requires firms to disclose information on the distribution of profit over their various lines of business. As a result, the information available to the investor increases and his expectations about future cash flows are revised. The investor decides to change his portfolio according his new expectations about future cash flows.

An example of the economic consequences of accounting regulation for producers is the effect on $R \& D$ spending of a regulation forbidding the capitalization of $R \& D$ expenses. If management is used to capitalizing $R \& D$ expenses, the requirement to expense directly can have a considerable negative effect on the amount of equity reported in the balance sheet. For 
various reasons management wants to avoid this lower reported equity and decides to spend less on R\&D.

An example of the economic consequences of accounting regulation for audirors would be a regulation which prescribes more complex measurement rules and more detailed disclosure. As a result, more working hours are required to audit a firm and the demand for auditing services increases.

An example of the economic consequences for regulators is the effects of regulation on the resources and time spent on enforcing compliance. Assume that in the past compliance was enforced through a mechanism based on the initiative of interested parties. The compliance of a firm was only checked if an interested party asked the regulatory body to do so. The regulator decides to establish an administrative body which checks all annual accounts filed, and as a result the time and resources spent by the regulators on ensuring compliance increases.

Most of the accounting literature on economic consequences is of North American origin. Zeff [1978a and 1978b] was one of the first authors who specifically referred to the economic consequences issue IIngram and Rayburn, 1989, p.62]. Zeff, in his 1978 articles, describes a fundamental change in the accounting literature and the accounting policy making process, starting in the late sixties: the "Rise of 'Economic Consequences'". This change included the following developments: (1) a greater awareness on the part of policy makers of the increasing involvement of outside parties in the standard setting process, (2) a growing literature on the impact of accounting standards on behavior of affected parties, and (3) an increasing body of literature on the growing interest by third parties in the establishment of accounting standards. According to Beaver $[1989$, pp. 17-18], the rise of the economic consequences issue is part of the "Revolution in Accounting" in the United States. The economic consequences issue is strongly related to three revolutionary changes: (1) a shift from an economic income perspective to an information perspective, (2) increased emphasis on the notion that many parties have an interest in accounting regulation, and (3) the recognition that selecting a particular accounting regulation is a social choice. The three changes and their relation to the economic consequences issue will be discussed below. This discussion depends heavily on Zeff [1978a and 1978b] and Beaver [1989].

The first change, the shift towards an information perspective, can be described as follows. Before the shift, regulators and the accounting literature favored the economic income perspective which evaluates accounting information according to the extent to which it approaches the ideal of 
'economic income'. In other words: what accounting information represents the "best" economic income of the firm? The assumption of this approach is that economic income is well defined. There is no explicit treatment of uncertainty in this approach. With the information perspective, the focus is on the use of accounting information for decision making. The normative version of this approach prescribes that accounting information should be useful for decision making. Under this approach, one of the functions of accounting information is to reduce uncertainty about future states. The strong relation between the informational perspective and the economic consequences issue is apparent. If the view is taken that accounting information is used for decision making, factors which change that information will affect decision making. Accounting regulation is one of the factors that can affect the information used by decision makers.

The second change concerns the perception that various groups or constituencies are affected by accounting regulation. Before the "Rise of Economic Consequences", it was assumed that accounting regulation was neutral with respect to its effects, or that regulators were not responsible for those effects [Zeff, 1978, p.20]. During the sixties it was realized, both in the literature and by policy makers, that third parties are affected by accounting regulation. Because parties are affected by the regulation, they have an interest in the choice of accounting regulation. Beaver [1989, p.16] distinguishes the following five main parties with an interest in accounting and its regulation: investors, information intermediaries, financial reporting regulators, management, and auditors. Of course, other parties can be added to the list (see e.g.[Klaassen and Bak, 1990, p.23; Wolk et al., 1989, pp.8-9]). In the Dutch accounting literature, the interests of employees are especially emphasized (see e.g. [Schreuder, 1981]).

The third change, the recognition that accounting regulation is a social choice, can be described as follows. Given that various parties are affected by accounting regulation, accounting regulation has the potential to affect [Beaver, 1989, p.188]:

(1) the wealth distribution among investors and others;

(2) the aggregate level of risk incurred and of risk sharing among individuals;

(3) the rate of capital formation;

(4) the allocation of resources among firms;

(5) the use of resources devoted to the production, certification, dissemination, processing analysis, and interpretation of disclosures;

(6) the use of resources in the development, compliance, enforcement, and litigation of disclosure regulations; and 
(7) the use of resources in the private-sector search for non-public information.

The actual occurrence and magnitude of these effects depends on the particular accounting regulation chosen. Besides, the suggested economic consequences affect various parties in society differently. Hence, the choice for a particular regulation is a choice for particular effects and particular parties in society. Therefore, the choice for a particular regulation is a social choice. It is a political choice that involves making trade-offs between parties in society. This issue will be discussed extensively in section 2.3 .

So far the changes discussed have been strongly related to the origin of the economic consequences issue. Since the "birth" of this issue in the late sixties, a considerable body of research on the economic consequences of accounting regulation has been developed. Research on the economic consequences of accounting regulation has served two objectives [Amershi et al., 1982, pp.19-20]. First, economic consequences are advocated as an input to accounting policy making and have actually been used for accounting policy making. Second, economic consequences are used to explain accounting practice. For example, economic consequences are used to explain lobbying activities, the adoption of certain accounting policies and effects on investment decisions [Ingram and Rayburn, 1989, p.63]. The second objective of economic consequences research will be dealt with in the next chapter, which will discuss the role of economic consequences research in explaining accounting regulation and give an overview of empirical research on economic consequences. This chapter will discuss the first objective: economic consequences as an input for accounting policy making. Before starting this subject, section 2.1.2 will discuss more extensively the division of economic consequences research on the basis of these two objectives. Also, the terms "normative" and "positive" and their relation to the analysis of economic consequences will be dealt with.

\subsubsection{Normative and Positive Analyses of the Consequences of Accounting Regulation}

The distinction between normative and positive accounting research, the validity of this distinction, and the merits of both areas of research have received considerable attention in the literature (see e.g. [Cristenson, 1983; Jensen, 1983; Whittington, 1987; Gaffikin, 1988; Demski, 1988; Walker, 1987; Watts and Zimmerman, 1978, 1979, 1986, and 1990; Whitley, 19881). Dutch scholars have also contributed to this area of research (see e.g. [Barkema, 1988; Van de Poel and Tempelaar, 1987; Van de Poel, 1988; 
Knoops, 1990; Schreuder, 1984; Maijoor, 1990]). Considering the great attention already given to this subject, both inside and outside the Netherlands, only brief comments will be given.

The main factors responsible for starting the discussion on positive and normative issues are the provocative articles by Watts and Zimmerman [1978 and 1979] of the "Rochester School of Accounting"2. They forcefully support accounting research aimed at explaining and predicting accounting phenomena. Because in the past accounting research was mainly focused on giving prescriptions, they strongly oppose this research (the "older" theories are labelled as "excuses"). Watts and Zimmerman's articles were followed by a row of publications opposing and supporting their standpoints on the normative-positive issue.

The discussion in the accounting literature of normative and positive issues is difficult to penetrate ${ }^{3}$. One reason is that there is terminological confusion. Authors use the same term for different concepts, or use different terms for the same concept. As a result, the terms "positive" and "normative" have lost all clarity of meaning [Schreuder, 1984]. A second reason is that the authors refer to different areas of research. For example, some authors refer mainly to the normative-positive discussion in the general methodological literature, while others refer mainly to the normative-positive discussion in the accounting literature (compare for example Schreuder [1984] and Gaffikin [1988]). A third cause of the inaccessibility of the discussion is that most of it is in very broad terms, without examples of the methodological problems of specific studies. From the standpoint of clearness, the discussion would improve if concrete suggestions are given for eliminating the methodological shortcomings of particular pieces of research. For example, the 1978 article of Watts and Zimmerman on firm lobbying for the FASB is frequently referred to by critics of positive accounting research. However, few critics actually provide, or even give specific suggestions for, research

${ }^{2}$ The use of the term "positive" by Watts and Zimmerman, which suggested that they were adherents of logical positivism, fueled the debate. In later publications, Watts and Zimmerman [1986, p.8, and 1990, p.148] explicitly deny that they support logical positivism.

${ }^{3}$ The discussion is centered around criticisms of the methodology of the "Rochester School of Accounting". The main issues concern: (1) positive theories are said to be value-laden, (2) the approach is said to be a "sociology of accounting" instead of an accounting theory, (3) are inappropriate methods used in constructing explanatory theories, (4) their choice of the term "positive", and (5) debate over "proper" methodology [Watts and Zimmerman, 1990, pp.146-149]. 
on firm lobbying for accounting standards that does not have the methodological shortcomings of Watts and Zimmerman's research.

One clear conclusion from the vast normative-positive discussion is that the choice of research methodology by a researcher is subjective. There is no generally superior methodology. As Watts and Zimmerman state [1990, p.149]: "debating methodology is a 'no win' situation". This is not to say that the choice of research methodology is trivial. The choice of research methodology will determine to a large extent the reception of the research by colleagues. It is up to a researcher whether and how he takes this factor into account. It will also determine the opportunities of using research from other disciplines. If a methodology that is current in other fields of research is chosen, some of the achievements of these fields can be imported. The research on regulation in the accounting literature is a clear example of this mechanism. It draws heavily upon the analysis of market regulation in the discipline of economics.

In this thesis the term "normative research" refers to research which is intended to give prescriptions, and the term "positive research" refers to research with the objective of giving explanations and predictions. The value-free criterion is not important for classifying accounting research. All accounting research is inevitably value-laden. Using the suggested definition, the term "positive accounting research" refers to a much larger body of research than it usually refers to in the accounting literature. In general, it refers to the type of research conducted at Rochester, that is, empirically testing economic explanations of accounting using econometric methods. If the suggested, broader definition of positive accounting research is used, the use of other explanations (e.g. psychological, sociological, and historical) and other research techniques (e.g. case-studies, interviews and questionnaires) are also included. Finally, concerning the definitions of positive and normative, the differences should not be exaggerated. For example, there is practically no difference between: (1) a "positive" researcher who is investigating the costs for firms of different types of measurement rules, and (2) a "normative" researcher who is asked by firms to give a prescription as to which measurement rule they should apply if they want to minimize costs. The many cross-references between chapters two and three will make clear that positive and normative research can be very closely related. Using the suggested definitions, this chapter can be described as mainly normative. It will be concerned with the contribution of accounting research on economic consequences to accounting policy making. Chapters three, four, and five are mainly positive. Chapter three will give a review of economic explanations for regulation in the accounting literature. Chapters four and five will 
describe and explain the economic effects of accounting regulation for public accountants and firms.

\subsection{The Economic Consequences Approach to Accounting Policy Making}

This section will discuss the economic consequences approach to accounting policy making. This approach entails that the (expected) economic consequences of accounting regulation should be taken into account by accounting policy makers. In other words, the (expected) economic consequences should affect the outcome of the policy making process. This section proceeds as follows. First, section 2.2 .1 will discuss the arguments provided in the literature, supporting the economic consequences approach. Next, section 2.2.2. will discuss whether the economic consequences are actually considered by policy makers, focusing especially on the policy making process leading to the 1970 and 1983 Dutch legislation. In the final section, the views of those who argue against making economic consequences an input in the process of formulating accounting policy will be discussed. This section will also discuss the "credibility" or "map making" approach, which is frequently supported by opponents of the economic consequences approach.

In contrast to section 2.3 , which is on the evaluation of economic consequences, this section is concerned with: (1) views in the literature as to whether the economic consequences of accounting regulation should be considered by regulators, and (2) whether regulators actually consider economic consequences. But supposing that regulators are willing to, and do in fact, consider economic consequences, how are they to judge the desirability of these consequences? Section 2.3 asks whether it is possible, when making accounting policy, to sum up the various economic effects of accounting regulation and judge the desirability of the sum.

\subsubsection{Arguments for an Economic Consequences Approach to Accounting Policy Making}

Justifications in the accounting literature for the input of economic consequences research to accounting policy making can be divided into the following three categories: 
(1) Accounting regulation is only necessary if it has beneficial economic consequences. Therefore accounting policy makers should consider the economic consequences of accounting regulation;

(2) Economic consequences research is indispensable for the survival of a regulatory body. Policy makers who cannot prove the beneficial economic consequences of their activities will be confronted with heavy political pressure which reduces its chances of survival;

(3) The rationales of accounting regulations are based on their assumed economic consequences. The existence of these consequences should be tested.

ad 1)

May and Sundem [1976], and Dopuch [1989, p.466], amongst others, are supporters of the argument that accounting regulation is only necessary if it has positive economic consequences. The assumption behind this argument is that beneficial economic consequences are a necessary condition to legitimize the existence of accounting regulation. In general, the beneficial economic consequences looked for are the correction of market failures. An important shortcoming of this argument is that correcting market failures is only one of the possible objectives of accounting regulation. Equitable considerations (e.g. the distribution of accounting information among individuals) can also provide the rationale of accounting regulation. The objective of accounting regulation is a political choice which cannot be judged from an economic point of view.

\section{ad 2)}

The statement that the economic consequences approach is essential for the survival of regulators is supported by, for example, Gerboth [1973, p.479], Horngren [1973], and Kelly-Newton [1980, pp.51-52/146]. The assumption is that only regulators who prove the beneficial economic contribution of their activities can survive. This assumption is disputed in the literature. It has also been argued that the economic consequences approach will lower the reputation of the regulator and so decreases the chances of survival [Solomons, 1978 and 1986; Dyckman 1989]. The reason is that the economic consequences approach will cause the politicization of accounting regulation and reduce its acceptability. This line of argument will be discussed extensively in section 2.2.3. It is ultimately an empirical question, whether the economic consequences approach results in increased acceptance of the regulator. However, it is very difficult to generate reliable empirical evidence on this problem. 


\section{ad 3)}

Beaver [1989, pp.192-193], Benston [1976, p.97], and Watts and Zimmerman [1986, p.157] are supporters of the argument that economic consequences research can give evidence of the economic rationales behind accounting regulations. According this point of view, the relevance of economic consequences research for accounting policy making depends on whether regulators expect particular economic effects from their regulation. However, proponents of this argument sometimes weakly document the assumed rationales for accounting regulation. For example, Benston [1976, p.97] states without any empirical reference that accounting regulation is passed because of its believed beneficial effects on efficiency. To assess the relevance of economic consequences research for accounting policy making in the Netherlands, the next section will investigate whether economic rationales were given for the 1970 and 1983 legislation. Another difficulty with this argument is that the rationales of accounting regulation are difficult to infer and regulators do not define the objectives of regulation unambiguously. Hence, there can be considerable debate about the rationales of accounting regulation.

In the Dutch accounting literature, the relation between accounting regulation and its economic consequences, like other economic consequences issues, receives hardly any attention (see [Klaassen and Schreuder, 1984; van de Poel, 1988, p.20]). Exceptions are Feenstra [1985, pp.75-88], Mertens [1990], and Bollen [1990a and 1990b]. In general, the objectives of accounting regulation receive minor attention in the Netherlands [Klaassen, 1978, p.589]. Probably the first proposal to use research on the effects for decision makers as an input to accounting policy making was made by Bouma [1972, p.104]. He criticized the policy makers responsible for the 1970 legislation for not taking into account recent developments in the economic consequences literature. In the Dutch accounting literature since then, more research on economic consequences has been proposed and advocated as an input to accounting policy making [van der Grinten, 1981, p.35; Bouma, 1988, p.285; Traas, 1980, pp.208/209].

\subsubsection{Regulators and the Economic Consequences Approach}

As stated earlier, the relevance of empirical evidence of economic consequences for accounting policy making depends on the willingness of regulators to consider these consequences. This section will be concerned with the actual consideration of economic consequences by regulators. First, the consideration of economic consequences by regulators in the United States and the United Kingdom will de dealt with briefly. Second, the consideration 
of economic consequences in the Netherlands will be discussed. The results of a review of the parliamentary debates and working documents relating to the two main Dutch accounting legislation changes in 1970 and 1983 will be reported. It will be concluded that economic consequences were a substantial issue in the discussions of both legislation changes.

Until the early seventies, third parties and economic consequences were only considered in a procedural way by the standard setter in the US [Zeff, 1978a and $1978 \mathrm{~b}]$. The procedures involved the circulation of drafts of standards and informal meetings with interested organizations. In the middle of the seventies, the approach of the FASB became more substantive, and economic consequences became a considerable part of the standard setting process. Part of this substantive approach was that the probable economic or social impact of standards were included in the conceptual framework, and the Board announced its interest in empirical studies of economic impacts. The attention given by the FASB to economic consequences since the middle of the seventies is considerable and can be summarized as follows [Amershi et al., 1982, p.19; Wolk et al., 1989, p.97; Dyckman, 1988, pp.20-24; Ingram and Rayburn, 1989, pp.62-64]:

(1) The FASB has consistently shown a concern for the costs and benefits of standards;

(2) On the cost side; the FASB has especially tried to estimate the direct costs for companies of implementing particular standards. In the benefit side, the information needs of investors were especially considered;

(3) The FASB has conducted, facilitated, and initiated a number of studies dealing with the economic consequences of its regulation;

(4) The research focused mainly on the effects of standards on stock prices (e.g the standards for reporting leases, changing asset values and foreign currencies), and on user surveys.

Compared to their North American colleagues, regulators in Britain are less explicitly concerned with the economic consequences of accounting regulation [Bromwich, 1985, p.81; Taylor and Turley, 1986, pp.92-93]. The economic consequences that are most often considered are changes in the production costs of information for firms subject to the regulation. In some cases, such as in setting the standards on leasing, price change accounting, and research and development, there is a clear concern with economic consequences in the policy making process (see [Hope and Gray, 1982; ASC, 1981; Bromwich, 1985, p.81]). In a relatively recent report of the Dearing Committee, economic consequences considerations are prominent [ICEAW, 1988]. The Dearing Committee was appointed in November 1987 
by the Consultative Committee of Accountancy Bodies (CCAB) and had to review and give recommendations on the standard setting process. The economic consequences of accounting regulation are considered throughout the report (see for example [ICAEW, 1988, p.10/pp.19-20/pp.40-41/pp.4345]).

In the Netherlands there is no official statement of whether economic consequences considerations were taken into account during the establishment of the regulation. Moreover the regulation in the Netherlands has no "official" objective. The probable reason is that by far the most important part of the regulation, the legislation, is the result of a parliamentary system. In this parliamentary process, each political party assigns its own objective to the legislation, depending on its political ideas ${ }^{4}$. The parliamentary working papers and reports of debates of the 1970 and 1983 accounting legislation changes were reviewed to determine whether economic consequences were considered by those who ultimately decide which accounting policy will be established ${ }^{5}$. It should be remarked that this review is only a first attempt to reveal the function of economic consequences in the Dutch accounting policy making process. First, the policy making process giving rise to accounting regulations other than the legislation is not considered (e.g. the Guidelines of the Council for Annual Reporting and the jurisprudence of the Enterprise Chamber). Second, only a part of the policy making process leading to the legislation is reflected in the parliamentary debates and working papers. The portion of the process which precedes the formal 'proposal for new legislation' is poorly documented and is difficult to reconstruct [van de Poel, 1988, p.20]. In the case of the 1983 legislation, this phase occurred mainly at EC

4 This is perhaps best illustrated with an anecdote: according to a representative of a conserwative Christian party (SGP), government control of firms' accounting practices was desirable because "in human society there is a tendency to evil, and people are living. in sin and are exposed to misery" [Handelingen II, 69-70, p.2876].

The following reports of parliamentary debates (handelingen) and parliamentary working papers (kamerstukken) were reviewed:

1970

Kamerstukken III: 67-68 9595, 68-69 9595, 69-70 9595;

Handelingen II: 69-70 pp.2856-2896, pp.2901-2931, pp.2941-2948;

Kamerstukken I: $69-709590(118,118 \mathrm{a}, 118 \mathrm{~b})$;

Handelingen I: $69-70 \mathrm{pp} .1087-1098$;

1983 Kamerstukken II: $1979-80 \quad 16326,1980-81 \quad 16326,198116326$, 198182 16326, 1982-83 16326;

Handelingen II: $1982-83$ pp.4464-4480, pp.4537-4555, pp.4692-4693;

Kamerstukken I: $1982-8316326$ (179), $1983-8416326$ (22, 22a, 22b, 22c);

Handelingen I: $1983-84$ pp. $153-160$. 
level. Third, the expression of concerns about economic consequences in the parliamentary debates and working papers does not necessarily show that economic considerations actually affected the established legislation.

The issues considered in the parliamentary debates and working documents of the 1970 and 1983 legislation changes are grouped below into: (1) issues not explicitly related to economic consequences, and (2) issues explicitly related to economic consequences. The references to these issues are given in appendix 2.1 .

\section{The 1970 Change}

Issues not explicitly related to economic consequences:

(1) duty and right. It was frequently argued that companies should disclose because it was their duty and other parties (employees, investors, society as a whole) had the right to have this information;

(2) democratization. It was frequently argued that the disclosure of financial information was essential for the democratization of society;

(3) openness. It was frequently argued that firms, especially large ones, were social institutions and should therefore disclose accounting information;

(4) representational faithfulness. A better view of the economic position of the company was frequently argued as an objective of the legislation. The annual accounts should faithfully represent the financial position of the firm;

(5) making up arrears. It was argued that Dutch accounting regulation was "behind" compared to other countries. This situation was judged to be undesirable.

Issues explicitly related to economic consequences:

(6) controlling (dishonest) management practices. One desired economic consequence of the legislation was increased control over management practices and a reduction of dishonest management practices;

(7) competition. Among the suggested consequences of the legislation on competition were; (1) that it would create a competitive disadvantage for small public companies active in only one sector, (2) the "generally negative effects" of accounting information used by competitors, (3) the negative effects of stringent legislation for Dutch companies competing in the European market, and (4) that the disclosure of 
information about investment decisions would reduce the value of these investments;

(8) demand for information. It was frequently suggested that information required by the legislation was demanded by various parties;

(9) general economic and social considerations. It was argued that the legislation should not have general harmful economic and social effects.

Reviewing the parliamentary pieces and reports of the 1970 change, it can be concluded that economic consequences received substantial attention. However, it does not appear that any empirical research was used by the policy makers, nor was a demand for this research expressed. The empirical knowledge of the policy makers was minimal. This can be illustrated with the following example: the predictions given in the parliamentary debates and working papers as to the number of firms who would be subject to the legislation range from 25,000 to 40,000 [Handelingen I 69-70, pp.10961097; Handelingen II 69-70, p.2864; Kamerstukken I 69-70, p.40]. However, it appears that the actual number of firms subjected to the legislation was significantly lower (the average annual number of disclosed audited annual accounts in the period 1974-1984 was 4,130.5, see table 4.11).

\section{The 1983 Change}

Issues not explicitly related to economic consequences:

(1) duty and right. See the 1970 case;

(2) openness. See the 1970 case;

(3) representational faithfulness. See the 1970 case.

Issues explicitly related to economic consequences:

(4) controlling (dishonest) management practices. It was suggested that the legislation would discourage dishonest management practices and support the legislation on the abuse of legal forms;

(5) competition. The legislation would improve fair competition in the EC. Excessively onerous Dutch legislation would have negative competitive effects for Dutch firms compared with European firms. The disclosure of line of business information, and its effects on competition, was an especially important issue;

(6) demand for information. Again it was stated that there was a demand for particular information items. Examples are: (1) it was stated that "many groups" wanted to have both historic and current 
value information, and (2) there was a dispute on the demand for line of business information;

(7) general economic considerations. It was suggested that the legislation would encourage the internal stability of firms and be beneficial to the general economic atmosphere;

(8) cost benefit analysis. The costs and benefits of the legislation were a substantial issue. The costs of the legislation for firms and the costs of enforcing compliance were mentioned. High costs for firms were undesirable considering the "general tendency towards deregulation". The costs for small firms were especially considered;

(9) "Flight" into other legal forms. It was proposed to subject more legal forms (e.g limited partnerships and foundations) to the legislation. Concerns were expressed that firms would avoid the regulation by switching to, or establishing, a legal form not subjected to the legislation;

(10) Effects on the audit market. In the parliamentary debates, substantial attention is given to the effect of the legislation on the market shares of registered accountants (registeraccountants) and accountants administratie consulenten, in the market for public accounting $^{6}$. It was expected that accountants administratie consulenten would lose the group of middle-sized private limited liability companies to the registered accountants. There was also discussion of whether there would be enough auditors for the increased amount of work.

In the 1983 case, economic consequences also received considerable attention. And again, hardly any empirical evidence of these consequences was available. The costs and benefits of the legislation, which were barely considered in the 1970 case, were an important issue. One explanation for the attention given to this issue is the general government ideology towards deregulation during the eighties. The members of parliament explicitly demanded a cost-benefit analysis of the legislation. The Minister of Justice briefly replied that a cost-benefit analysis was hardly possible. Another distinctive feature of the 1983 case is that the democratization issue did not receive any attention, whereas in the 1970 case this was one of the most frequently used arguments for legislation.

In sum, the evidence from the review clearly demonstrates the concern of the Dutch legislator with the economic consequences of accounting legislation.

${ }^{6}$ Registeraccountants and accountants-administratieconsulenten are two different groups of accountants. Both groups have the right to use the term "accountant". However, only registeraccountants have the right to attest financial accounting information. 
Research can test whether these economic consequences actually occurred after the passing of the legislation. For example, it can be established whether: (1) legislation reduced dishonest management practices, (2) particular information items are used by investors, (3) the market share of registered accountants increased, (4) firms avoided the legislation by switching legal form, and (5) whether the disclosure requirements implied a competitive disadvantage for Dutch firms. Evidence of these economic consequences can contribute both to the evaluation of established accounting legislation and to making predictions about the economic effects of future proposals for accounting legislation. Chapter four and five of this thesis will make some initial steps towards providing evidence of the economic consequences of Dutch accounting legislation.

\subsubsection{Arguments Against an Economic Consequences Approach to Accounting Policy Making}

Various studies have criticized the economic consequences approach to accounting policy making (see for example [Dyckman, 1988; Ruland, 1984 and 1989; Solomons, 1978 and 1986]). We will try to summarize and discuss their critique here. First of all, it should be mentioned that the critics do not deny the existence of economic consequences of accounting regulation [Sollomons, 1978, p.37; Ruland, 1984, p.225; Dyckman, 1988, p.21]. The criticisms of Solomons [1978 and 1986] and Dyckman [1989] are based on very similar grounds ${ }^{7}$, namely the believed negative effects of the economic consequences approach on the value of accounting to the economy. Ruland [1984 and 1989] has very different grounds to object to the economic consequences approach. He rejects the economic consequences approach on philosophical grounds.

Solomons [1986, p.222] and Dyckman [1988, p.23] state that the economic consequences approach results in the politicization of accounting regulation. Politicization will decrease the credibility of accounting regulation and reduce its acceptance. The loss of credibility and acceptance will have negative consequences for the value of accounting to the economy [Dyckman, 1988, p.22; Solomons, 1986, pp.235-236/246].

7Dyckman's article mainly discusses the implications of the economic consequences approach for the credibility and survival of the FASB. However, he also states that the economic consequences approach will have negative implications for the economy as a whole [Dyckman, 1988, pp.22-23]. 
The alternative approach suggested by the critics of the economic consequences approach is the credibility approach. Other terms for this alternative are "map making", "neutrality" or "representational faithfulness" approach. According to the credibility approach, accounting should accurately reflect economic phenomena without regard to the ultimate social implications [Dyckman, 1988, p.23; Solomons, 1978, pp.40-41 and 1986, pp.233-235]. This approach will lead to a credible regulator and will have a positive effect on the acceptability of regulation. A credible regulator, and acceptable regulation will give accounting a positive value to the economy. On one point Dyckman and Solomons differ slightly. According to Solomons [1986, pp.235-236/246], representational faithfulness will lead directly to increased social welfare, and he does not ask for empirical evidence on this point. Dyckman [1988, p.22] has a less strong position on this point. The economic consequences of accounting regulation should not be addressed by regulators themselves (i.e. the FASB) but by those elected by society (i.e. the Congress). However, he still strongly believes that as a result of adopting the economic consequences approach to regulation and foregoing the credibility approach, accounting will lose its value to society [Dyckman, 1988, p.22].

The main weakness in Solomons' and Dyckman's argument is that they justify the credibility approach by its believed positive contribution to the economy, without documenting this assertion with empirical evidence. It is precisely this evidence that the economic consequences approach tries to provide. Another problem with Solomons' and Dyckman's arguments is that it is not clear what exactly they mean by "the politicization of accounting". They use statements like "the injection of accounting with politics" and "resolving the issue politically". However, all accounting policy making inevitably entails political decisions. As we will show in detail in section 2.3, each regulation has its specific economic consequences, and benefits some while it hurts others. So why does the credibility approach involve less politics than the economic consequences approach? Moreover, as stated earlier, it is highly debatable whether regulation based on the credibility approach is more easily accepted than regulation based on the economic consequences approach. It has been argued that regulators who do not prove the beneficial economic effects of their activities will reduce their chance of survival (see [Gerboth, 1973, p.479; Horngren, 1973; Kelly-Newton, 1980, pp.51-52/146]). Finally, it seems that both writers are misled by the idea that a regulator who is respected and not disputed performs better than a regulator who is criticized and subjected to pressures of various parties. However, a priori it can also be argued that a regulatory body which is intensively monitored by various groups in society will perform better than a regulatory body lacking this intensive monitoring. 
Ruland"s [1984 and 1989] arguments against the economic consequences approach are confusing. In his first article, he rejects the economic consequences approach on philosophical grounds and states that regulators should pursue the representational faithfulness approach because it is their duty and ethically just. This assertion cannot be judged from an economic perspective. However, in his second article he takes a somewhat different point of view. There he suggests that the economic consequences approach is complementary to the credibility approach. He argues that economic consequences research can be helpful for evaluating the accounting policy making process and the usefulness of accounting standards [Ruland, 1989, p.74]. However, he strongly opposes an economic consequences approach which is consequentsialist. By this he means that he strongly opposes policy making which is only driven by economic consequences. With this argument he is shooting at something that does not exist. The economic consequences approach is in general proposed as the complement of the credibility approach (see e.g. [Zeff, 1978b, p.31; May and Sundem, 1976, p. 750; Ingram and Rayburn, 19891). The reason is that economic consequences themselves cannot be the objective of accounting policy making, because they do not sufficiently define the actions of regulators. For example, it would allow an accounting regulator to sell balloons if it appeared that this activity had beneficial economic consequences. Also, Ruland [1989] fails to give a reference to a writer who proposes that economic consequences should be the only objective of accounting regulation, and, as far as we know, there is no academic writer who explicitly supports this view. Ruland [1984, p.224] refers to May and Sundem [1976] as proponents of the economic consequences approach. However, May and Sundem [1976, p.750] suggest that economic consequences should be part of accounting policy making, alongside accounting theory. Ultimately, it does not seem that this approach differs significantly from Ruland's approach [1989, p.74]. Finally, it should be remarked that our review of the Dutch policy-making documents also indicated that credibility and economic consequences issues were considered jointly.

\section{The Map Making Analogy}

Some proponents of the credibility approach use the map making analogy to defend this approach [Solomons, 1978, pp.41-42 and 1986, pp.92-93/234235; Ruland, 1984, p.224 and 1989, pp.70-72]. Essentially, the assumption is that financial accounting is like map making. And maps are better the more accurately they represent the complex reality. Applying this to accounting, the implication is that accounting should try make the best, i.e. the most accurate, map of economic events. And also, so the argument goes, maps are not judged on their economic consequences but on their accuracy. 
The analogy with map making is a weak one for several reasons:

(1) The map making analogy is used to defend a certain way of making accounting policy, i.e. the credibility approach. Map making is not subjected to regulation. The analogy would lead to the conclusion that financial accounting should not be regulated. It is difficult to believe that the proponents of the credibility approach support this conclusion. The differences between the institutional arrangements in the market for map making and the market for accounting information suggest that these activities have very different characteristics;

(2) Map making and accounting differ very much with respect to the degree an empirical referent exists [Ingram and Rayburn, 1989, p.58]. As a result, it is easier for map making to reach consensus on the quality of a representation, than is the case in accounting. Deliberate misrepresentations are easier to discern in the case of map making than in the case of accounting. The difference with respect to the degree an empirical referent exists is a possible explanation for the regulated environment of accounting and the unregulated environment of map making;

(3) On the basis of the map making analogy it is argued that accounting should not be evaluated on the basis of its economic consequences but on the basis of its accuracy. This conclusion is false because maps are evaluated on their accuracy and their economic consequences. Producers and consumers of maps evaluate the economic consequences of maps. Consumers of maps will be willing to sacrifice accuracy, if highly accurate maps are very expensive. And producers of maps will react by producing less accurate and less expensive maps ${ }^{8}$. It is clear that the application of the representational faithfulness approach to map making would have odd implications! Producers of maps would only be allowed to produce the most accurate maps. As a consequence, tourists wanting to go for a casual city strol』 would be obliged to buy very accurate, and very expensive, maps.

- The economic consequences of map making are evaluated because there is no, or a less serious, problem with 'free-riding' in the case of maps than in the case of financial information. Consumers of maps generally buy their maps instead of using or copying them from other consumers. 


\subsection{Evaluating the Desirability of the Economic Consequences of Accounting Regulation}

To analyze the desirability of the economic effects of accounting regulation, a distinction is frequently made between effects on the efficiency of the allocation of society"s resources and those on the distribution of wealth among individuals in society [Bromwich, 1985, p.80; Beaver, 1989, p.179; Beaver, 1977, p.318; Sunder, 1988, p.33]. The actual determination of the social desirability of accounting regulation requires an analysis and evaluation of both sets of effects. The division is made along these lines because it is generally believed that the desirability of efficiency effects can be assessed by economists while the desirability of distributional effects cannot [Beaver, 1989, p.193; Taylor and Turley; 1986, pp.4-5; Sunder, 1988, p.40]. However, it will be argued that it is impossible to assess the desirability of either effect from a societal point of view. The following section will discuss the evaluation of efficiency effects and section 2.3 .2 will discuss the evaluation of the distributional effects of accounting regulation.

\subsubsection{Evaluating Efficiency Consequences of Accounting Regulation}

It can be expected that accounting regulation will change the efficiency of the allocation of society's resources. First, resources are spent on the production of accounting information which meets the requirements of the regulation, and alternative uses of those resources are therefore precluded. Second, resources are spent on establishing and maintaining the regulation. Third, regulation will affect the information used when making decisions on the allocation of resources (e.g. in the capital market). This section will cover: (1) the issue of whether it is possible to ascertain the efficiency effects of changes in the allocation of resources due to regulation, and (2) an overview of studies which have tried to measure the efficiency of accounting regulation (i.e. cost-benefit analyses).

Efficiency criteria "have been used to describe 'benchmark' characteristics of economies which are typically judged to be more or less desirable" [Ohlson and Buckman, 1980, p.543]. As such, efficiency criteria are just "rules of the game" [Holzhauer et al., 1989, p.33]. Two efficiency criteria frequently suggested in the accounting literature are: an actual Pareto improvement and a potential Pareto improvement [Sunder, 1988, p.33; Taylor and Turley, 1986 , pp.4-5; Beaver, 1989, p.179; May and Sundem, 1976, p.749; Gonedes and Dopuch, 1974, pp.48-49; Verrecchia, 1982, p.8]. An actual Pareto improvement implies that the implementation of accounting regulation makes 
no member of society worse off and at least one becomes better off. The actual Pareto improvement criterion circumvents the problems of interpersonal utility comparison because it only judges government intervention that does not harm any individual [Bromwich, 1985, p.80]. The actual Pareto improvement criterion is straightforward and easy to apply. However, it is difficult to give an example of a government policy that does not lower the welfare of one or more persons in society [Verrecchia, 1982, p.8; Sunder, 1988, p.33], and it has been said that no government policy will meet this criterion [Mishan, 1982, p.34]. A second criterion of whether accounting regulation produces higher efficiency is the potential Pareto criterion (other terms are the "Kaldor Compensation Principle" and "Kaldor-Hicks criterion" [Williams, 1987, p.176]). That is, accounting regulation is efficient if it is possible for the winners from the regulation to compensate losers so as to leave nobody worse off and at least one person better off [Bromwich, 1985, p.80]. The compensation of losers is hypothetical and assumed to be costless.

The frequently proposed cost-benefit analysis for the evaluation of accounting regulation is based on the potential Pareto criterion [Espahbodi and Hendrickson, 1986]. A cost-benefit analysis tries to measure the value of all produced goods and services in society before and after the change in government policy, in our case a change in accounting regulation. It is assumed that an increase in the value of production means that the efficiency of society is higher [Verrechia, 1982, p.8]. However, considerable technical and conceptual problems are associated with cost-benefit analyses.

One technical difficulty in carrying out a cost-benefit analysis is the difficulty of establishing market prices to value the produced goods [Stark, 1987, pp.211-212]. Because of market failures and imperfections, no market prices exist for many goods that are regulated by the government [Brown and Jackson, 1982, p.175]. Market prices are indispensable for revealing the preferences of consumers for various goods. The problems involved in establishing preferences have received considerable attention in the accounting literature, in relation to preferences for accounting information where no market prices are available (see for example [Amershi et al., 1982; Sunder, 1988, pp.34-35; Watts and Zimmerman, 1978; Foster, 1980, pp.531-532; Beaver, 1977, p.322]). Among the problems suggested are:

(1) If people are asked, they may not know their preferences;

(2) The process of revealing preferences is costly for participants. Voluntary participation in a preference revealing process will therefore result in unbalanced representation; 
(3) The respondents may exhibit strategic behavior and not reveal their real preferences.

As will be discussed later in this section, despite the evident shortcomings expressed, research on perceived preferences is used in cost-benefit analyses of accounting regulation.

Another technical problem when implementing a cost-benefit analysis is to decide which prices should be used to value the production before and after the change in government policy. The change in government policy will change the distribution and prices of goods. The choice between the prices of produced goods before and after the change in government policy is arbitrary [Mishan, 1982, p.205; Verrecchia, 1982, p.8]. To state these problems in a different way: it is not clear how the change in the distribution of goods affects the utility of persons in society. Because of these two problems with the valuation of the goods produced before and after a change, cost-benefit analyses are not suitable for measuring the efficiency effects of accounting regulation.

Two conceptual problems with cost-benefit analyses arise from the potential Pareto criterion [Schreuder, 1981, pp.68-69]. The first problem is that a cost-benefit analysis entails the implicit value judgement that Pareto efficiency should be the criterion when judging regulation. Pareto efficiency is not an inherently superior criterion. The choice of the Pareto criterion is a political choice and cannot be judged from an economic perspective [Espahbodi and Hendrickson, 1986, p. 48$]^{9}$. The second conceptual problem concerns the distributional effects of accounting regulation, which are not taken into account by a cost-benefit analysis. If the cost-benefit criterion is met, hypothetical costless transfers could make everyone better off. This implies that a regulation which meets the cost-benefit criterion can have considerable negative effects on equity [Sunder, 1988, p.33]. For accounting policy making, the separation of efficiency effects and distributional effects is somewhat artificial [Williams, 1987, pp.176-178].

\section{Studies on Costs and Benefits of Accounting Regulation}

There are not many empirical results from cost-benefit analyses of accounting regulation, and the methods used to measure costs and benefits are very

"This opposes the view of Watts and Zimmerman [1986, pp.7-8], who state that the efficiency objective is not subjective. 
diverse [Espahbodi and Hendrickson, 1986, pp.32-33]. First, a group of studies can be distinguished which try to establish respondents' perceptions of the costs and benefits of accounting regulations. Butterworth and Falk [1984] tried to measure the perceived costs and benefits of Canadian Accounting Standards. They sent questionnaires to 210 financial analysts, 1000 controllers and 1000 accountants. The average response rate was $41.9 \%$. The subjects had to indicate whether they thought that the benefits of an accounting standard were bigger than, smaller than, or equal to its costs. Butterworth and Falk [1984] concluded that the subjects doubted, on the basis of cost-benefit considerations, the desirability of accounting standards that required detailed information. Surprisingly, they found no significant relationship between occupation (i.e. financial analyst, controller, and accountant) and cost-benefit perceptions. McKinnon [1984] investigated the perceptions of US financial analysts and controllers as regards the costs and benefits of 20 disclosure items. Questionnaires were sent to 250 analysts and an equal number to controllers. The response rates were $69.7 \%$ and $69.6 \%$ respectively. Contrary to Butterworth and Falk [1984], the results indicated that controllers perceive the costs of disclosure to be higher than analysts do, while analysts perceive the benefits to be higher than was the case for controllers.

A second group of studies try to measure the actual costs of accounting regulation for firms. Bastable [1977] investigated the costs for firms of disclosing replacement cost data, using questionnaires. His sample was very small: only 18 US firms were included in the sample and 14 firms replied. The firms were asked to give an estimation of the incremental and full costs of the requirement to disclose replacement cost data. Extrapolating the results for the 14 firms, Bastable [1977] concludes that "society paid a multimillion-dollar figure for the rule requiring replacement cost data". The Advisory Committee on Corporate Disclosure [1977] investigated the costs for US firms of producing $10-\mathrm{K}, 8-\mathrm{K}$ and $10-\mathrm{Q}$ reports, using questionnaires and interviews. Again the sample is very small: 22 firms were included. Philips and Zecher [1981] extrapolate the data of the Committee for the whole group of US firms that are required to disclose. The 22 firms and the total number of firms were classified in three size-classes. The assumption is that disclosure costs vary with the size of the firm. Philips and Zecher concluded that the estimated minimum annual costs of disclosure for all disclosing US firms was 213 million dollars. Benston [1984b] examined the costs of the "Line of Business Program" of the Federal Trade Commission. This program forces approximately 440 firms in the United States to disclose detailed information about their different lines of business (LBs). The Federal Trade Commission and 150 firms that opposed this program disagreed about the costs of this program. The firms stated that the costs of this 
program for a firm are in the first year between $\$ 350,000$ and $\$ 1,800,000$ and in subsequent years between $\$ 95,000$ and $\$ 325,000$ a year. These estimates were based on a survey of nine companies by the General Accounting Office in 1974. The Federal Trade Commission had totally different estimates: between $\$ 10,000$ and $\$ 20,000$ in the first year and between $\$ 5,000$ and $\$ 10,000$ in subsequent years. The Federal Trade Commission derived their estimates on the basis of 25 letters from firms which contained estimates of the cost of providing lines of business information. The FTC adjusted these estimates for the bias in the sample: the average number of LBs in the sample was higher than the average number of LBs in the population of 440 firms. One important assumption of the adjustment made by the FTC is that compliance costs are positively correlated with the number of LBs. Benston [1984b] opposes this assumption with empirical results based on two different samples of 18 and 17 firms subjected to the FTC program. Benston [1984b] did not find a significant relationship between compliance costs and the number of LBs.

A third group of studies does not actually measures costs and benefits of accounting regulation but gives an overview of the various categories of costs and benefits, and the empirical evidence that is available on these categories. Examples of studies in this area are Phillips and Zecher [1981, chapter 3], Benston [1969], Benston [1976, chapter 4], and Easterbrook and Fischel [1984, section 4]. The empirical evidence provided in these studies concerns: (1) voluntary disclosure of accounting information, (2) the stock price effects of accounting regulation, (3) the Efficient Market Hypothesis, (4) the number of fraud cases before and after the passing of accounting regulation, (5) the effects of accounting regulation on new securities issues, and (6) the effects of accounting regulation on the ratio of private debt placements to public debt placements. The evidence presented in these studies does not provide conclusive results. On the one hand it is argued that there are no clear net benefits from accounting regulation [Benston, 1969, p.531; Benston, 1976, p.161; Philips and Zecher, 1981, p.51]. On the other hand it is argued that there is no evidence that accounting regulation is harmful or costly [Easterbrook and Fishel, 1984, p.714]. The studies in this area of research are frequently referred to in the accounting regulation debate and will be discussed further in section 3.1.4.

Finally, there is an idiosyncratic study by Espahbodi and Hendrickson [1986] which tried to estimate the present value of future benefits and costs of three alternative accounting inflation measurement models (i.e. historical cost adjusted for the general price level, current cost, and current cost adjusted for the general price level). Historic cost accounting data is used as a benchmark. The assumption of the study is that investors will change the 
allocation of resources among various firms if inflation data is disclosed. The hypothesized benefit of disclosing inflation data is an increase in the rate of return on resources due to a better allocation of resources among firms. The costs of disclosing inflation data are estimated through questionnaires sent to financial officers of the firms in the sample. The evidence of Espahbodi and Hendrickson [1986] suggests that according to the cost-benefit criterion, general price-level adjusted information yielded the best results. Besides, all three accounting inflation models yielded net benefits compared to the historical cost model. Two major assumptions of the study were heavily criticized by Stark [1987]: (1) resources were assumed to be redistributed between firms through a merger process, on the basis of expected profitability, and (2) an acquiring firm was assumed to yield the same return on its acquired assets as on its own assets. Stark [1987] provides convincing empirical evidence which is inconsistent with these two assumptions.

One limitation common to the cost-benefit studies discussed is that they only take a few cost and benefit categories into account. On the cost side, in general, only the direct administrative costs of accounting information are investigated. Indirect costs, such as competitive disadvantage effects for disclosing firms, are hardly considered. On the benefit side, in general only effects for stockholders are investigated. Possible benefits for other groups, such as debtholders, creditors and the general public, are scarcely considered. A second common limitation of the cost-benefit studies is that costs and benefits are poorly quantified in money terms. The studies rely on respondents' estimates, or do not quantify costs and benefits at all. The benefits of accounting regulation are especially difficult to quantify. Costs and benefits are difficult to compare if they are not quantified. In sum, it can be concluded that the empirical studies of costs and benefits of accounting regulation do not give a clear view on the efficiency of accounting regulation. The accounting policy implications suggested in these studies have very weak foundations.

Considering the problems associated with cost-benefit analyses of accounting regulation it does not seem that this area of research is promising [Sunder, 1988, p.34]. In the next chapter another approach to the assessment of the efficiency of accounting regulation will be discussed. This other approach is the discernment of characteristics of accounting information that give a priori reasons for expecting "market failures" in an unregulated market. These market failures result in an inefficient market and regulation might correct these inefficiencies. However, as will be discussed extensively in chapter three, there is considerable debate on whether the characteristics of the accounting information market provide a priori reasons for expecting the existence of "market failures" if there is no regulation. Besides, it should be 
remarked that such an approach only circumvents the problems of carrying out a cost-benefit analysis. The conceptual problems associated with using the Pareto-criterion to judge the desirability of accounting regulation still hold.

\subsubsection{Evaluating the Distributional Consequences of Accounting Regulation}

A second result of accounting regulation is that it affects the distribution of wealth between individuals in society. For example, the legal requirement to provide audited accounting information probably results in wealth transfers from firms to accountants. The costs for the firm of providing accounting information may be borne by the consumers of the firm's products, the stockholders, the managers, and even by taxpayers, if production costs are tax deductible. Although it is clear that accounting regulation causes the transfer of wealth, it is not clear who actually gains or loses wealth and what the magnitude of these transfers is. The effects of accounting regulation can be indirect and difficult to measure. Determination of the actual disposition of these costs is difficult [Bromwich, 1985, p.66]. Currently, it is widely recognized in the accounting literature that accounting regulations have distributional consequences. Accounting policy making is viewed as a social choice [Bromwich, 1985, p.81; Beaver, 1989, p.17]. Lobbying behavior for accounting regulation can be viewed as evidence supporting the hypothesis that accounting regulation is a social choice [Dopuch, 1989, pp.465-466]. In recent years, a considerable body of research has been developed that investigated explicitly or implicitly the distributional effects of accounting regulation. An overview of this research will be given in section 3.2.3. In the Dutch accounting literature, Vaassen and Blommaert's article [1987] is one of the few which explicitly considers accounting policy making as a social choice. A few other writers implicitly assume that accounting policy making is a social choice (see for example [Klaassen, 1982, p.111; Traas, 1980, p.209; Huizing, 1987, p.17] $)^{10}$.

Accounting regulation affects the wealth distribution of society and various modes of accounting regulation will affect the wealth distribution in different

10 In general, welfare economics hardly received any attention in the Dutch accounting literature. An exception is Schreuder"s [1981] dissertation, which contains an extensive discussion of welfare economics. However, he uses welfare economics for purposes not related to this study. He is concerned with reporting on the externalities of firms and concentrates on the welfare economic analysis of firms' activities. His work is not concemed with the welfare economic analysis of accounting or its regulation. 
ways. Therefore, the choice of a particular mode of regulation is inevitably a decision to assist some groups in society and harm other groups. Is it possible to evaluate the desirability of these distributional consequences?

Applying the Impossibility Theorem of Arrow [1963] to the choice between different modes of accounting regulation, and thus the choice between distributional consequences, implies that it is impossible to determine an optimal accounting policy. Arrow's Impossibility Theorem (formally "the General Possibility Theorem") can be summarized as follows. The subject of the theorem is the aggregation of individual preferences into a collective preference. Arrow [1963] formulates four conditions "which every reasonable social choice function should possess". These conditions are:

(a) unrestricted domain: the social welfare function must be able to aggregate all individuals' preferences;

(b) Pareto principle: the social welfare function must have the result that if everybody prefers $\mathrm{x}$ to $\mathrm{y}$, the social welfare function prefers $\mathrm{x}$ to $\mathrm{y}$;

(c) independence: the social welfare function must rank two alternatives independent of other available alternatives;

(d) non-dictatorship: the preference of the social welfare function is not dependent on the preference of one person.

According to Arrow, there is no social welfare function that satisfies these conditions. Crucial for this conclusion is the impossibility of interpersonal utility comparison.

Analyses like Arrow's [1963], are also applied to accounting information (see [Marshall, 1972; Demski, 1973 and 1974; Beaver and Demski, 1974; Cushing, 1977]). The central theme of this area of research is the possibility of an optimall accounting information system irrespective of the preferences and beliefs of a rational decision maker ${ }^{11}$. The results of the analyses in this area of research indicate that there is no general optimal accounting information system. The optimal accounting information is dependent on the individual preferences and beliefs of the decision maker. As a result it is inevitable that accounting regulation, prescribing the disclosure of a certain information set, benefits some and hurts others [Verrecchia, 1982]. In other words, accounting regulation has redistributional effects. Marshall [1972], Demski [1973 and 1974], and Beaver and Demski [1974] come to these pessimistic conclusions. Marshall [1972, p.286] considers the problem of determining

"The rational choice model is also described in the Dutch accounting literature (see [Feenstra, 1985; Bouma, 1981]). 
the optimal accounting information set of a rational decision maker whose preferences and beliefs are unknown. Marshall [1972, p.287] concludes that "the problem of determining an optimal system will not have a general solution". According to Demski [1973], no set of standards exists that will always rank alternatives in accordance with preferences and beliefs, no matter what these preferences and beliefs are. And the selection of regulation "ultimately must entail trading off one person"s gain for another's" [Demski, 1974, p.232]. Cushing [1977] criticizes the analyses of Marshall [1972], Demski [1973 and 1974], and Beaver and Demski [1974]. He challenges the assumption of diversity of tastes and beliefs among individuals. Cushing [1977] uses the rational choice framework to analyze three financial reporting controversies, but with the assumption of homogeneous beliefs and preferences. His conclusion is that rational choice theory does not preclude the possibility of an optimal accounting regulation subject to the assumption of a high degree of agreement between individuals' preferences. Examples of these agreements are: (1) "... all individuals agree that all financial statements should possess certain desirable features, ..." [Cushing, 1977, p.312], or (2) "... the cost of information usage could be quite high if users felt a need to derive pooled statements from those reported to them under purchase accounting: however, it seems likely that few, if any, users would wish to do this ..." [Cushing, 1977, pp.319-320]. Currently, there is no empirical evidence that there is a high agreement among individuals on their preferences and beliefs with respect to accounting information. Lobbying activities for accounting regulation, disputes about the "right" accounting regulation, and the existence of firms who do not comply with accounting regulations all indicate that preferences and beliefs differ significantly. Summarizing this area of research, it can be concluded that accounting policy making is inevitable a social choice; there is no optimal accounting regulation from a societal point of view. Besides, it should be remarked that this research only takes the users of accounting information into account: if other groups, such as those who prepare accounting information, were considered the conclusion would be even stronger:2.

12 For an overview and critical comment on the area of research discussed see Verrecchia [1982, pp.1-18]. His main criticism is:

(1) Only one general conclusion has resulted from this research, namely that accounting (regulation) has potential redistributional effects. This conclusion was already established fairly early and therefore it is difficult to see the value of the subsequent papers on this subject;

(2) The models used in this area of research are based on untestable assumptions. Besides, the conclusions depend heavily on the form of these assumptions. As a result the models are highly sensitive to small changes in the assumptions. 
In the accounting literature, attempts have been made to find solutions to the problem of the evaluation of the distributional effects of accounting regulation. One solution is based on the idea that equity can be justified on efficiency considerations. Other solutions are based on concepts from other fields of research like the fairness and justice literature. Both approaches to the problem of distributional effects will be discussed below.

The first solution circumvents the impossibility of evaluating the social desirability of a particular wealth distribution by stating that a more equal distribution of wealth makes everybody better off. This principle is frequently used in public policy [Lev, 1988, p.9]. Removing inequity reduces crime, results in a more livable life and makes people feel less guilty [Friedman, 1980, p.231]. As a result, increasing equity can be defended as being Pareto optimal. Applying this to accounting regulation, Lev [1988] and Cooper and Keim [1983, p.196] conclude that all investors (informed and uninformed) will be better of if they have equal opportunities to obtain accounting information. Equal information opportunities prevents uninformed investors withdrawing from trading. Withdrawal of investors might cause thin markets, higher transaction costs, lower liquidity of securities, and in general, decreased gains from trade. These adverse consequences of unequal information distribution are detrimental for all investors. Therefore, Lev [1988] concludes that an equal distribution of information opportunities may be Pareto optimal. Lev's analysis [1988] can be criticized on the following three grounds. First, he does not take into account the possible costs of accounting regulation for groups outside the capital market. Therefore, accounting regulation that establishes equal information opportunities might be Pareto optimal for the group of investors but not for society as a whole. Second, the detrimental effects of information asymmetry for capital markets are not clear. Whether capital market activity will decrease as a result of information asymmetry is an empirical question. Besides, it is frequently stated that there is a trade-off between equity and efficiency [Porcano, 1984, p.622]. It is at present not clear whether this holds for capital markets, and what the magnitude is of the effect of a change in equity on efficiency. For example, it might be that beyond a certain point, increasing equity results in decreasing efficiency. Third, Lev [1988] uses the potential Pareto criterion to advocate a higher degree of equity. As discussed in 2.3.1, this is only one possible criterion by which accounting regulation can be evaluated, and the use of this criterion is a political choice.

Verrecchia [1982] concludes that this area of research will not result in an useful solution to the problem of the social value of public information. 
Other solutions to the problem of evaluating the distributional effects of accounting regulation are based on concepts from non-economic fields of research. The results of the economic analysis of distributional consequences suggest that the evaluation of these effects is beyond the economic discipline. Links with other disciplines, for example philosophy, are proposed (see [Porcano, 1984; Gaa, 1986; Williams, 1987]). Others argue that consideration of distributional consequences falls beyond accounting expertise [Beaver, 1989, p.193]. However, we will argue that distributional consequences fall beyond economic expertise, rather than beyond the accounting expertise. Concepts from other disciplines can be imported to accounting research to tackle this problem. Four studies in the accounting literature will be discussed that used concepts from non-economic disciplines to consider distributional effects of accounting regulation.

Cooper and Sherer [1984, pp.213-217] state that the current economic analyses in accounting are not satisfactory for establishing the social value of accounting. As an alternative they suggest a political economy approach. Applying this approach to social welfare problems entails: (1) a view of accounting regulation in the context of social conflicts, (2) recognition that all social welfare notions are political, (3) a focus on social indicators of welfare (e.g. national income, adult literacy, and distribution of wealth), and (4) the use of accounting numbers to measure indicators of social welfare. In sum, a political economy approach "encourages" researchers to base their research and advice on accounting policy making on their personal political values.

Gaa [1986] investigates the logic of a frequently used and dominant distributional principle in accounting policy making, the user primacy principle. This principle implies that the interests of users of annual accounts have priority over preparers', or managers", interests. Gaa [1986] assumes that the user primacy principle is the result of a rational choice. This rational choice is made behind a "veil of ignorance" (see [Harsanyi, 1953; Rawls, 1971]). The rational choice behind the "veil" is a hypothetical situation in which individuals do not know their own position (i.e. whether they are manager or user). This abstraction makes it possible to construct a fair distributional principle that does not depend on the actual economic positions of individuals. Rawls [1971] and Harsanyi [1953] have different assumptions regarding the decision criteria of individuals behind the "veil". Rawls [1971] assumes that they decide on the basis of the maximin principle. Harsanyi [1953] assumes that they decide on the basis of the maximization of expected utility. Gaa analyzes various versions of the user primacy principle and investigates whether they are in line with Harsanyi's model. He gives no conclusive findings with respect to the question of whether user primacy is in line with Harsanyi's 
model; his study is restricted to considering the conditions under which the user primacy principle is in line with Harsanyi's model. According to Gaa [1986, pp.448-449], the analysis can both explain and justify the distributional principle chosen by a regulator. Gaa's study can be criticized for the problems that are inherent in the "veil of ignorance" concept. The results of the analysis depend on the assumed risk preferences of the individuals behind the "veil". If these individuals are highly risk averse, a high degree of equity can be expected. If risk seeking individuals are assumed, a low degree of equity can be expected. It does not seem that it is possible to determine the risk preferences of the individuals behind the "weil".

Williams [1987] analyzes a concept that is closely related to the user primacy principle, namely the decision usefulness principle. Williams' analysis differs from Gaa's analysis. While Gaa tries to explain the user primacy principle as a rational choice, Williams proposes more concern with the fairness of accounting policies than is the case with the decision usefulness approach. He advocates concern with fairness on the basis of the following arguments:

(1) The use of the fairness concept can improve the explanations of accounting phenomena;

(2) Consideration of fairness is unavoidable in solving accounting problems.

Williams states that the decision usefulness principle has serious shortcomings both for explaining accounting and for solving accounting problems. Here we will concentrate on William's second argument ${ }^{13}$. The decision usefulness principle is directed towards improving decision making, with the implicit ultimate goal of improving the efficiency of the allocation of resources. If this principle is used, regulation which improves decision making is considered to be desirable. However, as discussed earlier, efficiency and distributional issues are difficult to separate. Therefore, the consideration of distributional effects is inescapable for normative statements on accounting

13 William"s argument that the decision usefulness principle has limited explanatory power is as follows. The principle focusses on the role of accounting information in facilitating decision making. However, accounting information nol only facilitates decision making but also restricts decision making. Therefore, the accountability concept, which underlines the restriction function of accounting, has to be introduced to increase our ability to explain accounting practice. According to Williams "if restrictions on behavior are at issue, fairness necessarily attends". However, he does not make clear why this relationship exists. Constraining can also be explained in terms of private interests. For example, Watts and Zimmerman [1986] also use an accountability approach, but do not incorporate the fairness concept. 
regulation. A judgement on these distributional effects is not possible from an economic point of view. Justice theories are suggested as a possible solution to solving distributional problems. Williams provides an introduction to the literature on justice theories. One of his suggestions is to apply Rawls' approach to distributional problems of accounting regulation.

The fourth study concerns an area of research closely related to accounting regulation, namely tax regulation. Porcano [1984] investigated, in an experimental setting, the perceptions of 88 subjects of what would constitute a fair and equitable tax systern. The subjects were MBA students and business school faculty members. The rationale for his study is the assumption that a tax system that is considered to be equitable and fair will increase taxpayer compliance [Porcano, 1984, pp.623/635]. He takes the viewpoint that the judgement of taxpayers on equity and fairness should be taken into account when making tax policy with the ultimate objective of increasing taxpayer compliance. The results of his experiment indicate a high degree of consensus among different types of individuals as to what would be an equitable and fair tax system. In other words, there is a general referential standard of a fair tax system which overrides individual differences. The subjects agreed that a tax system should take taxpayer need (e.g. size family household) and ability to pay (i.e. a progressive tax rate) into account. The main limitation of Porcano's study concerns the selection of his subjects. They cannot be viewed as "average taxpayers". Hence, the consensus found in this group is probably not representative for the degree of consensus among all taxpayers.

\subsection{Summary and Conclusions}

This chapter has provided an overview of the accounting literature on the contribution of economic consequences to accounting policy making. The chapter started with an introduction to the economic consequences concept. The differences between normative and positive analyses of economic consequences were discussed. The chapter proceeded with the debate on the economic consequences approach to accounting policy making. Opponents of this approach advocate the credibility approach. We can at least say that evidence of economic consequences can contribute to accounting policy making if expected economic consequences are considered by regulators, and that it can also test whether these economic effects actually occur. 
Regulators in various countries say that they consider economic consequences in the policy making process. Reviewing the parliamentary debates and working documents relating to the two main Dutch accounting legislation changes in 1970 and 1983, it appeared that the Dutch legislator is also concerned with economic consequences. For example, there were concerns about the costs of the legislation for firms, the effects for competition between Dutch firms and firms in other European countries, and the effects on the demand for public accounting services. Therefore, it can be concluded that evidence of economic consequences is relevant for accounting policy making.

The last section discusses the possibility of evaluating the consequences of accounting regulation from an economic point of view. It appeared that the economic analysis of the desirability of the consequences of accounting regulation is problematic. A cost-benefit analysis, a method which assesses the efficiency effects of accounting regulation, is impossible. No market prices are available to measure costs and benefits. Besides, the acceptance of the cost-benefit criterion for judging accounting regulation is a political choice. Also, assuming the impossibility of interpersonal utility comparison, it appeared that the evaluation of distributional effects is outside the competence of the economic discipline. The use of concepts from other disciplines was advocated to approach the problem of evaluating distributional effects. Economic research can provide evidence of the consequences of accounting regulation. However, due to various problems, a judgement on the desirability of these consequences cannot be made from an economic standpoint. A judgement on the desirability of economic consequences is up to other disciplines or to the regulators themselves. The role of the researcher is restricted to providing evidence of the economic effects of accounting regulation [Sunder, 1988, p.41; Dopuch, 1989, p.466; Mishan, 1981, p.263]. Chapters four and five of this thesis will provide such empirical evidence for Dutch accounting legislation. 



\section{Chapter 3 \\ Economic Explanations of Accounting Regulation}

The central theme of this chapter will be the contribution of economics to the explanation of accounting regulation ${ }^{1}$. The explanation of accounting regulation is crucial for two reasons. First, it is needed for the explanation of accounting practice, which is subject to extensive regulation. Accounting regulation determines for example the disclosed items in financial reports, the standards that are permitted in financial reports, the reporting frequency, and the auditing of financial reports. Therefore, to explain accounting practice, accounting regulation needs to be explained. Second, an explanation of accounting regulation is essential for the formulation of recommendations for accounting policy making. An understanding of the factors affecting accounting regulation provides insights into how accounting practice might develop, for various models of regulation. For example, accounting regulation can be viewed as a codification and standardization of unregulated accounting practice which saves on contracting costs. This view leads to a different prediction of behavior in an unregulated environment than the view that regulation is costly for firms, but managers could not avoid its establishment due to their weak position in the political process. Also, theories explaining accounting regulation can help in formulating hypotheses on the effects of accounting regulation. As concluded in chapter two, empirical evidence of the effects of accounting regulation can be used in its evaluation. Finally, theories explaining regulation can provide insights into the function of accounting research in the establishment of accounting regulation. For example, is accounting research used to assess the efficiency of a particular regulation or is it used as an "excuse" to defend a particular position in the political process?

In the accounting literature on economic theories which explain accounting regulation, a distinction is frequently made between public interest theories and private interest theories [Dyckman, 1988, pp.2-3; Wolk et al., chapter four, 1989; Watts and Zimmerman, 1986, chapters seven and ten; Philips and Zecher, 1981, pp.17-25]. Both economic approaches to explaining accounting regulation will be discussed extensively in this chapter. The

1 This chapter is a revised version of the first part of Maijoor [1989a]. 
chapter proceeds as follows. Section 3.1 will deal with the public interest explanation of accounting regulation. Central to the discussion in this section will be the debate on the desirability of accounting regulation. Section 3.2 will discuss the private interest explanation. After a general introduction to the theory, its application to accounting regulation will be discussed. This application entails both theory development and empirical evidence. Section 3.3 will give a summary of the chapter and provide conclusions.

\subsection{Public Interest Theory ${ }^{2}$}

Public interest theory assumes that regulatory bodies try to make an economy more efficient through intervention in the market (e.g. through accounting regulation $^{3}$ ) [Dyckman, 1988]. Since regulatory bodies do in fact intervene, economic (i.e. efficiency) arguments in support of accounting regulation can be taken as support for this assumption as to their purpose in doing so, and vice-versa. The debate on the desirability of accounting regulation consists mainly of a priori arguments for, or against, accounting regulation [Easterbrook and Fischel, 1984, p.707]. The central issue of the debate is whether "market failures" or "externalities" exist in an unregulated accounting information market. Thus, the efficiency or inefficiency of an unregulated accounting information market is crucial. As such, the debate ignores the problems, discussed in chapter two, of using the efficiency criterion for judging the desirability of accounting regulation. If there are market failures, an unregulated environment would be inefficient, and government intervention could lead to a Pareto superior movement. The debate has not been conclusive with respect to the existence and seriousness of failures in the market for accounting information. To solve the controversy over the desirability of regulation, cost-benefit analyses are frequently demanded in

"Another term for "public interest theory" is "market failure theory" [Philips and Zecher, 1981, pp.18-211.

3. The difference between a regulated and a non-regulated environment can be described as follows [Ross, 1979, p. 184]. A non-regulated environment is an environment where the role of the government is restricted to enforcing contracts and penalizing fraud or breach of privately established contracts (thus a non-regulated environment is not a situation where the government is non-existent or has no function). A regulated environment is an environment where the government specifies contracts between individuals. For example, the government obliges managers to provide accounting information which meets certain requirements to various contractual parties (e.g. stockholders, bondholders and workers). 
the literature. However, in the light of the discussion in chapter two, costbenefit analyses have little chance of solving the controversy.

\subsubsection{Arguments For Accounting Regulation ${ }^{4}$}

Imperfect and incomplete markets are, prima facie, reason for expecting that there will be a need for accounting information and its regulation [Bromwich, 1985; Beaver and Demski, 1979; Beaver, 1989, chapter four]. There is no need for accounting information to measure the income of securities in an ideal world with perfect and complete markets. The trading of securities is the exchange of capital for claims on the future income of firms. In an ideal market, prices are based on the discounted cash flows of securities and are a perfect measure of the income a security holder can derive from a security. All security holders agree on the ranking of securities based on this measure because a security holder who prefers a different cash flow pattern from his securities can change this pattern without any costs. However, real world markets are not complete and perfect. For example, not all factors of production are marketable (e.g. goodwill) and, with a change from one security to the other, transaction costs are involved. If markets are not complete and perfect, market prices lose the character of an unanimous ranking for security holders [Beaver and Demski, 1979, p.41]. In these markets accounting information serves as a source of information for predicting the cash flow patterns of securities. The expected cash flow patterns determine the value of securities for the individual security holder.

It is argued that the provision of accounting information is not without problems in a non-regulated environment. These problems are called "market failures" or "externalities" [Beaver, 1977, p.320; Foster, 1980]. A market failure arises if the quality or quantity of a certain traded good which is produced deviates from an assumed social optimum. This social optimum is attained if the aggregated social welfare is at its maximum. In a free market, differences between the social costs and benefits of a good and its private costs and benefits will result in a deviation from the social optimum. It is argued that in that case intervention by regulatory bodies is desirable. Four problems will be discussed that may cause the underproduction or overpro-

4 The debate on the desirability of accounting regulation focuses on the provision of accounting information to (potential) suppliers of capital of the firm. Possible problems with respect to the provision of accounting information to other interested parties (e.g. workers, consumers, and the general public) receive considerably less attention. Examples of studies in this area of research are Schreuder [1981], Benston [1982 and 1984a], and Schreuder and Ramanathan [1984]. 
duction of accounting information: the public good problem, the information asymmetry problem, the speculation problem, and the problem of redundant information production ${ }^{5}$.

It has been argued that accounting information is a public good rather than a private good [Gonedes and Dopuch, 1974, p.65; Gonedes et al., 1976, p.395; Bromwich, 1985 , p.61; Beaver, 1977 , p.320]. The demand side of the accounting information market exhibits the difficulty of excluding nonpurchasers which is characteristic of a public good. This problem is called the free-rider problem. Another characteristic of a public good, the joint supply problem, is evident on the supply side of the accounting information market. These two problems may result in an underproduction of accounting information in an unregulated market.

The free-rider problem occurs when consumers rely on the buying and consuming of a good by another person because the consumption of this good by one person still allows others to consume the good [Gonedes et al., 1976, p.397; Beaver, 1977, p.320]. In the case of accounting information, free-riders can rely on the purchase and consumption of other consumers in two ways. First, if a report with accounting information is used by an investor it can still be used by other investors. Second, free-riders can rely on market prices, which reflect the use of private information by market participants. Because free-riders can rely on the buying and consumption of others, they are not willing to pay for accounting information. A producer of a public good does not take into account the free-riders' preferences for the good, because he cannot get any benefits from offering this good to them. Hence, free-riding tends to result in the underproduction of accounting information ${ }^{6}$.

\$ According to Leftwich $[1980$, p.201], popular criticisms of unregulated accounting information markets, not formulated in market failure terms, are in essence based on the idea that free markets will not produce the "right" amount or quality of accounting information. Among these popular criticisms are: that management has monopoly control over information, that investors are naive and functionally fixated, and that, due to the diversity of accounting procedures, the information provided is not useful. Because these criticisms can be viewed as popular versions of market failure problems, we will not discusis them here.

${ }^{\circ}$ Bromwich's [1985, pp.63-64] discussion of the public good problem of accounting information mentions that this problem is not a natural phenomenon but the result of institutional arrangements. Insider trading legislation, in particular, prohibits the possibililies of private consumption of information and the development of an accounting information market. There are no incentives to acquire private information because the use of this information is not allowed, or it must be disclosed to everybody. Insider 
Two frequently given examples of the free-rider problem with respect to accounting information are [Beaver, 1977, p.320]: (1) the use of accounting information by potential security holders who in the end do not buy a security, and (2) the use of accounting information by security holders of other firms. The first example concerns the selection of securities by potential security holders. In this selection process, the potential security holder uses accounting information from various firms. However, ultimately he or she may buy the securities of only a few firms or of none at all. The potential security holder is not charged for using the accounting information of firms that are ultimately not in his portfolio. In other words, the actual security holders bear the information costs of the potential security holder. The second example concerns the use of information by security holders of competing firms. If two firms are active in the same industry and have similar risk-return characteristics, the release of information by one firm will also be useful for the security holders of the other firm. However, the latter group cannot be charged for the use of this information [Foster, 1980, p.523; Easterbrook and Fischel, 1984, pp.685-686].

The free-rider problem may also exist on the supply side of the information market. The example concerns data that is sensitive from a competitive point of view [Beaver, 1977, p.320; Foster, 1980; Easterbrook and Fischel, 1984, pp.685-687; Solomons, 1986, p.185]. Assume that a firm has information that is relevant for the investment and financing decisions of other firms. If the firm discloses this competitively sensitive information, free-riding managers of other firms can use the information for investment and financing decisions without paying. Because they are not compensated, firms are not willing to disclose competitively sensitive information. As a result, accounting information is underproduced.

The second public good characteristic of accounting information is the joint supply problem, which arises where a good, once produced for one customer, can also be supplied to other customers without significant extra costs. In general, goods in joint supply have relatively high initial costs to produce the first unit and low costs of production for subsequent units. Its production is characterized by decreasing marginal costs. In an unregulated market, firms have no incentive to provide accounting information at marginal cost because the average cost of production will be greater. If investors are willing to pay the marginal costs of accounting information but are not supplied, then society's resources are not fully used [Bromwich, 1985, pp.67-68]. There are two ways to solve the problem of decreasing marginal costs. First,

trading regulations limit the incentive to produce accounting information. 
through monopoly power firms can charge for the accounting information they provide at the average cost of production. Secondly, through intervention in the market by the government the problem of decreasing marginal costs can be solved. However, exercising monopoly power is impossible in a market with free-rider problems. Therefore some type of government intervention seems to be the only solution for the problem of decreasing marginal costs.

The second problem, the information asymmetry problem, can lead to adverse selection, moral hazard and signaling behavior [Gonedes et al., 1976, p.99; Cooper and Keim, 1983, pp.197-200; Foster, 1980, p.527]. Information asymmetry is the result of different costs of, or opportunities for, information production. The adverse selection problem can be summarized as follows [Akerlof, 1970; Beaver, 1977, p.325]. Securities of varying quality, in terms of their expected cash return and risk, are traded on the market. If, through lack of information, buyers cannot distinguish superior securities from inferior securities, all securities will be viewed as average. If this is the case, negative consequences can be expected on both the supply and demand sides of the capital market. On the supply side, there is an incentive to offer low-quality securities. As a consequence, the market for good-quality securities will deteriorate. On the demand side the adverse selection problem may cause the withdrawal of uninformed investors, knowing that they are in a disadvantageous position compared to wellinformed investors. This problem was mentioned above in section 2.3.2. The withdrawal of investors from trading reduces the gains from trade. The negative consequences for trading might justify the removal of information asymmetry through accounting regulation [Gonedes et al., 1976, p.99; Lev, 19881 .

The moral hazard problem and signaling problem can be described as follows [Gonedes, 1978]. In the market for securities, managers may have better information concerning the firm's future income than potential security holders. Disclosed accounting information serves, among other things, as a signal of managers' beliefs about the future income of the firm. This may have two negative consequences from a societal point of view. First, because these signals affect security prices a manager may have an incentive to give distorted signals (the moral hazard problem). If he does, the accounting information which is disclosed will fall short of the information that has been produced, and security holders will not be able to choose portfolios that would be optimal in the light of all the information produced. The second negative consequence (the signaling problem) concerns the resources spent on signaling. Managers offering high quality securities will try to distinguish themselves from managers offering low quality securities. The resources 
spent on these activities are wasted from a societal point of view [Beaver, 1977, p.325]. These adverse consequences might also justify the removal of information asymmetry through accounting regulation [Gonedes, 1978, p.27; Gonedes et al., p.101].

Two problems may result in the overproduction of information: (1) the speculation problem, and (2) the redundant information production problem. Hirshleifer [1971] shows that the speculation problem may cause the over-production of information. This overproduced information does not result in a better allocation of resources but only redistributes wealth between individuals. Therefore, this information has no value to society. For example, suppose that the season for planting potatoes is over. The weather in the coming months will determine the success of the harvest and the future stock prices of firms trading potatoes. A speculator decides to spend resources on predictions of the weather in the coming months. Assume that bad (good) weather implies high (low) prices for the stocks of potato traders. The research predicts that the weather is going to be bad and that the stock prices of potato traders are going to be high. The speculator enters into an agreement with somebody who lacks the prediction of the weather and which gives the speculator the right to buy stocks for low prices after the harvest. It indeed appears that the weather is bad and that the stocks can be sold for high prices. Thus, the private information gives the speculator the possibility of earning high profits at the expense of others who lack this information. The private information which has been produced leads only to the redistribution of wealth between individuals involved in the speculation game. Since the season for planting potatoes is already finished, no production decisions will be, or can be changed as a result of the new information. Therefore, the information does not change the efficiency of the allocation of society's resources. This may be a reason to regulate the information market. The obligation to make information which has speculative importance publicly availablle may prevent the production of this information. The second problem that may result in the overproduction of information is redundant information production [Easterbrook and Fischel, 1984, pp.681-682; Gonedes et al., 1976, pp.390/402]. The essence of the problem is as follows. In a non-regulated environment various (potential) security holders will privately search for the same information about a firm. Information search is costly and if various individuals spend resources on the production of the same piece of information, resources are wasted. Accounting regulation mandating managers to disclose accounting information will reduce the incentives for (potential) security holders to privately search for the same information. 


\subsubsection{Arguments Against Accounting Regulation}

The arguments against accounting regulation do not correspond on a one to one basis to the arguments for accounting regulation. A particular argument against accounting regulation may address a certain aspect of a market failure or relate to more than one market failure. Here we will distinguish three groups of arguments against accounting regulation: (1) arguments concerning the possibility of the private consumption of accounting information, (2) arguments concerning the incentives for firms to disclose accounting information, and (3) arguments concerning the costs of both unregulated and regulated accounting information markets.

Arguments concerning the possibility of the private consumption of accounting information can be made, as objections to the public good justification of accounting regulation. It can be argued that in the case of disequilibrium, information can be consumed privately [Cooper and Keim, 1983, p.194; Watts and Zimmerman; 1986, p.164, Leftwich, 1980, pp.199-200; Benston, 1976, p.142; Easterbrook and Fischel, 1984, p.681]. Through the adjustment of security prices, investors will earn on average a normal return on their investment in information search. If information on undervalued securities is obtained, its use will drive the price up and reduce the information's value for other investors. Because accounting information loses value in use, investors are willing to pay and search for it. A second argument for the existence of the possibility of private consumption is that accounting information has no intrinsic collective characteristics. It may be that an unregulated market would develop systems to allow the exclusion of non-purchasers and for private contracting for accounting information. For example, there are at present firms that sell accounting information privately (e.g. Dun and Bradstreet). It is an empirical question whether the market for accounting information would develop in an unregulated market.

The second group of arguments against accounting regulation concern incentives which would persuade managers to provide accounting information. Various mechanisms are suggested which would provide incentives to managers to provide the right amount of accounting information. Here we will distinguish three variants: (1) signalling theory, (2) agency theory, and (3) the Coase Theorem.

Signaling mechanisms can overcome the adverse selection problem. Wellinformed insiders trying to sell high quality securities have mechanisms to distinguish themselves from low quality sellers [Ross, 1979; Strong and Walker, 1987, chapter seven; Easterbrook and Fischel, 1984, pp.675-676]. 
According to the self selection principle, sellers will take courses of action that vary with the quality of their product. If the signaling mechanism is to be effective, it is not desirable for low quality sellers to imitate the actions of high quality sellers. Therefore the costs of signaling "Quality Product" must be low for high quality sellers, and high for low quality sellers. Certification by an accountant is a relevant example of an effective signaling mechanism. Since his reputation is at risk the accountant will not provide, or will charge a great deal for, an unqualified opinion if the accounting information does not represent the financial position of the firm according to generally accepted accounting principles [Easterbrook and Fischel, 1984, p.675; Horwitz and Kolodny, 1982, p.7 $]^{7}$.

The second mechanism concerns the reduction of agency costs through the publication of accounting information [Horwitz and Kolodny, 1982, p.24]. Agency theory suggests that managers will disclose information in a nonregulated environment because it is in their self-interest. The disclosure of accounting information will reduce agency costs. These costs arise if ownership and control are separated. As a consequence of the divergence of interest between managers (i.e. the agents) and suppliers of capital (i.e. the principals), agency costs arise. Managers bear agency costs and thus have an incentive to reduce these costs via the disclosure of accounting information. Besides, other mechanisms can also decrease agency costs and reduce the need to disclose accounting information. Examples of these other mechanisms are [Strong and Walker, 1987]: (1) the market for corporate control, (2) bonus plans, (3) the managerial labor market, (4) mutual monitoring within the firm, and (5) outside directors. The agency mechanism will be discussed more extensively in section 5.1.

The third mechanism is based on the Coase Theorem. It emphasizes the coordination costs of various contractual arrangements. According this theorem, the decision by managers to provide accounting information voluntarily is an efficient alternative to an arrangement where all capital

7 Besides signaling via audited accounting information, other signaling mechanisms can reduce the need for audited accounting information and provide other means for communicating the expectations of managers about the future cash flows of the firm. Examples of these mechanisms are: (1) managers holding stock, (2) the issue of debt, and (3) a high divident payout ratio. These signaling mechanisms function as follows. Holding stocks implies a cost for managers because they are not diversified. However, these costs are considerably less for firms with high expected returns than for firms with low expected returns. Issuing debt implies an increased bankruptcy risk and, as a result, increased bankruptcy costs. However, this increase is more costly for firms with low expected returns. A high dividend payout ratio forces firms to return to the capital market and undergo screening by new investors. 
suppliers bargain privately with managers for the provision of accounting information [Easterbrook and Fischel, 1984, p.682]. The mechanism supposes that security holders can reveal their preferences for accounting information by holding the securities of firms which disclose according their needs. If security holders are not satisfied with the disclosed accounting information, they can "vote with their feet" and sell their securities [Horwitz and Kolodny, 1982, p.6]. This arrangement has mutual benefits by reducing contracting costs. Managers can profit by the provision of accounting information if it has value to its capital suppliers. The suppliers are willing to pay higher prices for the securities of the firm if information is disclosed according their needs.

The third group of arguments emphasize that both market failures and regulatory failures may exist. Market failure theories provide a standard for determining a social optimum without considering the institutional arrangements necessary for its attainment [Leftwich, 1980]. The desired social optimum referred to in market failure theories is based on the Utopian characteristics of a perfect market. This social optimum is unattainable whatever institutional arrangement (regulated or unregulated) of the market for accounting information is chosen. The market failure arguments ignore the contracting costs inherent in every institutional arrangement [Watts and Zimmerman, 1986, pp.169/178].

Consideration of the contracting costs of regulated and unregulated markets for accounting information does not lead to an unambiguous conclusion. On the one hand, there are two arguments based on contracting costs which favour regulation: first, assuming that establishing the specifications of contracts concerning the provision of accounting information entails substantial information and (re)negotiation costs, regulation may save on these costs by standardizing accounting practice [Ross, 1980, p.192; Sunder, 1987, p.32; Solomons, 1986, p.186; Easterbrook and Fischel, 1984, p.687; Horwitz and Kolodny, 1982, p.25]. In other words, the "production" of contracts between managers and capital suppliers is characterized by economies of scale. A second argument is that the "production" of contracts between managers and capital suppliers might fail in an unregulated environment due to public good problems [Sunder, 1988, p.33; Easterbrook and Fischel, 1984, pp.686-687]. The development by a firm of an optimal format to communicate accounting information between managers and capital suppliers entails substantial costs, but, because accounting information is publicly disclosed, this optimal format can be copied by other firms without paying for the production costs of the optimal format. 
On the other hand, the consideration of contracting costs might also lead to the conclusion that regulation is not desirable. First, it is frequently argued that government regulation simply reduces the number of permitted specifications in contracts. As a result, firms whose optimal contracts contain accounting disclosures and measurements that fall outside the allowed specifications are forced to write suboptimal contracts [Watts and Zimmerman, 1987, pp.209-210]. Second, standardizing contracts through government intervention entails the risk of hampering the improvement of contracts [Solomons, 1986, p.194; Sunder, 1988, p.32; Horwitz and Kolodny, 1982, p.25]. Newly invented and improved contracts might not fall within the regulations, and implementation will not occur, or will be postponed until the regulation is changed.

\subsubsection{Empirical Evidence Supporting Arguments For and Against Accounting Regulation}

The empirical research generally referred to in the regulation debate can be classified as follows: (1) research on the costs and benefits of accounting regulation, (2) research on voluntary disclosure, (3) research on the stock price effects of accounting regulation, and (4) research on the Efficient Market Hypothesis. The four areas of research will be discussed below.

Research on costs and benefits can provide the most direct evidence of the efficiency of accounting regulation. Cost-benefit analyses, and the problems associated with these analyses, have already been discussed extensively in section 2.3.1 and need no elaboration here. Despite their evident shortcomings, the studies on costs and benefits are frequently referred to in the accounting regulation debate (see e.g. [Watts and Zimmerman, 1986, pp. 169-171; Easterbrook and Fischel, 1984, p.707]).

Research on voluntary disclosure is used to vitiate the public good argument. The voluntary disclosure studies show that firms disclose accounting information in the absence of accounting regulation. In other words, free market forces obviously provide incentives to firms to disclose accounting information. For example, Watts and Zimmerman [1983] and Benston [1973] provide evidence that publicly listed U.S. companies disclosed audited accounting information before the establishment of the 1934 Act. Other voluntary disclosure studies will be discussed in section 5.2.1. Although the studies on voluntary disclosure provide an indication of the functioning of free markets, they are not a satisfactory method of assessing the efficiency of regulation. Accounting information might be produced and disclosed voluntarily, but the amount may still fall short of the social optimum. It is not at 
all clear that the amount of accounting information produced in unregulated markets is the efficient amount.

Various authors involved in the accounting regulation debate refer to the empirical evidence from research on the stock price effects of the 1933/34 Acts in the United States ${ }^{8}$ (see e.g. [Watts and Zimmerman, 1986, pp.172173; Easterbrook and Fischel, 1984, pp.709-714; Beaver, 1990, p.189]). The studies frequently referred to in this area are Stigler [1964] and Benston [1973]. The study by Stigler [1964] is on the effects of the 1933 Act on the return distributions of new issues. The study by Benston [1973] is on the effects of the 1934 Act for the return distributions of securities. Both studies conclude that the Acts had no effect on stock prices. However, both studies were strongly criticized for their research design (see e.g. [Friend and Herman, 1964; Friend and Westerfield, 1975]). One of the criticisms was the lack of a theory of the relationship between the effectiveness of regulation and its effects on security prices. Another criticism was that the research design was not powerful, so that regulatory effects might have existed but not have been detected.

The evidence from research on the Efficient Market Hypothesis (EMH) is used to support arguments against the information asymmetry justification of accounting regulation (see e.g. [Philips and Zecher, 1981, p.28; Leftwich, 1980, p.203; Easterbrook and Fischel, 1984, p.694; Watts and Zimmerman, 1986, pp.158-162]). It is claimed that the results of the studies on the EMH show that capital markets are semi-strong efficient (i.e, publicly available information is promptly reflected in the prices of securities). As a result, uninformed investors are price protected and can free-ride on the activities of market professionals. An uninformed investor will get the same price as a market professional who has extensively studied publicly available informa-

${ }^{8}$ There are of course also a considerable number of studies dealing with the stock price effects of accounting regulation changes after the 1933/1934 Acts. At the beginning of the seventies it was thought that these studies could be used to assess the desirability of each individual accounting change (see e.g. [Beaver and Dukes, 1972]). If newly required information is useful for investors, changes in security prices should be detectable. Hence, newly required information affecting security prices is desirable. However, there are two arguments against this method of regulation evaluation. The first argument is that it does not take into account the costs of various regulatory policies. Because the accounting information market is regulated, information is freely available to actors on the capital market. They use the freely available accounting information without considering its costs [Beaver(!), 1973, p.209]. The second argument is that this research cannot deliver insights into the different effects of accounting regulation for individual stockholders, and for individuals outside the group of stockholders [Gonedes and Dopuch, 1974]. Only the total outcome for stockholders is measured. 
tion, so that the claimed effects of information asymmetry do not occur. However, there are some weaknesses in the efficient markets argument against accounting regulation. First, if capital markets are semi-strong efficient, uninformed investors are still in an information-poor position as regards information which is not publicly available. Second, the studies are carried out in regulated markets. Unregulated markets might be semi-strong efficient, but less information might be publicly available. Or, even worse, unregulated markets might not be semi-strong efficient at all. In response to that, some authors state that the empirical evidence that the market is semistrong shows the need for disclosure regulation and has made measurement rule controversies irrelevant (see e.g. [Horwitz and Kolodny, 1982, p.6]). Third, although it is claimed that the empirical evidence supports the semistrong form of the $\mathrm{EMH}$, there is considerable debate over this interpretation of the evidence (see e.g. [Beaver, 1989, pp.142-147]).

\subsubsection{The Debate: a Discussion}

This discussion of the debate will deal with its general inconclusiveness, the quest for cost-benefit analyses of accounting regulation, and the formulation of alternative public interest hypotheses.

The inconclusiveness of the debate. The debate on the desirability of accounting regulation is inconclusive [Easterbrook and Fischel, 1984, p.707; Beaver, 1989, p.193; Horwitz and Kolodny, 1982, p.173]. There is a lack of empirical results and a priori reasoning cannot provide solutions for the regulation problem. Both proponents and opponents of regulation have been very successful in producing (complex) arguments for and against accounting regulation. The arguments concerning possible market failures in an unregulated environment are formulated in an abstract setting. Evidence of the actual existence and seriousness of these failures is not available and difficult to provide [Horwitz and Kolodny, 1982, p.173; Foster, 1980, p.532; Beaver, 1977, p.321]. The same holds for arguments against accounting regulation. It is always possible to "invent" a mechanism that would preclude market failure. The actual assessment of the efficiency and effectiveness of these mechanisms is extremely difficult. Considering the problems in determining the optimal institutional arrangements of the market for accounting information, there is no justification for taking extreme positions in the debate [Easterbrook and Fischel, 1984, pp.672/714-715].

The demand for cost-benefit analyses. As a result of the dissatisfaction with the inconclusive results of the debate, there is a demand in the accounting regulation literature for empirical research. Whether alleged forms of 
market failure really exist is an empirical issue [Gonedes et al., 1976, p.400]. The investigation of unfulfilled demands for accounting information due to its public good characteristics has been proposed [Bromwich, 1985, p.70]. The investigation of costs and benefits is especially encouraged [Horwitz and Kolodny, 1982, p.9]. Benston [1976], Beaver [1981], Leftwich [1980, p.200] and Watts and Zimmerman [1986, p.162] state that every institutional arrangement of the market for accounting information (free market or regulated market) has its specific costs and benefits. Therefore, the choice of a particular solution should be based on the specific costs and benefits of the institutional arrangement. The quest for cost-benefit analyses is a sledge-hammer solution. As we discussed in chapter two, cost-benefit analyses are not appropriate in determining the desirability of accounting regulation, and we observe that an investigation of costs and benefits is frequently demanded but rarely executed.

Alternative public interest hypotheses. Although the debate on the desirability of accounting regulation has been inconclusive, accounting practice is in fact subjected to extensive regulation. The economic arguments in favor of accounting regulation are too weak to support such an extensive regulation of accounting practice [Cooper and Keim, 1983]. The inconsistency between extensive accounting regulation and the weak support for its efficiency raises the question whether regulators really act in the public interest. It has been stated that this inconsistency is sufficient to reject the public interest theory. However, the conclusion that accounting regulation cannot be justified in terms of efficiency does not necessarily point to abandoning the public interest hypothesis, since the public interest does not necessarily entail an efficient economy. The statement that regulation can only be in the public interest if it removes market failures and increases efficiency is a political choice (see chapter two). The hypothesis that regulation only exists because of efficiency considerations is so naive that it has no chance of being confirmed [Cooper and Keim, 1983, p.200] $]^{9}$. One possible, and evident, alternative public interest hypothesis would include equity considerations. As

${ }^{y}$ Another shortcoming of the public interest hypothesis in the form presented in the literature is that it does not give a clear prediction on the under- or over-production of accounting information in a free market. Generally it is assumed that the implication of the public interest hypothesis is the under-production of accounting information. However, some market failures indicate an underproduction of information (c.g. the public good problem), other market failures indicate an overproduction of accounting information (e.g. the speculation problem) [Beaver, 1977, p.324]. Also, the public interest hypothesis does not explain the form of government intervention. Besides regulation, there are other possible approaches to market failures (e.g. taxes and/or subsidies) [Foster, 1980, p.525; Beaver, 1977, p. 319]. 
a second possibility, regulators might claim more modest goals than efficiency or equity, and simply state that their ultimate objective is to increase comparability among firms. The formulation of these alternative public interest hypotheses requires a closer examination of the objectives assigned to accounting regulation by regulators themselves or by those who gave them the right to regulate ${ }^{10}$. Economic research can help in determining whether the regulation accomplished these objectives. Is inequity reduced by the regulation? Is comparability increased due to the regulation? Here it is suggested that the public interest explanation should be abandoned if it can be established that regulation does not meet the objectives assigned to it. There seems to be little ground for hoping that the public interest hypothesis will be found to be viable. The hypothesis requires that an objective of the regulation should to be inferred. However, regulation often has no clear objective [Philips and Zecher, 1981, p.21]. Also, evidence of the efficiency of regulation or of a concern by regulators about effectiveness is lacking. These observations in themselves can be viewed as an indication of the failure of the public interest hypothesis to explain accounting regulation.

\subsection{Private Interest Theory"}

Private interest explanations of accounting regulation are based on the interest group theory of government, which has been developed in the literature of political science and public choice ${ }^{12}$. The interest group theory of government tries to explain actually observed regulatory behavior. The theory uses standard neo-classical economic analysis, which is traditionally applied to markets, to explain government behavior. Interest group theory

${ }^{10}$ Backhaus [1989b] suggests a similar approach to assessing the performance of public enterprises. He criticizes the use of indicators based on welfare economics (e.g. efficiency) to measure the performance of public enterprises. Instead he proposes to derive performance criteria from an empirical analysis of the public enterprise and the public authority to which the public enterprise is accountable. Backhaus [1989b] gives an outline of a stepwise procedure for such a performance analysis.

${ }^{11}$ In the accounting literature, private interest theory is also called "public choice theory" [Philips and Zecher, 1981, pp.21-24].

${ }^{12}$ Important contributions to the development of interest group theory are: Buchanan and Tullock [1965], Olson [1965], Buchanan and Tollison [1972], Stigler [1971], Posner [1974], Peltzman [1976], McCormick and Tollison [1981]. For an introduction and overview of interest group theory in the Dutch literature see Van Winden [1989] and Holzhauer [1989]. 
wiews the political process as a mechanism which transfers wealth between parties in society. Actors involved in the political process are assumed to act out of self-interest and to be in competition for wealth transfers. Existing regulation is the outcome of the lobbying ${ }^{13}$ of various interest groups. The success of a group in the political process depends on its information and organization costs. The outcome of the political process is assumed to be an equilibrium between groups exerting opposite forces: groups which receive wealth through regulation and groups that hand over wealth through regulation.

This paragraph will proceed as follows. Section 3.2.1 will provide a general introduction to the interest group theory of government. Section 3.2 .2 will discuss the application of interest group theory to accounting regulation. It will focus on theory development. Section 3.2.3 will provide empirical evidence regarding the application of interest group theory to accounting regulation. Finally, section 3.2 .4 will discuss some criticisms of the economic theory of regulation and alternative theories which have been suggested.

\subsubsection{Private Interest Theory: an Introduction}

A short introduction of the interest group theory of government and legislation will be given here, first because this theory is a relative novelty in general accounting literature, especially in Dutch accounting literature, and second because it is frequently claimed in the accounting literature which is the subject of this section that the interest group theory of government is being applied [Watts and Zimmerman, 1978, p.302, 1979 p.108 and 1990, p. 133; Puro, 1984]. A short overview of the interest group theory can be used as a benchmark for evaluating current accounting research on private interest explanations of regulation. The overview is based on Tollison [1982] and McCormick and Tollison [1981].

Traditional economic analysis of government behavior is mainly normative. Based on economic criteria, it derives what a government should do. The government is expected to correct market failures. However, there can be a large gap between recommendations based on economic analyses and actual

13 Following Sutton [1984, p.81], the term "lobbying" in the context of accounting regulation refers to the efforts of individuals and organizations to promote or obstruct accounting regulation. Examples of these efforts are making a presentation at a public hearing, placing advertisements, engaging a professional lobbyist to attempt to influence regulators, and subsidizing "research" which supports the position which has been taken in the political process. 
government intervention. For example, as discussed extensively in section 3.1, despite the fact that the economic arguments for accounting regulation are not convincing, actual accounting practice is heavily regulated. The interest group theory of government tries to explain the gap between standard economic rationalizations for government intervention and observed regulatory behavior [Tollison 1982 p.588]. It is based on the standard methodological viewpoint of neo-classical economics: (1) individuals act out of selfinterest and are rational maximizers of utility, and (2) methodological individualism. The argument for applying these basic neo-classical assumptions, traditionally applied to producer and consumer behavior in markets, is that there is no a priori reason to expect that individuals in markets should have different motives to individuals in the public sector.

The interest group theory of government and legislation is the positive branch of rent seeking theory. Rents are the benefits of a resource minus its opportunity costs. In other words, rent is any payment to a resource owner in excess of the payment for the next best use of the resource. In perfect and complete markets rents are zero. Two conditions can be distinguished that affect the perfection and completeness of markets. First, rents can arise naturally in the market through, for example, a change in the supply and demand curves. Second, rents can arise artificially through the political process. The competition for rents in the market process is called profit seeking. The competition for rents in the political process is called rent seeking. In other words, rent seeking is the expenditure of resources to procure the right to an artificially created rent. Accountants" efforts to monopolize their activities by lobbying for occupational licensing are an example of a rent seeking activity (the creation of rents). If occupational licensing is established, entry into the accounting profession is also a rent seeking activity (the allocation of rents). The normative analysis of rent seeking tries to estimate the costs of rent seeking (e.g. the costs of lobbying) for the economy. The positive analysis of rent seeking tries to explain the origin and existence of regulation.

The creation and allocation of rents imply wealth transfers between individuals. These wealth transfers exist because of voting costs (organization and information) costs. In a world with zero voting costs and a unanimily decision rule, only wealth transfers that are Pareto-optimal would occur (i.e. no wealth transfers with negative effects for one or more voters). All voters know exactly the wealth effects of a proposed collective decision. If a voter is negatively affected by the proposed collective decision, he will vote against the proposal. Under an unanimity rule, one vote against is sufficient to block a proposal. In a world with non-zero voting costs, the number of wealth transfers will increase. Transfer seeking activities will exist because 
voters will allow a part of their wealth to be taken away if the benefits of voting are lower than its costs. For example, if there are information costs, the precise wealth effects of a proposal for various voters might not be clear. However, a voter will spend little or no resources on more information on the wealth effects of the proposal, if he expects that the chance and magnitude of negative wealth effects are small. As a result, a proposal might be accepted under a unanimity rule which appears to have negative wealth effects for some voters if it becomes effective. If the unanimity rule is changed to a majority rule, rent-seeking activities will increase further because it becomes less costly to influence a collective decision. For example, assume that a proposed collective decision has serious negative wealth effects for a minority of all voters. Under a unanimity rule, the negative votes of the minority are sufficient to block the proposal. However, under a majority rule, the minority's votes can not prevent the acceptance of the proposal.

The success of a group of individuals in the rent seeking process depends an its information costs and organization costs. Two kind of information costs for individuals can be distinguished. First, an individual has to discover how a particular regulation affects his personal wealth. As mentioned earlier, the determination of the actual economic effects of accounting regulation for various parties is very difficult. Second, an individual has to identify individuals who will take the same position in the political process. This is essential for forming interest groups. Four cases can be distinguished with respect to the identification of winners and losers of a particular regulation (figure 3.1). According to interest group theory, wealth transfers are expected when winners are easy to identify and losers are hard to identify (i.e. case 3$)^{14}$. In this case, the benefits of the regulation are very clear to the winners while losers are hardly conscious of the negative effects of the regulation. As a result, there will be a strong lobby for the regulation and a weak lobby against the regulation.

14 In an elementary version of the interest group theory, the capture theory, it is assumed that producers, in particular, have low information and organization costs. As a result, producers are able to influence regulators at the expense of consumers. In other words, regulators are captured by producers' interests. 
Figure 3.1

Identification costs of winners and losers of regulation

\begin{tabular}{|c|c|c|c|}
\cline { 2 - 4 } \multicolumn{1}{c|}{} & \multicolumn{2}{c|}{ winners } \\
\cline { 2 - 4 } \multicolumn{1}{c|}{$\begin{array}{c}\text { identification } \\
\text { costs }\end{array}$} & low & high \\
\hline \multirow{3}{*}{ losers } & low & 1 & 2 \\
\cline { 2 - 4 } & high & 3 & 4 \\
\hline
\end{tabular}

Organization costs are the costs of translating the interests of individuals into support for politicians who will act in those interests. Organization costs will be lower for those groups that are already organized for reasons other than lobbying in the political process. Part of these organization costs are resources spent to prevent free-riding. Free-riders are in this case individuals who benefit from a particular regulation but did not help to establish this regulation.

The last crucial element of interest group theory is the role of politicians. It is assumed that they are an interest group themselves and not simply brokers between interest groups. Their interest is to grant favors to groups in society. Therefore it is assumed that politicians try to increase their control over resources. Intervention in the market gives politicians the ability to grant favors to interest groups.

\subsubsection{Application of the Private Interest Theory to Accounting Regulation}

This section deals with the private interest explanation of accounting regulation. The development of the private interest theory in the accounting literature will be discussed. The following section will discuss empirical tests of the private interest explanation of accounting regulation. It will be concluded that the application in the accounting literature has mainly focused on the relationship between the (expected) effects of accounting regulation and positions in the lobbying process. Important aspects of lobbying, such as coalitions, free-riding, and the amount of resources spent on lobbying, have received hardly any attention.

One of the first important attempts to apply the economic theory of regulation to accounting is the study by Watts and Zimmerman [1978] on the 
determination of accounting standards by the FASB in the US. Their study is concerned with "the costs and benefits generated by accounting standards which accrue to managements, thereby contributing to our understanding of the incentives of management to oppose or support various standards" [Watts and Zimmerman, 1978]. It is assumed that accounting standards affect managers' wealth through changes in share prices and changes in incentive cash bonuses. These effects will determine managers' preferences for particular accounting standards. The position of managers with respect to accounting standards is "measured" through their submission to regulators of reactions to proposed accounting standards. As we will see later in this section, the 1978 study of Watts and Zimmerman has lead to a series of similar studies. In brief, Watts and Zimmerman's [1978] study emphasizes the effects of accounting standards on managers" wealth. On the basis of these costs and benefits for managers, predictions of their voting behavior are made. The costs and benefits of lobbying or voting behavior itself receive considerably less attention ${ }^{15} 16$.

Another important early contribution to the private interest theory of accounting regulation is the "excuses" article of Watts and Zimmerman [1979]. It focuses on the role of accounting theories in the political process. Watts and Zimmerman [1979] take an interest group perspective of the political process. Accounting theories are used as justifications for the positions taken in the political process. These justifications are frequently couched in public interest terms because this increases the chance that these positions will be accepted by the regulators. The demand within the political process for justifications drives the supply of accounting theories or "excuses". To test their theory, Watts and Zimmerman [1979] formulate two competing hypotheses. The first hypothesis, based on private interest theory, is that accounting theories lag behind regulation. The alternative hypothesis, based on public interest theory, is that accounting theories are provided before the passing of regulation. Watts and Zimmerman [1979] provide evidence that in three cases in the US and the UK (i.e. railroad legislation, income tax acts, and securities acts), accounting theory lagged behind the legislation.

Reviewing the Watts and Zimmerman [1978 and 1979] articles from an interest group perspective, it appears that the costs and benefits of lobbying behavior itself receive little attention. Their first article in particular provides

${ }^{15}$ For example, Watts and Zimmerman [1978, p.307] admit that they do not take the gaming behavior of lobbyists into account.

${ }^{16}$ The Jobbying costs which Watts and Zimmerman [1978, p.308] take into account are the costs of the submission, which are mainly managers" opportunity costs of time. 
little evidence relating to interest group theory because it is mainly concerned with the economic effects of regulation for managers and not with the effects of managers' activities on regulation. Their second article provides evidence for one element of the interest group theory: the role of accounting theories in the political process.

Studies in the accounting literature which emphasize the costs and benefits of lobbying behavior are Sutton [1984] and Lindahl [1987]. On the basis of the costs and benefits of lobbying behavior, hypotheses concerning the characteristics of those who will actively lobby in the political process of accounting regulation are generated. The article by Sutton [1984] draws heavily on Downs [1957]. The model used to explain lobbying behavior assumes that an individual will only spend resources on lobbying if the expected benefits exceed the costs ${ }^{17}$. The benefits of lobbying are reduced through the freerider problem which arises when lobbyist bears all of the costs of lobbying while receiving only a part of the benefits. A regulation established by a lobbyist might also have beneficial effects for non-lobbyists, so an individual may decide not to lobby if he expects that other lobbyists will establish the desired regulation. This free-rider problem can be diminished with costsharing arrangements, which give the opportunity of sharing the costs of lobbying among those who would receive benefits from the desired outcome. The usual cost-sharing arrangement is an organization which tries to establish a regulation which is generally favorable for its members. The costs of lobbying are shared through membership payments. Sutton [1984] states that, considering the costs of lobbying, only those who expect large benefits from lobbying will invest resources in lobbying. Applying this to accounting regulation, he expects that producers of financial statements (i.e. accounting firms and corporations) will spend more resources on lobbying than users of financial statements. Sutton [1984, pp.85-86] gives three reasons for this expectation. First, producers are in general wealthier than users. Hence, it can be expected that the absolute size of the wealth affected by the regulation is larger for producers compared to consumers. Second, Sutton [1984] assumes that producers' income is dependent on a less diversified portfolio. In other words, the regulation will concern a relatively large part of producers' income, but only a small part of users' income. For example, it would be expected that an accounting firm's income will be more heavily affected

17 The expected benefits of lobbying are found by multiplying the gain from a favorable outcome of the regulatory process by the probability that lobbying will affect the outcome in the desired direction. The costs of lobbying are the resources spent on the promotion or obstruction of a particular accounting regulation (e.g. resources spend on advertisements, presentations for public hearings, and research supporting the lobbyists' standpoint). 
than the income of a user who holds only a limited number of assets relating to firms subjected to accounting regulation, and whose principle income comes from a regular salary. A third reason to expect that producers would spend more resources on lobbying is that they have a smaller free-rider problem. As compared to consumers, the number of producers is small, their economic interests are more homogeneous, and more existing organizations are available for lobbying efforts. These producer characteristics make it easier to establish cost-sharing mechanisms [Lindahl, 1987]. The latter study is complementary to Sutton's work and it proposes the use of the insights of Olson $[1965]^{18}$ to explain lobbying behavior for accounting standards. Compared to Sutton [1984], Lindahl [1987] stresses the public good nature of accounting standards and the need for cost-sharing arrangements to enable collective lobbying.

Both Lindahl [1987] and Sutton [1984] admit that their theories are difficult to test empirically. In particular, the provision of evidence of the magnitude, nature, and timing of lobbying activities is difficult. The effectiveness of lobbying would be expected to be inversely related to its observability, so the costs and benefits of lobbying are not observable. The testing difficulties give a plausible explanation for the low number of empirical studies in this area. Lindahl [1987] concludes that the results of empirical studies in this area should be interpreted with great care. The strong results sometimes suggested do not seem to be justified. Sutton [1984] proposes a qualitative analysis of the political process (e.g. through interviews and questionnaires) to test economic theories of accounting regulation.

\subsubsection{Empirical Evidence Regarding the Application of Private Interest Theory to Accounting Regulation}

In the past 20 years, a considerable body of empirical research of an economic nature and relevant for the private interest theory of accounting regulation has developed:

(1) Empirical reseatch on the effects of accounting regulation for affected parties;

18. Olson [1965] stresses that it is only under special circurnstances that the existence of groups of individuals with common interests will result in lobbying actions in the political process. Only small groups, and other groups that can provide selective incentives will be able to organize collective action. An example of a selective incentive is that registered accountants are only allowed to use the title "RA" and supply audit services if they are members of NIVRA and pay their membership fees. 
(2) Empirical research on the positions taken by parties in the political process;

(3) Empirical research on the effects of parties on the outcome of the politicall process.

This research will be discussed below ${ }^{19}$ :

\section{ad 1) Effects for affected parties}

Of the three categories, empirical research on the economic effects of accounting regulation is the most developed (for overviews and summaries of this area of research see for example [Holthausen and Leftwich, 1983; Chow, 1983a; Kelly, 1983; Watts and Zimmerman, 1986, chapter 12]). The overview presented here is mainly based on Chow [1983a]. Research on the effects of accounting regulation can be divided into studies that are directed towards detecting the economic effects, or impacts, of accounting regulation, and those that seek to test alternative explanations for economic impacts. Both groups of empirical studies will be discussed below, but we must first make one observation which applies to both kinds of studies equally: the focus of nearly all of these studies is on the effects of regulation for shareholders and/or managers [Cooper and Sherer, 1984]. Effects on other suppliers of capital (e.g. bondholders and creditors) are hardly examined, and effects on affected parties who are not capital suppliers (e.g. accountants and workers) also receive very limited attention. For both the normative and positive issues regarding accounting regulation this is a considerable limitation, and not in line with the expected contribution of the economic consequences approach to accounting policy making (see e.g. May and Sundem [1976]).

The studies of the economic effects of regulation can also be divided into two subgroups: studies of the stock price effects of accounting regulation and studies of the effects of accounting regulation on the financing and investment activities of firms. The general idea of the stock price studies is that compulsory accounting changes will affect the value of the firm. A firm's individual accounting policy has its specific costs and benefits. A compulsory change in a firm's accounting policy will change these costs and benefits and affects the value of the firm. These changes in the value of firms are detected through changes in security prices. With respect to the stock price

19 The first research category belongs to the "Old Law and Economics" while the second and third research categories belong to the "New Law and Economics" [Holzhauer et al., 1989]. "The "Old Law and Economics" is concerned with the effects of llaw on markets. The "New Law and Economics" is concerned with the economic analysis of law itself. 
studies ${ }^{20}$, Chow [1983a] is able to provide a list of 27 studies of 15 different accounting regulations. Fourteen of the 27 studies report significant effects caused by accounting regulation. The remaining studies did not report significant effects. The inconsistencies with respect to the results of these studies can be attributed to differences in research design (i.e. the selection and calculation of test variables, selection of the time period, controlling for confounding effects, sample selection, and the selection of statistical tests). The main weakness of these studies is that they try to provide evidence of the existence of an effect instead of testing an explanation of an effect. The hypotheses tested do not give a prediction of the sign of the effect, which results in less powerful tests and means that they give little guidance for the prediction of the effects of other regulations. Moreover, the results suggested by these studies are difficult to generalize to other accounting regulations. According to Chow [1983a, p.80], the general conclusion of this area of research is that accounting regulation can affect stock prices, even if it has no direct cash flow effects.

There are fewer studies in the second subgroup, research on the regulatory effects on financing and investment activities. Chow [1983a] summarizes and discusses three studies, which are concerned with the effects of accounting regulation on decisions by firms as to the amount of resources spent on research and development activities [Dukes et al., 1980; Horwitz and Kolodny, 1981] $]^{21}$ and on decisions by firms to issue debt via public or

20 An example of research in this area is the study by Noreen and Sepe [1981] of the stock price effects of FASB deliberations on requiring price level adjusted financial statements. The stock price effects of three events were examined: (1) the decision by the FASB in January 1974 to put the issue on the agenda, (2) the decision by the FASB in November 1975 to postpone the requirements with respect to price level adjusted information, and (3) the announcement in January 1979 of a new proposal to require firms to disclose price level adjusted information. Noreen and Sepe [1981] admit the difficulties of predicting the stock price effects of these events per firm. Therefore they use a "price reversal" technique. They expect that for any one firm: (A) the stock price effects of events 1 and 3 will be in the same direction, and (B) that the effect of event 2 will be in the opposite direction to the effect of events 1 and 3 . The empirical results of the study suggest that all three events had a stock price effect. Besides, the expected directions of the changes as specified by $A$ and $B$ were confirmed for most firms.

${ }^{21}$ As an example of the research in this area, the study by Horwitz and Kolodny [1981] examined the effects of the FASB and SEC regulations, of 1974 and 1975 respectively, which required firms to expense $R \& D$ costs immediately and did not allow capitalization of these costs. The sample of the study consisted of 43 small high-technology firms that capitalized $R \& D$ before the passing of the FASB and SEC regulations. The study assumes that if these firms did not change their R\&D expenditures, the requirement to expense R\&D costs would have negative effects on reported profit, equity, and debt- 
private placement [Benston, 1969]. The three studies are criticized for their weak experimental design, caused mainly by a lack of theory. For example, one serious problem of the R\&D studies is that they have no theory of the determinants of R\&D expenditure, so that it is difficult to control for nonregulation-related influences on $R \& D$ expenses in the pre- and postregulation periods. Both studies have to make ad hoc assumptions regarding the timeseries and cross-sectional variations of $R \& D$ expenditures. A second problem is that both studies have to assume a preregulation period, with no effects of accounting regulation, and a postregulation period, which contains the regulatory effects. From a theoretical standpoint it is difficult to distinguish these two periods. For example, managers knowing that regulation will be changed in the future might change their R\&D expenses in the "preregulatory" period. Similar problems are associated with the Benston [1969] study. $\mathrm{He}$ tried to assess the effects of accounting regulation on the decision of firms to issue debt either publicly or privately. Differences over time and between industries in the ratio of public to private debt are attributed to the enforcement of accounting regulation. However, it is difficult to distinguish the effects of accounting regulation on the public-private debt ratio from nonregulatory effects, without a theory of firms' decisions to issue debt either privately or publicly. Chow [1983a, p.95] concludes that further research on the effects of regulation on financing and investment decisions would be useful for theory development and accounting policy making. However, this statement is subject to the requirement that theory be used more explicitly and that a wider group of financing and investment effects should be examined.

There are also few studies which test theories of the effects of accounting regulation. Chow [1983a] discusses three studies [Leftwich, 1981; Collins et al., 1981; Chow, 1983b]. The first two studies investigated the effects of accounting regulation on stock prices, the last study investigated effects on stock and bond prices. Agency theory was used to formulate hypotheses on the effects of accounting regulation on stockholders' and bondholders' wealth. Accounting information is used in agency contracts between managers, shareholders, and bondholders. Contracts are written which minimize the agency costs. Accounting regulation is expected to reduce stockholders' wealth and increase bondholders" wealth because, first, accounting regulation decreases the number of permitted accounting procedures and reduces the

equity ratios. To avoid these negative effects it was hypothesized that the firms would lower their R\&D expenditures. To test this hypothesis, the firms were compared with 43 high technology firms that did not capitalize their R\&D before the FASB and SEC regulations. The hypothesis that the capitalizing firms would lower their R\&D expenditure, as compared to expensing firms, was confirmed. 
opportunities to write optimal contracts, and, second, accounting regulation limits the opportunities for managers and shareholders to use "creative accounting" at the expense of bondholders. The general results of these stucies do indeed suggest that accounting regulation affects security prices significantly and reduces shareholders' wealth and increases bondholders' wealth. However, hypotheses of different regulatory effects across firms, depending on variations in the nature of the shareholder-bondholder conflict (e.g. measured through leverage ratios), were only partially supported. Chow [1983a, p.103] concludes that, considering their mixed findings and the preliminary features of the results, the three studies cannot be used for evaluating the effects of accounting regulation. However, Chow [1983a] believes that this area of research, with its emphasis on the explicit use of theory, will in the future become useful for evaluating accounting regulation.

\section{ad 2) Positions taken by parties in the political process}

A considerable body of research has developed on the preferences expressed by organizations and individuals during the political process of setting accounting standards. The main source of this data is the reactions to proposals for new accounting standards which are submitted by various organizations and individuals (e.g. corporations, accounting firms, representative bodies and individual academics) ${ }^{22}$. The research on preferences expressed in the political process can be classified on the basis of the lobbying parties (see e.g. [Lindahl, 1987, p.60]. This discussion will be restricted to research concerning the two most frequently studied classes of lobbyists: (1) research on the preferences of corporations that are subjected to accounting standards, and (2) research on the preferences of public accounting firms. The discussion of the lobbying studies which follows will conclude by discussing some shortcomings of this area of research.

\section{Lobbying of corporations which are subject to financial accounting} standards. A considerable body of research has been developed on the relationship between the (expected) effects of accounting regulation for corporations and their lobbying positions in the political process (see e.g. [Watts and Zimmerman, 1978; Dhaliwal, 1982; Kelly, 1982 and 1985; King and O'Keefe, 1986; Griffin, 1983; McKee et al., 1984; Sutton, 1988; Deakin, 1990]). As stated earlier, the first study in this series of lobbying studies was that by Watts and Zimmerman [1978]. The lobbying studies can be viewed as a subset of the research on accounting choice (for a recent overview see [Watts and Zimmerman, 1990]). The central idea of accounting

22 The preferences are inferred from the written submissions and measured as a dichotomous variable, i.e. "favors standard" and "opposes standard". 
choice research is that alternative accounting policies have different effects on financial statements, and that managers and owners are not indifferent to these effects because of their economic consequences [Francis, 1987, pp.36$37]$.

In the research into corporation lobbying, the dependent variable is generally the position (i.e. "favors" vs. "opposes") of the corporation in the submitted reaction to the regulator. The most frequently used independent variables are firm size, management compensation schemes, and debt-to-equity ratios. Firm size is included because political costs are expected to increase with firm size. Large firms are expected to lobby more actively because their profit figures receive more political attention than those of small firms. The assumption is that large profits earned by large firms provoke government intervention, so large firms, in particular, would be expected to object to an accounting proposal that increases the corporation's reported earnings. Variables relating to management compensation schemes are included because managers of corporations with these schemes would be expected to support accounting regulations that increase reported earnings. Debt-to-equity ratios are used as an independent variable because corporations with high debt-to-equity ratios, who are thus closer to debt covenant violations, are expected to object to proposals which increase debt-to-equity ratios.

These empirical tests give the most consistent results with respect to size variables and debt-to-equity ratios [Francis, 1987, p.37]. With respect to compensation schemes the results are less consistent. One possible explanation is that there is no accurate data on these schemes. For example, in some studies corporations are classified according to the existence of a compensation scheme for managers. However, there is great variation in the use of accounting numbers in these schemes. Also, this area of research is in essence concerned with the (potential) effects of accounting regulation for corporations and not vice versa. The positions which corporations expressed in their submissions were expected to be directly related to the (potential) effects of accounting regulation for corporations. The lobbying process itself (resources spent on lobbying, free-riding corporations, mechanisms that encourage coalitions, etc.) and its effect on the outcome of the political process is hardly a part of this research. As such, the title of Watts and Zimmerman's [1978] article "Towards a Positive Theory of the Determination of Accounting Standards" is somewhat ambitious. 
Lobbying by Public Accounting Firms ${ }^{23}$. The number of studies of accounting firm lobbying for standards is small, compared to studies of corporation lobbying. One distinguishing feature of the studies on accounting firm lobbying is the consideration of the partly overlapping and conflicting interests of auditors and their clients ${ }^{24}$. Here, four studies on accounting firm lobbying will be discussed: Haring [1979], Watts and Zimmerman [1981], Puro [1984], and Kinney [1986].

Haring [1979] made one of the early studies of the positions of accounting firms in the political process. His research employed a simple methodology: he examined whether there is a statistically significant relationship between accounting firm preferences ("favors" vs. "opposes") and the percentage of the clients of an accounting firm clients favoring or opposing a rule. The study is based on the reactions of the 15 largest accounting firms to 20 issues relating to seven different FASB statements. A probit model is used to investigate the relationship between the positions taken by accounting firms and the positions of their clients. The results indicated a positive but not significant relationship between audit firm positions and their clients' preferences.

Watts and Zimmerman [1981] $]^{25}$ also try to explain the positions taken by auditors in the deliberations concerning accounting standards. Their model of the relationship between audit firm and clients' preferences is more complex than that used in Haring's [1979] study. The accounting firm positions were taken from written submissions to the FASB and the votes of auditing firms' voting members on the APB. The initial model suggested by Watts and Zimmerman [1981], which recognizes overlapping and conflicting interests of auditors and their clients, uses the audit firm"s position (again "favors" vs. "opposes") as dependent variable. The first independent variable is the weighted sum of their clients" positions. The expectation is that the position taken by auditors will be positively related to the positions of their clients. Two reasons for this expectation are given: (1) auditors provide lobbying

${ }^{23}$ A frequently given motive for research in this area is the allegation of the staff of the Subcommittee on Reports, Accounting and Management of the Committee on Governmental Operations of the US Senate (the Metcalf staff) that "the accounting profession is dominated by eight giant accounting firms".

24 An exception is the study by Kinney [1985] which explains accounting firm preferences on the basis of the auditing technology (structured vs. unstructured) of the firm.

${ }^{25}$ This study concerns an unpublished working paper. The summary given here is based on an overview in Watts and Zimmerman [1986, pp.328-334]. 
services to their clients, and (2) audit fees depend on the client's market value, so there is an incentive to support a position that increases the market value of clients. The second and third independent variables which were suggested relate to the conflict of interests between accounting firms and their clients. They are dummy variables for the complexity of the accounting standards being considered and their effect on the available set of accounting procedures. Accounting standards that are complex and increase the set of available accounting procedures are supported because they result in more work for the auditing firm. This model was tested against data from five proposed accounting standards. Because all five standards increased accounting complexity, this part of the model was not itself tested. In general, the empirical results were in line with the model suggested by Watts and Zimmerman [1981].

Puro [1984] builds on Watts and Zimmerman's [1981] work. In this study, two models are used to explain the positions taken by corporations: Watts and Zimmerman's [1981] model and a capture model. The latter model is based on Stigler's [1971] work and predicts that regulation benefits those who are regulated (i.e. accounting firms). It emphasizes the effects of the accounting standards on the amount of auditing work. The first model emphasizes the relationship between accounting firms and their client corporations. Two kinds of standards are distinguished by Puro [1984]. Standards requiring new disclosure of items, and standards on the measurement of items. The first group of standards affect mainly the amount of auditing work, the second group of standards affect mainly the reported income of corporations. Puro [1984] expects that the Watts and Zimmerman [1981] model will give good results for measurement issues, and the capture model will give good results for disclosure issues. The data for the study was the reactions to six FASB exposure drafts that were submitted by auditing firms and their clients. The exposure drafts concerned four disclosure issues and two measurement issues. The empirical results of the study were in line with the suggested hypotheses: for the disclosure issues, variables based on the capture model provide a better explanation of the auditing firms" positions than variables based on Watts and Zimmerman's model [1981], whereas, for the measurement issues, variables based on Watts and Zimmerman's [1981] model provide a better explanation than the capture model variables.

Kinney [1986] tries to explain lobbying positions in a different area than previous studies. Instead of examining lobbying positions on accounting standards, this study tries to explain voting behavior for auditing standards. The votes are those of the members of the Auditing Standards Board (ASB) who are representatives of auditing firms. The central hypothesis of the study 
concerns the relationship between the audit approaches of the members' auditing firms (structured vs. unstructured) and their votes. Kinney [1986] expects that firms with a structured approach will favor more auditing standards, while firms with an unstructured approach will oppose increased auditing standards. The empirical results of the study confirm this expectation. Besides, Kinney [1986] tested the frequently expressed assertion that the Board is dominated by Big Eight firms. It appeared that the members' positions were not related to the size of their auditing firm.

The following criticisms can be mounted against the studies on lobbying positions taken in the political process of accounting standards [Francis, 1987, pp.37-38; Lindahl, 1987, pp.69-71]:

(1) The preferences of lobbying parties cannot be inferred unambiguously from the submitted reactions. Preferences may vary for different parts of the proposal for new accounting regulation. Besides, lobbyists may reject proposals for various reasons. In sum, the classification of lobbying parties into "favors" and "opposes" is very crude.

(2) Lobbying parties may not reveal their true preferences on one proposal for strategic reasons [Amershi et al., 1982]. The studies use a single-issue one period model. However, lobbying can be viewed as a multi-period multi-issue game. For example, lobbying parties may make concessions on one proposal, which is less important to them, to increase the effect of their opposing position on a subsequent, more important, issue. If lobbying is viewed as a multi-period game, the positions taken on an issue may not reflect the lobbying party's real preference.

(3) The studies are not really addressing lobbying behavior. The comment letters are a low cost form of lobbying and could be viewed as voting. Only a relatively minor fraction of lobbying resources are likely to be invested in the submission of comment letters. More substantial lobbying resources are probably spent on other activities (placing an advertisement in a newspaper ${ }^{26}$, encouraging research supporting the standpoint of the lobbyist, having diner with a regulator, etc.).

(4) The studies fail to take the public good nature of accounting standards into account. This implies that firms not lobbying for a particular standard may either be unaffected by the regulation or may be affected but free-riding on the lobbying activities of other firms. For

${ }^{26}$ For example, the Dutch Organization for Registered Accountants (NIVRA) placed a page length advertisement in a national newspaper [NRC, 5/30/1990] which informs the 'general public' about the activities of NIVRA. 
example, the standard explanation for the finding that large firms lobby more actively is in terms of political costs (i.e compared to small firms, large firms will lobby more actively against accounting regulations that increase accounting measures of their income because their profits receive more political attention). However, the phenomena can also be explained in terms of lobbying costs and benefits. As suggested by Lindahl [1987] and Sutton [1984], considering the costs and benefits of lobbying activities, it can be expected that large firms will lobby more actively. Small firms may also be negatively affected by accounting regulations which increase their measured profit, but may free-ride on the lobbying activities of large firms.

\section{ad 3) Effects of parties on the outcome of the political process}

The studies in this area of research try to relate the outcome of the political process (i.e. regulation) to the lobbying activities of interested parties. Of the three areas of empirical research, this is the least developed. The number of studies is low, and there is a great variation in research design.

The studies by Haring [1979] and Brown [1981] examine the correlation between the positions of lobbying parties and the regulatory activities of the FASB. Haring [1979], uses a probit model to explain the FASB's actions. The explanatory variables are positions taken by sponsoring organizations of the FASB, positions taken by academicians, positions taken by accounting firms, and positions taken by business enterprises. All four explanatory variables yielded significant results. The results suggested that the support for a rule by the FASB was positively related to the positions of sponsoring organizations and accounting firms while the positions of academicians and business enterprises were inversely related. The objective of Brown's [1981] study is similar to Haring's [1979] study, but it employs other statistical techniques, namely multidimensional scaling and discriminant analysis. The MDS technique suggested that the FASB takes an outlying position relative to the lobbying parties. This result can indicate either that the FASB takes a compromise position or that the FASB simply ignores the preferences of respondents. The discriminant analysis revealed that FASB preferences are not more strongly related to accounting firms' preferences than to corporations' preferences. Haring's [1979] and Brown's [1981] study can be criticized for their lack of theory. They examine the degree of association between the FASB positions and lobbying party positions without formulating a theory of this relationship.

A study by Young [1988a] is one of the most integral applications of interest group theory to accounting regulation. It is concerned with the supply side regulation of the market for auditing services, namely occupational licensing, 
and uses the framework provided by Stigler [1971] and Peltzman [1976]. The subject of the study is the differences in regional licensing regimes for public accountants in the United States. For example, in some states occupational licensing is restricted to auditing services, while in other states review and compilation services are also included. Another example is that in some states CPAs have only the sole right of using the title "Certified Public Accountants", while in other states CPAs have also the sole right of using titles such as "accountant" and "auditor". For the model estimated, the degree of restrictiveness of a state's licensing regime was the dependent variable (e.g. states in which unlicensed accountants were not allowed to provide review and compilation services or use the title "accountant" were classified as "restrictive"). As independent variables various state indicators of the interest group structure, the political system, and the socioeconomic environment were included. The results of the study suggest that restrictive laws are more likely in states where the interest group strength of CPAs is high. Indicators of interest group strength are the ratio of CPAs to noncertified public accountants in a state, and the percentage of CPAs who are members of the state society for CPAs. For both indicators there is a positive relationship with the degree of restrictiveness, but only the first one is significant at conventional levels. The indicators of the political system, namely interparty competition and legislative turnover ${ }^{27}$, were respectively significant and marginally significant. There appeared to be no significant relationship between the socioeconomic variable ${ }^{28}$ (i.e. per capita income) and the degree of restrictiveness of the licensing regime ${ }^{29}$.

27 Interparty competition refers to the relative balance between Democrats and Republicans in state-level elective offices. Young [1988a] expects that if there is strong interparty competition (i.e. the number of Democrats and Republicans are in balance), interest group power is mitigated and as a result less restrictive licensing regimes will exist. High turnover of state legislators reduces the "professionalism" of the state legislature and interest groups can have more success in the political process. Therefore Young [1988a] expects that high legislative turnover will result in more restrictive licensing regimes.

2icensing increases the quality of accounting services supplied and raises their price. Hence, Young [1988a] expects that states with relative high per capita income will have more restrictive licensing regimes.

29 A nice example of the application of interest group theory to an area closely related to accounting regulation is Haddock and Macey [1987]. This study tries to explain the existence of insider trader regulation in terms of the Pelizman [1976] model. Haddock and Macey conclude that SEC insider trading regulations are beneficial for market professionals and not for ordinary investors. Compared to ordinary professionals, market professionals are well organized and can strongly promote their interests before the SEC. 
Dopuch and Sunder [1980] emphasize the role of research, or more specifically the conceptual framework of the FASB, in the regulatory process. They state that the conceptual framework of the FASB is the result of the private interest of the accounting profession. The conceptual framework is used by the accounting profession to avoid government intervention and maintain control over accounting standard setting. The conceptual framework can be used by the FASB to rationalize its choices and "boost its public standing" [Dopuch and Sunder, 1980, p.115]. From a private interest perspective the argument of Dopuch and Sunder [1980] has two shortcomings. The first is that they do not discuss the issue of why the accounting profession in particular is able to dominate the accounting regulation process. No explanations are provided in terms of information and organization costs. The second shortcoming is their implicit assumption that the accounting profession benefits by avoiding the government taking over the right to regulate accounting. Although this assumption is plausible, empirical evidence supporting this assumption is not available.

\subsubsection{Criticisms and Alternatives}

The discussion in the previous section has already included some criticisms of economic explanations of accounting regulation. However, these criticisms were within the framework of economic explanations of accounting regulation and concerned research design and research methodology issues (e.g. lack of empirical evidence, lack of theory, failure to control for other variables, and measurement errors). Another class of criticisms concern the emphasis on economic explanations. These criticisms of the economic foundations of accounting regulation theories are frequently used to introduce other ("better") non-economic explanations of accounting regulation. This section will briefly review this class of criticisms and the alternative explanations suggested.

\section{Criticisms of Economic Explanations of Accounting Regulation}

The criticisms of the economic explanation of accounting regulation can be classified as follows:

(1) partial analysis;

(2) economic reductionism;

(3) omitted explanations.

ad 1)

As stated earlier, the accounting regulation research discussed has been criticized for its partial analysis. In general only two groups, namely manag- 
ers and shareholders, are considered. It is suggested that a partial analysis is inherent to economic models [Cooper and Sherer, 1984, pp.213/217]. This suggestion is based on the observation that most of the economic accounting regulation research has consisted of partial analyses. However, it is not clear why economics cannot analyze the relationship between accounting regulation and other affected parties such as creditors and workers. An example is the study by Benston [1985] in which the interest in accounting information and its regulation of a large number of interested parties are discussed from an economic point of view. In sum, partial analysis is indeed a shortcoming, but there is no a priori reason to expect that this cannot be solved within the economic framework.

ad 2)

Economic reductionism refers to attempts to explain accounting regulation exclusively in terms of economics. According to Tinker [1984, p.61], economic reductionism is undesirable because of the "downfall of the economic paradigm". This conclusion is reached on the basis of a less than one-page discussion of "the state of neo-classical economics". Tinker [1984] discusses the problems of economic reductionism in very general terms. As a result, it is not clear what exactly the problems with the use of economics in accounting regulation research are. Finally, the researchers who are active in the area of research Tinker is criticizing do not claim that only economics can explain accounting regulation. Tinker does not provide a reference for such a strong claim and as far as I know it does not exist.

ad 3)

The economic research on accounting regulation is criticized for neglecting alternative explanations. Merino and Neimark [1982] state that the standard economic analysis of the SEC disclosure system lacks sociological and historical variables. According to Tinker [1984], the private interest analysis of accounting regulation is at an individual level and does not consider the social system in which the interest groups are established ("political voluntarism"). According to Tinker, the social system is essential for understanding interest group structures (e.g. a capitalistic society will have a different interest group structure than a communist society). Again it can be stated that the researchers on the private interest theory are accused of stronger claims than they actually expressed. It is not claimed in the economic accounting regulation literature that economics provides complete explanations of regulatory phenomena. Also, it is not claimed that an economic explanation precludes other explanations. 


\section{Alternative Theories of Accounting Regulation}

The critique of the economic approach is frequently used as an introduction to alternative approaches. However, as concluded, most of the faults described are not inherent to the economic approach. Among the suggested alternative approaches are: a political economy approach, a socio-historical approach, and a radical approach. These three alternative approaches will be discussed below.

A political economy approach to accounting regulation is proposed in the study by Cooper and Sherer [1984]. The distinctive features of a political economy approach are: (1) recognition of power and conflict in society, (2) recognition of the historical and institutional environment, and (3) recognition of the changing interests of people. Cooper and Sherer [1984] state that three imperatives must be followed to produce valuable political economy research in accounting: (1) be normative, (2) be descriptive, and (3) be critical. Finally, Cooper and Sherer provide some proposals for accounting research, such as an investigation of the use of accounting research to legitimize and rationalize regulatory activities.

A socio-historical approach to accounting is proposed by Merino and Neimark [1982]. The central theme of their study is the lack of historical and social considerations in the standard analysis of the SEC disclosure regulations. As a result, the explanations for the existence of the SEC regulations are not satisfactory. Besides, from an accounting policy making standpoint, very simple objectives are assigned to accounting regulation. As an alternative, Merino and Neimark [1982] provide a socio-historical analysis of the SEC disclosure regulations. According to this analysis, the disclosure regulations were enforced to resolve the contradictions between US public philosophy and increasing concentration in the economy. The individualistic market-based public philosophy, which encouraged widespread stock ownership, was not line with firm concentration. According to Merino and Neimark, disclosure regulations were a medium to resolve this contradiction.

The radical approach is proposed by Tinker [1984]. The subject of this approach is the relationship between accounting regulation and social conflict, especially the relationship between social conflict in political activities and social conflict in economic activities. Research topics such as "To what extent is accounting regulation the captive of vested interests?" and "Who are the sides in the struggle for control over setting accounting regulation, and how should accountants choose a side to support?" are proposed. 


\subsection{Comparing the Public and Private Interest Theory}

This chapter has provided an overview of the accounting literature on economic explanations of accounting regulation. First, the public interest explanation of accounting regulation was discussed. A main conclusion was that it is not clear whether accounting regulation raises efficiency. It was also concluded that the public interest does not necessarily require efficient regulation. The formulation of alternative public interest hypotheses requires a closer examination of the objectives assigned to accounting regulation. Second, the private interest theory of accounting regulation was discussed. Both theory development and empirical evidence were dealt with. It was concluded that the private interest explanation in the accounting literature focuses mainly on the effects of accounting regulation on interested parties. The effects of interest groups on the outcome of the regulatory process receive minor attention.

The extensive discussions in this chapter of the public and private interest theories of accounting regulation, allow a comparison of the theories at theoretical and empirical levels. The essential theoretical difference between the public and private interest theory concerns the relationship between regulators and regulation. In the public interest model, the relationship between regulators and regulation is not specified. On the basis of some characteristics of the market for accounting information, it is argued that accounting regulation could improve efficiency, and it is simply assumed that regulators will regulate if that increases efficiency. From an economic standpoint this is a weakness. There is no a priori economic reason to expect that regulators want to improve efficiency. The private interest view is an improvement in this respect. The relationship between regulators and regulation is specified. Activities of the regulator will affect parties in society. These effects, and the organization and information costs of various interest groups will determine the support for the regulatory activities. However, this does not imply that the private interest view leads to the conclusion that regulation is not in the public interest. It might be that political mechanisms encourage regulators to pursue the public interest ${ }^{30}$. Thus, comparing the public interest theory and interest group theory on a theoretical level it appears that they are not diametrically opposed [Haddock and Macey, 1987]. Regulation that is the result of the private interests of

${ }^{30}$ Backhaus [1989a] discusses the incentives in a democratic legislature, assuming that representatives seek to maximize their wealth, to produce efficient law. Given certain circumstances, he shows that legislatures can indeed be expected to pass law that is efficient. 
groups involved in the political process can serve the public interest. The wealth transfers caused by regulation can be a positive sum.

Comparing the public interest theory and private interest theory on an empirical level it appears that they both lack sufficient empirical evidence. To test both the public and private interest explanation of accounting regulation, empirical evidence is required of: (1) the effects of accounting regulation on various parties in society, and (2) the effects of various parties, through lobbying activities, on the outcome of the political process. To test the public interest explanation one must investigate whether the actual economic effects of accounting regulation are in line with the intended economic effects expressed by regulators. To test the private interest explanation one must determine whether the combination of economic effects on interested parties and the organization and information costs of interested parties can explain the outcome of the political process.

The relevant empirical evidence in the accounting literature deals mainly with the effects of accounting regulation on various parties in society. In essence, the empirical research on lobbying positions in the policy-making process also studies these effects. In the Dutch accounting literature, there is a lack of evidence of the effects of regulation and of the effects of groups on regulation. The following two chapters of this study will provide some evidence from two empirical studies of the effects of Dutch regulation, for public accountants and firms. The two studies provide evidence that is imperative for testing the private and public interest explanations of Dutch accounting regulation. However, it will not be $a$ sufficient test. As we will show in chapter six, this will require additional empirical evidence on: (1) the effects of Dutch accounting regulation for groups other than public accountants and firms, and (2) the effects of various parties, through lobbying activities, on the outcome of the Dutch accounting policy-making process. 



\section{Chapter 4 Economic Effects of Dutch Accounting Legislation for Registered Accountants in Public Accounting}

In the Netherlands regulations concerning the financial accounting practice of firms have been growing at a very high rate over the past 20 years. As concluded in chapters two and three, empirical evidence on the economic effects of accounting regulation is needed to obtain a clear view of the normative and positive issues concerning accounting regulation. However, the economic effects of Dutch accounting regulation have hardly been subjected to empirical analysis [Bouma, 1988; Van de Poel, 1988]. This chapter, and one following, will make some initial steps towards providing evidence of the economic effects of Dutch accounting regulation.

Dutch regulation of the financial accounting practice of firms consists of the following elements: company law, jurisprudence of the Enterprise Chamber (Ondernemingskamer), guidelines of the Council for Annual Reporting (Raad voor de Jaarverslaggeving), and the Rules Relating to Securities of the Amsterdam Stock Exchange. Company law is the most influential of these regulations, in terms of financial accounting practice [Klaassen and Bak, 1990, p.24]. Therefore this chapter and chapter five will investigate the economic effects of the provisions in company law concerning the financial accounting practice of firms. These provisions were termed "accounting legislation" in chapter one. Evidence of the effects of accounting legislation for two different groups will be provided. This chapter will present evidence of the effects of accounting legislation for public accountants. The next chapter will present evidence of the effects of accounting legislation for firms. For both groups the effects of two changes in Dutch accounting legislation, one in 1970 and one in 1983, will be investigated. It will be concluded that both legislation changes had significant economic effects for both groups.

The content of this chapter can be summarized as follows. As a result of the 1970 and 1983 changes in Dutch accounting legislation, it can be expected 
that the size of the market for public accounting services' ${ }^{1}$ would increase. The (crude) indicators of the size of the market for public accounting services used (the number of disclosed audited annual accounts and the number of employees in the public accounting sector), confirm this expectation. The economic effects of this increase for those who offer public accounting services depend on whether there is an adjustment of the number of suppliers in the market. In the Netherlands, the suppliers are registered accountants in public accounting (RAs) ${ }^{2}$. The empirical evidence presented in this chapter suggests that the effects differ for RAs who are employees of an accounting firm and RAs who are partners in an accounting firm. The size of the first group adjusted to the increased size of the market, the latter not. The positive economic effects for partners in public accounting indicated by these results are also confirmed by what data on their income is available. Finally, changes in other factors affecting the market for public accounting were investigated. It appeared that these factors (i.e. changes in the voluntary demand for public accounting, and in the degree of concentration on the supply side of the market, and technological changes) did not outweigh the effects of the increased demand in a market having some restriction to the growth of supply.

The chapter proceeds as follows. Section 4.1 will provide a general introduction to the relationship between accounting regulation, occupational regulation, the market for public accounting, and public accountants. Section 4.2 will discuss previous research on the effects of accounting regulation on the market for public accounting. Section 4.3 presents the results of an empirical analysis of the effects of Dutch accounting legislation on the market for public accounting. Section 4.4 will discuss factors other than accounting legislation which might have affected the market for public accounting. Finally, section 4.5 will provide a summary and conclusions.

"Throughout this chapter the term "market for public accounting services" refers to the market for services concerned with the attestation of financial accounting information and for services that facilitate the preparation of financial accounting information [Benston, 1985, p.35].

2. Registered accountants are not necessarily active in public accounting. However, for practical reasons the abbrewiation RA will stand in this chapter for registered accountant in public accounting. 


\subsection{Economic Effects of Accounting Regulation for Public Accountants}

It is frequently claimed that regulation substantially affects the market structure of the public accounting sector (see e.g. [Benston, 1985; Chow et al., 1988; Wallace, 1987]). It is also frequently claimed that public accountants, suppliers in the market for public accounting, benefit from the effects of regulation on the market structure (see e.g. [Ross, 1979, p.191; Dopuch 1989, pp.465-466; Benston, 1969, pp.529-531, and 1985, p.53; Puro, 1984, p.625; Philips and Zecher, 1981, p.44]). In considering the different economic effects, the regulation of the market for public accounting can be divided into demand regulation and supply regulation. Both types of regulation will be discussed below.

Demand regulation concerns the requirements for firms to disclose and audit accounting information. Note that this regulation has been labelled as "accounting regulation" in this study. As a result of this regulation, the demand for public accounting services is a derived demand [Pound and Francis, 1981, p.356]. Firms are "forced" to demand the services of public accountants. As a consequence, the regulatory demand for public accounting services has a very low price-elasticity. Firms subjected to accounting regulation must purchase a relatively fixed amount of audit services and the price can vary over a wide range without changing the decision to buy [Eichenseher and Danos, 1981, pp.485-486]. On the basis of the agency perspective it can be argued that the demand for audit services is elastic in an unregulated environment. According to this perspective, accounting information is just one possible mechanism that can be used for controlling agency problems. In an unregulated environment, if this mechanism becomes too costly other control mechanisms (e.g. outside directors) can be substituted. Assuming an elastic voluntary demand for public accounting, the establishment of demand regulation is beneficial for public accountants. The regulatory demand is inelastic and gives the opportunity to set higher prices without affecting the quantity demandled. However, Benston [1985, p. 74] argues that public accountants only receive short term, and not long term benefits, from demand regulation. The assumption that there will be an adjustment on the supply side, if demand increases, is essential to his argument. This adjustment is possible if there is no entry barrier to the market for public accounting. Without an entry barrier, positive economic effects are competed away through a growing number of suppliers. 
Supply regulation relates to occupational regulation. Various levels of occupational regulation can be distinguished: registration, certification ${ }^{3}$, and licensing [Young, 1986, p.6]. Here only the third kind of occupational regulation will be discussed because public accounting markets are subjected to this form of regulation. Occupational licensing prohibits the supply of public accounting services without a license. The occupational regulation of the market for public accounting is comparable to the regulation of the market for surgery. In this market only qualified surgeons are aliowed to supply services. Two different effects of occupational licensing on the market for public accounting services can be distinguished: (1) the establishment of an entry barrier to the market, and (2) restricting the quality variance in public accounting services (the "Cadillac effect"). Concerning the first effect, a frequently suggested hypothesis is that occupational licensing functions as an entry barrier to the market for public accounting [Pound and Francis, 1981, p.357]. Those who have a license can influence the entry to the market via the professional organization, which often has the right to determine the qualifications needed to receive a license. Licensing makes entry more costly, increases the prices of services provided and decreases the number of people in the sector [Young, 1986, p.8]. As a result, restrictions on entry will have positive economic effects for public accountants and will raise salaries above competitive levels [Pichler, 1974, p.55; Hakansson, 1978, p.723]. The second effect, the "Cadillac Effect", can be described as follows. Licensing may indeed raise the quality of accounting services provided. As a result, it is not possible to buy low cost, low quality services (a "Plymouth" or "Lada"). However, for some firms it might be efficient to buy low quality services. These firms can only buy high quality services (a "Cadillac" or "Mercedes") and so spend too many resources on public accounting services. In general it can be concluded that, as a consequence of these two effects, licensing is in the economic interest of the licensed group because it limits market competition [Stigler, 1971; Young, 1986, p. 7] $]^{4}$.

${ }^{3}$ Young [1986] describes "registration" and "certification" as follows. "Registration" is the simplest form of occupational regulation and only requires individuals to list their names in official lists. All persons listed have the right to supply. "Certification" does not prevent anyone from supplying, but the use of particular titles in the market is limited to persons who have a certificate.

${ }^{4}$ For example, the minutes of the NIVA (the predecessor of the current professional organization of RAs) stated that "the organization will act in the interest of its members and assistants" (minutes NIVA 1964, section 1b). One of the means of achieving this objective was "striving for legal regulation of the profession" (minutes NTVA 1964, section $2 \mathrm{~g} / \mathrm{h}$ ). 
The economic effects of the demand and supply regulation of the market for public accounting services are dependent. If demand regulation increases the size of the market for public accounting, its economic effects depend on the adjustment at the supply side. If there is free entry to the market, positive economic effects are competed away and only short term positive economic effects exist [Benston, 1985, p.74]. However, an entry barrier to the market for public accounting, due to occupational licensing, probably implies long term positive economic effects. Similarly, the economic effects of supply regulation are dependent on demand regulation. If the supply side of the market for public accounting is regulated through occupational licensing, the economic effects depend on the degree to which firms are "forced" to demand. If there is no demand regulation and firms can easily replace accounting information with other control mechanisms, the positive economic effects are limited. However, if firms are required by regulation to demand, occupational licensing probably implies considerable positive economic effects for public accountants.

\subsection{Previous Research}

Empirical research relevant for this chapter can be classified under the following three subjects: (1) restrictions on entry to the market for public accounting, (2) the effects of activities of public accountants in the political process on the regulation of the market for public accounting, and (3) firm concentration in the market for public accounting. Before discussing each area of research more extensively, here are some introductory remarks about these areas of research. Empirical results of direct tests of the economic effects of accounting regulation for public accountants is hardly available. The first area of research investigates most directly the economic effects of regulation for accountants. It is concerned with the use of the occupational license to restrict entry to the market for public accounting. The second area of research has already been discussed (section 3.2.3) and can be viewed as indirect tests of the effects of accounting regulation on the market for public accounting. On the basis of assumed effects of a particular regulation for the market for public accounting, hypotheses on the preferences of public accountants for this regulation are deduced. The hypothesized preferences are compared with the preferences expressed in comment letters to regulators. In the third area of research, concentration in the market for public accounting, regulation has a very modest role. It has been suggested as a possible factor affecting the degree of concentration in the sector [Eichenseher and Danos, 1981, pp.486-487]. The research on surrogates for auditing fees as a measure of the market, and on the demand for public accounting in 
an unregulated environment, is relevant for this chapter also, although it is not directly focused on market regulation. Research on other measures of market size is conducted because in many countries data on auditing fees are not available. The surrogate measures are used, for example, in studies of the concentration in the market for auditing services. Research on the public accounting market in an unregulated environment is done to assess whether, and to what extent, firms voluntarily demand public accounting services. Both areas of research will be discussed in the relevant sections of this chapter.

It should be remarked that the number of studies of the characteristics of the market for public accounting (supply concentration, factors affecting fees charged, entry to the market, etc.) is relatively low. A potential explanation for this is the difficulties in gathering data on this market [Zind and Zéghal, 1989$, p. 26$]^{5}$.

Concerning the first area of research, restrictions on entry to the market for public accounting, there are few empirical studies. Here we will discuss two studies, one by Pichler [1974] and one by Young [1988a]. Both studies are concerned with the use of the CPA examination in the US as an entry barrier. On the basis of casual empirical evidence, Pichler [1974] suggests that the CPA examination is used as a barrier to entry. This conclusion is based on: (1) the assumption that in the period '52-'72 there was a relatively constant pass rate for the CPA examination, and (2) the observation that the educational preparation of the examinees increased strongly in this period. However, Pichler's [1974] conclusion is criticized for not taking into account possible quality improvements [Revsine and Juris, 1974]. The increasing complexity of public accounting services can provide an alternative explanation of the higher educational background of public accountants. The second study by Young [1988a] reported on the relationship between exam failure rates of the CPA examination and downturns in economic activity ${ }^{6}$. The expectation is that the accounting profession will use the CPA examination to restrict entry during economic downturns. In the period that the CPA examination was graded at state level, failure rates indeed increased with

"For example, Langendijk [1988] tried to collect the annual accounts of large Dutch accounting firms over the fiscal years 1984, 1985, and 1986. Only $32 \%$ of the accounting firms were willing to submit their annual accounts.

${ }^{6}$ Downturns in economic activity are measured by unemployment rates. 
economic downturns. This relationship did not exist when exams were graded at a national level?.

Studies on the effects of activities of the accounting profession in the political process of accounting regulation, the second area of research, were already discussed in section 3.2.3. These studies assume that it is in the private interest of the accounting profession to have a regulated market for public accounting. On the demand side it is in their interest to have regulations that require firms to buy the services of accountants and that make work for them [Watts and Zimmerman, 1986, p.329; Puro, 1984, p.627]. On the supply side it is in their interest to restrict entry to the market through occupational licensing [Young, 1988b]. On the basis of these assumptions, hypotheses on the positions and activities of public accountants in the political process of accounting regulation are generated and tested.

In the third research area, concentration in the public accounting sector, a subdivision can be made. First, a number of studies are concerned with audit firm activity across industry categories (see e.g. [Zeff and Fossum, 1967; Rhode et all., 1974]). In general, these studies are restricted to describing concentration differences between industries. An exception is the study by Eichenseher and Danos [1981], in which an attempt is made to explain differences in audit firm concentration across industries. The explanatory variables 'client-industry regulation' and 'capital market activity" were found to be significant. The first variable was expected to have explanatory power because the expertise needed for specific industry accounting regulation results in substantial economies of scale. The hypothesis for the second variable is that industries with frequent issues of new publicly traded securities also require specific expertise and this results in economies of scale.

The second group of concentration studies concern the relationship between audit firm concentration and the auditing fees charged. The number of studies in this area of research is considerable (see e.g. [Simunic, 1980; Pound and Francis, 1981; Francis, 1984; Palmrose 1986]). In general, these studies test for price differences between Big-Eight and non-Big-Eight firms. The hypothesis is that the market for large auditees, with only a few suppliers (i.e. the Big-Eight), is not competitive. On the other hand, the market for small auditees, with a large number of supplying accounting firms, is assumed to be competitive. Hence, price differences between the two markets can be expected. The results of the studies are mixed. Some studies

${ }^{7}$ These results are in line with Benston's [1985, pp.46-47] statement that the CPA exam is not used as an entry barrier. Currently all CPA examinations in the US are graded at a national level. 
found no price differences, other studies did. According to Francis and Stokes [1986], some of the conflicting results can be attributed to differences in research design. Besides, evidence of price differences does not necessarily imply a not-competitive market for large auditees. Other factors, such as differences in quality and economies of scale, might also cause price differences between Big-Eight and non-Big-Eight accounting firms [Palmrose, 1986, p. 981 .

Empirical research on regulation of the market for public accounting, and research on the market for public accounting in general, is hardly developed in the Netherlands. There are a number of studies on the voluntary auditing of annual accounts (see e.g. [Sternheim, 1933; Kraayenhof, 1955; Buijink, 1990]). These studies will be dealt with later in this chapter. Some other Dutch auditing studies are concerned with the costs of public accounting services for firms, the willingness of accounting firms to disclose accounting information, and the degree of concentration of the Dutch market for public accounting services [Langendijk, 1988; Dekker and Langendijk, 1986; Langendijk and Deetman, 1990].

\subsection{Effects of Dutch Accounting Legislation on the Market for Public accounting}

In the Netherlands, the right to attest the annual accounts of firms is restricted by law to registered accountants (the Registered Accountants Act or De Wet op de Registeraccountants of 1962) ${ }^{8}{ }^{9}$. They are organized in the Dutch Institute of Registered Accountants (Nederlands Instituut van Registeraccountants or NIVRA) ${ }^{10}$. The standards of entrance to the pro-

* Firms may also appoint an expert who, by a revocable permission based on a foreign proof of competence, has been admitted by the Minister of Economic Affairs (section 70 of the Registered accountants Act). However, the number of permissions granted is very low. For the period 1971-1986 an average of 3.6 permissions were granted per year (see table 4.10 in appendix 4.1 ).

See Hulshoff Pol [1988].

${ }^{10}$ NIVRA was established in 1967. All members of four professional organizations for accountants were allowed to enter the register of NIVRA (i.e members of the Nederlands Instituut wan Accountants or NIVA, the Vereniging van Academisch Gevormde Accountants or VAGA, the Nederlandse Broederschap van Accountants, and the Nederlandse Unie van Accountants). In addition, 700 other accountants filed an application to be registered. Only $15 \%$ of these applications were awarded. This "over- 
fession and the training of its members are considered to be very high (see e.g. [Nobes and Parker, 1985, pp.135-136]). The number of active members in 1989 was 5214, of whom 2624 were in public accounting ${ }^{\prime \prime}$.

Economic effects for RAs due to changes in Dutch accounting legislation can be expected for the following three reasons. First, accounting legislation. affects the number of firms that have to disclose audited annual accounts. Thus the legislation changes the size, measured by the number of audits, of the market for public accounting. Second, legislation determines to a large extent the form and content of annual accounts. In other words, the legislation affects the extensiveness of the services per audit. Third, the market for public accounting is the main source of income for RAs ${ }^{12}$. Besides, RAs' income generated in other markets, such as consulting, depends on their auditing activities. The latter probably imply a competitive advantage in the markets for other services [Pound and Francis, 1981, pp.354-356]. A priori it can be expected that if a firm wants to buy consulting services, its public accountant is in a better position than other suppliers of consulting services.

Two recent material changes in Dutch accounting legislation can be observed $^{13}$ :

(1) 1970: from section 42 of the Code of Commerce (Wetboek van Koophandel or WvK) to the Act on Annual Accounts of Enterprises (Wet op de Jaarrekening van Ondernemingen or WJO)

subscription" can be viewed as an indication of the desirability of the status of registered accountant [Pen, 1985, p. 100].

${ }^{\sharp}$ August 31, 1989, see NIVRA Gids 1990, [1990b].

${ }^{12}$ On the basis of interviews with representatives of 8 large Dutch public accounting firms in 1971, Bindenga [1973, p.291] concludes that up to $80 \%$ to $90 \%$ of total fee income is generated from auditing. Auditing income as a percentage of total income was 61\% for 13 large Dutch accounting firms in 1986 [International Accounting Bulletin, 1987]. It should be remarked that public accounting firms attract employees for nonauditing departments who are not RAs. Therefore, only a part of non-auditing income is generated by RAs.

11 The change from the Act on Annual Accounts to Titel 6 of Book 2 of the Dutch Civil Code in 1976 (Titel 6, Boek 2 van het Burgelijk Wetboek) is not a material change. It was the result of the recodification of the Civil Law. The field of application of accounting legislation did not change and the changes in the law were mainly of a technical character [Burgert and Timmermans, 1987, p.22]. Therefore it would be expected that this event would not have material economic effects for accountants or firms. 

(Titel 8, Boek 2 BW)

The assessment of the economic effects of these two material changes for RAs requires empirical evidence on two variables. First, it will require investigating how these legislation changes affected the number of chargeable hours in the market for public accounting. The term "chargeable hours" refers to the number of hours actually supplied and demanded in the market for public accounting and indicates its size. Second, it will require investigating the development of the number of suppliers in the market for public accounting services. It will be assumed that an increase of the ratio (chargeable hours in the market for public accounting)/(registered accountants in public accounting) implies an increase in the average income of registered accountants in public accounting (ceteris paribus). It should be noted that accounting legislation might have affected RAs through mechanisms other than the number of chargeable hours. For example, as a result of changed requirements with respect to the disclosed audited information and changed enforcing mechanisms, the legislation might have changed the risk for accountants of legal prosecution [Benston, 1985, p.55]. However, this study will be restricted to the analysis of the effects of legislation on the ratio between market size and the number of suppliers. This limitation will be discussed further in chapter six.

\subsubsection{Effects of Dutch Accounting Legislation on the Size of the Market for Public Accounting}

Ideally, data on the total number of chargeable hours should be used to assess the effects of accounting legislation on the size of the market for public accounting. The number of chargeable hours should be a measure of the "quantity" traded on the market for public accounting. However, for the Dutch market, these data are only available for a limited number of accounting firms in the last few years.

As an alternative, two other indicators of the size of the market for public accounting will be used. The first is the number of audited annual accounts disclosed. This measure does not take into account changes in the average number of chargeable hours per audit (i.e, changes in the extensiveness of supplied services per audit), or allow for the fact that RAs might supply public accounting services to firms that do not disclose audited annual accounts. An example of the latter is a RA who audits annual accounts for internal purposes. The implication might be that the growth of the market for 
public accounting, measured on the basis of the number of disclosed audited annual accounts, is larger than the growth of the market for public accounting in terms of chargeable hours. The measured growth, in terms of an increased number of audited annual reports disclosed, can partly be attributed to a shift from hours spent on the auditing of annual accounts for internal purposes to hours spent on the auditing of annual accounts that will be disclosed.

The second indicator of the size of the auditing market is the number of professional employees in the public accounting sector. The market for public accounting is labor intensive. Therefore it can be expected that changes in the quantity of chargeable hours traded on the market for public accounting should be reflected in the number of employees in the public accounting sector ${ }^{14}$. The two main limitations of the professional employees measure are: (1) changes in auditing technology also affect the number of employees, and (2) the number of hours supplied will differ between employees, and per employee over time.

To present empirical evidence of the effects of the two accounting legislation changes on the size of the market for public accounting, the remaining part of this chapter is organized as follows. First the legislation changes will be discussed in more detail and a priori reasons for expecting increases in the size of the market for public accounting will be provided. Next, empirical evidence will be presented of the effects of accounting legislation on our surrogate measures of the size of the market for public accounting: the number of disclosed audited annual accounts and the number of employees in the public accounting sector. The following section will analyze the number of suppliers in the market for public accounting.

The term "public company", used in this chapter, refers to a public limited liability company (naamloze vennootschap or NV), and "private company" refers to a private limited liability company (besloten vennootschap or BV).

${ }^{14}$ A recent study by Zind and Zéghal [1989] of the Canadian audit industry suggests a strong correlation between audit firm revenue and number of employees. The Spearman's rank correlation found for audit firm revenue vs. the number of professionals exclusive of partners is 0.98 . The correlation between revenue and the number of partners is 0.92 . Other surrogate measures for audit firm revenue have lower scores. The correlations for the number of organizations audited and for the assets held by audited organizations are 0.84 and 0.77 respectively. 


\section{Hypothesized Effects of the 1970 and 1983 Accounting Legislation Changes on the Size of the Market for Public accounting}

Before the Act on Annual Accounts of 1970, Dutch legislation on annual accounts was mainly limited to section 42 (established in 1928) of the Code of Commerce. This section only contained prescriptions for the annual accounts of a particular group of public companies, the so-called 'open' public companies (open naamloze vennootschappen) ${ }^{15}$. The prescriptions in section 42 were not extensive. Only instructions for the compilation of the asset side of the balance sheet were given ${ }^{16}$. The legislation did not require 'open' public companies to audit their annual accounts. However, nearly all 'open' public companies were listed at the Amsterdam Stock Exchange (see e.g. [Wiardi Beckman Stichting, 1959, p.125; Brands, 1967, pp.15-21; Vecht, 1977, p.32; CBS 1970, p.10; Eindverslag WJO, 1969]). Since 1961 the Rules Relating to Securities (het fondsenregelement) of the Association for the Trade in Securities (Vereniging voor de Effectenhandel) required the auditing of annual accounts published in the prospectuses of securities [Groeneveld, 1965, pp.7-8]. In addition, a large share of the firms listed at the Exchange disclosed audited annual accounts voluntarily. Empirical evidence supporting this will be discussed later.

It would be expected that the Act on Annual Accounts of 1970 would change the financial accounting practices of firms considerably. It has also been suggested that it increased the demand for public accounting services (see e.g. [Metzemaekers and Maastrigt, 1983, p.173]). In addition to all public companies, private companies and co-operative societies (coöperatieve

15 The public companies subjected to Section 42 of the Code of Commerce were called 'open' public companies. According to section $42 \mathrm{c}$ a public company was 'open' if:

a. the articles of association of the public company permitted bearer shares totaling more than $f 50,000 .-$, or the public company had either bearer shares or bearer certificates afloat totaling more than $f 50,000 .-$; or

b. the public company had either bearer debentures outstanding or had bearer certificates of its issued registered debentures afloat; or

c. shares or debentures, or certificates of such securities of the public company were listed on the Stock Exchange; or

d. it was wholly or partly the company's business to draw money from third parties or to operate in the field of insurance.

${ }^{16}$ Section 42 of the Code of Commerce required 'open' public companies to disclose ten separate items on the asset side of the balance sheet. Examples of these items are: liquid assets, marketable securities, accounts receivable, and investments. 
verenigingen or coöps) of a certain size were subjected to the $\mathrm{Act}^{17}{ }^{18}$. All public companies, large private companies, and large co-operative societies had to disclose audited annual accounts. The Act on Annual Accounts was announced in the Official Gazette on 10 September 1970. The law was enforced step by step [NIVRA, 1972f, pp.132-139]. Large cooperative societies and public companies, as a first step, had to disclose and audit their annual accounts over the fiscal year 1971. Private companies subjected to the Act had to audit and disclose annual accounts over the fiscal year 1973. Thus, the first increase in the number of disclosed audited annual accounts due to the new legislation can be expected in 1972 (assuming that annual accounts for the fiscal year 1971 are disclosed in 1972). The last increase due to the new legislation would be expected in 1974. In addition to an increase of the number of firms disclosing and having their annual accounts audited, the disclosure requirements of the annual accounts were intensified [Vecht, 1977, pp.35-37; Burgert and Timmermans, 1987, p.20]. The Act contained prescriptions for both sides of the ballance sheet, the profit and loss account and the explanatory notes. More detailed information requirements result in more work for the auditor [Watts and Zimmerman, 1986, pp.329-330; Puro, 1984, p.267]. Thus, it can also be expected that audits of annual accounts became more extensive after the passing of the Act. The two effects of the Act on the size of the market for public accounting will be measured using the number of disclosed audited annual accounts and the number of employees in the public accounting sector.

It would be expected that the second legislation change, the passing of Title 8 in 1983, would also considerably affect the financial accounting practices of firms. It has been suggested that Title 8 increased the demand for public accounting services [Van der Grinten, 1981, pp.35/47; Bak and Boukema, 1983, pp. 502-503]. Under the new legislation all public companies, private companies, and co-operative societies are obliged to disclose annual accounts. However, small and medium-sized firms are allowed to submit

17 In addition to public companies, the following firms were also subjected to the requirements of WJO: (1) Co-operative societies with total assets greater than or equal to $f 3,000,000 .-$, (2) private companies with total assets greater than or equal to $f 8,000,000$.-, and a total number of workers greater than or equal to 100 , and (3) private companies with shareholders' equity greater than or equal to $f 500,000 .-$.

18 Mutual insurance companies (Onderlinge Waarborgmaatschappijen) and agricultural credit banks (Landbouwkredietbanken) with a co-operative nature were also subjected to WJO, but their number is relatively small and they are therefore omitted in this study. A representative of the Chambers of Commerce estimated that 100 audited annual accounts were disclosed each year by these two groups. 
abridged annual accounts ${ }^{19}$. The requirements concerning the auditing of annual accounts were also changed. All large and medium-sized firms subjected to Title 8 had to audit their annual accounts. Besides the obligation to audit and disclose, Title 8 changed the requirements for the content of annual accounts. The new legislation is more detailed with respect to (1) the presentation and lay-out of the balance sheet and profit and loss account, (2) the information conveyed in the notes, (3) the measurement rules for profit, and (4) the creation and dissipation of the revaluation reserve [Burgert and Timmermans, 1987, p.29; Bak and Boukema, 1983]. Title 8 was announced in the Gazette on 7 December 1983 and was effective in 1984. The 1984 annual accounts of firms subjected to this new legislation had to be up to the standard of Title 8. However, there is a temporary provision for middlesized private companies with respect to the obligatory audit. Until 1990 only large private companies (size criterion based on 'old' legislation) are required to audit their annual accounts.

Two main expected effects of Title 8 for the market for public accounting services can be distinguished [Bak and Boukema, 1983, pp.502-503; Van der Grinten, 1981, pp.35/47; Commissie Advisering Stroomlijning Accountantswetgeving, 1990, p.25]. First, the accounting services per audit were expanded. This is the result of the more detailed requirements of Title 8. This effect can be expected initially with respect to the annual accounts of the fiscal year 1984. Second, the requirement for middle-sized private companies to audit their annual accounts will result in an increasing number of firms that have to audit their annual accounts ${ }^{20}$. Due to the temporary

19 According to Titel 8 a firm is small if it meets all or two of the following three criteria (section 396):

- value of assets less than or equal to $f 3,000,000$.

- net turnover per fiscal year less than or equal to $f 6,000,000$.-

- average number of employees less than 50

In 1985 the first two criteria were changed to $f 4,000,000$.- and $f 8,000,000$.- respectively. According to Titel 8 a firm is medium-sized if it meets all or two of the following three criteria (section 397):

- value of assets less than or equal to $f 12,000,000$.-

- net-turnover per fiscal year less than or equal to $f 24,000,000$.-

- average number of employees less than 250

In 1985 the first two criteria were changed to $f 17,000,000$.- and $f 35,000,000$.respectively.

${ }^{20}$ Formally, Title 8 has two other affects on the number of firms that have to audit their annual accounts. The two effects changed the market for public accounting services in opposing directions. First, as a result of Title 8, after 1983 small public companies were exempted from the requirement to audit their annual accounts. Second, after 1983 middle-sized co-operative societies were also required to audit under Title 8. Concerning 
provision, this effect can only be measured after 1990. Therefore, it can not be considered in this study. Because the first effect of Title 8 affects the services per audit and not the number of audits, the latter variable can not be used to measure the effects on the size of the market for public accounting services $^{21}$. Only the number of employees in the public accounting sector will be used to measure the effect of Title 8 .

\section{The Effects of the 1970 Accounting Legislation Change on the Number of Disclosed Audited Annual Accounts}

To get an estimate of the number of audited annual accounts disclosed by public companies before the passing of the Act of 1970, we can look at the number of companies listed at the Amsterdam Stock Exchange. We can concentrate on this category, because public companies not subjected to section 42 of the Code of Commerce (the so called 'closed' public companies or besloten naamloze vennootschappen) disclosed no annual accounts [Tempelaar, 1966, p.272]. As stated earlier, although an 'open' public company was not required to be listed on the Amsterdam Stock Exchange, it is frequently suggested in the literature that the group of 'open' public companies was nearly equal to the group of publicly listed companies. There are various studies on the number of audited annual accounts disclosed by listed companies before the passing of the Act. The study by Groeneveld [1965] was the last one before the passing of the Act. According this study, of a group of 402 publicly listed companies, $340(85 \%)$ audited their annual accounts voluntarily. Of these annual accounts, only two were not audited by a member of the predecessor of NIVRA. Studies on disclosure in earlier years [Sternheim, 1933; Lafeber, 1948; Kraayenhof, 1955; Vecht 1960;

the first effect, casual observation suggests that virtually none of the disclosing companies before 1983 falls under this category. Of a random sample of 270 companies with less than 50 employees active in the retail, wholesale, or construction industry in the district of the Chamber of Commerce of Maastricht, only one was a public company (data are by courtesy of Laury Bollen, University of Limburg). In this chapter it will be assumed that the sum of the two effects on the size of the market for public accounting services is not negative.

${ }^{21}$ Besides this time problem, there are problems in getting data on the number of private companies disclosing audited annual accounts. The data on disclosed annual accounts of the Chambers of Commerce cannot be used after the passing of Title 8, because the connection between disclosing and auditing was abolished. Before Title 8 , firms that were required to disclose were also required to audit. After the passing of Title 8 , not all disclosing firms were also required to audit. The Chambers of Commerce only register whether firms disclose. 
Groeneveld, 1965; Builink, 1990], which go back to 1926, report lower percentages. In general it can be stated that over time a larger share of the publicly listed companies audited their annual accounts ${ }^{22}$.

The number of listed public companies in 1970 (692) will be taken as an estimate of the maximum number of audited annual accounts disclosed by public companies before the passing of the Act (see tables 4.1 and 4.11 in appendix 4.1). There are no data (known to us) on the number of disclosed audited annual accounts from co-operative societies, before the passing of the Act. In order to form an estimate of the growth of the total number of disclosed audited annual accounts, it will be assumed that the passing of the Act at least did not reduce the number for co-operative societies. Thus the estimated maximum number of audited annual accounts disclosed by cooperative societies prior to 1970 is 881 (see tables 4.1 and 4.11).

The first fiscal year in which public companies, private companies, and cooperative societies were subject to the requirement to audit and disclose accounts was 1973. Since this year, the Dutch Chambers of Commerce have reported, for the three groups, the number of firms that meet the requirement to disclose (see table 4.11). The total number of disclosed annual accounts was 4094 for 1974 (annual accounts over the fiscal year 1973 are disclosed in 1974). Therefore the estimated growth in the total number of disclosed audited annual accounts in the period '71-'74 is $160 \%$. However, so far it is assumed that all disclosed annual accounts are audited. The Chambers of Commerce only register whether annual accounts are disclosed, not whether they are audited. A study in 1977 [Limperg Instituut, 1980, p.43] on a sample of disclosed annual accounts by companies indicates that $22 \%$ had no auditor's opinion. If the 1974 observations for the number of public and private companies which disclosed accounts are corrected on the assumption that $22 \%$ of these were not audited, the growth in the number of audited annual accounts is $115 \%$.

${ }^{22}$ The percentages of disclosed audited annual accounts are as follows: $192646 \%$, $193251 \%, 194768 \%, 195156 \%, 195780 \%$, and $195869 \%$. For the 1951 and 1957 studies, the percentage of audited annual accounts that were audited by a member of NIVA or VAGA was given. The results are: $195193 \%$ and $195796 \%$. The studies are not completely comparable. They differ slightly in terms of the samples taken and the definition of "audited annual accounts". In general, the samples consist of public companies listed at the Amsterdam Stock Exchange. However, some studies take companies from specific sectors, while other studies have companies from a wide range of sectors. Concerning the definition of audited annual accounts, some studies have onlly two categories (audited and not audited annual accounts), while other studies have various categories (e.g. no mention of auditor, only mention of name auditor, signature of auditor, and auditor's opinion with signature). 
The real growth of the market for public accounting is probably higher than $115 \%$ for four reasons. First, the number of co-operative societies disclosing audited annual accounts voluntarily before 1971 is probably nuch lower than the number of co-operative societies disclosing under the Act. Metzemaekers and Maastrigt [1983, pp.226-227] suggest that the requirement for large cooperative societies to audit and disclose their annual accounts increased the demand for public accounting services. Second, it would be expected that the audits of companies that already disclosed audited annual accounts before the Act would became more extensive as a result of the Acts" more severe requirements, as compared with section 42 of the Code of Commerce. Third, not all private companies that were obliged to audit their annual accounts were also required to disclose their annual accounts (only private companies with total assets larger or equal to $f 8,000,000 .-$, and a total number of workers larger or equal to 100 were required to disclose $)^{23}$. Fourth, only the data for the number of annual accounts disclosed in 1974 has been corrected for non-audited disclosed annual accounts. In fact the 1970 observations probably also contain some non-audited annual accounts.

\section{Table 4.1}

Number of annual accounts disclosed by NVs, BVs, and Coops before and after the passing of the Act on Annual Accounts of 1970

For sources and construction see table 4.11 in appendix 4.1.

\begin{tabular}{lcccc}
\hline & NV & BV & Coop & Total \\
\hline 1971 & 692 & n.r. & 881 & 1573 \\
1974 & 2539 & 674 & 881 & 4094 \\
\hline
\end{tabular}

n.r. = not relevant

${ }^{23}$ In 1970 , the number of public companies with shareholders' equity larger than $f 500,000$.-was 3632 [CBS, 1976, p.19]. Companies in this category were subjected to the requirement of the Act to audit the annual accounts. Assuming that this category was not significantly affected through legal form switches to non-company legal forms (which will be confirmed in chapter five), this implies that about $419(3632-(2539+674))$ private companies had to audit their annual accounts but were not required to disclose. Whether this group actually engaged an auditor is hardly verifiable. 
During the period 1974-1984, with no material change in Dutch accounting legislation, the average number of audited annual accounts disclosed per year was 4130.5 (st. dev. $=304.73$ ). Over the whole period, the total number of disclosed audited annual accounts decreased by $13 \%$. This decrease can be attributed to the category of public companies. The number of firms having the public company form declined by about $50 \%$ in this period (see table 5.6). The number of annual accounts disclosed by co-operative societies was stable, while the figure for private companies showed a slight increase. The latter can be attributed to an increasing number of firms with the private company form (see table 5.7). As stated earlier, the effect of the 1983 legislation change (Title 8) on the number of audited annual accounts disclosed will occur after 1990 and will be difficult to measure. A crude measurement indicates that about 6600 private companies fall in the middlesized category ${ }^{24}$.

\section{Effects of the 1970 and 1983 Accounting Legislation Changes on the Number of Employees in the Public Accounting Sector}

Since public accounting is labor intensive, it can be expected that changes in the size of the market will be reflected in the number of professional employees in public accounting. If the number of chargeable hours increases, more professional employees are needed to support this increase. Two main groups of professional employees can be distinguished in the public accounting sector: (1) assistant-accountants in public accounting, and (2) RAs. Assistant-accountants are in general carrying on a part-time study to become registered accountants. Two alternative educational programmes are available for a person wanting to enter the register of NIVRA: (1) the accountancy programme conducted by NIVRA, and (2) the accountancy programme conducted by Dutch universities. In this chapter, the term "NIVRA students" refers to the part-time students enrolled in the accountancy program of NIVRA, and the term "university students" refers to the part-time students enrolled in the accountancy program of a Dutch university ${ }^{25}$.

24 This measurement is from the Dutch Chambers of Commerce and takes only one criterion of size, namely the number of employees, into account.

25 To study for the NIVRA examination or the university examination, a person is required to (1) have reached the level of secondary school education required for admission to a university (VWO), or (2) to have completed a study at a college of higher education (HBO). The nominal duration of the programmes is about eight years for the NIVRA program and six years for the university program. NIVRA students study parttime during the whole program while university students are part-time for only the last two years. Compared to the NIVRA program, the university programs give more 
There is no central registration of professional employees in the public accounting sector. The sum of NIVRA students and RAs associated with a public accounting firm will be used to reveal changes in the size of the market for public accounting. It should be remarked that this variable has some limitations as a measure of the number of professional employees in public accounting for the following three reasons: (1) not all RAs associated with a public accounting firm are concerned with auditing activities, (2) not all assistant-accountants are registered as NIVRA students (e.g. those who have suspended or stopped their NIVRA study, Accountant-Administratieconsulenten ${ }^{26}$ associated with a RA accounting firm, and part-time university students ${ }^{27}$ ), and (3) not all NIVRA students are working for an accounting firm ${ }^{28}$. In defense of the measure it can be remarked that it is frequently suggested that the number of NIVRA students is highly dependent on the recruitment policy of accounting firms [NIVRA 1982e, p.17; NIVRA 1983e, p.15; NIVRA 1985e, p.19]. Also, NIVRA students are the group which can be expected to be the most indicative of changes in the size of the market, because they can be recruited from a very large group of potential candidates, namely high school graduates. As a result, the number of NIVRA students employed can be adjusted quickly in response to changes in

attention to general courses in economics and business administration. For an extensive discussion of the requirements for qualification as a registered accountant see NIVRA [1985g].

26 Accountants-administratieconsulenten are also active in the market for public accounting services. This group is also regulated by Dutch law (Accountants-administratieconsulenten Act of 1972). They have the right to use the term "accountant" but are not allowed to attest financial accounting information.

${ }^{27}$ The number of university students in public accounting is relatively small compared to the number of NIVRA students. There are no direct numbers on academic students in public accounting, but this conclusion can be inferred from the following data. Over the period 1968-1989 a yearly average of $63.54 \%$ (st. dev. $=5.09$ ) of the students who entered the register were NIVRA students. However, the average number of years in practice before entry is 10 years for NIVRA students and only 3 years for academic students [NIVRA, 1985g, p.9]. Besides, the failure rate for NIVRA students is much higher. In other words, a considerable number of NIVRA students never enter the register although they have worked for some years in public accounting. Finally, the education of NIVRA students is strongly geared towards public accounting, while university students receive a more broad-based business program. Casual observation suggests that a larger share of the university students work for a business firm than is the case for NIVRA students.

${ }^{28}$ A survey covering 1600 NIVRA students in 1969 revealed that $67 \%$ had a position in an accounting firm, $15 \%$ in government, and $13 \%$ in business (NIVRA, [1969a, p.22]). 
the demand for public accounting ${ }^{29}$. The supply of candidates for other employee categories, e.g. part-time university students and RAs, is in the short term relatively fixed.

Data on the number of NIVRA students, and of RAs associated with a public accounting firm, were collected for the period "68-' 89 (see table 4.12 in appendix 4.1). The most consistent data are available on the number of NIVRA students who took courses during the year. This data will be used for the analysis below. The numbers of registered NIVRA students might also have been used, but this figure was not available for all years. What data is available suggests that the results presented below would not be greatly affected if the number of registered NIVRA students had been used $^{30}$.

This data was analyzed by first calculating the annual changes in the total number of NIVRA students plus RAs. Because one observation is lacking for NIVRA students in the period "68-' 89 , the number of annual changes is 20 . Then the annual changes were grouped into annual changes for "regulatory years" and "non-regulatory years". Years in which a change in the size of the market for public accounting can be expected due to changing accounting legislation were classified as "regulatory" years, other years as "non-regulatory". Because it is difficult to predict the exact year in which the number of employees will be affected, this identification procedure is somewhat arbitrary. Therefore, four variant groupings of "regulatory" and "nonregulatory" years were made (see table 4.2 , variants $\mathrm{A}, \mathrm{B}, \mathrm{C}$, and D). For the four variants, the number of "regulatory" years varies between two and five.

The annual changes would be expected to be larger in "regulatory years" than in "non-regulatory years". To check this, a permutation test (or randomization test) was applied to test for significant differences from the mean. As a test of a significant difference between the means of two independent samples when the sample sizes are small the permutation test is a powerful

29 As an indication of the elasticity of supply of NIVRA students, in the 10 year period 1978-1988 the average annual number of newly registered NIVRA students was 861 (st. dev. $=234.27$ ). The highest and lowest observations were 1152 and 429 respectively.

30 The increases in the total number of registered students in the periods $1970-1973$ and 1984-1985, the "regulatory" periods, are the highest observations for the period 1968-1989 (see table 4.12 in appendix 4.1). 
non-parametric test [Siegel and Castellan, 1988, p.151] ${ }^{31}$. The permutation test takes into account that the data are ratio scaled, and so is in this case more powerful than the Mann-Whitney test. The results are presented in table 4.2. In the first collumn the four variants (i.e. A, B, C, and D) of the group of "regulatory years" are listed. The second column shows the results for students and RAs together. The third and fourth column show the results separately for the two groups. Per column, the average annual change in regulatory years and the average annual change in non-regulatory years are given.

The results for students and RAs together show that for all four variants the mean in the "regulatory years" is larger than in "non-regulatory" years. For two variants the difference is significant at a $5 \%$ level, for one variant at a $10 \%$ level. These results generally support the hypothesis that, as a consequence of the accounting legislation, changes in the market for public accounting increased.

If the results are separated for NIVRA students and RAs, it appears that the increase in the total number of employees during "regulatory years" can only be attributed to the group of students. The results for students, presented in the second column, are comparable to the results for the whole group of employees. In fact, they are slightly stronger. The results for RAs are not in line with the general results. For three combinations of regulatory years, the mean change is lower during "regulatory years" than in "non-regulatory" years. The notable difference between the results for students and RAs could be expected, considering the difference between the opportunities to hire new employees in these categories. As stated earlier, there is always a large pool of potential NIVRA students (i.e. high school graduates) available. A specific study is required to become an RA and the supply of potential candidates is relatively fixed in the short term.

${ }^{31}$ A (one-tailed) permutation test can be described as follows. It calculates the chance that an equal, or larger difference between the means of the two samples would be the outcome, if all observations were randomly assigned to the two samples. If this chance is very small, the null-hypothesis of no difference is rejected. Hence, the p-value that is calculated indicates how many other combinations of the observations over the two samples would give a larger or equal difference between the means of the two samples. The $p$-value is equal to the following ratio: (number of other combinations of the observations that would give an equal or larger difference between the means of the two samples)/(total number of possible combinations of the observations over the two samples). 


\section{Table 4.2}

Effects of Dutch accounting legislation on the number of professional employees (NIVRA students + RAs) in public accounting in the period 1968-1989 33

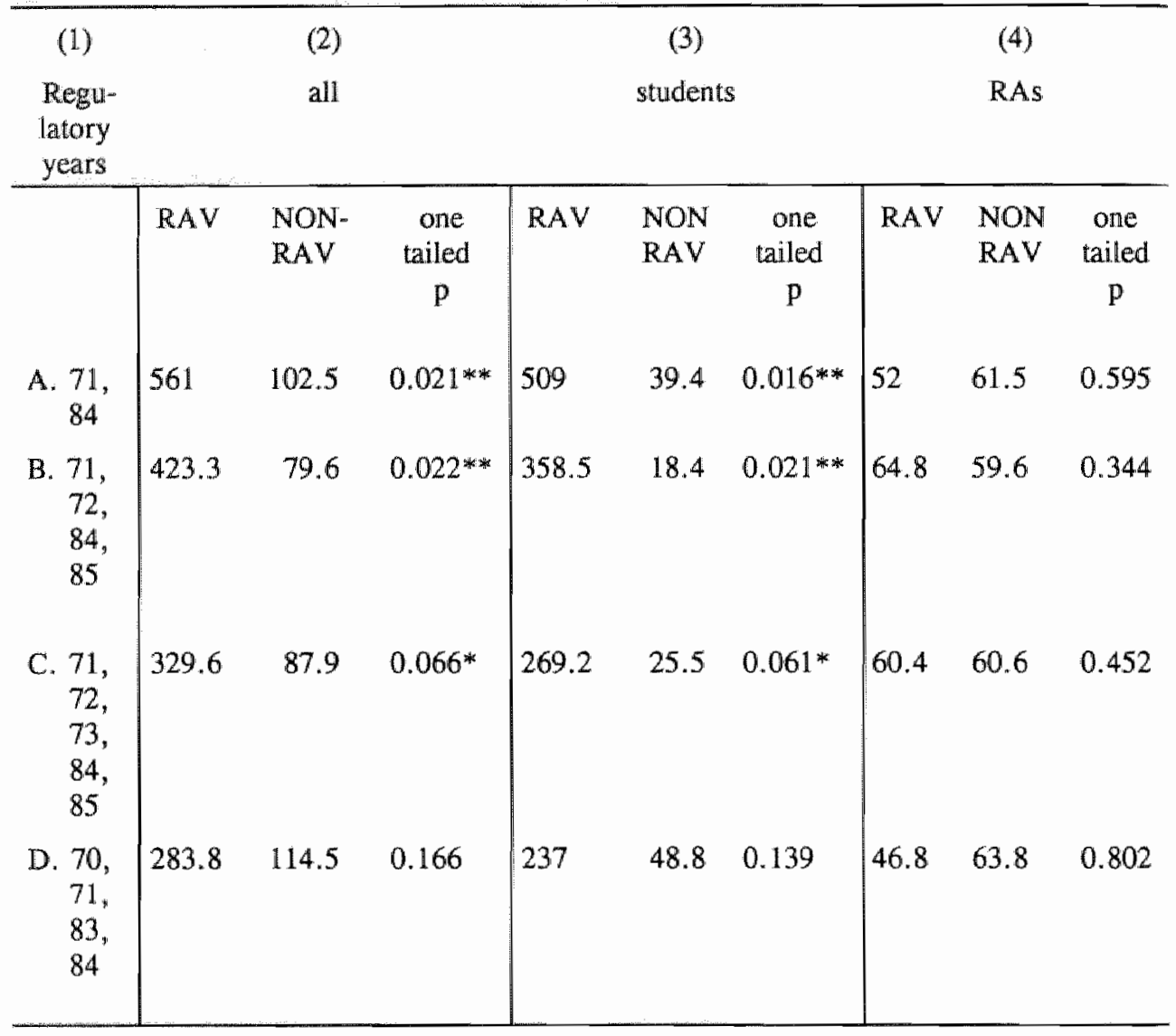

RAV $=$ average annual change in regulatory years, number of observations $=2 \ldots 5$; NONRAV = average annual change in non-regulatory years, number of observations = $15 \ldots 19 ; *=$ significant at a $10 \%$ level; $* *=$ significant at a $5 \%$ level.

${ }^{32}$ Because one observation for the students is lacking (1989), the NONRAV of the 2nd column is not equal to the sum of the NONRAV of the 3rd column and the NONRAV of the 4th column.

${ }^{33}$ The annual change for the year $19 \mathrm{XX}$ is the result of $(19 \mathrm{XX}+1)-19 \mathrm{XX}$ as presented in tables 4.12 and 4.13 in appendix 4.1 . 


\subsubsection{Developments on the Supply side of the Market for Public Accounting}

In the introduction to this chapter it was said that the economic effects of accounting legislation for public accountants depend not only on changes in the number of hours "traded" in the market for public accounting but also on the number of suppliers on the market. If an increase in the size of the market for public accounting is accompanied by an increase in the number of suppliers, positive economic effects for suppliers are dissipated [Benston, 1985, p.74]. The number of suppliers can only be expected to adjust to an increase in the market for public accounting in the long term and gradually, because the period of study required to become a RA is long. The results presented in table 4.2 confirm the expectation that RA numbers can only adjust in the long term. The short term increases in the number of employees in public accounting are explained by increased numbers of students, not RAs.

To analyze the number of suppliers in the market for public accounting, the group of RAs in public accounting will be divided in two groups: (1) RAs who are employed by an accounting firm, and (2) RAs who are partners in an accounting firm. The first group can be viewed as potential suppliers in the market for public accounting services. The RAs in this group have the right to supply public accounting services but have decided to hire themselves to an accounting firm. The second group consists of RAs who are owners of an accounting firm and can be viewed as actual suppliers of public accounting services (another important characteristic on the supply side of the market for public accounting, namely the degree of concentration of RAs in accounting firms, will be discussed in section 4.4.2).

Because adjustments on the supply side can only be expected in the long term and will be gradual, it is not possible to select "regulatory" and "nonregulatory" years after the passing of the legislation changes. If there is an adjustment, all years after the passing of the legislation might have been affected. To compare the growth in the number of suppliers after the passing of the legislation changes with the annual growth before 1970, the time series data for NIVRA for 1968-1989 were extended by adding data for NIVA for the period 1946-1967. NIVA was the biggest professional organization of accountants before the foundation of NIVRA. Its members accounted for $81 \%$ of the new entries in the NIVRA register in 1967 and 1968. For comparison purposes the data for NIVA was adjusted by a fixed percentage 
of $23.13 \%{ }^{34}$. This adjusted data for NIVA is presented in table 4.13 in appendix 4.1 . The empirical analysis below will use these data.

\section{Table 4.3}

Comparison of annual changes in the numbers of suppliers in the market for public accounting for non-regulated and regullated periods (1946-1970 and 1971-1989 respectively)

\begin{tabular}{lccccc}
\hline & \multicolumn{2}{c}{$1946-1970$} & \multicolumn{2}{c}{$1971-1989$} & \\
\hline & NONRAV & st.dv & RAV & st.dv & $\begin{array}{c}\text { Two } \\
\text { tailed } p\end{array}$ \\
RA employee & 16.88 & $\mathbb{1 7 . 9 7}$ & 45.56 & 36.76 & $0.0014^{* * *}$ \\
RA partner & 21.80 & 19.31 & 17.83 & 13.10 & 0.7960 \\
Total & 38.68 & 13.45 & 63.39 & 38.09 & $0.0181^{* *}$ \\
\hline
\end{tabular}

NONRAV = average annual change in non-regulatory years, number of observations $=$ $25 ; \mathrm{RAV}=$ average annual change in regulatory years, number of observations $=18$; st.dv $=$ standard deviation; $* *=$ significant at a $5 \%$ level; $* * *=$ significant at a $1 \%$ level.

The data on the number of suppliers was divided in two periods, 1946-1970 and 1971-1989, the latter ("regulatory') period covering the enforcement of the Act on Annual Accounts and Title 8. Table 4.3 presents the average annual changes in the number of RA employees and RA partners in public accounting for these periods. The average annual change of the total number of public accountants is higher in the regulatory period than in the nonregulatory period (63.39 vs. 36.68). A Mann-Whitney test was applied to test for significant differences from the mean. A Mann-Whitney test can be viewed as a permutation test applied to the ranks. For large samples, the Mann-Whitney test is a good approximation to the permutation test [Siegel and Castellan, 1988, p.155]. The test indicates that the average annual

34 This adjustment is based on the following estimates of entry to the register: 2153 NIVA members, 294 VAGA members, 100 members of the Nederlandse Broederschap van Accountants en de Nederlandse Unie van Accountants, and 104 members of remaining professional organizations (data are by courtesy of $\mathrm{Mr}$. W. Hulshoff Pol of the NIVRA bureau). 
change in the total number of public accountants is significantly higher in the regulatory period (two tailed $p=0.0181$ ). However, there are considerable differences between RA employees and RA partners. The average annual change for RA employees in the period 1971-1989, at 45.56, is considerably higher than the average of 16.88 for the first period. It appears that the increase is highly significant (two tailed $\mathrm{p}=0.0014$ ). The average annual change for RA partners in the period 1971-1989 is 17.83, lower than the average of 21.80 for the first period. Applying a Mann-Whitney test shows that the decrease is not significant (two tailed $p=0.7960$ ).

To check for trends in the annual changes in the number of suppliers in nonregulatory years, the supply data within the first period was analyzed. Table 4.4 presents the average annual changes in the total number of RA employees and RA partners for the periods 1946-1957 and 1958-1970. For RA employees there is no significant difference between the means of these two periods. However, for RA partners the average of 29.07 for $1958-1970$ is significantly higher than the average of 13.91 for 1946-1957.

\section{Table 4.4}

Comparison of annual changes in the number of suppliers in the market for public accounting within the non-regulatory period (1946-1957 and 1958-1970 respectively)

\begin{tabular}{llcccc}
\hline & \multicolumn{2}{c}{$1946-1957$} & \multicolumn{1}{c}{$1958-1970$} & \\
\hline & $\begin{array}{l}\text { NON- } \\
\text { RAV }\end{array}$ & st.dw & $\begin{array}{l}\text { NON- } \\
\text { RAV }\end{array}$ & st.dv & $\begin{array}{c}\text { Two } \\
\text { tailed p }\end{array}$ \\
RA employee & 18.67 & 14.83 & 15.23 & 20.93 & 0.8704 \\
RA partner & 13.91 & 14.58 & 29.07 & 20.72 & $0.0387^{* *}$ \\
Total & 32.58 & 13.16 & 44.30 & 11.42 & $0.0338^{* *}$ \\
\hline
\end{tabular}

NONRAV = average annual change in non-regulatory years, number of observations is 12 (1946-1957), and 13 (1958-1970); st.dv = standard deviation; ${ }^{* *}=$ significant at a $5 \%$ level.

Inspection of the data for RA partners for the period 1946-1970 shows that the annual changes can be better described as a constant annual percentage than as a constant absolute change. If the annual change for partners in accounting for the period 1946-1989 is expressed in percentages, the mean 
for the regulatory period is significantly lower (!) than the mean for the nonregulatory period (two tailed $p=0.0342$ ). To check for a trend in the annual percentages for the period 1946-1970, the means of the periods 19461957 and 1958-1970 were compared. There was no significant difference between these two periods (two tailed $\mathrm{p}=0.1573$ ).

The results of the empirical analysis of the number of suppliers in the market for public accounting presented so far can be summarized as follows. For RA employees in public accounting, the average annual changes are significantly higher in the regulatory period. This suggests that the positive economic effects of an increased demand for their services were dissipated through an accelerated increase in the number of employees in public accounting. However, for partners in public accounting, the average annual changes are not significantly higher in the regulatory period. On the contrary, if the annual changes are expressed in percentages, the observations for the regulatory period are significantly lower compared with the nonregulatory period. These results suggest that the positive economic effects of an increased demand for the services of partners were not dissipated.

It can be concluded that the evidence presented is not in line with the proposition that the licensing of RAs functions as an entry barrier. The total number of RAs increased significantly after the passing of the legislation. However, it appeared that there is a barrier preventing employed RAs entering partnership positions. The increased growth in employed RAs is not accompanied by an increased growth in the number of partners. As a result the ratio (average annual change employed RAs)/(average annual change RA partners) increased. The ratio was 0.77 and 2.56 in the non-regulatory and the regulatory period respectively. This indicates that it is becoming more difficult to get a partner position. Apparently partners have changed their policy on the acceptance of new partners. The question of why the acceptance policy of partners has changed is beyond the competence of this study. The result that partners, and not employed RAs, benefitted from the legislation is in line with Young's findings [1986, pp.16-17]. He compared the average hourly fees of certified and non-certified public accountants in 1981 in the US. He found significantly higher average hourly fees for certified partners, as compared to non-certified partners, whereas certified employed professionals and clerical staff did not have higher rates than their noncertified colleagues.

The statement that during the regulatory period it was becoming more difficult to become a partner seems to be inconsistent with the fact that every RA can become partner by starting his own accounting firm. The entry of RAs cannot be restricted because every RA has the right to start his own 
business if he wants to become a partner. In other words, it would be expected that, if it is more difficult to become a partner in existing accounting firms, more RAs would start their own business. Table 4.5 presents the annual changes for co-operating partners and for independent partners for the unregulated and the regulated period. The difference between these two groups of partners is remarkable. While there was a significant decrease in the number of co-operating partners, there was a significant increase in independent partners. This evidence supports the hypothesis that it is getting more difficult for RAs to entry partner positions in existing accounting firms.

\section{Table 4.5}

Comparison of annual changes in the numbers of co-operating and independent partners in non-regulated and regulated periods (1946-1970 and 1971-1989 respectively)

$$
1946-1970 \quad 1970-1989
$$

\begin{tabular}{lccccc}
\hline & NONRAV & st.dv & RAV & st.dv & $\begin{array}{c}\text { Two } \\
\text { tailed } p\end{array}$ \\
co-operating employee & 23.88 & 18.56 & 10.56 & 18.79 & $0.0353^{* *}$ \\
independent partners & -2.09 & 16.82 & 7.28 & 9.74 & $0.0094^{* * * *}$ \\
\hline
\end{tabular}

NONRAV = average annual change in non-regulatory years, number of observations $=$ 25; RAV = average annual change in regulatory years, number of observations $=18$; st.dv $=$ standard deviation; $* *=$ significant at a $5 \%$ level; $* * *$ = significant at a $1 \%$ level.

One possible explanation for the different findings for partners and employed accountants is related to the explanation based on occupational licensing already discussed. Within the group of registered accountants there is a conflict of interest between employed accountants and partners. Partners need sufficient registered accountants to do the increased amount of work caused by legislation, while employed accountants' salaries will increase if the number of registered accountants is restricted (see e.g. [Benston, 1985, pp.46-47]). Part of the Dutch licensing regime is the corporate organization NIVRA, which has a strong influence on the supply side of the market for public accounting services. Partners would be expected to have a stronger influence on the activities and policies of NIVRA than the group of employed registered accountants. Hence, partners can use NIVRA to settle the 
conflict of interest between employed accountants and partners to their advantage. This implies that sufficient registered accountants are available to do the increased amount of work while the number of partners is restricted.

\subsubsection{The Result of Demand and Supply: Income Data}

More reliable statements on the economic effects of accounting legislation for RAs would be possible on the basis of data on their personal income. However, for the past 30 years, reliable data are only available for the years '61, '66, and "72, and then only for the income of RAs who are partners in an accounting firm. The data for '61 and ' 66 is based on the reports of an umbrella organization for professionals [FOIB, 1964 and 1968] ${ }^{35}$. The data for '72 is based on a report of the Netherlands Central Bureau for Statistics [CBS, 1981a]. If the 1970 change in legislation had favorable economic effects for partners in public accounting, an increase in their personal income would be expected after the passing of this change. The data makes it possible to construct income growth figures for the periods '61-'66 and '66'72. The latter period includes the 1970 legislation and the first year that all public companies and large co-operative societies were subjected to the requirement to disclose and audit their annual accounts. A larger increase in the personal income of partners in the period ' 66 -' 72 , as compared to ' 61 ' 66 , is consistent with the hypothesis that the 1970 legislation change had favorable economic effects.

Table 4.6 shows the median income for RAs who were partners in an auditing firm. The income growth was $50 \%$ in the first period and $83 \%$ in the second period. To evaluate these growth figures we will use the income growth figures of other occupations as a benchmark. Table 4.7 shows the growth in income of other occupations together with the growth figures for RA partners. The growth figures are not corrected for inflation. The RA partners had the lowest growth of all occupations in the first period. They were far behind the income growth of other professionals (lawyers, pharmacists, physicians, veterinary surgeons, and dentists). However, in the second period RA partners had the second highest income growth and were very close to the average income growth of other professionals.

35 During an informal telephone call, a current representative of the umbrella organization for professionals remarked that the FOIB probably stopped publishing these reports because it was not beneficial for them to disclose data on their personal income! 
Table $4.6^{36}$

Income growth of partners in public accounting in the periods ' 61 -" 66 and "66-"72

\begin{tabular}{lrcc}
\hline & $\begin{array}{c}\text { median } \\
\text { income }\end{array}$ & $\begin{array}{c}\text { growth } \\
\text { per period }\end{array}$ & $\begin{array}{l}\text { growth } \\
\text { per year }\end{array}$ \\
\cline { 1 - 1 } & 40.833 & $50 \%$ & $8.45 \%$ \\
${ }^{\prime} 66$ & 61.250 & $50 \%$ & $10.55 \%$ \\
${ }^{\prime} 72$ & 111.800 & & \\
\hline
\end{tabular}

Table $4.7^{37}$

Income growth various occupations in the periods ' 61 -' 66 and ' 66 -'72
(1)
(2)
(3)
(4)
(5)
(6)

\begin{tabular}{lrrrrrr}
\hline '61-'66 & $59 \%$ & $69 \%$ & $67 \%$ & $78 \%$ & $79 \%$ & $50 \%$ \\
'66-'72 & $78 \%$ & $75 \%$ & $76 \%$ & $70 \%$ & $84 \%$ & $83 \%$ \\
\hline
\end{tabular}

(1) = earned wages employees in industry and service sector; (2) = regulated wages;

(3) = regulated wages in business; $(4)=$ regulated government wages; $(5)=$ income professionals (excluding RA partners in public accounting); $(6)=$ income RA partners in public accounting.

36 Sources: CBS, Inkomens Vrije Beroepsbeoefenaren 1972, een methodologische studie, [1981a]. FOIB, Rapport Statistisch Onderzoek intellectuelen 1961, [1964]. FOIB, Rapport Statistisch Onderzoek intellectuelen 1966, [1968].

37 Sources: CBS, Indexciffers van Regelingslonen, methodebeschrijing en reeksen 1926-1985, V21, [1987c], pp.66-67. CBS, Inkomens Vrije Beroepsbeoefenaren 1972, een methodologische studie, [1981a]. CBS, Verdiende Lonen van Werknemers in Nijverheid en Dienstensector ontleend aan het Halfjaarlijks Loononderzoek, methodebeschrijving en reeksen 1947-1983, V13, [1985b], p.33. FOIB, Rapport Statistisch Onderzoek intellectuelen 1961, [1964]. FOIB, Rapport Statistisch Onderzoek intellectuelen 1966, [1968]. 
In sum, the data on the personal income of accountants is consistent with the hypothesis that the passing of the 1970 legislation had favorable economic effects for partners in public accounting. However, it should be remarked that this analysis is only based on observations for three years, and no observations are available for the period after 1972 .

\subsection{Other Factors Affecting the Market for Public accounting}

The results presented suggest that the number of actual suppliers in the market for public accounting did not adjust to the regulatory demand for their services and, as a result, the suppliers received positive economic benefits. However, other factors in the market for public accounting might have nullified the positive economic effects of accounting legislation. Here, three other factors affecting the market for public accounting will be discussed: (1) the voluntary demand for public accounting services, (2) concentration on the supply side of the market for public accounting services, and (3) technological change.

\subsubsection{Voluntary Demand for Public Accounting}

One factor affecting the demand for public accounting is the voluntary, or non-regulatory, demand for public accounting services. It is clear from the studies on the disclosure of audited annual accounts before 1971 (see section 4.3.1) that firms demand auditing services without regulation. This voluntary demand might have changed in the regulatory period. It might have changed, for example, if the number of firms that are financed with outside capital changes or if the general condition of the economy changes. A drastic reduction of the voluntary demand for public accounting, larger than the increased demand due to regulation, might have caused the lack of an adjustment in the number of partners. That this is not the case, is evident from the increase of the number of NIVRA students and the number of RAs as a whole. The increases in these employee categories suggest that the sum of the regulatory demand and voluntary demand increased.

\subsubsection{Concentration of Suppliers}

The evidence presented in this chapter has focused on the number of suppliers (RAs employed in, and partners in, public accounting) relative to the size 
of the market. However, another suggested characteristic of the market for public accounting which can affect the fees charged, and the income of partners in public accounting, is the degree of concentration among suppliers [Pound and Francis, 1981, pp.356-360; Palmrose, 1986, pp.97-98/108]. The lack of an adjustment in the number of actual suppliers on the Dutch market for public accounting might have been compensated for, by increased competition among suppliers due to lower concentration. It should be mentioned that it is also suggested that higher (lower) concentration does not necessarily result in higher (lower) audit fees. High concentration may also be the result of economies of scale [Pound and Francis, 1981, p.357; Palmrose, 1986, p.98; Eichenseher and Danos, 1981]. For the analysis below it will be assumed that less concentration may result in more competition and lower audit fees.

Table 4.8

Concentration data of Dutch public accounting firms for 1971 and 1989

\begin{tabular}{rccccr}
\hline $\begin{array}{c}\text { (1) } \\
\text { firm } \\
\text { category }\end{array}$ & \multicolumn{2}{c}{$\begin{array}{c}\text { (2) } \\
\text { number of firms }\end{array}$} & \multicolumn{2}{c}{$\begin{array}{c}\text { (3) } \\
\text { number of RAs }\end{array}$} \\
\hline & & 1971 & 1989 & 1971 & 1989 \\
$>100$ & RAs & 3 & 5 & 467 & 1663 \\
$51-100$ & RAs & 5 & 2 & 411 & 143 \\
$21-50$ & RAs & 4 & 5 & 123 & 156 \\
$11-20$ & RAs & 4 & 5 & 53 & 59 \\
$6-10$ & RAs & 10 & 10 & 73 & 80 \\
$3-5$ & RAs & 34 & 37 & 109 & 131 \\
2 & RAs & 37 & 44 & 74 & 88 \\
1 & RA & 173 & 304 & 173 & 304 \\
total & & 270 & 412 & 1483 & 2624 \\
& & & & & \\
\hline
\end{tabular}

Data were collected on the degree of concentration on the supply side of the market for public accounting. The most consistent data available on the degree of concentration is provided by the annual reports of the NIVRA ${ }^{38}$.

${ }^{38}$ Market shares of accounting firms cannot be observed directly because accounting firms are not required to disclose annual reports and firms hiring an accountant do not have to disclose the fees charged by their accountant. An usual alternative is to collect data via the clients of accounting firms, and use their sales or assets as a surrogate 
The data give an annual classification of all accounting firms according to the number of RAs in the firm. To use this data for measuring concentration, it is assumed that if the market share of an accounting firm increases, its share in the total number of RAs will also increase. As stated earlier, the study by Zind and Zéghal [1989] suggests a very high correlation betwee accounting firms" revenues and their number of public accountants.

As an example, table 4.8 presents the NIVRA data for the years 1971 and 1989. The first column gives 8 size categories of accounting firms according to the number of RAs in the firm. The second column gives the absolute number of firms in the 8 size categories. Finally, the third column gives the total number of RAs associated with accounting firms in the 8 size categories.

On the basis of the NIVRA data, two concentration measures were calculated (see [Eichenseher and Danos, 1981, p.482]): (1) a five firm concentration ratio $^{39}$, and (2) the Herfindahl index ${ }^{40}$. The first concentration ratio is the percentage of all RAs associated with the five largest accounting firms. The second concentration ratio is calculated by first computing, for each firm, the percentage of all RAs which it accounted for (expressed as a proportion of 1). The H-index is the sum of the squares of these values. Because data for individual firms is not readily available, the average number of RAs per firm for each size category was used ${ }^{4 !}$.

measure of the fees charged (see e.g. [Moizer and Turley, 1987; Eichenseher and Danos, 19811). However, there are no accessible databases in the Netherlands that permit the collection of this data.

${ }^{39}$ Eichenseher and Danos [1981] calculate a four firm concentration ratio. Here a five firm concentration ratio is preferred because in 17 out of 22 years, the largest size category contained five firms.

${ }^{40}$ In the accounting literature, the $\mathrm{H}$-index is also used for measuring harmonisation of financial reporting practice (see [Van der Tas, 1988]).

${ }^{41}$ Individual public accounting firm data on the number of RAs can be generated from the membership lists of the NIVRA. These lists include data on all Dutch accounting firms and the names of the RAs associated with these firms. Disadvantages of using these data are: (1) membership lists were disclosed for only 14 years in the period 1968-1990, and (2) it is time-consuming to generate the individual firm data from the membership lists. The tentative results of a study using the membership list data suggest that there are no major differences between concentration ratios based on individual firm data and ratios based on size category averages. 
Table 4.9

Concentration of suppliers in the Dutch market for public accounting in the period 19681989

Concentration measures are based on the number of public accountants per accounting firm.

\begin{tabular}{llllll}
\hline \multicolumn{2}{c}{ C5 } & H-index & C5 & H-index \\
\hline 1968 & 0.314 & - & 1979 & 0.585 & 0.0739 \\
1969 & 0.341 & 0.0332 & 1980 & 0.622 & 0.0810 \\
1970 & 0.422 & 0.0480 & 1981 & 0.614 & 0.0795 \\
1971 & 0.426 & 0.0510 & 1982 & 0.610 & 0.0783 \\
1972 & 0.566 & 0.0688 & 1983 & 0.611 & 0.0783 \\
1973 & 0.590 & 0.0743 & 1984 & 0.591 & 0.0735 \\
1974 & 0.585 & 0.0733 & 1985 & 0.572 & 0.0694 \\
1975 & 0.597 & 0.0762 & 1986 & 0.563 & 0.0676 \\
1976 & 0.594 & 0.0760 & 1987 & 0.559 & 0.0676 \\
1977 & 0.599 & 0.0771 & 1988 & 0.510 & 0.0655 \\
1978 & 0.592 & 0.0756 & 1989 & 0.634 & 0.0829 \\
& & & & & \\
\hline
\end{tabular}

C5 = five firm concentration ratio; $\mathrm{H}$-index $=$ Herfindahl index.

Table 4.9 presents the annual values of the five firm concentration ratio (C5) and the H-index for the period 1968-1989. For both concentration ratios there is a strong increase in the period 1968-1973. In this period, both concentration ratios approximately doubled. After 1973 the concentration ratios are fairly stable until $1989^{42}$. In this year there is again a strong

42 These results are not in line with the study of Langendijk and Deetman [1990]. The latter study measured the degree of concentration of the Dutch market for public accounting services in the years 1979 and 1988. It was concluded that concentration in 1988 was higher than in 1979 while the results in table 4.9 indicate the reverse. In Langendijk and Deetman [1990] the concentration measures were based on the clients of accounting firms. Data were collected on the sales of 173 "larger" companies, and who their auditor was. The estimated fees charged by auditors were calculated on the basis of their client sales and the number of clients. The concentration measures (i.e. the $\mathrm{C} 4$ and $\mathrm{H}$-index) were calculated on the basis of the number of clients of accounting firms and the sales of their clients. The different results of Langendijk and Deetman [1990] can be attributed to two factors. First, they use different surrogate measures for audit fees. The study by Zind and Zéghal [1989] suggests that the number of public accountants is a better surrogate than the number of clients and clients. sales. Second, Langendijk and Deetman [1990] include in their study only a small part of the market for public account- 
increase. These results indicate that changes in market concentration cannot compensate for the lack of adjustment on the supply side. On the contrary, the degree of concentration has increased strongly on going from a nonregulated to a regulated environment. The question whether the strong increase of concentration is caused by regulation is difficult to answer and lies outside the scope of this study.

\subsubsection{Technological Changes}

Another factor affecting the demand for RAs is technological change. Examples of technological changes that have occurred in the public accounting sector in the past 20 years are the use of risk analysis in the audit process, the use of computers in the audit process, and the development of structured audit approaches. Through changes in auditing technology, the productivity of RAs might have increased. In other words, the number of chargeable hours required to audit a firm might have diminished. Technological change could reduce the demand for RAs and might have fully compensated for the increased demand caused by regulation. That this is not the case is supported by the increase of the number of NIVRA students and the number of employed RAs after the passing of the new accounting legislation. The total sum of increased demand due to regulation and a possible decrease due to technological changes is positive. Technological changes affecting the ratio of partners to other employees in public accounting could have reduced the demand for partners, but we have found no evidence that such an effect occurred after 1971 .

\subsection{Summary and Conclusions}

Sections 4.3 and 4.4 can be summarized as follows:

(1) After the passing of the 1970 and 1983 Dutch accounting legislation changes, an increase in the market for public accounting services would be expected.

(2) The data on the number of disclosed audited annual accounts and the number of employees in the public accounting sector are consistent with this expectation.

ing services. The actual number of customers for public accounting services is much larger than the 173 companies investigated. The concentration measures in table 4.9 are based on the whole Dutch market for public accounting services. 
(3) The data on the number of employees in the public accounting sector are consistent with the expectation that the 1983 change would cause an increase in the market for public accounting. Due to a temporary provision for middle-sized private companies and data problems, the effects of the 1983 change on the number of disclosed audited accounts cannot be measured.

(4) A comparison of the non-regulatory pre-1970 period with the regulatory post-1970 period indicates that the number of RA employees, but not of RA partners, adjusted to the increased size of the market for public accounting.

(5) The different growth patterns for co-operating partners and independent partners support the hypothesis that during the regulatory period it became more difficult for RAs to gain partner's positions in existing accounting firms.

(6) Other factors affecting the market for public accounting services (i.e. voluntary demand, concentration, and technology) did not compensate for the increased regulatory demand for auditing services.

These statements suggest that there were positive economic effects for partners in public accounting as a consequence of the 1970 and 1983 legislation changes. The scarce income data for RA partners presented in section 4.3 .3 are in line with this suggestion.

The main limitations of the study presented in this chapter are as follows. First, a main problem of studies of this kind is that they imply predictions of how the market would have developed in an unregulated environment. A perfect study would require us to "replay the past 20 years without accounting regulation" [Benston, 1969, p.524]. This is of course impossible. As a practical solution to this problem, this study has compared supply and demand data between pre-regulatory and post-regulatory periods. Second, the numbers of disclosed audited annual accounts, and of employees in the public accounting sector, are crude measures of the size of the market for public accounting (see section 4.3.1 for their limitations). Third, the analysis of the developments on the supply side of the market for public accounting took into account only a limited number of factors that might have affected the number of suppliers and their income. Other factors not considered in this study might have affected the number of suppliers and their income. Finally, as mentioned in the introduction, the legislation changes might have affected RAs through mechanisms other than the number of hours supplied and demanded. An increase in the legal liabilities of RAs is a possible negative effect of the legislation which is not considered in this study. These greater liabilities might have increased the resources spent by partners on insurance. 



\section{Chapter 5 \\ Economic Effects of Accounting Regulation for Contracts of the Firm: Dutch Accounting Legislation and Legal Form Choice}

This chapter will continue with providing empirical evidence of the economic effects of Dutch accounting legislation. The effects of the 1970 and 1983 changes on the contracting costs ${ }^{1}$ of firms will be discussed ${ }^{2}$. Thus, this chapter will study the same legislation as in the previous chapter, but now from the viewpoint of firms. A common feature of these changes is that the categories of legal forms (e.g. the public company form, and the private company form) which were subjected to accounting regulation were affected. As a consequence of both legislation changes, firms that were previously free to choose their disclosure policy were confronted with extensive disclosure requirements. To generate hypotheses on the economic effects of these accounting legislation changes for firms, a contracting view will be used. It will be hypothesized that increasing accounting regulation raises some firms' agency costs and, therefore, gives an incentive to switch legal form and avoid the regulation (e.g. a public company changing its legal form to a partnership form). However it may be expected that in deciding whether to switch legal form, a firm will take switching costs into account (e.g. taxes). The hypotheses are tested with time series data based on the total number of firms in various categories of legal forms and the number of firms switching between categories of legal forms. The results indicate that both Dutch accounting legislation changes affected legal form choice but that the effects of the 1970 change on legal form choice were much stronger than those of the 1983 change. This difference can be explained on the basis of differences in switching costs: a firm affected by the 1970 accounting legislation could switch to an alternative legal form that had very similar contractual characteristics, without substantial switching costs. In the 1983 case a similar alternative was not available. Avoiding the new accounting legislation through a legal form switch would adversely affect managers' and capital

'In this chapter, the term "contracting costs" refers to two cost categories: agency costs and switching costs. These two cost categories will be discussed extensively later in this chapter.

${ }^{2}$ This chapter is a revised version of Maijoor [1989b]. 
suppliers' risk, control mechanisms, contracting freedom, and taxes. These switching costs prevented a massive legal form switch.

The chapter proceeds as follows. The next section provides a conceptual framework for hypothesis development. Section 5.2 will deal with relevant previous research. Section 5.3 discusses the hypothesized economic effects of the two legislation changes, and presents empirical results. Section 5.4 provides a summary, conclusions, and proposals for further research.

\subsection{Economic Effects of Accounting Regulation for Firms: a Contracting Perspective}

A firm can be conceived as a nexus of contracts [Jensen and Meckling, 1976, p.310], among which financial contracts form a distinct group. Financial contracts are concluded between the suppliers of capital and executives who are ultimately responsible for the management of the capital ("managers"). Financial contracts are the result of the separation of ownership and control with respect to the capital of the firm. This separation allows for specialization of management and risk bearing functions [Fama and Jensen, 1983a, pp.301-302]. The contractual problems associated with financial contracts are called agency problems. Firms will try to define contracts so as to minimize the negative consequences of agency problems, i.e. agency costs. Agency problems can be divided into incentive problems and risk sharing problems. Incentive problems concern the divergence of self-interest between managers and capital suppliers. Control mechanisms such as monitoring, bonding, the managerial labor market, and the market for corporate control can mitigate these incentive problems (see [Jensen and Meckling, 1976; Fama, 1980; Manne, 1965]). The disclosure of annual accounts by managers is an example of a monitoring mechanism [Watts, 1977] $]^{3}$. The agency costs of the incentive problem can be classified as follows: monitoring costs, bonding costs, and the residual loss [Jensen and Meckling, 1976]. Risk-sharing problems relate to the risks associated with the effects of unforeseeable events on the value of the capital invested in the firm (see [Posner, 1986, pp.368-372; Fama and Jensen, 1983a, p.307]). These risks are not controllable by managers, so they have to be shared

${ }^{3}$ The monitoring costs of disclosing accounting information are not only the direct costs of the information production. Monitoring costs are also the indirect costs of disclosing accounting information. Examples of these indirect costs are political costs, competitive disadvantage costs, and the costs of a weaker position in labor negotiations. 
between managers and capital suppliers. Contracts are written which specify the allocation of risk between capital suppliers and managers. For example, debt holders receive a fixed reward regardless the results of the firm, while managers generally receive a reward which depends to some extent on the value of the firm's capital (e.g. through holding stocks of the firm). Agency costs can arise as a result of the risk-sharing problem, in the form of forgone risk-sharing benefits. For example, if an owner/manager has unlimited liability for capital losses, his opportunities to diversify his risks are reduced.

Accounting information has two functions in financial contracting: in defining the contract terms and in monitoring the performance of the contracts [Watts and Zimmerman, 1986, p.196]. The role in defining contract terms arises because accounting information is used to specify the contracts between capital suppliers and managers. For example, restrictions on the payment of dividends are often based on accounting figures. In the Netherlands, the ability to pay dividends depends on calculated profits and legal reserves, and both measurements are partly determined by accounting procedures. The role in monitoring contracts refers to the fact that accounting information is used by capital suppliers to assess managers' performance and whether they meet the contractual arrangements.

The accounting policy of a firm is determined by considerations of efficiency [Ball, 1989, p.3]. Firms with serious agency problems will spend more resources on contracting and monitoring than firms with limited agency problems. The agency problems of firms with a high degree of separation of ownership and control are more serious than those of firms with a low degree of separation [Fama and Jensen, 1983a and 1983b], so it would be expected that their optimal level of disclosure would be higher ${ }^{4}$. More specifically, it can be expected that the optimum level of disclosure increases if the ratio of the managers' equity to outside equity falls [Jensen and Meckling, 1976, pp.346-347; Watts, 1977, p.60]. Also, it can be expected that the larger the absolute outside debt the higher the optimum level of disclosure will be [Jensen and Meckling, 1976, p.347; Watts, 1977, p.60].

4his relationship is also implicitly suggested in older articles in the Dutch accounting literature. The argument in these articles is that the development of accounting practice is strongly related to the increasing separation of ownership and control in Dutch industries (see e.g. [Bruinessen, 1975, pp.6-7; Burgert, 1965, pp.264-265; Groeneveld, 1968 , p. 21; Kraayenhof, 1955, p.62]). 
Legal form legislation, including accounting legislation", offers various "contract packages" that substitute for fully contingent agency contracts (see [Ball, 1989, pp.44-46; Baysinger and Butler, 1985, p.180; Posner, 1986, pp.369-372]). Legal forms differ with respect to the specification of the contractual relations between capital suppliers and managers. First, legal forms vary with respect to the contractual solutions for the incentive problems. For example, currently in the Netherlands large public and private companies are required to have a board of outside directors, while partnerships are not. Second, legal forms vary with respect to the contractual solutions for risk problems. The risk for managers varies between legal forms. For example, managers of public and private companies have limited liability for the debts of the firm, while managers of a general partnership have unlimited liability. In addition, the risk for suppliers of capital varies between legal forms. A partner who provides capital in a general partnership has unlimited liability for the debts of the firm while a stockholder in a public company has limited liability.

In the Netherlands, the contractual characteristics of legal forms also contain specifications for the accounting policy of the firm. The prescriptions with respect to the disclosure of accounting information vary between legal forms. For example, a large private company currently has the obligation to have a monitoring system based on the diselosure of audited annual accounts while a partnership escapes this obligation. Managing partners are only obliged to disclose the books of the firm to the other partners.

Changes in accounting regulation may increase the agency costs of firms. A firm is required to comply with the disclosure requirements tied to its legal form. These requirements may be more extensive than, or demand other information than, an individual firm's optimal disclosure policy. Accounting regulation which requires a firm to execute an accounting policy that differs from its optimal accounting policy causes increased agency costs [Watts and Zimmerman, 1987, pp.209-210]. Accounting regulation results in the loss of opportunities to minimize agency costs. For example, assume that for a small firm with a low degree of separation of ownership and control, a monitoring system based on personal control is an efficient solution for its agency problems. The passing of accounting legislation which requires this firm to

${ }^{5}$ It should be emphasized that accounting legislation will be treated as a datum in this chapter. No assumptions are made regarding the reason for its establishment. Thus it is not assumed that it is established with the intention of reducing agency costs. The reasons behind the establishment of accounting legislation and the function of (legally required) accounting information for firms (i.e. minimizing agency costs) are not necessarily in line with each other. 
disclose audited annual accounts which comply with generally accepted accounting principles will increase the agency costs of this firm.

The framework described above will be used to explain: (1) the reduced number of firms choosing the public legal form after the 1970 legislation change, and (2) the reduced number of firms choosing the private legal form after the 1983 legislation change. The differences between agency costs and agency problems should be stressed. Legislation demanding more extensive disclosure of accounting information increases the monitoring costs of the firm and thus also the agency costs. However, the legislation does not affect the agency problems of the firm if it does not change its management ownership share or the capital that is provided by the various capital suppliers. This chapter will be concerned with the effects of the legislation on agency costs and not with the effects on agency problems.

Increased agency costs due to the passing of new accounting legislation give firms an incentive to switch legal forms ${ }^{6}$. Firms will change to a legal form which allows them to implement an accounting policy that is closer to the firm's optimal accounting policy. However, a firm will weigh the costs of a suboptimal disclosure policy against the costs of switching legal form $^{7}$. A firm changing its legal form incurs direct and indirect switching costs. Direct costs refer to the costs associated with the legal requirements of a switching procedure ${ }^{8}$. Indirect costs refer to the costs associated with changes in the

${ }^{6}$ It will be assumed that managers, at least, benefit from the reduced agency costs of the relationship between managers and capital suppliers. However, other parties (e.g. capital suppliers) might also benefit (see [Watts and Zimmerman, 1987, pp.193/198]).

${ }^{7}$ The approach taken here is similar to the approach of Scholes, Wilson, and Wolfson [1989] in the tax area. In their study the presence of "not optimal" tax policies among banks is explained in terms of non-tax costs.

${ }^{8}$ The switching procedures that are relevant for this study are from the public to the private form, from the private to the public form, and from the public or private form to a partnership form. The switching procedure from the public to the private form and vice versa is very simple and is regulated by law [Sanders and Westbroek, 1985, pp. 202/226; Van der Heijden and Van der Grinten, 1976, p.208]. It is comparable to a normal change in the statutes of a company. The main requirements of the switching procedure are: (1) a decision to switch by the stockholders, (2) a change in the statutes of the company, (3) a notarial act, and (4) a statement of non-objection from the Ministry of Justice. Since 1981 a switch from the private to the public form has required the disclosure of audited annual accounts. The procedure for switching from the public or private form to a partnership form is more complicated and is not regulated by law. Various procedures are possible (see [Heyman et al., 1988, pp.38-41; Mohr, 1988, p.142]). As a minimum, the normall procedure for the establishment of a partnership applies. 
contractual characteristics of the firm which are the result of the legal form switch. Because of the numerous contractual differences between legal forms, there are many sources of switching costs. Four differences that can give rise to indirect switching costs will be discussed:

(1) Risk for managers and capital suppliers. Differences with respect to risk for managers and capital suppliers have already been discussed. Both managers' and capital suppliers' liabilities vary between legal forms. Limited liability gives potential benefits from the diversification of risk and allows one to raise outside capital [Posner, 1986, pp.370-371]. However, limited liability causes serious incentive problems and therefore resources have to be invested in control mechanisms. Unlimited liability means forgoing risk-sharing benefits, but the incentive problems are less serious [Fama and Jensen, 1983a, p.306]. As a result, fewer resources have to be devoted to control mechanisms.

(2) Control mechanisms. Legal forms differ with respect to their prescribed control mechanisms such as (1) disclosure requirements, (2) having a board of outside directors, and (3) regulations which restrict the actions managers are allowed to take. An example of the third category are the regulations which restrict the freedom of the managers of public and private companies to distribute the proceeds of the capital to capital suppliers, according to measurement rules for profits and legal reserves (see for example [van Schilfgaarde, 1988, pp.7375]). By contrast, managers and capital suppliers of partnerships have, to a large extent, freedom to specify the rules for the division of the proceeds of capital [Mohr, 1988, pp.42-48].

(3) Contracting freedom. Legal forms differ with respect to the freedom to specify contractual relations. For some legal forms, such as the public and the private company, many regulations specify extensively the contractual relations between capital suppliers and managers. For other legal forms, such as partnerships, very few regulations exist and partners are relatively free to specify the contractual relations between the suppliers and managers of capital (see [Boukema and Dorresteijn, 1986, p.39]).

(4) Taxes. Legal forms differ with respect to the firms" contracts with the taxing authorities. For example, the profit of private companies is subjected to the corporate tax system while the profit of partnerships is subjected to the income tax system, if the partners are individuals [Bink and Wasch, 1986, pp.13-22]. In the current Dutch tax system, 
corporate tax rate is basically proportional and is lower than the highest rate of the progressive income tax system [Heyman et al., 1988, p.44].

Legal forms provided by Dutch company law are described in appendix 5.3 along the lines of the four characteristics discussed above. The switching costs associated with these characteristics will be used to explain: (1) the high number of public companies switching to the private legal form after the 1970 change, and (2) the low number of private companies avoiding the requirements of the 1983 change. Finally, it should be stressed that accounting legislation can affect the contracting costs of firms (i.e. agency costs and switching costs) in either of two ways. First, if a piece of legislation increases agency costs, a firm can decide not to switch, and thus to bear the increased agency costs. Second, a firm can decide to avoid the increased agency costs by switching to another legal form and bearing the switching costs.

\subsection{Previous Research}

This section will deal with previous research related to the subject of this chapter. Two areas of research will be discussed; (1) empirical accounting literature on agency problems and on financial accounting as an efficient mechanism to control these problems, and (2) Dutch legal literature on legal form choice by firms.

\subsubsection{Empirical Literature on Financial Accounting and Agency Problems}

Several studies have tried to provide empirical evidence of the relationship between the disclosure of accounting information and the agency problems of firms. In essence these studies attempt to relate cross-sectional differences regarding disclosure to firms' agency problems. This section will discuss four studies in this area: Leftwich et al. [1981], Chow [1982], Chow and Wong-Boren [1987], and Buijink [1990]. Three elements of these studies will be discussed: (1) the variables used to measure the extent of disclosure per firm, (2) the variables, or firm characteristics, used to explain differences with respect to disclosure, and (3) the results of these studies. 
Table 5.1

Empirical studies on the extent of disclosure and agency problems

\begin{tabular}{|c|c|c|c|}
\hline & $\begin{array}{l}\text { (1) } \\
\text { variable for extent } \\
\text { of } \\
\text { disclosure }\end{array}$ & $\begin{array}{c}\text { (2) } \\
\text { variables explaining } \\
\text { extent of disclosure }\end{array}$ & $\begin{array}{l}\text { (3) } \\
\text { significant explana- } \\
\text { tory variables in } \\
\text { expected direction }\end{array}$ \\
\hline $\begin{array}{l}\text { Leftwich, } \\
\text { Watts and } \\
\text { Zimmerman } \\
{[1981]}\end{array}$ & reporting frequency & $\begin{array}{l}\text { firm size } \\
\text { assets in place/firm size } \\
\text { debt/firm size } \\
\text { pref. stock/firm size } \\
\text { outside directors } \\
\text { exchange listing }\end{array}$ & exchange listing \\
\hline Chow [1982] & $\begin{array}{l}\text { voluntary external } \\
\text { audit }\end{array}$ & $\begin{array}{l}\text { firm size } \\
\text { debt/firm size } \\
\text { debt convenants }\end{array}$ & $\begin{array}{l}\text { firm size } \\
\text { debt/firm size } \\
\text { debt convenants }\end{array}$ \\
\hline $\begin{array}{l}\text { Chow and } \\
\text { Wong-Boren } \\
\text { [1987] }\end{array}$ & $\begin{array}{l}\text { all voluntary dis- } \\
\text { closed items in } \\
\text { annual accounts } \\
\text { (composed score) }\end{array}$ & $\begin{array}{l}\text { firm size } \\
\text { debt/firm size } \\
\text { assets in place/total assets }\end{array}$ & firm size \\
\hline $\begin{array}{l}\text { Buijink } \\
{[1990]}\end{array}$ & $\begin{array}{l}\text { voluntary external } \\
\text { audit }\end{array}$ & $\begin{array}{l}\text { firm size } \\
\text { non-man. ownership share } \\
\text { debt/firm size } \\
\text { outside directors } \\
\text { assets in place/total assets }\end{array}$ & $\begin{array}{l}\text { debt/firm size } \\
\text { outside directors }\end{array}$ \\
\hline
\end{tabular}

Variables used as a measure of the extent of disclosure are (see table 5.1, column 1): (1) the reporting frequency of the firm, (2) the presence of an external audit, and (3) a composed score of disclosed items. Each variable gives an indication of the possibilities for capital suppliers of monitoring the activities of managers. A higher reporting frequency (quarterly) implies that capital suppliers can monitor the activities of managers more continuously. If managers use a voluntary audit, the information used by capital suppliers to monitor the activities of managers becomes more reliable. The composed score is based on various items disclosed in an annual report. A higher composed score implies that capital suppliers have in general more information about the financial consequences of the activities of managers. 
Firm variables used to explain differences with respect to the extent of disclosure are (see table 5.1, column 2); (1) firm size, (2) non-management ownership, (3) debt/firm size, (4) preferred stock/firm size, (5) debt covenants, (6) proportion of assets in place, (7) exchange listing, and (8) outside directors. The arguments, based on agency theory, for the use of these variables are as follows. Firm size, non-management ownership, and leverage ratios (leverage ratio for debt and leverage ratio for preferred stock) are considered to be indicators of the divergence of interest between managers and capital suppliers. The conflicts of interest vary according to the relationships of managers with stockholders, managers with preferred stockholders, and stockholders with debt holders. Thus the agency problems depend on the division of capital among managers, (preferred) stockholders and debt holders. Firm size is considered to be an indicator of the relative amount of capital owned by managers. Larger firms tend to have a higher proportion of outside capital and a lower proportion held by the managers. The use of the non-management ownership ratio and leverage ratios as indicators of the proportion of capital held by (preferred) stockholders and debt holders is self-evident. Agency theory suggests that serious agency problems make it beneficial to monitor the activities of managers, since monitoring can lower the costs of agency problems. Therefore the extent of disclosure is assumed to be dependent on the proportions of capital held by managers and the various classes of capital suppliers. Concerning the explanatory variable debt covenants, Chow [1982] argues that the greater the number of accounting measures in contracts with debt holders, the higher is the probability that a firm will voluntarily audit their annual accounts. An audit gives more reliable information to debt holders on the violation of accounting based contracts. The argument for the use of the proportion of assets in place as an indicator of agency problems is as follows. Wealth transfers by managers are more difficult if assets are already owned. In other words, the conflicts and agency problems are less if there is a large proportion of assets in place, so the benefits from disclosure are inversely related to the proportion of assets in place. The prediction is that there will be more voluntary disclosure if there is a low proportion of already owned assets.

Outside directors and the listing requirements of stock exchanges are also considered as explanatory variables for the extent of disclosure [Buijink, 1990; Leftwich et al., 1981]. The argument is that outside directors and listing requirements, like the disclosure of accounting information, can be viewed as monitoring devices. Outside directors monitor the activities of managers on behalf of the suppliers of capital. The listing requirements of stock exchanges require firms to have particular covenants in their corporate bylaws and to disclose accounting information on a regular basis. The presence of both outside directors and listing requirements decrease the 
probability that managers will take actions that are not in the interest of capital suppliers. Leftwich et al. [1981] and Buijink [1990] assume that the use of one form of monitoring depends on the use of other forms of monitoring. How various monitoring devices depend on each other is not clear, but they assume that monitoring devices can substitute for and complement each other.

The results of the four studies are mixed (see table 5.1, column 3 ). In two out of the four studies, firm size appeared to be a significant variable explaining the extent of disclosure. Leverage variables appeared to be significant and in the expected direction in two studies, while the presence of outside directors was a significant explanatory variable in one study. Assets in place did not have significant results in any of the studies. A possible explanation for the mixed results is the difficulty of quantifying firms' various levels of disclosure. Only partial measures for the intensity of disclosure are used (e.g. reporting frequency [Leftwich et al., 1981] or the presence of an audit [Chow, 1982; Buijink, 1990]). A second explanation for the mixed results is the presence of control mechanisms other than outside directors and listing requirements. Agency problems can be mitigated through a wide range of mechanisms. There might be significant differences between firms with respect to the presence of control mechanisms that are not considered in these studies.

The accounting legislation changes in the Netherlands give the opportunity to reduce the problem of these partial measures of the level of disclosure. The legislation changes meant that firms were confronted with a high level of disclosure, and their preferences for different levels of disclosure should be revealed more strongly. In comparison to the four studies discussed above, a weakness of the research presented in this chapter is that it does not compare agency problems between firms. It only uses aggregated data on the capital structure of firms.

\subsubsection{Dutch Literature on Legal Form Choice}

The Dutch academic literature on the choice of legal form by firms in the Netherlands is of a legal nature. Dutch accounting researchers and economists have hardly given any attention to this subject. In the legal literature, legal form choice is in general not discussed as an independent subject: changes of legal form by firms are viewed as a possible consequence of new legislation. From a review of the Dutch legal literature on legal form choice we can say that (1) many factors are suggested which can affect legal form choice but there is no development of a coherent theory of legal form choice, 
and (2) there is no systematic empirical research on legal form choice by firms. Both subjects will be discussed.

Numerous factors that affect legal form choice by firms are suggested in the legal literature. On one hand, very vague explanations of legal form choice are given. For example, Van der Heijden et al. [1989, p.42] state that the small firm "discovered" the private form, and that the "psychological resistance" to the establishment of a private company is less, as compared to the establishment of a public company. According to Sanders and Westbroek [1985, p.3] the choice between the private and public company is "mainly based on practical considerations". And De Bakker [1973, p.53] states that "the limited partnership form does not live sufficiently in the legal consciousness".

On the other hand, numerous characteristics of legal forms, which might influence legal form choice by firms, are suggested, including:

(1) the risk or liability of managers and suppliers of capital [De Bakker, 1973, p.53; Westbroek, 1977, p.35; Heyman et al., 1988, p.51];

(2) taxes [Boukema and Dorresteijn, 1986, p.35; Heyman et al., 1988, p.43; Duynstee, 1986, p.172; Meeles, 1975, pp.56-57; Solinge, 1975, p.211; Boukema, 1974, p.262];

(3) opportunities to raise capital [Boukema and Dorresteijn, 1986, p.35; Schwarz, 1986, pp.58/61];

(4) disclosure requirements [Mohr, 1988, pp.121; De Bakker, 1973, p.53; Sanders, 1972, p.2; Schilfgaarde, 1985, p.1; Kamp, 1971; p.152, Boukema, 1974, pp.261-263; Brenninkmeijer, 1975, pp.10-11; Slagter, 1972, pp.93-96];

(5) requirements to have a board of outside directors [Mohr, 1988, p.121; Heyman et al., 1988, p.55];

(5) contracting freedom [Mohr, 1988, p.119; Heyman et al., 1988, p.43];

(6) capital requirements [Mohr, 1988, p.121; Slagter, 1983, p.150];

(7) opportunities to use the legal form for dishonest practices [Corstens, 1985, p.48; Slagter, 1983, p.144; Mohr, 1988, p.121].

In the legal literature, there is no attempt to integrate these factors and construct a coherent theory of legal form choice. However, it is frequently implicitly assumed that firms chose their legal form on the basis of costbenefit, or efficiency, considerations. These costs and benefits depend on the characteristics of the firm and the characteristics of the legal form (see for example [Boukema, 1974, p.262; Slagter, 1983, p.150; Westbroek, 1977, p.35; Heyman et al., 1988, pp.51-66]). Slagter [1983, p.150] describes the disadvantages ("costs") and advantages ("benefits"), for a private company, 
of a switch to the limited partnership form. And Westbroek [1977, p.35] states that for many private companies the disadvantage of disclosure requirements are less than the disadvantages of a switch to a partnership form.

In the legal literature it is frequently hypothesized that the passing of legislation which changes the characteristics of legal forms affects the number of firms choosing a particular legal form. For example, effects are expected from legislation changes with respect to the presence of a board of outside directors [Brenninkmeijer, 1975, pp.10-11], the abuse of the private form [Sanders and Westbroek, 1988, p.3; Slagter, 1983, p.144], and the disclosure of accounting information [Sanders, 1977, p.165; Sanders and Westbroek, 1985, p.2]. However, these hypothesized effects are hardly documented with empirical evidence. Exceptions are Heyman [1988, pp.43-44] and Slagter [1983, p.142-144]. However, their analyses of the empirical evidence are very casual.

As mentioned above, accounting regulation is frequently suggested as a factor affecting legall form choice. However, the explanation goes no further than to state that firms would like to avoid the requirements. Besides, there is no systematic empirical research on the effects of disclosure requirements for legal form choice. In the next section an attempt will be made to provide empirical evidence of the effects of two accounting legislation changes for legal form choice by firms. To predict these effects, the legal form choice framework described in section 5.1 will be used. Accounting legislation changes increase some firms' agency costs and give an incentive to switch to another legall form. However, switching costs reduce the incentive to switch.

\subsection{Effects of Dutch Accounting Legislation on Legal Form Choice}

Changes in Dutch accounting legislation have meant that, over the past 20 years, a growing number of legal form categories have been subjected to financial reporting requirements. This section will analyze, at an aggregated level, the effects of the 1970 and 1983 changes in Dutch accounting legislation on legal form choice. Both changes increased the number of categories of legal forms subjected to accounting legislation. In general terms it can be stated that as a result of the 1970 change disclosure requirements applying to a small fraction of public companies were extended to cover all public companies. And as a result of the 1983 change the disclosure requirements 
applying to a small fraction of private companies were expanded to all private companies. Sections 5.3.1 and 5.3.2 will discuss the effects of the first and second legislation change respectively. Each section will first discuss the change in accounting legislation and generate hypotheses on the effects on legal form choice by firms. Next the empirical evidence of legal form choice will be presented. The last part of each section will discuss alternative explanations for the observed changes of legal form choice by firms.

The effects of the two major changes in accounting legislation will be discussed in relation to the following legal forms: the public company, the private company, the general partnership (vennootschap onder firma), the limited partnership (commanditaire vennootschap), the civil law company (maatschap) and the one-man business (eenmanszaak). These legal forms are extensively described in appendix 5.3. The selected legal forms comprise nearly all of the contractual arrangements available for firms. Remaining legal forms, such as co-operative societies and mutual guarantee associations, have very different contractual arrangements and are chosen by firms engaged in specific economic activities. These remaining legal forms are omitted from the analysis in this chapter. The term "partnerships" will refer to the whole group of general partnerships, limited partnerships, and civil law companies.

The data on the total number of firms in various categories of legal forms and the number of firms switching legal forms had to be collected from various sources. For some legal forms and some years the necessary data was not available and had to be estimated. The estimation procedure applied was interpolation. For some legal forms a whole industry had to be omitted because of a change in industry definition, or there were no industry data available. The main sources are: (1) the Netherlands Central Bureau for Statistics (Centraal Bureau voor de Statistiek), (2) the Dutch Chambers of Commerce (De Nederlandse Kamers van Koophandel en Fabrieken), and (3) the Ministry of Justice (Ministerie van Justitie). The accurate and systematic registration of data on legal forms started in 1979, and it is published by the Netherlands Central Bureau for Statistics. For the period before 1979 , the available legal form data is generally restricted to the public and private company form. Sources and construction of the data are further discussed in appendix 5.1 . 


\subsubsection{Effects of the 1970 Change on Legal Form Choice}

The Act on Annual Accounts of 1970 has already been discussed extensively in section 4.3. Here a summary of the legislation change, with an emphasis on its effects for firms will be given. Before the enforcement of the Act on Annual Accounts of 1970, the main Dutch accounting legislation was section 42 of the Code of Commerce (established in 1928). Its field of application was limited to open public companies and the prescriptions were not extensive $^{9}{ }^{10}$. Nearly all open public companies were listed at the Amsterdam Stock Exchange and practically all disclosed audited annual accounts voluntarily.

${ }^{9}$ See chapter four, footnote 15 for the legal description of open public companies.

10. The annual number of reguests submitted to the Ministry of Justice for the establishment of a public company (not disaggregated for open or closed public companies) provides some evidence of the effects of the 1928 legislation on legal form choice. In 1928, the number of requests totalled 3024. This is the highest observation for the period 1915-1960 (average observation = 1316) [Van der Heijden et al., 1989, pp.4244]. The finding that the passing of disclosure legislation for open public companies is associated with a high number of newly established public companies is at first sight counter-intuitive. However, a plausible explanation for this observation can be given. The proposals that preceded the 1928 legislation go back to at least 1910. The proposals that led to the 1928 change had always had the intention to regulate all public companies and not only open public companies. A final proposal, discussed first in parliament in 1927 , intended to regulate all public companies and survived the Second Chamber. However, the proposal was vigorously debated in the First Chamber in 1928 and was passed subject to the promise of the minister to establish a commission which would give an advice on the field of application of the legislation. In the same year, the commission proposed to restrict the legislation to open public companies. This proposal was enforced by law in 1929. In other words, the initial proposals for the 1928 legislation fueled the expectation that all public companies would have to disclose in the future and reduced the attractiveness of the public company form. The limitation of the actual accounting requirements to a small group of all public companies strongly increased the attractiveness of the public company form in 1928. This provides a plausible explanation for the high number of requests for the establishment of a public company in 1928. For an overview of the political process of the 1928 change see Vecht [1977, pp.29-35] and Van der Heijden and Van der Grinten [1946, pp.14-24]. Another effect of the 1928 legislation change that can be expected is a shift within the group of public companies from open to closed. There are no data that could document this shift. However, in the interim report of the Commission for Civil and Criminal Law (Commissie voor Privaat- en Strafrecht) (Handelingen der Staten-Generaal, Tweede Kamer, Bijlagen, 1928-1929, May 2nd 1929, p.10y it is stated that a number of public companies changed their bearer shares into registered shares in order to avoid the new accounting requirements (I would like to thank Roland van der Vliet, the business economics student at the University of Limburg who pointed out to me the effect of the 1928 change on the total number of requests for the establishment of a public company). 
The Annual Accounts Act of 1970 changed the field of application of accounting legislation considerably. It was extended from open public companies to all public companies. In general, other legal forms were not subjected to the prescriptions of the Act. The exception was that large private companies were also subjected to the $\mathrm{Act}^{11}$. The Act required public companies to audit their annual accounts and it contained prescriptions for both sides of the balance sheet, the profit and loss account and the explanatory notes. All public companies had to disclose audited annual accounts over the first financial year which included the 29th December of 1972 [NIVRA, 1972 , p.137; Boukema, 1973, p.100]. If a public company wanted to avoid the requirements it had to switch legal form before the 1st of Aprill 1973 [Boukema, 1973, p.100; Westbroek, 1971b, p.317]. This implied that public companies had to file a request to switch with the Ministry of Justice before the 15th December of 1972 [Boukema, 1973, p.100].

Open public companies accounted for only a very small fraction of the total number of public companies $(1.5 \%$ of all public companies in 1970 , see column 1 and 5, table 5.6 in appendix 5.1). The hypothesis that the 1970 accounting legislation change was the motive for many public companies to switch to another legal form, so as to avoid the requirement to audit and disclose annual accounts, is frequently stated in the Dutch legal literature (see for example: [Schuit et al., 1978, p.138; Boukema and Dorresteijn, 1986, p.61; Sanders and Westbroek, 1985, p.222; van der Heijden et al., 1989; p.146; Slagter, 1985, pp.106/258; van Schilfgaarde, 1988, p.33; Sanders, 1977, p.165; Schwarz, 1986, p.59; Slagter, 1971, p.173; Slagter, 1983, p.143]). An economic underpinning of the hypothesis that many public companies avoided the obligation to disclose through a legal form switch is provided by agency theory. The passing of the 1970 change implied that firms with the public company form were required to have a control mechanism based on the public disclosure of audited annual accounts in line with Act on Annual Accounts. Many of the public companies involved were small firms with a low degree of separation of ownership and control. In 1970, the group of public companies can be characterized as follows:

(1) in 1970 the share capital of $92 \%$ of all public companies was below $f$ 500,000.- [CBS, 1976, p.19];

(2) of all public companies, $98.5 \%$ did not meet the characteristics of an open public company. These public companies were called closed public companies. See footnote 15 , chapter four for the characteristics of open public companies;

${ }^{11}$ See chapter four, footnote 17 for the legal description of large private companies. 
(3) closed public companies were small (family) firms [Schwarz, 1986, p.25; Sanders and Westbroek, 1985, p.222];

(4) most public companies had restricted the transfer of stock, and did not have much public debt [Slagter, 1971, p.173; Schwarz, 1986, pp.31/33; van Schilfgaarde, 1988, p.32];

(5) the managers of most closed public companies supplied (partially) the capital of the firm and/or were the founder of the firm [Brenninkmeijer, 1975, p.12; Schwarz, 1986, p.30].

It can be concluded that the agency problems of most of these public companies are limited, and they would be expected to avoid costly mechanisms to monitor the decision of managers [Fama and Jensen, 1983a, p.307, and $1983 \mathrm{~b}, \mathrm{p} .332]$. For those companies a monitoring system based on personal control and non-public annual accounts specific to the firm is a more efficient control mechanism than the public disclosure of audited annual accounts. As a result of the passing of the 1970 legislation change it would be expected that the agency costs of public companies would be increased. These increased agency costs gave an incentive for public companies to switch legal form. Hence, the following alternative-form hypothesis was developed:

\title{
Hypothesis 1
}

\begin{abstract}
After the 1970 legislation change, a decreased number of firms chose the public company form, and an increased number of firms chose alternative legal forms.
\end{abstract}

It would be expected that most of the switching public companies would choose the private company form. The introduction of the private company form in Dutch company law in $1971^{12}$ was the result of the First EC Directive on company law, which obliged all public companies to disclose annual accounts [Kamp, 1971, p.150; Westbroek, 1971a, p.275; Boukema, 1974, p.261; Slagter, 1971, pp.173-174]. The preference of switching public companies for the private company can be explained in terms of switching costs. The contracts of the private company are very similar to the contracts of the public company except with respect to the disclosure and auditing of annual accounts [Westbroek, 1971a, p.276; Slagter, 1971, p.173]. The main differences between the public and private form at the beginning of the seventies were [Boukema and Dorresteijn, 1986, p.58; Kamp, 1971, pp.150151; Westbroek, 1971a, p.276; Slagter, 1983, p.145]:

1.2 The Act on Private Companies of the 3rd May of 1971 (Stb. 286), came into force on the 29 th of June 1971. By this Act the private company was introduced in Dutch law as a new corporate form. 
(1) a public company is allowed to have both registered and non-registered stocks. A private company is only allowed to issue registered stocks;

(2) a public company is allowed to restrict the transfer of stocks, a private company is obliged to restrict the transfer of stocks.

Note that with respect to both differences, a public company can be contracted as if it were a private company. Therefore, the obligation to have registered stocks and restrict the transfer of stocks will not result in a preference for the private company. The tax system for private companies is identical to that for public companies [Bartel, 1971, p.154]. As a result, there are no tax effects of a switch from the public to the private form [Bartel, 1971, p.156]. It is suggested in the Dutch legal literature that the switch from public to private forms implied large costs because firms had to give up the right to issue non-registered stocks and have them freely transferable (see [Schwarz, 1986 , p.59]). However, it can be argued that for small firms with a low degree of separation of ownership and control the obligation to issue only registered stocks and block their transfer does not imply substantial costs. Besides, most public companies had registered their stock and blocked the transfer of stock before 1971 [Slagter, 1971, p.173; Schwarz, 1986, p.4]. The assumption that the private company requirements with respect to stock did not imply large costs is confirmed empirically by the results of the 1983 change. As we will see later in this chapter, the enforcement of equal disclosure requirements for the private and public company did not result in a massive switch from the private to the public company legal form after 1983. In sum, it can be concluded that a switch from the public to the private legal form is nearly costless [Westbroek, 1971a, p.276; Westbroek, 1971 b, p.318]. By contrast, a switch to the partnership forms would significantly affect many contractual arrangements of the firm. The contractual characteristics referred to in section 5.1 (risk for managers and suppliers of capital, control devices, contracting freedom and taxes) would certainly be affected (see appendix 5.3). These contract changes would cause substantial switching costs. Therefore, the private company seems to be the most efficient alternative for the public company. The alternate form of the hypothesis with respect to legal form choice by switching public companies is stated as follows:

Hypothesis 2

Public companies that switched legal form due to the 1970 legislation change, chose the private company form. 


\section{Results $^{13}$}

In general, hypotheses 1 and 2 are confirmed by the results. The total number of public companies and the number of newly established public companies support the expectation that a decreasing number of firms would choose the public company form. The total number of public companies decreased from 46,400 in 1970 to 8,061 in 1974 (see column 1, table 5.2). The number of newly established public companies per year was reduced from 3,183 in 1970 to 82 in 1972 (see column 2, table 5.2).

\section{Table 5.2}

Effects of the 1970 change on legal form choice

For sources and construction see tables 5.6 and 5.9 in appendix 5.1.

(1)

total number newly estab-

public

companies
(3)

switching from public to private
(4)

disclosing total number public enterprises

\begin{tabular}{cccccc}
\hline 1966 & 36,200 & 1,876 & n.r. & 993 & n.a. \\
1967 & 37,900 & 1,625 & n.r. & n.a. & n.a. \\
1968 & 40,400 & 2,526 & n.r. & n.a. & n.a. \\
1969 & 43,400 & 3,070 & n.r. & n.a. & 431,022 \\
1970 & 46,400 & 3,183 & n.r. & n.a. & 426,172 \\
1971 & n.a. & 2,797 & 1,275 & 692 & 425,672 \\
1972 & n.a. & 82 & 42,498 & n.a. & 424,868 \\
1973 & n.a. & 79 & 999 & 2,928 & 426,658 \\
1974 & 8,061 & 51 & 203 & 2,539 & 428,890 \\
1975 & 6,871 & 33 & 95 & 2,848 & 429,339 \\
1976 & 6,183 & 30 & 140 & 2,507 & 430,206 \\
& & & & & \\
\hline
\end{tabular}

n.a. = not available; n.r. = not relevant.

Nearly all switching public companies chose the private company legal form (during the years 1971-1974 at least $95 \%$ of all switching public companies, see column 3, table 5.6 in appendix 5.1, and appendix 5.2). During 1972,

13 Because of the clear effects of the 1970 accounting legislation change on the legal form time series, no statistical tests were employed. 
the first financial year subjected to the Act, 42,498 public companies switched to the private company form (see column 3 , table 5.2). The number of switchers from public to private decreased rapidly after 1972 to 140 in 1976.

For the beginning of the seventies there are no accurate data on the number of public companies switching to legal forms other than the private form. Also, data on the total number of firms with legal forms other than the public and private form are not available for this period. On the basis of the available data, the estimated maximum number of public companies choosing a legal form other than the private form during the period 1971-1974 is 2,373 (see appendix 5.2). However, it is generally believed that only one large public company avoided the disclosure requirements by switching to the partnership form [Boukema, 1974, p.263; Brenninkmeijer, 1975, pp.1011/13]. This case will be discussed in the next paragraph.

The observation that at least one switching public company did not choose the private form can be explained as follows. For some public companies a change to the private form would not imply exemption from disclosure requirements. Large private companies were also required to disclose audited annual accounts. Therefore, large public companies wanting to avoid the requirement to disclose had to switch to a form other than the private form. As mentioned, there is no systematic empirical evidence of public companies switching to legal forms other than the private form. The frequently given example is the conversion of the large Dutch clothing retail chain store NV Algemene Confectiehandel C \& A Brenninkmeijer from the public form to the limited partnership form [Heyman et al., 1988, pp.56-57; de Ridder, 1971, p.158; Kamp, 1971, p.152]. C \& A is a large firm that would not have been exempted from disclosure requirements if it had chosen the private form [Heyman et al., 1988, pp.56-57]. At the beginning of the seventies, C \& A was among the ten largest Dutch firms in terms of sales [de Ridder, 1971, p.159]. C \& A's capital is mainly provided by one family and its management is dominated by the same family [de Ridder, 1971, p.159]. Bartel [1972, pp.2-3] tried to estimate one category of switching costs for the conversion of $\mathrm{C} \& \mathrm{~A}$ to the partnership form. He concludes that $\mathrm{C} \& \mathrm{~A}$ incurred substantial negative tax consequences as a result of the switch. The low degree of separation of ownership and control of $\mathrm{C} \& \mathrm{~A}$ provides a plausible explanation for the willingness to bear these costs. It can be expected that for $\mathrm{C} \& \mathrm{~A}$ the disclosure of audited annual accounts is an inefficient and costly control mechanism and therefore $\mathrm{C} \& \mathrm{~A}$ was willing to bear substantial switching costs. 
Not all public companies that were not obliged to disclose before the passing of the Act switched to another legal form to avoid the new disclosure requirements. As a result, the number of public companies disclosing annual accounts increased from 692 in 1971 to 2,928 in 1973 (see column 4 table 5.2). A first explanation for this observation is that some public companies had securities listed at the stock exchange or had unlisted non-registered stocks. For these firms the public company was the only suitable legal form. A second explanation for this observation is the high switching costs for large public companies. As mentioned, for large public companies a switch to the private form would not imply exemption from disclosure requirements. A switch to alternative legal forms without disclosure regulations would imply high switching costs. The observation that C \& A switched to the partnership form is in line with this explanation. The low degree of separation of ownership and control of C \& A is exceptional for large firms. Currently, there is no systematic empirical evidence of the characteristics of the public companies that did not switch legal form.

\section{Other Explanations}

Sources of alternative explanations for legal form switches are: (1) general changes in the economy, and (2) other changes in company law. With respect to the first of these, it can be expected that changing economic growth will affect legal form choice. To ascertain the importance of this effect, the time series of the total number of enterprises was examined. It appears that general changes in the economy cannot explain the large number of switches in 1972. The time series of the total number of enterprises shows no significant change at the beginning of the seventies (see column 5 , table $5.2)$.

With respect to the second source of alternative explanations, it is very unlikely that other changes in company law motivated the switch of public companies to the private legal form. First, as discussed, the contracts of a public company can be specified as if it is a private company, except with respect to disclosure regulations [Sanders and Westbroek, 1985, p.3; Schwarz, 1986, p.59]. Second, the private legal form was already available in 1971 but most applications to switch from the public to the private legal form were filed in 1972. This suggests that the motive to switch is not the introduction of the private legal form in 1971 but the obligation to disclose audited annual accounts over 1972. Third, although a number of other changes in company law became effective at the beginning of the seventies, these changes do not give a satisfactory explanation for the large number of switchers. The other main changes in Dutch company law during 1970 and 
1971 were (see for example [Bak and Boukema, 1986, pp.60-61; van der Heijden et al. 1989, pp.19-20]):

(1) the Act relating to the right of investigation;

(2) the Act relating to the workers' councils;

(3) the Act relating to the ministerial declaration of non-objection to the establishment of a company;

(4) the Act relating to the obligation of large companies to have a board of outside directors.

The prescriptions of the four acts hold equally for public and private companies. Therefore these acts cannot explain a preference for the private company. There were no other material changes in Dutch company law during the period 1966-1976 (see [Boukema and Dorresteijn, 1986, pp.58-63; van der Heijden et al., 1989, pp.18-25]).

\subsubsection{Effects of the 1983 Change on Legal Form Choice}

The 1983 legislation change (title 8) has already been discussed in section 4.3. Like the earlier change, it substantially enlarged the field of application of accounting legislation. All private companies were required to disclose annual accounts. Before the passing of the 1983 legislation only large private companies were required to disclose annual accounts. Title 8 was announced in the Gazette on the 7th of December 1983 (Stb. 663) and enforced as of the first of January 1984. All private companies had to disclose annual accounts over the first financial year starting after the announcement of the Act [Burgert and Timmermans, 1987, p.30].

The fraction of private companies that disclosed annual accounts before the 1983 change was very small (for the period 1979-1983, the maximum was $1.38 \%$ per year, see table 5.7 in appendix 5.1). As a result of the 1983 change in disclosure regulations, which required all private companies to disclose, interest in the private legal form was expected to decrease. This expectation is frequently expressed in the Dutch legal literature (see for example Sanders and Westbroek, 1985, p.2; Schwarz, 1986, pp.61-62; Slagter, 1983, p.143). Along with this, one would expect an increased interest in other legal forms, such as the public company [van Schilfgaarde, 1988, pp.33/41; Sanders and Westbroek, 1985, p.2; Schwarz, 1986, p.62] and the partnership form [Mohr, 1988, p.121; Slagter, 1983, p.152; Heyman et al., 1988, p.56]. The economic underpinning for the hypothesized increase in interest in the public company legal form is as follows. Before 1984, the preference for the private company form was the result of the freedom of 
private companies not to disclose annual accounts. After 1984, this advantage of the private company was abolished. For firms wanting to increase their outside capital, the obligation to block the transfer of stocks and issue only registered stock can be viewed as a disadvantage of the private legal form. As a result of the 1983 change this disadvantage was no longer compensated for by an exemption from disclosure requirements. As a result, it would be expected that for some private companies an incentive was given to switch to the public company form. The economic underpinning of the expected increased interest in the partnership forms is similar to that for the increased interest in private companies after the 1970 change. The passing of the 1983 change meant that firms with the private company form were forced to have a contracting and monitoring mechanism based on the disclosure of annual accounts in line with Titel 8. Many private companies were small firms with a low degree of separation of ownership and control. The group of private companies in 1983 can be characterized as follows:

(1) $63 \%$ of all private companies had nine or less employees in 1983 [CBS, Central bureau for the coordination economic statistics];

(2) $98 \%$ of all private companies did not meet the characteristics of a large private company (see column 1 and 3 , table 5.7 , appendix 5.1). See footnote 17, chapter four for the characteristics of large private companies;

(3) the private company legal form was mainly chosen by small firms [Sanders and Westbroek, 1985, p.222; van der Heijden et al., 1989, p.42; Boukema and Dorresteijn, 1986, p.63; Slagter, 1983, p.144];

(4) the typical private company can be characterized as a firm with no separation of ownership and control [Slagter, 1983, p.143.].

The agency problems of these private companies are limited and therefore it would be expected that costly mechanisms to monitor the decisions of managers would be avoided [Fama and Jensen, 1983b, p.332]. For those firms a monitoring system based on personal control and non-public annual accounts specific to the firm is a more efficient control mechanism. As a result of the 1983 legislation change, the agency costs of many private companies were increased. These increased agency costs give an incentive for private companies to switch to the partnership form. The third hypothesis of this study in the alternative-form is:

After the 1983 legislation change less firms chose the private company form, and more firms chose the public and partnership forms. 
It would be expected that the number of private companies switching legal form after 1983 would be low compared to the number of public companies switching legal form after 1970 . One reason for this expectation is that the costs imposed by the 1970 legislation were higher than those of the 1983 legislation. Small and medium sized private companies are partly exempted from the 1983 prescriptions ${ }^{14}$. They can submit abridged annual accounts and are not required to audit until 1990. A second reason is that, as we have seen, many public companies could avoid the 1970 legislation through a nearly costless legal form switch from the public to the private legal form. By contrast, in 1983 private companies were confronted with high switching costs. The various kinds of partnership are alternative legal forms that are exempt from disclosure requirements, but a switch from the private company form to these legal forms would affect many other contractual characteristics: managers" and capital suppliers' risk, control devices, contracting freedom and taxes [Slagter, 1983, p.150; Westbroek, 1977, p.35] (see appendix 5.3). These switching costs would be expected to reduce the incentive for private companies to switch legal form. The final alternative-form hypothesis of this study is:

Hypothesis 4

The number of private companies switching legal form after the 1.983 legislation change will be lower than the number of public companies switching legal form after the 1970 legislation change.

\section{Results}

In general, hypotheses 3 and 4 are confirmed by the results. To test hypothesis 3, legal form data was collected for the years 1979-1988 (see appendix 5.1). This period was selected because the systematic registration of most legal forms started in 1979. Data on the number of switchers are only available for the conversion from the public to private form and vice versa. For the other legal forms (limited and general partnerships, and civil law companies) only the time series of the total number of firms in a particular legal form were taken. Only firms that employed at least one employee were considered. Next, the available time series on legal forms were divided into two groups. Considering hypothesis 3 , group A contains five time series for which a positive effect can be expected after 1984: the annual number of

14 For the legal description of small and medium-sized private companies see chapter four, footnote 19 . 
private companies switching to the public legal form, the annual change in the total number of public companies, the annual change in the total number of general partnerships, the annual change in the total number of limited partnerships, and the annual change in the total number of civil law companies. Group B contains two time series for which a negative effect can be expected after 1984: the annual number of public companies switching to the private legal form, and the annual change in the total number of private companies.

\section{Table 5.3}

Effects of the 1983 change on legal form choice

Descriptive statistics of time series of legall forms. Averages and standard deviations for the periods 1979-1983, 1984-1988, and the observation for 1984. Group A contains five time series for which a positive effect can be expected after 1984, group B contains two time series for which a negative effect can be expected after 1984. For sources and construction see tables 5.6,5.7, 5.8 and 5.9 in appendix 5.1.

\begin{tabular}{lrrrrr}
\hline & \multicolumn{2}{c}{$1979-1983$} & \multicolumn{2}{c}{$1984-1988$} & 1984 \\
& average & \multicolumn{1}{c}{ st.dev } & average & \multicolumn{1}{c}{ st.dev } & \\
\hline group A & & & & & \\
& & & & & \\
switchers priv. to publ. & 3.8 & 3.71 & 29.8 & 14.16 & 12.0 \\
public companies & -285.0 & 116.75 & -61.4 & 46.43 & -120.0 \\
general partnerships & -77.0 & 88.99 & 442.8 & 690.01 & 483.0 \\
limited partnerships & -27.6 & 28.98 & 74.4 & 26.60 & 112.0 \\
civil law companies & 127.0 & 33.32 & 254.0 & 140.98 & 201.5 \\
& & & & & \\
group B & & & & & \\
switchers publ. to priv. & 114.4 & 9.39 & 94.2 & 44.53 & 149.0 \\
private companies & 1262.6 & 1774.41 & 1021.2 & 924.27 & 1784.0 \\
\hline
\end{tabular}

Table 5.3 provides some descriptive statistics. It shows the averages for the time series in the periods 1979-1983, 1984-1988, and the observations for 1984. In group A, all averages in the period 1984-1988 are larger than the averages in the period 1979-1983. By contrast, for group B the averages in the period 1984-1988 are lower than the averages in the period 1979-1983. These results are in line with hypothesis 3 . The last column shows the observations for 1984 , the first year that firms were subjected to Title 8 . 
Comparing these observations with the averages for the period 1979-1983 suggests a strong effect for general partnerships and limited partnerships. The average annual change in the number of general partnerships in the period 1979-1983 is -77 (standard deviation $=88.99$ ), and the observation for 1984 is 483 . For limited partnerships the average change for the period $1979-1983$ is -27.6 (standard deviation $=28.98$ ), and the observation for 1984 is 112 .

To make comparisons between the time series, they were standardized. For all time series, each observation was divided by the average of the 10 absolute values of the observations from 1979 to 1988 . The standardized time series were used to construct the following 7 variables. All variables are the result of a subtraction of a standardized time series in group B from standardized time series in group A:

1. (public companies + partnerships) $)^{15}-/$ - private companies

2. public companies -/- private companies

2a. switching from private to public $-/-$ switching from public to private

3. partnerships ${ }^{15}-1-$ private companies

3a. general partnerships $-/$ - private companies

3 b. limited partnerships $-/$ - private companies

3c. civil law companies -/- private companies

If hypothesis 3 holds, the values of these 7 variables would be expected to increase after 1984. The observations for each variable were divided in two samples: observations before 1984 and observations after 1984. To test for a significant difference in the means of the samples of observations before and after 1984 the permutation test was applied on the seven variables ${ }^{17}$. For all the time series, the null hypothesis of no difference between the means was tested against the alternative hypothesis that the mean of the observations after 1984 is larger than the mean of the observations before 1984.

Table 5.4 presents the results of the permutation test of the legal form samples before and after 1984. The hypothesis that the 1983 change should have resulted in less firms choosing the private company form and more

15 In this term the standardized observations for public companies and the three partnership forms received an equal weight.

16 In this term the standardized observations for the three partnership forms received an equal weight.

${ }^{17}$ For a description of the permutation test see footnote 31 , chapter four. 
firms choosing alternative legal forms is generally supported by the results. For five variables out of seven, the null hypothesis of no increase can be rejected at a $10 \%$ significance level (one tailed test). For the permutation test of the first variable, an "overall" test of hypothesis 3 , the p-value is significant at a $5 \%$ level (one-tailed $\mathrm{p}=0.0476$ ). For all variables the mean of the sample of observations after 1984 is larger than the mean of the observations before 1984.

\section{Table 5.4}

Effects of the 1983 change on legal form choice.

Results of permutation test of legal form data. A test for a significant difference between the means of the sample of observations before 1984 and the sample of observations after 1984. For sources and construction see tables 5.6, 5.7, 5.8, and 5.9 in appendix 5.1.

\begin{tabular}{|c|c|c|}
\hline $\begin{array}{c}\text { variable } \\
\text { nr... }\end{array}$ & Variable & one-tailed $\mathrm{p}$ \\
\hline 1. & $\begin{array}{c}\text { (public companies + partnerships) } \\
-/ \text { private companies }\end{array}$ & $0.0476 * *$ \\
\hline 2. & public comp. -1 - private comp. & 0.1111 \\
\hline $2 a$ & $\begin{array}{l}\text { switchers private to public }-1- \\
\text { switchers public to private }\end{array}$ & $0.0079 * *$ \\
\hline 3. & partnerships $-1-$ private companies & $0.0317 * *$ \\
\hline $\begin{array}{l}3 \mathrm{a} . \\
3 \mathrm{~b} . \\
3 \mathrm{c} .\end{array}$ & $\begin{array}{l}\text { general part. }-1 \text { - private comp. } \\
\text { limited part. }-1 \text { - private comp. } \\
\text { civil law comp. }-/ \text { - private comp. }\end{array}$ & $\begin{array}{l}0.0714 * \\
0.0198 * * \\
0.1548\end{array}$ \\
\hline
\end{tabular}

$*=$ significant at a $10 \%$ level; $* *$ = significant at a $5 \%$ level.

To test hypothesis 4 (that the number of private companies switching legal form after 1983 is lower than the number of public companies switching legal form after 1970), the time series of the annual changes in the total number of private companies was tested for a significant decrease after 1984 . A permutation test of the null hypothesis of no difference against the alternative hypothesis of a significant decrease was applied. The null hypothesis of no difference could not be rejected at a $10 \%$ significance level (the permutation test resulted in a p-value of 0.3929 ). This result contrasts heavily with the effects of the 1970 legislation change on the number of public compa- 
nies. As a consequence of the first change, which obliged all public companies to disclose, the total number of public companies was drastically reduced in 1972 by approximately $90 \%$. Therefore, it can be concluded that hypothesis 4 is confirmed by the data.

As a result of the insignificant decrease in the number of private companies, the number of disclosing private companies increased tremendously, from 1,058 in 1983 to 45,812 in 1986 (see table 5.7 in appendix 5.1).

\section{Other Explanations}

As stated in paragraph 5.3.1, possible sources of alternative explanations for the observed legal form changes are: (1) general changes in the economy, and (2) other changes in company law. To check for the effects of general changes in the economy, the time series of the annual changes in the total number of one-man businesses and the annual changes in the total number of enterprises were used as controls. The results of a permutation test suggest that there is no significant change in the time series in the control groups. The p-values for the one-man businesses and the total number of enterprises were 0.2937 and 0.2579 respectively.

With respect to the second source of alternative explanations, one material change in company law that could have affected legal form choice during the investigated period is the passing of anti-abuse legislation and other legislation related to the abuse of legal forms (see [Sanders and Westbroek, 1988, p.3; Slagter, 1983, p.144]). This legislation was passed because the private company form was frequently used for dishonest practices. Anti-abuse legislation and related legislation passed during the period 1979-1988 consisted of:

(1) the first anti-abuse legislation, enforced in 1982, which held main contractors liable for the social contributions, income and sales taxes of subcontractors [van Schilfgaarde, 1988, pp.34-35; Sanders and Westbroek, 1988, p.3];

(2) the second anti-abuse legislation, enforced in 1987, which held managers of companies liable for the social contributions, income and salles taxes of the company [Sanders and Westbroek, 1988, p.3; van Schilfgaarde, 1988, p.35; van der Grinten, 1986, p.19];

(3) the third anti-abuse legislation, enforced in 1987, increases the liability of company managers for acts of negligence in the case of bankruptcy [Sanders and Westbroek, 1988, p.3; van der Grinten, 1986, p.19]; 
(4) legislation with respect to capital maintenance of companies [van Schilfgaarde, 1988, p.35]. These acts apply, on the whole, equally to public and private companies. They were enforced for the public and private company in 1981 and 1986 respectively [van der Heijden et al., 1989, p.26]. Increases in the required minimum capital of companies are part of these regulations [Boukema and Dorresteijn, 1986, p.64; van der Heijden et al., 1989, p.26];

(5) more restrictive regulations with respect to the investigations of the antecedents of founders passed in 1979 and 1986 [Sanders and Westbroek, 1988, p.17; Boukema and Dorresteijn, 1986, p.64; van Schilfgaarde, 1988, p.35].

The observed reduction in the number of firms choosing the private company form, and increase in the number of firms choosing other legal forms, might be the result of the passing of anti-abuse legislation. To control for these possible effects the following procedure was followed. Legal forms that were used for dishonest practices were in general firms with one employee, or with none, and/or active in the construction industry [van Schilfgaarde, 1988, p.34; Slagter, 1986, p.147]. Therefore, the procedure described above was repeated using the time series of firms with at least five employees, and excluding the construction and installation industry (SIC 5). It was not possible to separate the data for larger firms in some legal forms, and these had to be omitted from the analysis (private companies switching to the public company legal form, civil law companies, public companies switching to the private company legal form).

The results of the permutation test of legal form choice variables for firms with five or more employees, excluding the construction industry, are presented in table 5.5. The results are weaker but still generally confirm hypothesis 3. For three out of five variables, the null hypothesis of no increase can be rejected at a $10 \%$ significance level (one-tailed test). For the permutation test of the first variable, the "overall" test of hypothesis 3 , the $p$-value is significant at a $10 \%$ level $(p=0.0794)$. Again for all variables the mean of the observations after 1984 is larger than the mean of the observations before 1984 .

Repeating the test for hypothesis 4 on the data for larger firms, excluding the construction industry, does not change its conclusions. The null hypothesis of no difference between the means of the samples before and after 1984, could not be rejected at a $10 \%$ significance level for the changes in the total number of private companies (the p-value is 0.2302 ). 


\section{Table 5.5}

Effects of the 1983 change on legal form choice by larger firms, excluding the construction and instaillation industry

Results of permutation test of legal form data for larger firms (five or more employees), excluding the construction and installation industry (SIC 5). A test for a significant difference between the means of the sample of observations before 1984 and the sample of observations after 1984. For sources and construction see tables 5.8 and 5.9 in appendix 5.1.

\begin{tabular}{|c|c|c|}
\hline $\begin{array}{l}\text { variable } \\
\text { nr. }\end{array}$ & Variable & one-tailed $p$ \\
\hline 1. & $\begin{array}{c}\text { (public companies + partnerships) } \\
-/- \text { private companies }\end{array}$ & $0.0794 *$ \\
\hline 2. & public comp. $-/$ - private comp. & 0.1548 \\
\hline 3. & partnerships $-/$ - private companies & $0.0556 *$ \\
\hline $\begin{array}{l}3 \mathrm{a} . \\
3 \mathrm{~b} .\end{array}$ & $\begin{array}{l}\text { general part. }-/ \text { - private comp. } \\
\text { limited part. }-/ \text { - private comp. }\end{array}$ & $\begin{array}{l}0.2262 \\
0.0516\end{array}$ \\
\hline
\end{tabular}

$*$ = significant at a $10 \%$ level.

\subsection{Conclusions and Proposals for Further Research}

The evidence presented in this chapter supports the hypothesis that the two changes in Dutch accounting legislation affected the contracting costs of firms. Both changes had significant effects on legal form choice (hypothesis 1 and 3). Also, evidence is provided that switching costs affect legal form choice (hypothesis 2 and 4 ).

One limitation of this study results from performing the analysis at an aggregated level. The study can only weakly test the agency cost explanation of the firm's readiness to avoid the accounting legislation. The evidence presented is consistent with this explanation. However, only aggregated data on the agency problems of firms subjected to the legislation are used. No systematic evidence is provided that the agency problems of switching and non-switching firms are different. A second limitation relates to the time series analyses. This study assumed that accounting legislation affects legal form choice by firms. A priori, there are numerous other economic and legal factors that might have affected legal form choice over the periods during 
which the legislation changes were enacted. The control of these other factors affecting legal form choice is especially difficult in a study which analyzes legal form choice at an aggregated level.

To get stronger evidence of the effects of accounting legislation on agency costs of firms, studies at a micro level are proposed. Ideally, a micro analysis of switchers and non-switchers would investigate whether switchers' and non-switchers' agency problems differ systematically. For example, private companies that switched to the limited partnership form after the 1983 change can be compared with private companies that did not switch after 1983. Variables which have been suggested in studies of the relationship between the extent of disclosure and agency problems can be used to quantify agency problems (see section 5.2.1). However, it is very difficult to get data on switching firms. First, switching firms are not systematically registered in the Netherlands. As a result, switching firms can only be identified at high $\operatorname{costs}^{18}$. Second, if switching firms are identified, it is not likely that they would provide accounting information, since the probable reason for their switch is their desire to avoid providing accounting information. In sum, a micro analysis of switching and non-switching firms does not seem to be a feasible study. However, two alternatives are proposed: (1) a comparison between the agency problems of public companies established before the 1983 change, and public companies established after the 1983 change, and (2) a comparison between the agency problems of private companies that did not disclose after the 1983 change (and were fined), and private companies that disclosed after the 1.983 change. Both studies have the potential to give stronger evidence of the relationship between agency problems and legal form choice and to increase our knowledge of the disclosure of accounting information as an efficient contracting and monitoring mechanism.

Comparison between public companies established before and after the 1983 change. Through the 1983 change, the disclosure requirements for public and private companies were more or less equalized ${ }^{19}$, so that these requirements are not a relevant consideration for companies choosing between the private and public company forms after 1983. Firms with limited agency problems who had previously been choosing the private form, because of the disclosure exemptions, would be expected now to choose the

${ }^{18}$ The easiest alternative is to generate the names of switchers from the Staatscourant. However, this would be a very time consuming method.

19 Due to a temporary exemption until 1990 , middle-sized private companies were not required to audit their annual accounts after the passing of Title 8. 
public form. The benefit of the public form over the private form is easier capital acquisition as a consequence of not being required to restrict the transfer of stocks. The agency problems of public companies established after 1983 would be expected to be less than those of public companies established after that date, and this can be tested. Data on newly established public companies are available from the NV Databank of the Chambers of Commerce.

Comparison between disclosing and non-disclosing (fined) private companies after 1983. After the 1983 change, it appeared that a considerable number ${ }^{20}$ of private companies did not meet their disclosure requirements [Poorthuis, 1990]. Instead of switching, they were willing to pay a fine for not disclosing 21 . This fine gives a minimum indication of the switching costs of these firms. The agency problems of non-disclosing, and fined, private companies would be expected to be less than those of disclosing private companies. The underlying hypothesis is that firms with less serious agency problems will be especially inclined not to disclose and to be willing to pay the fine, because for them disclosure of accounting information is an inefficient control mechanism. The non-disclosing private companies are identified by the Economische Controle Dienst. Accounting information is available on these firms because they do eventually disclose, since total refusal to disclose carries the risk of imprisonment.

${ }^{20}$ The exact number is difficult to give because it is not known how many private companies are formally required to disclose under the 1983 legislation. Poorthuis [1990, p.55] estimates that there were up to $40 \%$ to $45 \%$ non-complying private companies with respect to the fiscall year 1984 .

${ }^{21}$ The initial fine for not disclosing is $f 10,000$ for large private companies, $f 5,000$ for medium sized private companies, and $f 1,000$ for small private companies. 



\section{Chapter 6 \\ Summary and Discussion}

This chapter will summarize and discuss the research undertaken, and will provide some suggestions for further research and accounting policy making. The first section will summarize the results of this study, and section two will discuss its strengths and weaknesses. Section three will provide some general remarks on the application of economic analyses to Dutch accounting regulation. Section four will provide some suggestions for future research. Finally, section five will give some suggestions for accounting policy making.

\subsection{Summary}

This study addressed two main questions: why does financial accounting regulation exist, and how can it be evaluated? Chapter two dealt with the subject of evaluating accounting regulation. A review of the parliamentary debates and working documents indicated that Dutch policy makers expected specific economic consequences from the two main changes in accounting legislation. Research can test whether these economic consequences actually occurred. However, due to various problems, the desirability of these economic consequences, in terms of efficiency effects and distributional effects, cannot be judged from an economic point of view.

Chapter three was concerned with the explanation of accounting regulation. The evidence for the public interest theory, formulated in terms of efficien$c y$, is not conclusive. The empirical evidence in the international accounting literature for the private interest explanation mainly concerns the effects of accounting regulation on affected parties and not vice versa. In the Netherlands, there is in general a lack of empirical evidence of the effects of accounting regulation on affected parties and vice versa. It was concluded that evidence of the economic consequences of Dutch accounting regulation can contribute to its explanation.

Chapters four and five of this study have provided evidence of the economic effects of two Dutch accounting legislation changes for public accountants 
and firms. The evidence regarding accountants suggests that the legislation changes had beneficial effects for partners in public accounting. As a result of the regulations, the actual amount of services supplied and demanded in the market for public accounting increased. The number of actual suppliers, partners in public accounting, did not adjust to this increase. This implies, ceteris paribus, that the income of partners increased. This is confirmed by the limited data which is available on their income.

The evidence regarding firms suggests that the two changes in accounting regulations increased contracting costs (i.e. agency costs or switching costs). In the 1970 case, switching costs for public companies were low, and a large proportion avoided an increase in their agency costs. In the 1983 case, switching costs for private companies were high, and few private companies avoided an increase in their agency costs. This study did not examine which parties within the firm bear the increased contracting costs, but it was assumed that managers bear at least part of these costs.

Combining the empirical evidence regarding accountants and firms suggests that the legislation caused a wealth transfer from firms to public accountants. The two new regulations required firms to spend more resources on monitoring. Due to switching costs, firms' opportunities to avoid these increased monitoring costs were limited. Increased spending on the disclosure of accounting information caused an increase in the demand for public accounting services, and implied positive economic effects for partners in public accounting.

\subsection{Strengths and Weaknesses of the Study}

This section will make some general comments on the strengths and weaknesses of the study. Specific comments on issues concerning the research design of the empirical analyses (e.g. use of certain substitute measures, limited control over "other" variables, lack of data) have already been given in the relevant chapters.

As concluded in the first chapter, the explanation and evaluation of accounting regulation is not yet well developed in the Dutch accounting literature. This study has made a start in eliminating this deficiency. It gives a review of the literature on the contribution of economics to the evaluation and explanation of accounting regulation. Besides, it actually provides empirical economic analyses which can contribute to the explanation and evaluation of Dutch accounting regulation. As such, it is one of the few empirical studies 
of the economic effects of Dutch accounting regulation. Assumptions concerning the economic effects of Dutch accounting legislation for public accountants and firms are frequently made but seldom stated explicitly or documented with empirical evidence. This study has given these assumptions stronger theoretical foundations and provides empirical evidence of the hypothesized economic effects of Dutch accounting legislation.

Both studies of the economic effects of accounting legislation were concerned with "real world phenomena". Hence, there was not intervention by the researcher into the object of study. This entails both strengths and weaknesses. An evident strength is that realistic behavior is studied. The subjects cannot "mislead" the researcher, which is a clear problem in studies using questionnaires, interviews or laboratory experiments. One disadvantage of studying real world behavior is the problem of controlling for the many factors that affect behavior. This study tried to provide evidence regarding the relationship between accounting legislation and the behavior of public accountants and firms. However, this behavior is affected by many factors, so the results might have been caused by variables other than those considered. This is especially so for the study concerning public accountants, which has a very long time span.

Another disadvantage of studying real world behavior is that the desirable data is not always available or may have the wrong format. In the case of public accountants, a clear example is the lack of income data. Income data is only available for three years and only for partners in public accounting. In the case of firms a clear example is the lack of data on switchers. These switchers are not registered in a separate list, and gathering data on their characteristics is very costly. Where appropriate data are lacking, a real world study has to look for other measures of the relevant variables. An example is the study of the effects on accountants, in which the number of professionals in the public accounting sector is used as an indicator of the total number of hours supplied and demanded in the market for public accounting services.

From a policy making viewpoint, a shortcoming of the study is that only the effects of two legislation changes, for two groups, were considered. Policy makers probably want to know the effects of more accounting regulations for a larger number of groups. This limitation is inherent to a first study on the economic consequences of Dutch accounting regulation. The number of regulations and the number of affected groups are simply to large to be dealt with in one study. Hence, further research in this area is proposed (see section 6.4). 


\subsection{Application of Economic Analyses to Dutch Accounting Regulation}

This section will give some general comments on the application of economic analyses to Dutch accounting regulation in comparison with the empirical analyses reviewed in chapters three and four which were mainly conducted in the US. Differences with respect to the actual economic consequences of accounting regulation, and differences with respect to providing empirical evidence for economic analyses will both be dealt with.

As a result of the different institutional arrangements, the economic consequences of these institutional arrangements can be expected to be different in the Netherlands. First, significant different effects can be expected as a result of the different fields of application. In the US, accounting regulation is mainly focused on publicly listed firms while in the Netherlands unlisted firms form the largest group subjected to accounting regulation. Therefore there are economic effects of accounting regulation for small firms in the Netherlands, which do not occur in the US.

The Dutch mechanism to enforce compliance with accounting regulation differs significantly from the US mechanism. In the US, companies have to file their annual accounts to the SEC and all are checked with respect to compliance. In the Netherlands, there is no systematic check of firms' compliance. Compliance depends on the initiative of interested parties who ask the Enterprise Chamber to subject the annual accounts of a firm to its judgement. The number of cases subjected to the judgement of the Enterprise Chambers is small (see [Burgert, 1982; Limperg Instituut, 1990]) ${ }^{\mathbb{1}}$. A priori it would be expected to be less costly for Dutch firms to deviate from the regulation. The chance of regulatory sanctions is low. Hence, it would also be expected that the negative economic consequences of accounting regulation for individual firms would be limited. If the regulation has serious negative effects for firms, they can choose not to comply without a high risk of sanctions.

A distinctive feature of the Dutch institutional arrangements is that accounting practice was relatively unregulated until recently. As a result, it is

1 Proceedings in the Enterprise Chamber can be viewed as a public good. If an action has a favorable outcome for an interested party, the firm concerned has to adjust its annual accounts. The benefits of this adjustment are of course received not only by the party starting the procedure but also by all other interested parties. An action in the Enterprise Chamber cannot result in private benefits, such as pecuniary compensation for damages, for the interested party. 
possible to study the economic effects of a change from an unregulated to a regulated environment. This is an ideal opportunity to measure the effects of accounting regulation (see [Schipper, 1989]). This study has taken advantage of this special feature of the Dutch environment. First, it has studied the effects of a change from an unregulated to a regulated environment on the demand and supply sides of the market for public accounting services. Second, it has studied the effects of a change from an unregulated environment to a regulated environment on firms.

Another distinctive feature of the Netherlands is the strong influence of legislation on accounting practice. The studies reviewed in chapters two and three mainly concern the effects of regulations in the US and UK, which are made by accounting standards boards. The regulation changes by legislation in the Netherlands are in general more drastic than those in a system with a strong influence from standard setting bodies. Legislation changes usually affect many aspects of accounting practice, while standard-setting generally affects only one item in the annual accounts. As a result, regulation changes in the Netherlands are drastic but infrequent, whereas regulation changes in a system with a strong influence from a standards board are relatively small but more frequent. An advantage of the Dutch situation is that it would be expected, a priori, that the economic effects of regulation changes would be stronger and easier to measure. A disadvantage is of course that it is difficult to distinguish the economic effects of the different parts of the legislation.

In chapter three we saw that a large proportion of the empirical studies which attempt an economic analysis of accounting regulation are based on the comment letters submitted by interested parties to regulators. In the Netherlands, this type of research is not possible. The legislature consults interested parties, but the procedure is not formalized and the results are not systematically published. In 1968, the legislators organized a hearing on the 1970 Act for interested parties. This hearing was not public and only a short report on the event was published ${ }^{2}$. This report indicates that only nine organizations gave their comments on the proposals for the Act on Annual Accounts. These comments are difficult to compare or standardize because they address different parts of the proposals. The Council for Annual Reporting has not formalized the consultation with interested parties or disclosed their comments, and it does not publish the positions of its members.

${ }^{2}$ See Zitting 1968-1969, no. 9595 and 9596. 


\subsection{Suggestions for Further Research}

This section contains some proposals for future research in two different areas: the economic consequences of Dutch accounting regulation and the political process which creates Dutch accounting regulation.

\subsubsection{Research on Economic Consequences}

The research on economic consequences in this study could be extended in three directions: (1) research on other economic consequences for public accountants and firms, (2) research on the economic consequences of other regulations, and (3) research on economic consequences for other groups.

(1)

This study has provided evidence of the main economic effects for accountants and firms. However, the legislation changes might have had economic consequences other than those considered in this study. In the case of accountants, another possible economic effect is the changed risk of legal prosecution (see chapter four). The legislation changes affected the requirements for the annual accounts and thus also the requirements for an auditor's opinion. Besides, the passing of the 1970 legislation was accompanied by the establishment of the Enterprise Chamber. All "interested parties" are allowed to start a proceeding regarding disclosed annual accounts in the Enterprise Chamber. The legislation changes and the establishment of the Enterprise Chamber might have affected the risk of prosecution for public accountants. Data can be collected on the cases in the Enterprise Chamber and on cases before the disciplinary commissions of NIVRA. This data could be used to assess the effects of the legislation on the risk of legal prosecution. A study by the Limperg Instituut [1990] provides useful data for such an analysis. It gives an overview of the decisions of: (1) the NIVRA's Disciplinary Court and its Court of Appeal, (2) the Enterprise Chamber, and (3) a committee of the NIVRA on the improvement of the quality of auditors' opinions. However, the Limperg Instituut study does not explicitly relate changes in the number of cases to changes in regulation.

In the case of economic consequences for firms, this study did not distinguish between the different economic effects for managers and the various classes of capital suppliers. It was assumed that managers, at least, were negatively affected by the legislation. Further research could study specific economic effects for managers and various classes of capital suppliers. For 
example, are there different effects of the legislation for shareholders and bondholders?

(2)

This study has been limited to the economic consequences of two pieces of legislation. Future research could study the economic consequences of other legislation changes. Chapter five mentioned the 1928 change in Dutch accounting legislation briefly and provided some evidence of its effects on legal form choice. For the 1928 case, further research could be done on the number of firms in various legal form categories, the characteristics of public companies, and the switching costs of public companies. In addition, the effects of the 1928 legislation on the market for public accounting services could be studied. It would be expected that the requirements of the 1928 case would have increased the demand for public accounting services.

Another material accounting legislation change, mentioned in chapters four and five, is the requirement for private companies to audit their annual accounts for the first fiscal year starting on or after the first of January, 1989. This event can be expected to affect legal form choice. The attractiveness of the private company form decreases, and the attractiveness of the public company form and the partnership forms increases. Also, it can be expected that this event will have significant effects on the market for auditing services. An increase in the amount of services supplied and demanded can be expected. Data on this change will be available soon.

Research on economic consequences could also be extended to regulations other than those stemming from legislation. One example would be the economic effects of the requirement of the Amsterdam Stock Exchange to disclose half-yearly reports. A second example is the economic effects of the Guidelines of the Council for Annual Reporting. However, it should be remarked that these regulations probably have considerably less impact than legislation changes on accounting practice. The requirements for the halfyearly reports are minimal, and firms are not obliged to follow the Guidelines of the Council.

This study has concentrated on the effects for accountants and firms. Research could be done on economic effects for other groups. A very obvious group is employees and their representative organizations. The legislation changes have affected the information that is available for employees. This information can be used in labor negotiations. One could study whether the use of accounting information by employees has changed and whether this has affected the outcome of the negotiations. This research topic is especially 
valid in the light of the importance that was given to the issue of employees' information demands in the political process leading to the 1970 legislation.

\subsubsection{Research on the Political Process}

Future research on the political process can contribute to testing the private interest explanation of accounting regulation. The results of this study suggest that the accounting legislation caused a wealth transfer from firms to public accountants. Casual empirical evidence of the group characteristics of accountants and firms suggests that a wealth transfer from firms to accountants is consistent with the private interest theory of regulation. These groups' characteristics indicate that the net benefits of the lobbying activities of accountants are high compared to firms' net benefits. Some group characteristics of accountants and firms, indicating the costs and benefits of lobbying for them, will be discussed below: (1) size, (2) relative magnitude of the effects of legislation, (3) identification costs, and (4) representative organizations.

Size. Small groups are more likely to lobby than large groups [Lindahl, $1987, \mathrm{p} .63]$. The group of public accountants is small compared to the group of firms that were affected by the legislation. The number of registered accountants who are partners in an accounting firm has never been higher than 1,295. The number of firms that were affected by the 1970 legislation is at least 46,400 , and the number that actually disclosed audited annual accounts is 4,602 . In the 1983 case, at least 69,892 firms $^{3}$ were affected by the regulation, and had to disclose annual accounts.

Relative magnitude of the effects of legislation. The incentive to lobby for a regulation depends on the magnitude of its expected effects for individual wealth [Sutton, 1984, pp.85-86]. For public accountants, legislation on the disclosure and auditing of accounting information concerns their main source of income. Thus the legislation will affect a relatively large part of their wealth. By contrast, for firms the cost of disclosing accounting information is just one category of production costs. Hence, the legislation will affect only a relatively small part of their wealth.

3his is the total number of disclosing public companies, private companies, and cooperative societies in 1987. In 1985, the first year in which an effect of the legislation can be expected, a relatively large number of firms did not comply with the legislation. 
Identification costs. The two pieces of Dutch accounting legislation are clear examples of low identification costs for "winners", and high identification costs for "losers". The "winners", partners in public accounting, are relatively easy to identify. Intuitively it is obvious that a legislation which requires more disclosure and more auditing will have beneficial effects on the market for public accounting services. Concerning the "losers", the evidence in this study supports the supposition that firms had to incur increased contracting costs as a result of the legislation. However, it is not clear which party within the firm actually pays for these costs. It was assumed that managers had to bear at least a part of these costs. However, it is not clear which classes of capilal suppliers shared these costs and to what extent. Hence, the "losers" are difficult to identify.

Representative organizations. Accountants have been organized in professional associations for many years. These organizations make it possible to restrict the benefits of lobbying to those who pay for lobbying. Only members of the professional organization of accountants could receive the benefits because only members of the professional organizations are allowed to audit annual accounts. The interests of firms that were affected by the legislation are represented by a large number of different organizations. This entails a free-rider problem. The benefits of active lobbying by one of these organizations will also be shared by members of other organizations which have not lobbied.

Casual empirical evidence of the group characteristics of firms and accountants suggests that the benefits of lobbying were higher for accountants than for firms. Further research is proposed to (1) provide more empirical evidence of the group characteristics of accountants and firms, and (2) assess whether accountants actually spent more resources on lobbying activities than firms. Research issues in these areas are: (1) what was the professional background of those who made the proposals for the legislation, (2) which parties were consulted by the accounting policy makers, (3) which parties expressed their opinion on the legislation and what was their standpoint, (4) which organizations represent the interests of accountants and firms, and (5) what "theories", "research", and "evidence" were used by accounting policy makers? Answering these questions would probably require research methods such as interviewing individuals who were involved in the policy making process, and examining reports, publications, and newspaper articles related to the legislation changes. 


\subsection{Suggestions for Accounting Policy Making}

This section will make some suggestions for accounting policy making. They are based on the theoretical and empirical analyses in this study. The suggestions concern the following topics: (1) the effects of accounting regulation on behavior, (2) cost-benefit analyses of accounting regulation, (3) the positive economic effects for partners in public accounting, (4) disclosure and audit requirements for other legal forms, and (5) size-criteria for disclosure and audit requirements.

Effects of accounting regulation for behavior. One of the general conclusions of this study is that accounting regulation affects behavior. This conclusion seems of course very obvious. However, sometimes accounting policy makers appear to have neglected this conclusion. One clear example concerns the number of firms that were expected to fall under the requirements of the 1970 legislation. It was expected that 25,000 to 40,000 companies would disclose annual accounts after the 1970 legislation [Handelingen I 69-70, pp.1096-1097; Handelingen II 69-70, p.2864; Kamerstukken I 6970, p.40]. As a result of the mass switch from the public to the private form, the actual number was about 4,000 . This example shows that not taking into account possible changes in behavior may result in a large gap between the expected and actual effects of accounting regulation.

Cost-benefit analyses of accounting regulation. Proposals for a cost-benefit analysis of accounting regulation were one of the major issues during the discussion of the 1983 legislation change (see section 2.2.2). It was thought that a cost-benefit analysis could give an answer to the question of whether the legislation was desirable. However, as discussed extensively in chapter two, a cost-benefit analysis has a low chance of answering questions on the desirability of accounting legislation. First, due to various problems, it is very difficult to actually identify and measure the costs and benefits of accounting regulation. Second, the cost-benefit criterion is only one of the many criteria on which regulation can be judged. Hence, the result of such an analysis will only be accepted if there is broad political support for the cost-benefit criterion.

Positive economic effects for partners in public accounting. The empirical studies conducted suggest that the legislation changes caused a wealth transfer from firms to public accountants. Also, this wealth transfer was not competed away because the number of partners did not adjust to the increased demand for auditing services. If accounting policy makers judge this wealth transfer to be undesirable, what measures can they take? A first solution is to simply abolish (partly) the requirement for firms to audit their 
annual accounts. However, this measure is probably unacceptable to account ing policy makers. They would be expected to be more interested in measures which would encourage an adjustment of the number of actual suppliers when auditing requirements increase. To find such a measure it is necessary to explain why the number of partners did not adjust to the increase in the market for public accounting. As discussed in section 4.1, occupational licensing is frequently given as an explanation for the beneficial effects of accounting regulation for public accountants. The license is used as a barrier limiting entry to the market for public accounting services. Howev$\mathrm{er}$, this explanation is not sufficient because it was only the number of partners in public accounting that did not adjust. The number of licensed accountants employed by an accounting firm strongly increased after the legislation changes. Hence, further research is needed to explain the different findings for partners in public accounting and registered accountants employed by an accounting firm (see chapter four).

Disclosure and audit requirements for other legal forms. One of the issues in the parliamentary debates leading to the 1983 legislation changes was the establishment of disclosure and audit regulations for partnerships and foundations (see section 2.2.2). One of the motivations for these proposals was the risk of a "flight" of firms into these forms to avoid the requirements of the company forms. The evidence of the effects of accounting legislation for firms indicate that the switching costs, going from company forms to other legal forms, are substantial. Although the number of partnerships increased significantly, in absolute terms the number of firms switching from company to partnership forms is very small and the total number of private companies was not significantly affected. Thus, switching costs form an effective barrier which reduces the need for regulations for other legal form categories, aimed at avoiding a "flight".

Size-criteria for disclosure and audit requirements. Dutch accounting policy makers have expressed some concern with the costs of accounting regulation for firms (see section 2.2.2). Under current Dutch accounting regulation, the onerousness of disclosure and audit requirements depends on the size-criteria of total assets, total sales, and number of employees. According to agency theory, these criteria are weak indicators of the costs and benefits of disclosure and audit requirements for firms. An implication of agency theory is that the costs and benefits of disclosure and audit requirements depend on the degree of separation of ownership and control. Hence, it might be better to base disclosure and audit requirements on criteria indicating the firm's degree of separation of ownership and control. The absolute number of stockholders is one example of such a criterion. In the US, one criterion of the disclosure and audit requirements is that firms 
should at least have 500 stockholders. Another criterion indicating the separation of ownership and control is suggested by Schwarz [1986]. He proposed to tie the requirement to audit and disclose to the free transfer of stocks. Under this proposal, companies that have not restricted the transfer of stocks are required to audit and disclose. Companies that restrict the transfer of their stocks could be expected to have a relatively low degree of separation of ownership and control. The low liquidity of stocks limits the opportunities to have a large number of stockholders. By contrast, companies with a free transfer of stocks would be expected to have a relatively high degree of separation of ownership and control. High liquidity of stocks makes it possible to have a large number of stockholders. For these companies, audit and disclosure requirements are an efficient mechanism to control agency problems. Another example of a criterion indicating the separation of ownership and control is the proportion of capital held by management. The smaller the proportion of capital held by managers the more serious are the agency problems of the firm. Hence, the heaviness of disclosure and audit requirements should be inversely related to the proportion of capital held by managers. 


\section{Appendices}

\section{Appendix 2.1}

The references to the issues in the parliamentary working documents and reports of debates are given below. Each reference consists of a code and a page number. The codes of the working documents (kamerstukken) and reports of debates (handelingen) are given first. Subsequently the references with the codes and page numbers are given.

1970

document

code

Working documents II:

67-68 9595

A

68-69 9595

A

69-709595

A

Reports debates II:

$\begin{array}{lll}69-70 & \text { pp. } 2856-2896 & \text { B } \\ \text { pp. } 2901-2931 & \text { B } \\ \text { pp. } 2941-2948 & \text { B }\end{array}$

Working documents I:

$\begin{array}{cccc}69-70 & 9590 & (118) & C \\ & & (118 a) & C \\ & & (118 b) & C\end{array}$

Reports debates I:
$69-70$
pp. $1087-1098$
$\mathrm{D}$

For 1970, the working documents (code A and C) were taken from Jaarrekening van Ondernemingen, band I, P. Sanders, R. Burgert, and C.W.A. Timmermans (eds.), Samsom Uitgeverij, III Toelichting Algemeen. The references will correspond to the page numbers in that publication. 
1983

$$
\text { document }
$$

code

Working documents II:

$\begin{array}{lll}1979-80 & 16326 & \text { A } \\ 1980-81 & 16326 & \text { B } \\ 1981 & 16326 & \text { C } \\ 1981-82 & 16326 & \text { D } \\ 1982-83 & 16326 & \text { E }\end{array}$

1983 Reports debates II:

$\begin{array}{lll}\text { 1982-83 } & \text { pp. } 4464-4480 & \text { F } \\ & \text { pp. } 4537-4555 & \text { F } \\ & \text { pp. } 4692-4693 & \text { F }\end{array}$

Working documents I:

\begin{tabular}{|c|c|}
\hline $1982-83 \quad 1.6326$ & (179) \\
\hline $1983-8416326$ & (22) \\
\hline & (22a) \\
\hline & $(22 \mathrm{~b})$ \\
\hline & $(22 c)$ \\
\hline
\end{tabular}

Reports debates I:

1983-84 pp. 153-160 L 
The 1970 Change

Issues not explicitly related to economic consequences:

(1) duty and right A 1824, B 28572863286828892902

(2) democratization A 17-18, B 285828662868287128742880 , D 10901092

(3) openness A 17-18 21-22 26

(4) representational faithfulness A 1219 , B $28602863286628722876-28772911$ 2925

(5) making up arrears B 28572862 , D 1089

Issues explicitly related to economic consequences:

(6) controlling (dishonest) management practices B 2861286828742893

(7) competition A 13 23, B $286628872907-2908293129422944$

(8) demand for information B 286128652945

(9) general economic and social considerations B 28892902

The 1983 Change

Issues not explicitly related to economic consequences

(1) duty and right $\mathrm{F} 4479$

(2) openness D 1, F 4544, L 154

(3) representational faithfulness A 2-3 32

Issues explicitly related to economic consequences

(4) controlling dishonest management practices F 4476 4547, L 155158

(5) competition C 2, D 2, F 4478-4479 4544 4551-4552 4554

(6) demand for information C 7, F 44684478, F 45404551

(7) general economic considerations $F$ 4464-4465

(8) cost benefit analysis F $446744694472447645414544-454645494555, \mathrm{H} 4$, I 2, L 154, L 159

(9) "flight" into other legal forms C 1, D 13 8, E 1, F 4476, L 155

(10) effects on the audit market F 4465-4446 4471 $44744539-4540, \mathrm{~J} 1, \mathrm{~K} 1$ 


\section{Appendix 4.1}

\section{Table 4.10}

Number of experts who received a licence to practice from the Minister of Economic Affairs

\begin{tabular}{ll}
\hline 1971 & 5 \\
1972 & 2 \\
1973 & 2 \\
1974 & 1 \\
1975 & 9 \\
1976 & 4 \\
1977 & 3 \\
1978 & 2 \\
1979 & 3 \\
1980 & 7 \\
1981 & 4 \\
1982 & 4 \\
1983 & 3 \\
1984 & 2 \\
1985 & 2 \\
1986 & 4 \\
\hline
\end{tabular}

The data in this table are by courtesy of Mr. W. Hulshoff Pol of the NIVRA bureau. According the Ministry of Economic Affairs, the total number of received licenses to practice was at most nine in the years 1987-1990. 


\section{Table 4.11}

Estimated number of annual accounts disclosed by public companies, private companies, and co-operative societies in $1971 \ldots 1987$

\begin{tabular}{|c|c|c|c|c|}
\hline & $\begin{array}{c}\text { public } \\
\text { companies } \\
(\mathrm{NVs})\end{array}$ & $\begin{array}{c}\text { private } \\
\text { companies } \\
\text { (BVs) }\end{array}$ & $\begin{array}{l}\text { co-operative } \\
\text { societies } \\
\text { (Coops) }\end{array}$ & total \\
\hline 71 & 692 & n.a. & n.a. & n.a. \\
\hline 72 & n.a. & n.a. & n.a. & n.a. \\
\hline 73 & 2928 & 695 & 979 & 4602 \\
\hline 74 & 2539 & 674 & 881 & 4094 \\
\hline 75 & 2848 & 895 & 927 & 4670 \\
\hline 76 & 2507 & 884 & 952 & 4343 \\
\hline 77 & 2221 & 904 & 1049 & 4174 \\
\hline '78 & 2380 & 902 & 1088 & 4370 \\
\hline 79 & 2108 & 923 & 1046 & 4077 \\
\hline 80 & 2112 & 920 & 1084 & 4116 \\
\hline 81 & 2022 & 1063 & 1119 & 4204 \\
\hline 82 & 1831 & 1052 & 1058 & 3941 \\
\hline ' 83 & 1716 & 1091 & 1028 & 3835 \\
\hline ' 84 & 1516 & 1058 & 1001 & 3575 \\
\hline 85 & 869 & 11553 & 871 & 13293 \\
\hline 86 & 994 & 45812 & 1537 & 48343 \\
\hline 87 & 1114 & 66986 & 1792 & 69892 \\
\hline
\end{tabular}

n.a $=$ not available

The observation for 1971 is based on the number of listed companies in 1970 (see [Centraal Bureau voor de Statistiek, Winststaristiek van naamloze vennootschappen en overige rechtspersoonlijkheid bezittende ondernemingen 1970, 1976, p.19]). Sources for the period 1973-1987 are: Statistische Gegevens 1973 ... 1987, Kamers van Koophandel en Fabrieken in Nederland. These yearly publications present data on the disclosure of annual accounts in the 38 districts of the Dutch Chambers of Commerce. Missing data were estimated through interpolation. For the estimation of the number of co-operative societies disclosing annual accounts, one district (Zutphen) had to be omitted because data was missing for too many years. Seven years had no missing data, aside from the category of co-operative societies in Zutphen. In four years data were missing for one district, in two years for two districts, in one year for five districts, and in one year (1982) for 13 districts. A study by the Limperg Instituut [1980] tried to estimate the number of annual accounts disclosed by public and private companies in 1978, using the announcements of disclosing companies in the Official Gazette. The estimates were 2091 disclosing public companies and 823 disclosing private companies. 
Tablie 4.12

Total number of NIVRA students in the period 1968-1989

(1) (2)

\begin{tabular}{lrr}
\hline 1968 & 2062 & n.a. \\
1969 & 2054 & 4354 \\
1970 & 2163 & 4263 \\
1971 & 2360 & n.a. \\
1972 & 2796 & n.a. \\
1973 & 2998 & 5744 \\
1974 & 2910 & n.a. \\
1975 & 2813 & n.a. \\
1976 & 2955 & n.a. \\
1977 & 2708 & 5700 \\
1978 & 2945 & 5924 \\
1979 & 3102 & 5905 \\
1980 & 3310 & 5846 \\
1981 & 4031 & 5885 \\
1982 & 3638 & 5845 \\
1983 & 3263 & 5423 \\
1984 & 2996 & 5073 \\
1985 & 3578 & 5611 \\
1986 & 3792 & 5863 \\
1987 & 3993 & 5962 \\
1988 & 3790 & 6199 \\
1989 & n.a. & 6091 \\
& & \\
\hline
\end{tabular}

n.a. = not available

(1) NIVRA students taking courses during the course-year starting in August. As an example, the value 3638 for the year 1982 implies that a total number of 3638 NIVRA students took courses during the period August 1982 - June 1983. The term used in the annual reports of the NIVRA is course-members (cursisten)

(2) Registered NIVRA students at the 31 st of August (except the observation for 1973, which is based on students registered in April).

Sources: NIVRA, NIVRA Jaarverslag '67/'68 ...'72/'73, [1968 ... 1973]; NIVRA, De Accountant, [April 1973]; NIVRA, Verslag van de Werkzaamheden '73/74 ... 76/77, [1974 ... 1977]; NIVRA, NIVRA Jaarverslag Onderwijsbureau en examenbureau '77/'78 ... '78/'79, [1978 ... 1979]; NIVRA, NIVRA-opleiding en examen '79/80 ... '88/'89, $[1980 \ldots 1989]$. 
Table 4.13

Panel A

Total number of NIVA and NIVRA members in the period 1946-1970
(1)
(2)
(3)
(4)
(5)
(6)
(7)
(8)
(9)

\begin{tabular}{rrrrllllll}
\hline 1946 & 419 & 76 & 343 & n.r. & n.r. & n.r. & 516 & 94 & 422 \\
1947 & 434 & 90 & 344 & n.r. & n.r. & n.r. & 534 & 111 & 424 \\
1948 & 467 & 85 & 382 & n.r. & n.r. & n.r. & 575 & 105 & 470 \\
1949 & 489 & 99 & 390 & n.r. & n.r. & n.r. & 602 & 122 & 480 \\
1950 & 511 & 118 & 393 & n.r. & n.r. & n.r. & 629 & 145 & 484 \\
1951 & 536 & 128 & 408 & n.r. & n.r. & n.r. & 660 & 158 & 502 \\
1952 & 549 & 130 & 419 & n.r. & n.r. & n.r. & 676 & 160 & 516 \\
1953 & 557 & 136 & 421 & n.r. & n.r. & n.r. & 686 & 167 & 518 \\
1954 & 591 & 170 & 421 & n.r. & n.r. & n.r. & 728 & 209 & 518 \\
1955 & 628 & 203 & 425 & n.r. & n.r. & n.r. & 773 & 250 & 523 \\
1956 & 657 & 223 & 434 & n.r. & n.r. & n.r. & 809 & 275 & 535 \\
1957 & 698 & 250 & 448 & n.r. & n.r. & n.r. & 859 & 308 & 552 \\
1958 & 736 & 258 & 478 & n.r. & n.r. & n.r. & 906 & 318 & 589 \\
1959 & 771 & 283 & 488 & n.r. & n.r. & n.r. & 949 & 348 & 601 \\
1960 & 816 & 311 & 506 & n.r. & n.r. & n.r. & 1005 & 383 & 623 \\
1961 & 851 & 327 & 524 & n.r. & n.r. & n.r. & 1048 & 403 & 645 \\
1962 & 878 & 325 & 553 & n.r. & n.r. & n.r. & 1081 & 400 & 681 \\
1963 & 922 & 356 & 566 & n.r. & n.r. & n.r. & 1135 & 438 & 697 \\
1964 & 966 & 374 & 592 & n.r. & n.r. & n.r. & 1189 & 461 & 729 \\
1965 & 994 & 396 & 598 & n.r. & n.r. & n.r. & 1224 & 488 & 736 \\
1966 & 1025 & 393 & 632 & n.r. & n.r. & n.r. & 1262 & 484 & 778 \\
1967 & n.r. & n.r. & n.r. & n.r. & n.r. & n.r. & 1307 & 464 & 843 \\
1968 & n.r. & n.r. & n.r. & 1352 & 445 & 907 & n.r. & n.r. & n.r. \\
1969 & n.r. & n.r. & n.r. & 1372 & 471 & 901 & n.r. & n.r. & n.r. \\
1970 & n.r. & n.r. & n.r. & 1419 & 476 & 943 & n.r. & n.r. & n.r. \\
& & & & & & & & & \\
\hline
\end{tabular}

n. $\mathrm{r}=$ not relevant 
Panel B

Total number of NIVA and NIVRA members in the period 1971-1989

\begin{tabular}{lllllllllll}
\hline & (1) & $(2)$ & $(3)$ & $(4)$ & $(5)$ & $(6)$ & $(7)$ & $(8)$ & $(9)$ \\
\hline 1971 & n.r. & n.r. & n.r. & 1483 & 516 & 967 & n.r. & n.r. & n.r. \\
1972 & n.r. & n.r. & n.r. & 1563 & 569 & 994 & n.r. & n.r. & n.r. \\
1973 & n.r. & n.r. & n.r. & 1628 & 623 & 1005 & n.r. & n.r. & n.r. \\
1974 & n.r. & n.r. & n.r. & 1671 & 662 & 1009 & n.r. & n.r. & n.r. \\
1975 & n.r. & n.r. & n.r. & 1729 & 693 & 1036 & n.r. & n.r. & n.r. \\
1976 & n.r. & n.r. & n.r. & 1761 & 723 & 1038 & n.r. & n.r. & n.r. \\
1977 & n.r. & n.r. & n.r. & 1823 & 747 & 1076 & n.r. & n.r. & n.r. \\
1978 & n.r. & n.r. & n.r. & 1846 & 754 & 1092 & n.r. & n.r. & n.r. \\
1979 & n.r. & n.r. & n.r. & 1951 & 818 & 1133 & n.r. & n.r. & n.r. \\
1980 & n.r. & n.r. & n.r. & 2026 & 870 & 1156 & n.r. & n.r. & n.r. \\
1981 & n.r. & n.r. & n.r. & 2087 & 907 & 1180 & n.r. & n.r. & n.r. \\
1982 & n.r. & n.r. & n.r. & 2127 & 933 & 1194 & n.r. & n.r. & n.r. \\
1983 & n.r. & n.r. & n.r. & 2197 & 993 & 1204 & n.r. & n.r. & n.r. \\
1984 & n.r. & n.r. & n.r. & 2216 & 975 & 1241 & n.r. & n.r. & n.r. \\
1985 & n.r. & n.r. & n.r. & 2240 & 994 & 1246 & n.r. & n.r. & n.r. \\
1986 & n.r. & n.r. & n.r. & 2330 & 1066 & 1264 & n.r. & n.r. & n.r. \\
1987 & n.r. & n.r. & n.r. & 2509 & 1227 & 1282 & n.r. & n.r. & n.r. \\
1988 & n.r. & n.r. & n.r. & 2591 & 1296 & 1295 & n.r. & n.r. & n.r. \\
1989 & n.r. & n.r. & n.r. & 2624 & 1336 & 1288 & n.r. & n.r. & n.r. \\
& & & & & & & & & \\
\hline
\end{tabular}

$\mathrm{n} . \mathrm{r}_{\mathrm{r}}=$ not relevant

(1) NIVA members in public accounting

(2) NIVA members who were employed in an accounting firm

(3) NIVA members who were partners in an accounting firm

(4) NIVRA members in public accounting

(5) NIVRA members employed in an accounting firm

(6) NIVRA members who were partners in an accounting firm

(7) NIVA members in public accounting adjusted for ' 67 merger

(8) NIVA members who were employed in an accounting firm adjusted for "67 merger

9) NIVA members who were partners in an accounting firm adjusted for "67 merger.

Sources: NIVA, NIVA Jaarverslag '55/56, '57/'58, '64/'65, .. '66/67, [1956, 1958, 1965 ... 1967]; J.W. de Koning, "70 Jaren Instituut in Cijfers," De Accountant, [December 1964], pp. 290-303; NIVRA, NIVRA, Jaarverslag '67/'68 ...'72/'73, [1968 ... 1973]; NIVRA, NIVRA Gids "68, '70 ... '75, "78, '80, '82, '84, "86, "88, '90, [1968, $1970 \ldots$ $1975,1978,1980,1982,1984,1986,1988,1990]$; NIVRA, NIVRA, Verslag van de Werkzaamheden '73/74 ... 88/89, [1974 ... 1989]. 


\section{Appendix 5.1}

Table 5.6

Public companies (NVs)

\begin{tabular}{|c|c|c|c|c|c|}
\hline & $\begin{array}{c}\text { (1) } \\
\text { total } \\
\text { number } \\
\text { public } \\
\text { companies }\end{array}$ & $\begin{array}{c}\text { (2) } \\
\text { public } \\
\text { companies } \\
\text { with at } \\
\text { least one } \\
\text { employee }\end{array}$ & $\begin{array}{l}\text { (3) } \\
\text { switching } \\
\text { from } \\
\text { public to } \\
\text { private }\end{array}$ & $\begin{array}{c}\text { (4) } \\
\text { newly } \\
\text { established } \\
\text { public } \\
\text { companies }\end{array}$ & $\begin{array}{c}\text { (5) } \\
\text { disclosing } \\
\text { public } \\
\text { companies }\end{array}$ \\
\hline 1966 & 36,200 & n.a. & n.r. & 1,876 & 993 \\
\hline 1967 & 37,900 & n.a. & n.r. & 1,625 & n.a. \\
\hline 1968 & 40,400 & n.a. & n.r. & 2,526 & n.a. \\
\hline 1969 & 43,400 & n.a. & n.r. & 3,070 & n.a. \\
\hline 1970 & 46,400 & n.a. & n.r. & 3,183 & n.a. \\
\hline 1971 & n.a. & n.a. & 1,275 & 2,797 & 692 \\
\hline 1972 & n.a. & n.a. & 42,498 & 82 & n. $a_{n}$ \\
\hline 1973 & n.a. & n.a. & 999 & 79 & 2,928 \\
\hline 1974 & 8,061 & n.a. & 203 & 51 & 2,539 \\
\hline 1975 & 6,871 & n. $\mathbf{a}$. & 95 & 33 & 2,848 \\
\hline 1976 & 6,183 & n.a. & 140 & 30 & 2,507 \\
\hline 1977 & 5,667 & n.a. & 60 & 29 & 2,221 \\
\hline 1978 & 5,238 & n.a. & 85 & 22 & 2,380 \\
\hline 1979 & 4,883 & 2,465 & 110 & 22 & 2,108 \\
\hline 1980 & 4,620 & 2,087 & 119 & 23 & 2,112 \\
\hline 1981 & 4,307 & 1,641 & 98 & n.a. & 2,022 \\
\hline 1982 & 4,038 & 1,372 & 123 & 18 & 1,831 \\
\hline 1983 & 3,847 & 1,156 & 122 & 37 & 1,716 \\
\hline 1984 & 3,684 & 1,040 & 149 & 46 & 1,516 \\
\hline 1985 & 3,435 & 920 & 147 & 61 & 869 \\
\hline 1986 & 3,348 & 807 & 70 & 118 & 994 \\
\hline 1987 & 3,304 & 762 & 58 & 99 & $1,1 \rrbracket 4$ \\
\hline 1988 & 3,241 & 750 & 47 & 102 & n.a. \\
\hline 1989 & n.a. & 733 & 44 & 160 & n.a. \\
\hline
\end{tabular}

n.a $=$ not available; n.r $=$ not relevant.

(1) Total number of public companies as at the 31 st of December. The source of the data for the period from 1966 to 1970 is the Central Bureau for Statistics (CBS) or Centraal Bureau voor de Statistiek (see [van der Heijden et al., 1989, p.44]). The CBS uses data from the taxation authority (Ministry of Finance or 
Ministerie van Financiên). This data underestimates the number of registered public companies because some public companies are exempted from paying tax. The estimated number of public companies exempted from paying tax in 1970 was 6,000 [CBS, 1976, p.8]. No data are available for the period 1971-1973. The data for the period from 1974 to 1988 are published by the Chambers of Commerce or Kamers van Koophandel en Fabrieken in Nederland [Statistical Data $1974 \ldots 1988$ or Statistische Gegevens 1974 ... 1988, Chambers of Commerce, 1975 .... 1989].

(2) Total number of public companies with at least one employee ( 1 employee $=250$ man-days, except 1988-1989: 1 employee $=260$ man-days) as at the first of January of each year. Source: Industrial unions and Databank foundation of the Chambers of Commerce [CBS, 1980d ... 1990d]. Public companies active in the mining and quarrying industry (SIC 1), public utilities (SIC 4), the construction and installation industry (SIC 5), and other services (SIC 9) are not included.

(3) Total yearly number of public companies switching to the private company legal form. The year 1971 was the first year that the private company legal form was available. The data for all years is based on the number of statements of nonobjection issued by the Ministry of Justice or Ministerie van Justitie (see [van der Heijden et al., 1989, pp.41-44]).

(4) Total yearly number of newly established public companies. The number of public companies established was not registered in the period 1966-1970. However, the CBS has aggregated data on the number of newly established and disclosing firms for this period [van der Heijden et al., 1989, pp.41-45]. To get an estimate of the number of public companies newly established, these series were used and corrected for the estimated number of disclosing firms (see column 4). The number of disclosing public companies for the years 1967-1970 were estimated through interpolation. The data for 1971-1988 is based on the number of statements of non-objection issued by the Ministry of Justice (see [van der Heijden et al., 1989, pp.41-45]).

(5) Total yearly number of disclosing public companies. The number of disclosing public companies was not registered in the period 1966-1972. In this period only "open" public companies were obliged to disclose and nearly all of these were listed on the Amsterdam Stock Exchange [CBS, 1970, p.10; Vecht, 1977, p. 32]. Therefore, the total number of public companies listed on the stock exchange in 1965 and 1970 were used as a proxy for the number of disclosing public companies in 1966 and 1971 [CBS, 1970, p.35; CBS, 1976, p.19]. For the period 1973-1986 the total number of disclosing public companies was registered by the Chambers of Commerce [Staristical Data 1973 ... 1987, Chambers of Commerce, 1974 ... 1988]. 
Table 5.7

Private companies (BVs)

\begin{tabular}{lccc}
\hline & $(1)$ & $(2)$ & $(3)$ \\
& $\begin{array}{c}\text { private } \\
\text { with at least } \\
\text { one employee }\end{array}$ & $\begin{array}{c}\text { switching } \\
\text { from private } \\
\text { to public }\end{array}$ & $\begin{array}{c}\text { disclosing } \\
\text { private } \\
\text { companies }\end{array}$ \\
\hline 1971 & n.a. & n.a. & n.a. \\
1972 & n.a. & n.a. & n.a. \\
1973 & n.a. & 6 & 695 \\
1974 & n.a. & 15 & 674 \\
1975 & n.a. & 6 & 895 \\
1976 & n.a. & 3 & 884 \\
1977 & n.a. & 4 & 904 \\
1978 & n.a. & 15 & 902 \\
1979 & 73,137 & 1 & 923 \\
1980 & 77,371 & 3 & 920 \\
1981 & 79,653 & 1 & 1,063 \\
1982 & 79,294 & 3 & 1,052 \\
1983 & 78,904 & 11 & 1,091 \\
1984 & 79,450 & 12 & 1,058 \\
1985 & 81,234 & 21 & 11,553 \\
1986 & 83,206 & 41 & 45,812 \\
1987 & 83,285 & 51 & 66,986 \\
1988 & 83,026 & 24 & n.a. \\
1989 & 84,556 & 37 & n.a. \\
& & & \\
\hline
\end{tabular}

n.a = not awailable

(1) Total number of private companies with at least one employee (1 employee = 250 man-days, except 1988-1989: 1 employee $=260$ man-days) as at the first of January of each year. Source: Industrial unions and Databank foundation of the Chambers of Commerce [CBS, $1980 d$... 1990d]. Private companies active in the mining and quarrying industry (SIC 1), public utilities (SIC 4), and other services (SIC 9) are not included.

(2) Total yearly number of private companies switching to the public company legal form. The data for all years is based on the number of statements of nonobjection issued by the Ministry of Justice (see van der Heijden et al., 1989 , pp.41-44).

(3) Total number of disclosing private companies. The total number of disclosing private companies is registered by the Chambers of Commerce [Statistical Data 1973 ... 1987, Chambers of Commerce, 1974 ... 1988]. 
Table 5.8

General and limited partnerships, civil law companies and one-man businesses ${ }^{1}$

(1)

\begin{tabular}{ccccc} 
& $\begin{array}{c}\text { general } \\
\text { partnerships } \\
\text { (VOFs) }\end{array}$ & $\begin{array}{c}\text { limited } \\
\text { partnerships } \\
\text { (CVs) }\end{array}$ & $\begin{array}{c}\text { civil law } \\
\text { companies } \\
\text { (maat- } \\
\text { schappen) }\end{array}$ & $\begin{array}{c}\text { one-man } \\
\text { businesses } \\
\text { (eenmans- } \\
\text { zaken) }\end{array}$ \\
\hline 1979 & 15,465 & 1,310 & 1,890 & 72,758 \\
1980 & 15,439 & 1,307 & 2,017 & 78,760 \\
1981 & 15,457 & 1,242 & 2,152 & 78,707 \\
1982 & 15,258 & 1,235 & 2,333 & 76,828 \\
1983 & 15,089 & 1,233 & 2,447 & 76,574 \\
1984 & 15,080 & 1,172 & 2,525 & 75,298 \\
1985 & 15,563 & 1,284 & $2,726.5$ & 76,371 \\
1986 & 15,596 & 1,318 & 3,120 & 75,808 \\
1987 & 15,372 & 1,391 & 3,238 & 75,431 \\
1988 & 15,549 & 1,452 & 3,347 & 76,011 \\
1989 & 17,294 & 1,544 & 3,795 & 81,262 \\
& & & & \\
\hline
\end{tabular}

(1) General partnerships with at least one employee $(1$ employee $=250$ man-days, except 1988-1989: 1 employee $=260$ man-days) as at the first of January. Source: Industrial unions and Databank foundation of the Chambers of Commerce [CBS, 1980d ... 1990d]. General partnerships active in the mining and quarrying industry (SIC 1), public utilities (SIC 4), and other services (SIC 9) are not included.

(2) Limited partnerships with at least one employee (1 employee $=250$ man-days, except 1988-1989: 1 employee $=260$ man-days) as at the first of January. Excluding: limited partnerships active in the mining and quarrying industry (SIC 1), public utilities (SIC 4), religious organizations (SIC 90), education (SIC 92), private households with wage-earning staff (SIC 99), and publiekrechtelijke bedrijfsorganisaties (statutory business organisations) (SIC 971). Source: CBS, hoofdafdeling coordinatie economische statistieken (Central bureau for the coordination of economic statistics).

'The CBS has an estimated number of civil law companies with one employee for the year 1979 (=1345). However, this number is an underestimate. Accurate data for the civil law company is available from 1980 . The reason that the accurate and systematic registration of the civill law company started later than other legal forms is that civil law companies are not obliged to register with the Chambers of Commerce. The estimate given in the table (1890) is based on the average growth in the period 1980-1984. 
(3) Civil law companies with at least one employee as at the first of January (1 employee $=250$ man-days, except 1988-1989: 1 employee $=260$ man-days $)$. Including civil law companies active in: trade, hotels, cafes, restaurants and the repair of consumer goods (SIC 6), banking, insurance, and other business services (SIC 8), and community, social and personal services (SIC 9). Within SIC 9, the following civil law companies are excluded: religious organizations (SIC 90), education (SIC 92), private households with wage-eaming staff (SIC 99), corporate industrial organizations (SIC 971), and civil law companies with 10 or more employees. Source: CBS, hoofdafdeling coordinatie economische statistieken.

(4) One-man businesses with at least one employee ( 1 employee $=250$ man-days, except 1988-1989: 1 employee $=260$ man-days) as at the first of January. Source: Industrial unions and Databank foundation of the Chambers of Conmerce [CBS, 1980d ... 1990d]. One-man businesses active in the mining and quarrying industry (SIC 1), public utilities (SIC 4), and other services (SIC 9) are not included. 
Table 5.9

All enterprises

\begin{tabular}{ccc}
\hline & $\begin{array}{c}(1) \\
\text { all } \\
\text { establishments }\end{array}$ & $\begin{array}{c}(2) \\
\text { enterprises } \\
\text { with at least } \\
\text { one employee }\end{array}$ \\
\hline 1969 & 431,022 & n.a. \\
1970 & 426,172 & n.a. \\
1971 & 425,672 & n.a. \\
1972 & 424,868 & n.a. \\
1973 & 426,658 & n.a. \\
1974 & 428,890 & n.a. \\
1975 & 429,339 & n.a. \\
1976 & 430,206 & n.a. \\
1977 & 431,613 & n.a. \\
1978 & 442,000 & n.a. \\
1979 & 451,209 & 94,267 \\
1980 & 464,512 & 98,221 \\
1981 & 472,974 & 100,145 \\
1982 & 482,095 & 99,492 \\
1983 & 491,379 & 98,829 \\
1984 & 504,775 & 99,267 \\
1985 & 521,358 & 101,727 \\
1986 & 571,571 & 104,047 \\
1987 & 553,259 & 104,048 \\
1988 & 573,900 & 104,124 \\
1989 & n.a. & 107,922 \\
& & \\
\hline
\end{tabular}

n.a = not available

(1) Total number of enterprises (including branch offices) registered by the Chambers of Commerce as at the first of January of each year. Sources: [Statistical Data 1969 ... 1986, Chambers of Commerce, 1970 ... 1987].

(2) Total number of enterprises with at least one employee (1 employee $=250$ mandays, except 1988-1989: one employee $=260$ man-days) as at the first of January. Enterprises included are: public companies, private companies, general partnerships, limited partnerships, and civill law companies (for construction data see other tables). 


\section{Table 5.10}

Enterprises with at least five employees, excluding the construction and installation industry (SIC 5)

\begin{tabular}{ccccc}
\hline & $\begin{array}{c}\text { (1) } \\
\text { public } \\
\text { companies } \\
\text { (NVs) }\end{array}$ & $\begin{array}{c}(2) \\
\text { private } \\
\text { companies } \\
\text { (BVs) }\end{array}$ & $\begin{array}{c}\text { (3) } \\
\text { general } \\
\text { partnerships } \\
\text { (VOFs) }\end{array}$ & $\begin{array}{c}\text { (4) } \\
\text { parmited } \\
\text { (CVs) }\end{array}$ \\
\hline 1979 & 1,399 & 34,015 & 2,973 & 507 \\
1980 & 1,205 & 35,200 & 2,868 & 514 \\
1981 & 986 & 36,294 & 2,811 & 504 \\
1982 & 861 & 36,632 & 2,792 & 500 \\
1983 & 692 & 36,126 & 2,662 & 490 \\
1984 & 646 & 36,027 & 2,637 & 471 \\
1985 & 582.5 & 36,176 & 2,538 & 497 \\
1986 & 525 & 36,326 & 2,464 & 508 \\
1987 & 510 & 36,924 & 2,450 & 519 \\
1988 & 508 & 38,077 & 2,458 & 523 \\
1989 & 515 & 39,642 & 2,735 & 552 \\
& & & & \\
\hline
\end{tabular}

(1) Total number of public companies with at least five employees $(1$ employee $=$ 250 man-days, except 1988-1989: 1 employee $=260$ man-days $)$ as at the first of January of each year. Sources: Industrial unions, and the Databank Foundation of the Chambers of Commerce [CBS, 1979 ... 1989]. Public companies active in the mining and quarrying industry (SIC 1), public utilities (SIC 4), the construction and installation industry (SIC 5), and other services (SIC 9) are not included.

(2) Total number of private companies with at least five employees (1 employee $=$ 250 man-days, except 1988-1989: 1 employee $=260$ man-days) as at the first of January. Sources: Industrial unions, and the Databank Foundation of the Chambers of Commerce [CBS, 1979 ... 1989]. Private companies active in the mining and quarrying industry (SIC 1), public utilities (SIC 4), the construction and installation industry (SIC 5), and other services (SIC 9) are not included.

(3) General partnerships with at least five employees ( 1 employee $=250$ man-days, except 1988-1989: 1 employee $=260$ man-days) as at the first of January. Source: Industrial unions, and the Databank Foundation of the Chambers of Commerce [CBS , 1979 ... 1989]. General partnerships active in the mining and quarrying industry (SIC 1), public utilities (SIC 4), the construction and installation industry (SIC 5), and other services (SIC 9) are not included. 
(4) Limited partnerships with at least five employees (1 employee $=250$ man-days, except 1988-1989: 1 employee $=260$ man-days) as at the first of January. Excluding: limited partnerships active in the mining and quarrying industry (SIC 1), public utilities (SIC 4), the construction and installation industry (SIC 5), religious organizations (SIC 90), education (SIC 92), private households with wage-earning staff (SIC 99), and corporate industrial organizations (SIC 971). Source: CBS, hoofdafdeling coordinatie economische statistieken (Central bureau for the coordination of economic statistics). 


\section{Appendix 5.2}

The computation of the maximum number of public companies switching to a legal form other than the private company form during the years $1971,1972,1973$ and 1974 is presented below. The real number will be lower because the estimated maximum is not corrected for discontinued public companies.

Total number of public companies in 1970 as at the 31 st of December:

(see table 5.6, column 1 and note 1)

46,400

6,000

Established companies:

\begin{tabular}{rr}
1971 & 2,797 \\
1972 & 82 \\
1973 & 79 \\
1974 & 51 \\
\hline
\end{tabular}

3,009

Public companies switching to

the private company legal form:

$1971 \quad 1,275$

$1972 \quad 42,498$

$1973 \quad 999$

$1974 \quad 203$

$-44,975$

Total number of public companies in 1974 as at 31 st of December:

$-8.061$

Maximum number of public companies switching to other legal forms: 


\section{Appendix 5.3}

This appendix describes the contractual characteristics of the following Dutch legal forms: the public company, the private company, the general partnership, the limited partnership, the civil law company and the one-man business. They will be described in terms of the characteristics mentioned in section 5.1: risk for managers and suppliers of capital, control mechanisms, freedom to specify contracts, and taxes. It should be remarked that this appendix is not an exhaustive overview of the legislation for the various legal forms.

1) Public company or naamlloze vennootschap (NV). A public company is an ancorporated enterprise with an authorized capital divided into transferable shares [Sanders and Westbroek, 1988, pp.4-5]. A public company is allowed to block the transfer of their shares [Sanders and Westbroek, 1985, p.3]. Its shares can be traded on the stock exchange upon application. The NV parallels the US corporation or the British public limited liability (Ltd).

a. Risk suppliers/managers capital. Shareholders' liability is limited to the par value of their shares [Sanders and Westbroek, 1988, p.4]. Managers only have unlimited liability for acts of negligence [van Schilfgaarde, 1988, p. 128].

b. Controll mechanisms. Since 1971 large public companies are obliged to have a supervisory board. Until 1972 only open public companies were obliged to disclose their annual accounts. Between 1972 and 1983 all public companies were obliged to audit and disclose their annual accounts. Since 1984 exemptions with respect to the audit requirement have been introduced, depending on the size of the company. Since 1981 much legislation restricts the actions of managers of public companies with respect to issuing new securities, buying stock, and distributing the proceeds of capital.

c. Freedom of contracting. Public companies have less contracting freedom than partnerships: their freedom is comparable to the contracting freedom of private companies [Boukema and Dorresteijn, 1986, p.39]. Many regulations specify the contracts between managers and several classes of capital suppliers.

d. Taxes. The profit of public companies is subjected to the corporate tax system. If the profit is distributed to the stockholders, it is subjected to dividend tax.

2) Private company or besloten vennootschap (BV). A private company is an incorporated enterprise with an authorized capital divided into shares which cannot be freely transferred [Sanders and Westbroek, 1988, p.4]. The BV parallels the British private limited company.

a. Risk suppliers/managers capital. See the public company.

b. Control mechanisms. Large private companies are obliged to have a supervisory board. Until 1984 only large private companies had to audit and disclose their 
annual accounts. Since 1984 all private companies have to disclose their annual accounts. Since 1986 many regulations restrict the actions of managers of private companies with respect to issuing new securities, buying stock, and distributing the proceeds of capital.

c. Freedom of contracting. Private companies have less contracting freedom than partnerships: their freedom is comparable to the contracting freedom of public companies [Boukema and Dorresteijn, 1986, p.39]. Many regulations specify the contracts between managers and several classes of capital suppliers.

d. Taxes. see the public company.

3) General partnership or vennootschap onder firma (VoF). A general partnership is an association of two or more persons (who may be individuals or legal entities) who agree to co-operate. A partner may contribute labor and/or capital. The $\mathrm{VoF}$ is an agreement to co-operate and not a legal entity [Boukema and Dorresteijn, 1986, p.34]. Since its introduction in 1938, the legislation for the general partnership has experienced few changes [Boukema and Dorresteijn, 1986, p.39].

a. Risk suppliers/managers capital. Each partner individually has unlimited liability for all partnership acts [Mohr, 1988, pp. 106-109].

b. Control mechanisms. There is no obligation to disclose annual accounts. However, the partnership is obliged to keep books and all partners have the right of inspection [Boukema and Dorresteijn, 1986, p.34]. All partners are allowed to take actions on behalf of the firm, as long as they are not in conflict with the objective of the firm [Boukema and Dorresteijn, 1986, p.52].

c. Freedom of contracting. General partnerships have high contracting freedom compared to public and private companies. Their freedom is comparable to the contracting freedom of other partnerships [Boukema and Dorresteijn, 1986, p.39]. Few restrictions exist on the specification of contractual relations between partners [Boukema and Dorresteijn, 1986, p. 34].

d. Taxes. Because a partnership is not treated as a separate legal entity, the partners are taxed separately on their share of income received from the partnership on the same basis as any corporate or individual taxpayer.

5) Limited partnership or commanditaire vennootschap (CV). A limited partnership is an association similar to the general partnership with at least one general partner with unlimited liability, and one or more partners with limited liability [Mohr, 1988, pp.117-118]. The $\mathbf{C V}$ is, like the VoF, an agreement to co-operate and not a legal entity [Boukema and Dorresteijn, 1986, p.34]. The legislation for the limited partnership has not changed since the introduction of this legal form in 1938, except for the abolishment of the limited partnership by stocks (Commanditaire vennootschap op aandelen) in 1975 [Boukema and Dorresteijn, 1986, pp.39/54]. The number of limited partnerships by stocks was very low (47 in 1970 [CBS, 1976, p.16]). 
a. Risk suppliers/managers capitall. The general partner has unlimited liability for all partnership acts while the other partners, the "quiet" partners, have limited liability to the amount of the agreed contribution to the partnership capital.

b. Control mechanisms. There is no obligation to disclose annual accounts [Heyman et al., 1988, p.112]. However, the partnership is required to keep books and all partners have the right of inspection [Boukema and Dorresteijn, 1986, p.40/41]. Only general partners are allowed to take actions on behalf of the firm [Boukema and Dorresteijn, 1986, p.54].

c. Freedom of contracting. Limited partnerships have high contracting freedom compared to public and private companies. Their freedom is comparable to the contracting freedom of other partnerships [Boukema and Dorresteijn, 1986, p.39; Mohr, 1988, p.119; Heyman et al., 1988, p.43]. Few restrictions exist on the specification of contractual relations between partners [Boukema and Dorresteijn, 1986, p.34].

d. Taxes. Because a partnership is not treated as a separate legal entity, the partners are taxed separately on their share of income received from the partnership on the same basis as any corporate or individual taxpayer. If the contracts of the partnership allow the entrance and withdrawal of partners without permission of the other partners, the partnership is subjected to the corporate tax system [Heyman et al., 1988, p.99]. However, this kind of partnership is not popular in practice because the managing partners are severally liable for the taxes of the partnership [Heyman et al., 1988; p.103].

6) Civil law company or maatschap. A civil law company is an association similar to the VoF. The main differences with the $\mathrm{VoF}_{\mathrm{O}}$ are: (1) the use of the civil law company is restricted to organizing the activities of professionals (accountants, lawyers, etc.), (2) the actions of the partners in a civil law company on behalf of the firm are more restricted and sometimes need the explicit permission of the other partners, and (3) the liability of partners for the acts of the civil law company is less far-reaching. The maatschap is, like the VoF and the CV, an agreement to co-operate and not a legal entity [Boukema and Dorresteijn, 1986, p.34]. The legislation for the civil law company has not changed materially since the introduction of this legal form in 1938 [Boukema and Dorresteijn, 1986, p.39].

a. Risk suppliers/managers capital. The liability for acts of the civil law company is shared between all partners, and is equal for all partners.

b. Control mechanisms. There is no obligation to disclose annual accounts. However, the partnership is obliged to keep books and all partners have the right of inspection [Boukema and Dorresteijn, 1986, p.34]. The actions which partners of a civil law company are allowed to take on behalf of the firm are restricted as compared to a general partner of a limited partnership or the partners of an unlimited partnership. If a partner wants to take an action on behalf of the firm that does not belong to the "normal activities" of the firm, he has to ask permission of all other partners [Boukema and Dorresteijn, 1986, p.44]. 
c. Freedom of contracting. Civil law companies have high contracting freediom as compared to public and private companies. Their freedom is comparable to the contracting freedom of other partnerships [Boukema and Dorresteijn, 1986, p.39].

d. Taxes. See the general partnership.

7) One-man business or eenmanszaak. A one-man business is the result of an individual who uses a part of his private capital for business activities [Boukema and Dorresteijn, 1986, p.29]. Agency problems can arise between the managerowner and private lenders.

a. Risk of manager-owner. The manager/owner of the one-man business has unlimited liability for all the acts of the firm [Boukema and Dorresteijn, 1986 , p.30].

b. Control mechanisms. Private lenders and the manager-owner are free to specify control mechanisms.

c. Freedom of contracting. High contracting freedom as compared to public and private companies.

d. Taxes. The income received form the one-man business is subjected to income tax. 


\section{References}

Accounting Standards Committee, Accounting for Leases and Hire Purchase Contracts, ED29, 1981.

Akerlof, G.A., "The Market for 'Lemons': Quality Uncertainty and the Market Mechanism," Quarterly Joumal of Economics 84, (August 1970), pp.488-500.

Amershi, A.H., J.S. Demski, and M.A. Wolfson, "Strategic Behavior and Regulation Research in Accounting," Journal of Accounting and Public Policy 1, (Fall 1982), pp.1932.

Arrow, K.J., Social Choice and Individual Values, 2nd edition, New Haven: Yale University Press, 1963.

Backhaus, J.G., Efficient Statute Law, Research memorandum 89-004, University of Limburg, 1989a.

Assesing the Performance of Public Enterprises: a Public Choice Approach, Research memorandum 89-036, University of Limburg, $1989 \mathrm{~b}$.

Bakker, de J., "De Commanditaire Vennootschap als Samenwerkingsvorm tussen Rechtspersonen," De Naamlooze Vennoorschap 51, (July/August 1973), pp.53-58.

Ball, R., The Firm as a Specialist Contracting Intermediary: Application to Accouning and Auditing, Unpublished manuscript, University of Rochester, April 1989.

Barkema, H.G., Variations in Ownership Structure, Managerial Pay Packages and Managerial Effort Across Firms and Industries, Groningen: Van Denderen, 1988.

Bartel, J.C.K.W., "Fiscale Kanttekeningen," Maandblad Bedrijfskunde 43, (November 1971), pp. 154-157.

pp. 1-3.

"De Kosten van een Metamorfose," Maandblad Bedriffkunde 44, (January 1972),

Bastable, C.W., "Is SEC Replacement Cost Data Worth the Effort?," The Joumal of Accountancy 144, (October 1977), pp.68-76.

Baysinger, B.D., and H.N. Butler, "The Role of Corporate Law in the Theory of the Firm," Journal of Law and Economics 28, (April 1985), pp.179-191. 
Beaver, W.H., "What Should be the FASB"s Objectives?," The Journal of Accountancy 135, (August 1973), pp.49-57, reprinted in Financial Accounting Theary: Issues and Controversies, 3rd edition, S.A. Zeff and T.F. Keller (eds.), (1985), New York: McGraw-Hill, pp. 200-211.

"The Nature of Financial Accounting Objectives: A Summary and Synthesis," Studies on Financial Accouning Objectives: 1974, supplement to vol. 12 of the Journal of Accounting Research, (1974), pp.170-187.

"The Nature of Mandated Disclosure," source: Report of the Advisory Committee on Corporate Disclosure to the SEC (1977), reprinted in: Economics of Corporation Law and Securities Regulation, R.A. Posner and K.E. Scott (eds.), Boston: Little Brown and Company, (1980), pp.317-331.

Financial Reporting: an Accounting Revolution, 2nd edition, Englewood Cliffs, N.J.: Prentice-Hall, 1989.

, and J.S. Demski, "The Nature of Income Measurement," The Accounting Review 54, (January 1979), pp.38-46.

, and R.E. Dukes, "Interperiod Tax Allocation, Earnings Expectations, and the Behavior of Security Prices," The Accounting Review 48, (April 1972), pp.320-333.

Benston, G.J., "The Value of the SEC"s Accounting Disclosure Requirements," The Accouning Review 44, (July 1969), pp.515-532.

, "Required Disclosure and the Strock Market: An Evaluation of the Securities Exchange Act of 1934," American Economic Review 63, (March 1973), pp. 132-155.

, Corporate financial disclosure in the U.K. and the U.S.A., Farnborough, Hants.: Saxon House, 1976.

"Accounting and Corporate Accountability," Accounting, Organizations and Society 7, no. $2,(1982)$, pp.87-105.

"Rejoinder to 'Accounting and Corporate Accountability: an Extended Comment," Accounting, Organizations and Society 9, no. 1, (1984a), pp.417-419.

, "The Costs of Complying with a Government Data Collection Program: the FTC's Line of Business Report," Journal of Accounting and Public Policy 3, (Spring 1984b), pp. 123-137.

"The Market for Public Accounting Services: Demand, Supply and Regulation," Journal of Accounting and Public Policy 4, (1985), pp.33-79.

Bindenga, A.J., Het Vrije Beroep van Accountant, Alphen aan den Rijn: Samsom, 1973.

Bink, N., and E.P.J. Wasch, Fimma of B. V.?, Deventer: Kluwer, 1986. 
Billen, L.H.H., "Regulering van Jaarverslaggeving: een Onderzoek natr Percepties van Ondememingen (1)," Maandblad Bedrijfsadmimistratie en Bedrifforganisanie 94, no. 1120/1121, (1990a), pp.184-188.

"Regulering van Jaarverslaggeving: een Onderzoek naar Percepties van Ondernemingen (2)," Maandblad Bedrijsadministratie en Bedriffsorgamisatie 94, no. 1122 , (1990b), pp. 228-235.

Boukema, C.A., "Nieuwe Literatuur Vennootschapsrecht," Maandblad woor Alccountancy en Bedriffsuishoudkunde 47, (March 1973), pp.100-101.

pp. $257-263$.

"De Werking van de Nieuwe Vennootschapswetgeving," TVWS, no. 10, (1974),

and A.F.M. Dorresteijn, De Juridische Organisatie wan de Ondememing, 2nd edition, fiscale studieserie no.21, Deventer: FED, 1986.

Bouma, J.L., "Het Rapport van de Commissie Verslaggeving," De Naanlooze Vennootschap 50, (September 1972), pp.102-104.

, "Over de Relevantie van Informatie," in: F. Krens, J. Maat, and Ph.J. Maat (eds.), Resuitaat, Alphen aan den Rijn: Samsom, (1981), pp.244-259.

, "Exteme Verslaggeving: een Probleemgebied in Ontwikkeling," Maandblad voor Accountancy en Bedrijfshuishoudkunde 62, (July/August 1988), pp. 282 285 .

Brands, J., "Associaties van Accountants. Accountant-Commissaris," in: Tot de Orde Geroepen, R. Burgert, A.A. De Jong, A.C.M. Van Keep, J.G. De Weger (eds.), Deventer: Deventer, (1967), pp.9-21.

Brenninkmeijer, A.M., "De Rechtsvorm van de Grote Onderneming; het Rapport van de Commissie Vennootschapsrecht,"' De Naamlooze Vemnootschap 53, (January 1975), pp. 10-19.

Brink, H.L., 's Lands Wijs, 's Lands Eer, Groningen: Wolters-Noordhoff, 1989.

Bromwich, M., The Economics of Accounting Standards Setting, Englewood Cliffs, London: Prentice-Hall International (UK), 1985.

Brown, C.V., and P.M. Jackson, Public Sector Economics, 2nd edition, Oxford: Robertson, 1982.

Brown, P.R., "A Descriptive Analysis of Select Input Bases of the FASB," Journal of Accounting Research 19, (Spring 1981), pp.232-246.

Bruinessen, W. van, "Accounting Standards and Rules - Voluntary or Regulatory Determination?," Maandblad voor Accountancy en Bedrifshuishoudkunde 49, (January 1975), pp.3-14. 
Buchanan, J.M., and G. Tullock, The Calculus of Consent; logical foundations of constitutional democracy, Ann Arbor, Michigan: University of Michigan Press, 1965.

and R.D. Tollison (eds.), Theory of Public Choice; Political Applicarions of Economics, Ann Arbor, Michigan: University of Michigan Press, 1972.

Buijink, W.F.J., Some Evidence on the Demand for External Auditing in an Unregulated Environment, the Case of the Netherlands, paper presented at the 1990 EAA conference, Budapest, 1990.

Burgert, R., "De Jaarrekening van Ondernemingen," TVVS, (1965), no. 11, pp.263-270.

, "Tien Jaar Wet en Rechtspraak Omtrent de Jaarrekening van Ondernemingen," Maandblad voor Accountancy en Bedrijfshuishoudkunde 56, (April 1982), pp.158-176.

, and C.W.A. Timmermans, De Jaarrekening Nieuwe Stijl, part 1, 5th edition, Alphen aan den Rijn: Samsom H.D. Tjeenk Willink, 1987.

Butterworth, J.E., and H. Falk, Accounting Standards: Perceived Cost/Benefit Relationships - A Survey, unpublished working paper, 1984.

Centraal Bureau voor de Statistiek, Winststatistiek van Naamloze Vennootschappen en overige Rechtspersoonlijkheid Bezittende Ondernemingen 1965, I4, 's-Gravenhage: Staatsuitgeverij, 1970.

. Winststatistiek van Naamloze Vennootschappen en overige Rechtspersoonlijkheid Bezittende Ondernemingen 1970, I4, 's-Gravenhage: Staatsuitgeverij, 1976.

, Inkomens Vrije Beroepsbeoefenaren 1972, een methodologische studie, M13, 'sGravenhage: Staatsuitgeverij, 1981a.

, Verdiende Lonen van Werknemers in Nijverheid en Dienstensector ontleend aan het Halfjaarlijks Loononderzoek, methodebeschrijwing en reeksen 1947-1983, V13, 'sGravenhage: Staatsuitgeverij, $1985 \mathrm{~b}$.

Indexcijers van Regelingslonen, methodebeschrijving en reeksen 1926-1985, V21, "s-Gravenhage: Staatsuitgeverij, $1987 \mathrm{c}$.

Statistical Yearbook of the Netherlands 1979 ... 1988, A23, 's-Gravenhage: Staatsuitgeverij/CBS-publications /SDU /Publishers, 1980d ... 1989d.

, Statistiek wan het Ondernemingen- en Vestigingen Bestand, 161, 's-Gravenhage: Staatsuitgeverij, $1985 \mathrm{e}$... 1987e.

, Statistiek van het Ondernemingenbestand, 161, 's-Gravenhage: Staatsuitgeverij, $1988 f$... 1989f.

Chow, C.W., "The Demand for External Auditing, Size, Debt and Ownership Influences," The Accounting Review 57, (April 1982), pp.272-291. 
, "Empirical Studies of the Economic Impacts of Accounting Regulations: Findings, Problems and Prospects, "Journal of Accouning Literature 2, (Spring 1983a), pp.73-109.

,"The Impact of Accounting Regulation on Bondholder and Shareholder Wealth: The Case of the Securities Acts," The Accouning Review 58, (July 1983b), pp.485-520.

, and A. Wong-Boren, "Voluntary Financial Disclosure by Mexican Corporations," The Accounting Review 62, (July 1987), pp.533-541.

, L. Kramer, and W.A. Wallace, "The Environment of Auditing," in: Research Opportunities in Auditing: the Second Decade, A. Rashad Abdel-Khalik and I. Solomon (eds.), AAA: Auditing Section, 1988.

Christenson, C., "The Methodology of Positive Accounting," The Accouning Review 58, (January 1983), pp.1-22.

Collins, D., M. Rozeff, and D. Dhaliwal, "The Economic Determinants of the Market Reaction to Proposed Mandatory Accounting Changes in the Oil and Gas Industry," The Journal of Accounting and Economics, (March 1981), pp.37-71.

Commissie Advisering Stroomlijning Accountantswetgeving, Rapport, April 1990.

Cooper, D.J., and S. Essex, "Accounting Information and Employee Decision Making," Accounting, Organizations and Saciety 2, no.3, (1977), pp.201-217.

, and M.J. Sherer, "The Value of Corporate Accounting Reports: Arguments for a Political Economy of Accounting," Accounting, Organizations and Society 9, no.4, (1984), pp.207-232.

Cooper, K. and G.D. Keim, "The Economic Rationale for the Nature and Extent of Corporate Financial Disclosure Regulation: A Critical Assessment." Journal of Accounting and Public Policy 2, (Fall 1983), pp.189-205.

Corstens, G.J.M., "Strafrechtelijke Bestrijding van Misbruik van Vennootschappen," De Naamloze Vennootschap 63, (March/April 1985), pp.48-54.

Cushing, B.E., "On the Possibility of Optimal Accounting Principles," The Accounting Review 52, (April 1977), pp.308-321.

Dekker, H.C., and H.P.A.J. Langendijk, "De beheersing van de (kosten van) accountantscontrole," Maandblad voor Accouniancy en Bedrijfshuishoudkunde 60, (September 1986), pp.326-343.

Demski, J.S., "The General Impossibility of Normative Accounting Standards," The Accounting Review 48, (October 1973), pp.718-723.

" "Choice among Financial Reporting Alternatives," The Accounting Review 49, (April 1974), pp.221-232. 
"Positive Accounting Theory: a Review," Accounting, Organizations and Society 13, no. 6, (1988), pp.623-629.

Dhaliwal, D., "Some Economic Determinants of Management Lobbying for Alternative Methods of Accounting: Evidence from the Accounting for Interest Cost Issue," Journal of Business, Finance and Accounting 9, (Summer 1982), pp.255-265.

Dopuch, N., "Discussion of 'Proof that in an efficient market, event studies can provide no systematic guidance for revision of accounting standards and disclosure policy for the purpose of maximizing shareholder wealth'," Comtemporary Accounting Research 5, (Spring 1989), pp.461-467.

and S. Sunder, "FASB's Statements on Objectives and Elements of Financial Accounting: A Review," The Accounting Review 55, (January 1980), pp. 1-21, reprinted in Financial Accounting Theory: Issues and Controversies, 3rd edition, S.A. Zeff and T.F. Keller (eds.), New York: McGraw-Hill, (1985) pp.19-33.

Downs, A., An Economic Theory of Democracy, New York: Harper \& Row, 1957.

Dukes, R., T. Dyckman, and J. Elliot, "Accounting for Research and Development Costs: the Impact on Research and Development Expenditures," Journal of Accounting Research 18, Supplement, (1980), pp.1-26.

Duynstee, J.E.F.F.M.,"Publikatieplicht en Privacy," De Naamlooze Vennootschap 64, (September/October 1986), pp.172-176.

Dyckman, T.R., "Credibility and the Formulation of Accounting Standards Under the Financial Accounting Standards Board,"' Journal of Accounting Literature 7, (1988), pp.130.

Easterbrook, F.H., and D.R. Fischel, "Mandatory Disclosure and the Protection of Investors," Virginia Law Review 70, (1984), pp.669-715.

Eichenseher, J.W., and P. Danos, "The Analysis of Industry-Specific Auditor Concentration: Towards an Explanatory Model," The Accounting Review 56, (July 1981), pp.479-492.

Espahbodi, R., and H. Hendrickson, "A Cost-Benefit Analysis of Accounting for Inflation, "Journal of Accounting and Public Policy 5, (Spring 1986), pp.31-55.

Fama, E.F., "Agency Problems and the Theory of the Firm," Journal of Political Economy 88, (April 1980), pp. 288-307.

and M.C. Jensen, "Separation of Ownership and Control," Journal of Law and Economics 26, (June 1983a), pp.301-325.

and M.C. Jensen, "Agency Problems and Residual Claims," Journal of Law and Economics 26, (June 1983b), pp.327-349. 
Federatie Organisaties Intellectuele Beroepen, Rapport Statistisch Onderzoek intellecruelen 1961, Den Haag, 1964.

, Rapport Statistisch Onderzoek intellectuelen 1966, Den Haag, 1968.

Feenstra, D.W., Oordeelsvorming Rond de Exrerne Berichtgeving, Groningen: WoltersNoordhoff, 1985.

Foster, G., "Externalities and Financial Reporting," Journal of Finance 35, (May 1980), pp.521-533.

Francis, J.R., "The Effect of Audit Firm Size on Audit Prices," Journal of Accounting and Economics 6, (1984), pp.133-151.

, "Lobbying Against Proposed Accounting Standards: The Case of Employers" Pension Accounting," Journal of Accounting and Public Policy 6, (Spring 1987), pp.3557.

and D.J. Stokes, "Audit Prices, Product Differentiation, and Scale Economies: Further Evidence from the Australian Market," Journal of Accounting Research 24, (Autumn 1986), pp.383-393.

Friedman, D., "Many, Few, One: Social Harmony and the Shrunken Choice Set," American Economic Review, (March 1980), pp.225-232.

Friend, I., and E.S. Herman, "The SEC Through a Glass Darkly," Journal of Business 37, (June 1964), pp.382-405.

and R. Westerfield, "Required Disclosure and the Stock Market," American Economic Review 65, (1975), pp.467-472.

Gaa, J.C., "User Primacy in Corporate Financial Reporting: A Social Contract Approach," The Accounting Review 61, (July 1986), pp.435-454.

Gaffikin, M.J.R., "Legacy of the Golden Age: recent developments in the methodology of accounting," Abacus 24, (March 1988), pp.16-36.

Gerboth, D. L., "Research, Intuition, and Politics in Accounting Inquiry," The Accounting Review 48, (July 1973), pp.475-482.

Gonedes, N.J., "Corporate Signaling, External Accounting, and Capital Market Equilibrium: Evidence on Dividends, Income and Extraordinary Items," Journal of Accounting Research 16, (Spring 1978), pp.26-79.

and N. Dopuch, "Capital Market Equilibrium, Information Production, and Selecting Accounting Techniques: Theoretical Framework and Review of Empirical Work," Studies on Financial Accounting Objectives: 1974, Supplement to vol. 12 of Journal of Accounting Research, (1974), pp.48-130. 
and S.H. Penman, "Disclosure Rules, Information-Production, and Capital Market Equilbrium: The Case of Forecast Disclosure Rules," Journal of Accounting Research 14, (Spring 1976), pp.89-137.

Griffin, P., "Management's Preferences for FASB Statement no. 52: Predictive Ability Results," Abacus 19, (December 1983), pp.130-138.

Grinten, W.C.L. van der, "Juridische Aspecten wan de Totstandkoming van de Jaarrekening; de Publicatieplicht," De Jaarrekening en de Vierde EEG-Richtijn, Monografieën vanwege het Van der Hejjden-Instituut te Nijmegen, deel 20, Deventer: Kluwer, $(1981)$, pp $35-47$.

"De Nieuwe Misbruil
(January/February 1986), pp. 19-23.

Groeneveld, G.L., "De Jaarverslaggeving Volgens het Rapport van de CommissieVerdam, Bezien vanuit het Gezichtspunt van de Accountant," De Naamlooze Vennootschap 43, (April/May 1965), pp.6-10.

De Accountant en de Ondermeming, Serie Onderneming en Leiding, Alphen aan den Rijn: Samsom, 1968.

Haddock, D.D., and J.R. Macey, "Regulation on Demand: A Private Interest Model with an Application to Insider Trading Regulation," Journal of Law and Economics 30, (October 1987), pp. 311-352.

Hakansson, N.H., "Where We Are in Accounting: A Review of 'Statement on Accounting Theory and Theory Acceptance'," The Accownting Review 53, (July 1978), pp. $717-725$.

Haring, J.R., "Accounting Rules and 'The Accounting Establishment', Joumal of Business 52, (October 1979), pp. 507-519.

Harsanyi, J.C., "Cardinal Utility in Welfare Economics and in the Theory of RiskTaking," Joumal of Political Economy 61, (October 1953), pp.434-435.

Heijden, E.J.J. van der, and W.C.L. van der Grinten, Handboek voor de Naamlooze Vennootschap naar Nederlandsch Recht, 4th edition, Zwolle: Tjeenk Willink, 1946.

, Handboek voor de Naamloze Vennoorschap en de Besloren Vennootschap, 9 th edition, Zwolle: Tjeenk Willink, 1976.

H.J.M.N. Honee, and H.M.N. Schonis, Handboek woor de Naamloze Vennootschap en de Besloten Vennootschap, 11 th edition, Zwolle: Tjeenk Willink, 1989.

Heyman, H.W., J.J.M. Brood-Grapperhaus, W.J. Slagter, J.J.M. Leysen, and H. Beckman, De Commanditaire Vennootschap in de Actuele Prakrijk, serie recht en praktijk 48, Deventer: Kluwer, 1988. 
Hirshleifer, J., "The Private and Social Value of Information and the Reward to Inventive Activity," The American Economic Review 61, (September 1971), pp.561-574

Holthausen, R.W., and R.W. Leftwich, "The Economic Consequences of Accounting Choice: Implications of Costly Contracting and Monitoring," Joumal of Accouning and Economics 5, (August 1983), pp.77-117.

Holzhauer, R.W., R. Teijl, J. Backhaus, M. Faure, H. Franken, and T. Hol, Inleiding Rechtseconomie, Arnhem: Gouda Quint, 1989.

Hope, A., and R.Gray, "Power and Policy Making: The Development of an R\&D Standard," Joumal of Business Finance and Accounting 9, (Winter 1982), pp.531-558.

Horngren, C.T., "The Marketing of Accounting Standards," Journal of Accowntancy 135, (October 1973), pp.61-66.

Horwitz, B., "The Economic Effects of Involuntary Uniformity in the Financial Reporting of R\&D Expenditures," Joumal of Accounting Research 18, Supplement (1980), pp.3875.

and R. Kolodny, Financial Reporting Rules and Corporate Decisions: A Siudy of Public Policy, Contemporary Studies in Economic and Financial Analysis, vol. 36, Greenwich, Conn.: JAI Press, 1982.

Hurzing, A., "De Gebruikersbenadering: Gewenste Feiten?" Maandblad voor Accountancy en Bedrijfshishoudkunde 61, (January 1987), pp. 13-24.

Hulshoff Pol, W., Wet op de Registeraccountants, 5th edition, Zwolle: Tjeenk Willink, 1988.

Huizinga, P.W., De Jaarrekening wan Ondernemingen, Beschouwingen over de Voorstellen tot Wettelijke Regeling, Deventer: Deventer, 1969.

Ingram, R.W., and F.R. Rayburn, "Representational Faithfulness and Economic Consequences: Their Roles in Accounting Policy," Journal of Accouning and Public Policy 8, (Spring 1989), pp.57-68.

The Institute of Chartered Accountants in England and Wales, The Making of Accouning Standards; Report of the Review Committee, London, September 1988.

Intemational Accounting Bulletin, "A Year of Upheavel in Holland," London England: Lafferty Publications, (November 1987), pp. 10-11.

Jensen, M.C., "Organization Theory and Methodology," The Accounting Review 58, (April 1983), pp.319-339.

and W. Meckling, "Theory of the Firm: Managerial Behavior, Agency Costs, and Ownership Structure," The Joumal of Financial Economics 3, (October 1976), pp.305. 360 . 
Kamers van Koophandel en Fabrieken in Nederland, Statistische Gegevens 1969 ... 1988, (1970... 1989).

Kamp, J.J., "De Grote Besloten Vennootschap en de Plicht tot Publicatie," Maandblad. Bedriffskunde 43, (November 1971), pp.150-153.

Kelly-Newton, L., Accounting Policy Formulation: the Role of Corporate Management, Reading, Mass.: Addison Wesley, 1980.

, "Corporate Lobbying and Changes in Financing or Operating Activities in Reaction to FAS No. 8," Journal of Accounting and Public Policy 1, (Winter 1982), pp. $153-173$.

"The Development of a Positive Theory of Corporate Management"s Role in External Financial Reporting," Journal of Accounting Literature 2, (Spring 1983), pp.111-150.

"Corporate Management lobbying on FAS No.8: Some Further Evidence," Journal of Accounting Research 23, (Autumn 1985), pp.619-632.

King, R.D., and T.B. O'Keefe, "Lobbying Activities and Insider Trading," The Accounting Review 61, (January 1986), pp.76-90.

Kinney, W.R., "Audit Technology and Preferences for Auditing Standards," Journal of Accounting and Economics 8, (March 1986), pp.73-89.

Klaassen, J., "De Doelstellingen van de Financiële Verslaggeving," Maandblad voor Accountancy en Bedrijfshuishoudkunde 52, (December 1978), pp.581-590.

, "Ontwikkeling van de Eisen te Stellen aan de Jaarrekening," Maandblad voor Accountancy en Bedrijsshuishoudkunde 56, (March 1982), pp.111-122.

, and G.G.M. Bak, Externe Verslaggeving, 2nd edition, Leiden-Antwerpen: Stenfert Kroese, 1990.

and H. Schreuder, "Accounting Research in the Netherlands," European Contributions to Accounting Research: the achievements of the last decade, A.G. Hopwood and H. Schreuder (eds.), Amsterdam: Free University Press, (1984), pp.113131.

Knoops, C.D., "Positive Accounting Theory," FMA Kroniek 1990, C.D. Knoops, J. Dijksma, and W.M. Du Pon (eds.), Groningen: Wolters-Noordhoff, (1990), pp.221-237.

Koning, J.W. de, "70 Jaren Instituut in Cijfers," De Accountant 71, (December 1964), pp. 290-303.

Kraayenhof, J., Het Accountantsberoep in Nederland na 60 Jaar, Jubileumrede NIVA, Scheveningen, May 1955. 
Lafeber, A.F., "Een Onderzoek naar Aanwezigheid van Accountantsverklatingen in Jaarverslagen van Naamloze Vennootschappen, welker Aandelen of Obligaties Officheel Genoteerd Zijn," Maandblad woor Accoumtancy en Bedriffowishoudkunde 22, (May" 1948), pp. 140-145.

Langendijk, H.P.A.J., Verslaggeving door Accomtantskantoren, Research Memorandum 8817 , University of Amsterdam, 1988.

and H.J. Deetman, "Concentratie op de Markt voor Accountantscontrole in Nederland," FMA Kroniek 1990, C.D. Knoops, J. Dijksma, and W.M. Du Pon (eds.), Groningen: Wolters-Noordhoff, (1990), pp.377-394.

Leftwich, R., "Market Failure Fallacies and Accounting Information," Jowmal of Accounting and Economics 2, (December 1980), pp. 193-211.

, "Evidence of the Impact of Mandatory Changes in Accounting Principles on Corporate Loan Agreements," Journal of Accouning and Economics 3, (March 1981), pp. 3-36.

, R.L. Watts, and J.L. Zimmerman, "Voluntary Corporate Disclosure: the Case of Interim Reporting," Studies on Standardization of Accounting Practices: An Assessment of Altemative Imstitutional Arrangements, supplement to vol. 19 of Joumal of Accouning Research, (1981), pp.50-77.

Lev, B., "Toward a Theory of Equitable and Efficient Accounting Policy," The Accouning Review 63, (January 1988), pp.1-22.

Limperg Instituut, Onderzoek Gedeponeerde Jaarrekeningen 1977, Amsterdam, May 1980.

, Risico's en Oordeelsworming in de Accountantspraktijk, Amsterdam, August 1990.

Lindahl, F.W., "Accounting Standards and Olson's Theory of Collective Action," Journal of Accounting and Public Policy 6, (Spring 1987), pp.59-72.

Majjoor, S.J., On the Desirability of Accouning Regulation, Research memorandum 88008 , University of Limburg, 1988.

The Economic Theory of Accounting Regulation: an Application to Durch

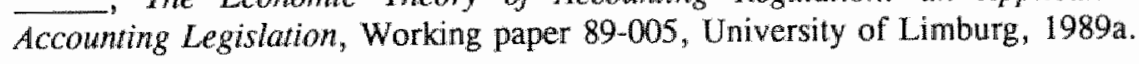

Effects of Accounting Regulation for Contracts of the Firm: Dutch Accounting Legislation and Legal Form Choice, Working paper 89-022, University of Limburg, $1989 \mathrm{~b}$.

"Commentaar op "Positive Accounting Theory" van C.D. Knoops," FMA Kroniek 1990 , C.D. Knoops, J. Dijksma, and W.M. Du Pon (eds.), Groningen: WoltersNoordhoff, (1990), p.238. 
Manne, H., "Mergers and the Market for Corporate Control," Journal of Political Economy 73, (April 1965), pp.110-120.

Marshall, R.M., "Determining an Optimal Accounting Information System for an Unidentified User," Journal of Accounting Research 10, (Autumn 1972), pp.286-307.

May, R.G., and G.L. Sundem, "Research for Accounting Policy: an Overview," The Accounting Review 51, (October 1976), pp.747-763.

McCormick, R.E., and R.D. Tollison, Politicians, Legislation, and the Economy, An Inquiry into the Interest-Group Theory of Government, Boston/The Hague: Martinus Nijhoff, 1981.

McKee, A.J., T.B. Bell, and J.R. Boatsman, "Management Preferences over Accounting Standards: A Replication and Additional Tests," The Accounting Review 59, (October 1984), pp.159-183.

McKinnon, S.M., "A Cost-Benefit Study of Disclosure Requirements for Multinational Corporations," Journal of Business Finance and Accounting 11, (Winter 1984), pp.451468 .

Meeles, D.A.M., "Nieuwe Standaardvoorwaarden voor Geruisloze Inbreng in Naamloze en Besloten Vennootschappen," De Naamlooze Vennoorschap 53, (March 1975), pp.5662.

Merino, B.D., and M.D. Neimark, "Disclosure Regulation and Public Policy a Sociohistorical Reappraisal," Joumal of Accounting and Public Policy 1, (Fall 1982), pp.33-57.

Mertens, G., Accounting Choice: Evidence on the Effects of the Introduction of Accouning Regulation in the Netherlands in 1971, paper presented at EIASM-workshop, Brussels, May 1990.

Metzemaekers, L.A.V.M., and A.J. van Maastrigt, Een Eeww in Balans; de wordingsgeschiedenis van Moret \& Limperg, 1883-1983, Moret \& Limperg, 1983.

Mishan, E.J., Economic Efficiency and Social Welfare, London: George Allen \& Unwin, 1981.

Introduction to Political Economy, London: Hutchinson, 1982.

Mohr, A.L., Van Maatschap, Vennootschap onder Firma en Commanditaire Vennootschap, 3rd edition, Arnhem: Gouda Quint, 1988.

Moizer, P., and S. Turley, "Surrogates for Audit Fees in Concentration Studies," Auditing: a Journal of Practice \& Theory 7, (Fall 1987), pp.118-123.

NIVA, NIVA Jaarverslag '55/'56, '57/'58, '64/'65 ... '66/'67, 1956, 1958, $1965 \ldots$ 1967. 
NIVRA, NIVRA Jaarverslag "67/"68 ... "72/73, 1968. ... 1973a.

NIVRA, NIVRA Gids '68, '70, ... '75'78, '80, '82, '84, '86, "88 '90, 1968b, $1970 \mathrm{~b} \ldots$ $1975 \mathrm{~b}, 1978 \mathrm{~b}, 1980 \mathrm{~b}, 1982 \mathrm{~b}, 1984 \mathrm{~b}, 1986 \mathrm{~b}, 1988 \mathrm{~b}, 1990 \mathrm{~b}$.

NIVRA, Verslag van de Werkzaamheden '73/74 ... '88/'89, 1974c ... 1989c.

NIVRA, Jaarverslag Onderwijsbureau en examenbureau '77f'78 ... '78/'79, 1978d ... 1979 d.

NIVRA, NIVRA-opleiding en examen '79/80 ... '88/'89, 1980e ... 1989e.

NIVRA, Wet op de Jaarrekening van Ondernemingen, NIVRA geschrift no.6, 1972f.

NIVRA, Requirements for Qualification as a Registeraccountant in the Netherlands, PILOT (Netherlands) 17, H. Volten RA (ed.), May 1985g.

Nobes, C.W., and R.H. Parker, Comparative International Accounting, 2nd edition, Oxford: Philip Allan/St Martin's Press, 1985.

Noreen, E., and J. Sepe, "Market Reactions to Accounting Policy Deliberations: The Inflation Accounting Case," The Accounting Review 56, (April 1981), pp.253-269.

Ohlson, J.A., and A.G. Buckman, "Toward a Theory of Financial Accounting," The Journal of Finance 35, (May 1980), pp.537-547.

Olson, M., The Logic of Collective Action, Cambridge, Mass.: Harvard University Press, 1965.

Palmrose, Z.V., "Audit Fees and Auditor Size: Further Evidence," Journal of Accounting Research 24, (Spring 1986), pp.97-110.

Peltzman, S., "Toward a More General "Theory of Regulation," Journal of Law and Economics 19, (August 1976), pp.211-40.

Pen, T., Wet op de Accountants-Administratieconsulenten, Zwolle: Tjeenk Willink, 1985.

Philips, S.M., and J.R. Zecher, The SEC and the Public Interest: An Economic Perspective, Cambridge, Mass.: MIT Press, 1981.

Pichler, J.A., "An Economic Analysis of Accounting Power," in: Institutional 1ssues in Public Accounting, R.R. Sterling (ed.), Kansas: Scholar Book Co, (1974), pp.45-73.

Poel, J.H.R. van de, Als de Tekenen Bedriegen..., Groningen: Wolters-Noordhoff, 1988. and F.M. Tempelaar, On the Applicability of Positive Agency Theory, Research Memorandum, Limburg University, 1987 
Poorthuis, F., "Depontert u uw Jaarstukkwn al?," Financieel Economisch Magazine, (January 1990 ), pp. 55-57.

Porcano, T.M., "Distributive Justice and "Tax Policy," The Accounting Review 59, (October 1984), pp.619-636.

Posner, R.A." "Theories of Economic Regulation," Bell Journal of Economics and Management Sclence 5, (Autumn 1974), pp.335-358.

1986.

, Economic Analysis of Law, 3rd edition, Boston: Little Brown and Company,

Pound, G.D." and J.R. Francis, "The Accounting Services Market: Theory and Evidence, "Journal of Business Finance \& Accounting 8, (1981), pp.353-371,

Puro, M., "Audit Firm Lobbying Before the Financial Accounting Standards Board: An Empirical Study," Joumal of Accounting Research 22, (Autumn 1984), pp.624-646.

Rawls, J., A Theory of Justice, Cambridge, Massachusetts: The Belknap Press, 1971.

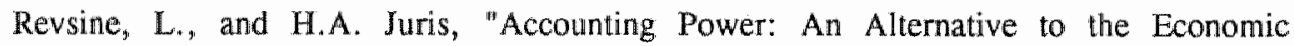
Analysis," in: Institutional Issues in Public Accounting, R.R. Sterling (ed.), Kansas.". Scholar Book Co, (1974), pp.74-91.

Rhode, J.G., G.M. Whitsell, and R.L. Kelsey, "An Analysis of Client-Industry Concentration for Large Public Accounting Firms," The Accounting Review 49, (October 1974), pp.772-787.

Ridder, W.J. de, "Is de Commanditaire Vennootschap voor C\&A toch Voordeliger?," Maandblad Bedriffskunde 43, (November 1971), pp.158-159.

Ross, S.A., "The Economics of Information and the Disclosure Regulation Debate," in: Ssues in Financial Regulation, F. Edwards (ed.), NY: McGraw-Hill, (1979), pp.177-202.

Ruland, R.G., "Duty, Obligation, and Responsibility in Accounting Policy Making," Journal of Accouning and Public Policy 3, (Fall 1984), pp.223-237.

-"The Pragmatic and Ethical Distinction Between Two Approaches to Accounting Policy Making," Jowrnal of Accounting and Public Policy 8, (Spring 1989), pp.69-80.

Sanders, P., "De Vierde Richtijn en onze Wet op de Jaarrekening," TVVS 15, no.1, (1972), pp. $1-15$.

Dutch Company Law, R.R. Pennington (ed.), European Commercial Law Library number 6, London: Oyez, 1977.

Kaluwer, 1985. 
, BV en NV, 5th edition, serie recht en praktijk 23, Deventer: Kluwer, 1988.

Schilfgaarde, P. van, "De Besloten Vennootschap - Kapitaalbescherming en nadere Profilering ten opzichte van de NV," De Naamlooze Vennootschap 63, (January/February 1985), pp.11-5.

Van de BV en de NV, 7th edition, Arnhem: Gouda Quint, 1988.

Schipper, K., "Commentary on Earnings Management," Accounting Horizons 3, (December 1989), pp.91-102.

Scholes, M.S., G.P. Wilson, and M.A. Wolfson, Tax Planning, Regulatory Capital Planning, and Financial Reporting Strategy for Commercial Banks, Unpublished Working Paper, Graduate School of Business, Stanford University, February 1989.

Schreuder, H., Maatschappelijke Verantwoordelijkheid en Maasschappelijke Berichtgeving van Ondernemingen, Bedrijfseconomische Monographieën 62, Leiden, Netherlands: Stenfert Kroese, 1981.

"Positively Normative (Accounting) Theories," European Contributions to Accounting Research: the achievements of the last decade, A.G. Hopwood and $\mathrm{H}$. Schreuder (eds.), Amsterdam: Free University Press, (1984), pp.213-231.

and K.V. Ramanathan, "Accounting and Corporate Accountability: an Extended Comment," Accounting, Organizations and Society 9, no.3/4, (1984), pp.409-415.

Schuit, S.R., J.M. van der Beek, and B.K. Raap, Dutch Business Law: Legal, Accounting and Tax Aspects of Business in the Netherlands, Deventer: Kluwer, 1978.

Schwarz, C.A., Blokkering van Aandelen, vennootschaps- en rechtspersonenrecht 27, serie monografieen vanwege het Van der Heijden-instituut, Deventer: Kluwer, (1986).

Securities and Exchange Commission, Report of the SEC Advisory Committee on Corporate Disclosure, Washington, D.C.: U.S. Government Printing Office, 1977.

Siegel, S., and N.J. Castellan, Non-Parametric Statistics for the Behavioral Sciences, second edition, New York: McGraw-Hill, 1988.

Simunic, D.A., "The pricing of Audit Services: Theory and Evidence," Journal of Accounting Research 18, (Spring 1980), pp.161-190.

Slagter, W.J., "Nieuw Vennootschaps- en Ondernemingsrecht," TVVS, no.6, (1971), pp.169-185.

, "Ontgaan van de Publicatieplicht,"' TVVS, no.3/4, (1972), pp.93-96.

, "De Toekomst van de BV," TVVS, no.6, (1983), pp.142-152.

, Compendium van het Ondernemingsrecht, 4th edition, Deventer: Kluwer, 1985. 
Solinge, A.G. van, "Eeri Minimumkapitaal bij Oprichting van N.V.'s en B.V."s," De Naamlooze Vennootschap 53, (December 1975), pp.211-214.

Solomons, D., "The Politicization of Accounting," The Journal of Accountancy November 1978): 65-72, reprinted in Financial Accounting Theory: Issues and Controversies, 3rd edition, S.A. Zeff and T.F. Keller, New York: McGraw-Hill, (1985), pp.34-44.

, Making Accounting Policy, the Quest for Credibility in Financial Reporting, New York, NY: Oxford University Press, 1986.

Stark, A.W., "Some Thoughts on 'A Cost-Benefit Analysis of Accounting for Inflation," Journal of Accouning and Public Policy 6, (Fall 1987), pp.209-217.

Sternheim, A., "lets over den Vorm der Accountants-Verklaring," De Bedriffseconoom 11, (December 1933), pp.65-67.

Stigler, G.J., "Public Regulation of the Securities Market," Joumal of Business 37, (1964), pp.117-142.

, "The Theory of Economic Regulation," Bell Joumal of Economics and Management Science 2, (Spring 1971), pp.3-21.

Strong, N., and M. Walker, Information and Capital Markets, Oxford: Basil Blackwell, 1987.

Sunder, S., "Political Economy of Accounting Standards," Journal of Accounting Literature 7, (1988), pp.31-41.

Sutton, T.G., "Lobbying of Accounting Standard-Setting Bodies in the UK and the USA: A Downsian Analysis," Accounting, Organizations and Society 9, no.1, (1984), pp.81-95. Accounting and Economics $10,(1988)$, pp.127-149.

Tas, L.G. van der, "Measuring Harmonisation of Financial Reporting Practice," Accounting and Business Research 18, (1988), pp.157-169.

Taylor, P., and S. Turley, The Regulation of Accounting, Oxford: Basil Blackwell, 1986.

Tempelaar, A.F., "De Jaarverslaggeving van Naamloze Vennootschappen," De Accountant 72, (January 1966), pp.271-292.

Tinker, A., "Theories of the State and the State of Accounting: Economic Reductionism and Political Voluntarism in Accounting Regulation Theory," Journal of Accounting and Public Policy 3, (Spring 1984), pp.55-74.

Tollison, R.D., "Rent Seeking: a Survey," Kyklos 35, no.4, (1982), pp.575-602. 
Traas, L., "Het Winstbegrip als 'Politiek' Vraagstuk," Maandblad voor Accounrancy en Bedriffsuishoudkunde 54, (May 1980), pp.206-212.

Vaassen, E.H.J, and A.M.M. Blommaert, "Knelpunten bij Regelgeving," Maandblad Bedrijsadministratie en Bedrijfsorganisarie 91, (1987), pp.320-323.

Vecht, J.M., "De Accountantsverklaring in Gepubliceerde Jaarverslagen van Nederlandse Naamloze Vennootschappen," Maandblad voor Accountancy en Bedriffihuishoidkunde 34, (March 1960), pp.100-108.

, Onderneming en Jaarverslag, 5th edition, Alphen aan den Rijn: Samsom, 1977.

Verrecchia, R.E., "The Use of Mathematical Models in Financial Accounting," Journal of Accounting Research 20, Supplement, (1982), pp.1-42.

Walker, M., "Positive Accounting Theory: A Review Essay," British Accounting Review $19,(1987)$, pp.305-311.

Wallace, W.A., "The Economic Role of the Audit in Free and Regulated Markets: A Review," in: Research in Accouming Regulation 1, G.J. Previts (ed.), JAI Press (1987), pp. 7-34.

Watts, R.L., "Corporate Financial Statements, a Product of the Market and Political Processes," Australian Journal of Management 2, (April 1977), pp.53-75.

and J.L. Zimmerman, "Towards a Positive Theory of the Determination of Accounting Standards," The Accounting Review 53, (January 1978), pp.112-134.

Excuses," The Accounting Review 54, (April 1979), pp.273-305.

"Auditors and the Detemination of Accounting Standards, unpublished working paper. Rochester, N.Y.: University of Rochester, 1981.

, "Agency Problems, Auditing and the Theory of the Firm: Some Evidence," Journal of Law and Economics 26, (October 1983), pp.613-634.

, Positive Accounting Theory, Englewood Cliffs, NJ: Prentice-Hall, 1986.

, "Agency Theory Research in Accounting," in Usefulness to Investors" and Creditors of Information Provided by Financial Reporting, P.A. Griffin (ed.), 2nd edition, Stamford, CT. . FASB, (1987), pp. 193-212.

Review 65, (January 1990), pp.131-156.

Westbroek, W., "De Wetgeving op de B.V. en de Betekenis van haar Invoering voor het Mechanisme der Besloten Vennootschappen (1), "TVWS 14, no.9, (1971a), pp.275-281. 
"De Wetgeving op de B.V. ent de Betekenis van haar Invoering voor het Mechanisme der Besloten Vennootschappen (II), "TVVS 14, no.10, (1971b), pp.315-321.

- "Openbaarmaking Jaarrekening C.V. en V.O.F.?," De Naamlooze Vennootschap 55, (February 1977), pp. 33-36.

Whitley, R.D." "The Possibility and Utility of Positive Accounting Theory," Accounting, Organizations and Sociery 13, no.6, (1988), pp.631-645.

Whittington, G., "Positive Accounting: A Review Article," Accounting and Business Research 17, (Autumn 1987), pp.327-336.

Wiardi Beckman Stichting, De Hervorming van de Onderneming, Herziening van het vennootschapsrecht in verband met medezeggenschap in en toezicht op de onderneming, 2nd edition, Amsterdam: De Arbeiderspers, 1959.

Williams, P.F., "The Legitimate Concern with Faimess," Accounting, Organizations and Society 12, no.2, (1987), pp.169-189.

Winden, F.A.A.M. van, "De Economische Theorie van de Politieke Besluitvorming," Economisch Statistische Berichten (11-1-1989), pp.1068-1077.

Wolk, H.I, J.R. Francis, and M.G. Tearney, Accounting Theory, A Conceptual and Institutional Approach, 2nd edition, Boston: PWS-Kent, 1989.

Young, S.D., "Accounting Licensure, Quality, and the 'Cadillac Effect'," Journal of Accounting and Public Policy 5, (Spring 1986), pp.5-19.

"The Economic Theory of Regulation: Evidence from the Uniform CPA Examination," The Accounting Review 63, (April 1988a), pp.283-291.

The Economic Theory of Regulation and the Licensing of Public Accountants, Unpublished Working Paper, August 1988 .

Zeff, S.A., "The Rise of "Economic Consequences'," The Journal of Accountancy (December 1978a), pp.56-63.

"The Rise of 'Economic Consequences'," Stanford Lectures in Accounting, (1978b), pp.11-19, reprinted in Financial Accouning Theory: Issues and Controversies, S.A. Zeff and T.F. Keller (eds.), 3rd edition, New York: McGraw-Hill, (1985) pp.19-33.

, and R.L. Fossum, "An Analysis of Large audit Clients," The Accounting Review 42, (April 1967), pp.298-320.

Zind, R.G., and D. Zéghal, "Some Characteristics of the Canadian Audit Industry," Contemporary Accounting Research 6, (Fall 1989), pp.26-47. 


\section{Nederlandse Samenvatting (Summary in Dutch)}

Een omvangrijk stelsel van regels is bepalend voor de huidige praktijk op het gebied van de externe verslaggeving. Diverse kenmerken van de externe verslaggevingspraktijk worden beïnvloed door regelgeving, waaronder de hoeveelheid en wijze van presentatie van gegevens, welke ondernemingen dienen te publiceren en de frequentie van publikatie. De krachtige invloed van regelgeving op de praktijk van de externe verslaggeving geldt voor Nederland pas sinds twintig jaar. Tot 1971 was de regelgeving beperkt maar sinds het begin van de zeventiger jaren is er, mede door de harmonisatiepogingen op EG niveau, een aanzienlijk aantal wijzigingen geweest en is de praktijk van de externe verslaggeving meer en meer aan regels gebonden.

Het huidige complexe stelsel van regels is slechts één van de vele mogelijkheden van regelgeving op het gebied van de externe verslaggeving. De keuzemogelijkheden met betrekking tot de specificatie van de regelgeving zijn buitengewoon talrijk. Dit impliceert een keuzeprobleem. Welke regelgeving is de "beste" of "beter"? In Nederland hebben zowel regelgevers als onderzoekers hun twijfels geuit over de wenselijkheid van de huidige regelgeving. Deze twijfels geven tevens aanleiding tot een meer fundamentele vraag, namelijk: waarom wordt de huidige regelgeving gehandhaafd terwijl haar voordelen onduidelijk zijn?

De volgende twee problemen staan centraal in de onderhavige studie: (1) Hoe kan de bestaande regelgeving op het gebied van de externe verslaggeving worden verklaard? en (2) Hoe kan de wenselijkheid van regelgeving op het gebied van de externe verslaggeving beoordeeld worden? Voor de analyse van de beide problemen is gekozen voor een economische invalshoek. Een belangrijk kenmerk van deze benadering is dat financiële informatie wordt beschouwd als een economisch goed. Hierdoor kan gebruik worden gemaakt van het economische instrumentarium dat al eerder is ontwikkeld en toegepast voor economische analyses van andere markten.

$\mathrm{Na}$ de inleiding staat in hoofdstuk twee de economische analyse van de wenselijkheid van regelgeving voor de externe verslaggeving centraal. Zowel de analyse van efficiëntie-effecten als verdelingseffecten van regelgeving komen aan de orde. Een overzicht wordt gegeven van studies die getracht hebben de efficiëntie van de regelgeving te bepalen door het meten van kosten en baten. Geconcludeerd zal worden dat een empirische analyse van de integrale kosten en baten van regelgeving op het gebied van de externe berichtgeving niet mogelijk is. Wèl kan een bijdrage worden geleverd door empirisch onderzoek te doen naar de partiële economische effecten van regelgeving. Tevens worden in het hoofdstuk de resultaten gegeven van een empirisch onderzoek naar de vraag of, en zo ja welke specifieke economi- 
sche effecten de Nederlandse regelgevers met de wetgeving op het gebied wan de externe verslaggeving hebben beoogt.

In hoofdstuk drie komen economische verklaringen voor het bestaan van regelgeving aan de orde. Grofweg kunnen de gangbare verklaringen in de literatuur voor het bestaan van de regelgeving in een tweetal groepen worden gesplitst. De eerste groep van verklaringen veronderstelt dat regelgevers streven naar een efficiënte economie en dat de markt voor financiële informatie met regelgeving "beter" werkt dan zonder regelgeving. In het hoofdstuk wordt een overzicht gegeven van het uitgebreide debat over de efficiëntie van de regelgeving. De tweede groep van verklaringen is gebaseerd op een economische analyse van het politieke proces dat tot de regelgeving leidt. De veronderstelling daarbij is dat regelgeving het resultaat is van een proces waarbij pressiegroepen, handelend op basis van hun eigenbelang, voordelen trachten te behalen door middel van lobbyactiviteiten. Een overzicht wordt gegeven van het empirisch onderzoek dat relevant is voor deze verklaring van regelgeving op het gebied van de externe berichtgeving. Geconcludeerd zal worden dat empirisch onderzoek naar de effecten van de Nederlandse regelgeving kan bijdragen aan het geven van verklaringen voor haar bestaan.

In de hoofdstukken vier en vijf worden de resultaten gegeven van twee empirische studies naar de effecten van een tweetal wetten op het gebied van de externe verslaggeving voor: (1) Registeraccountants in het openbaar beroep en (2) ondernemingen. De twee wetten zijn de Wet op de Jaarrekening van Ondernemingen van 1970 en Titel 8 welke is ingevoerd in 1983.

In hoofdstuk vier worden de resultaten gepresenteerd van het onderzoek naar de effecten van de twee wetten voor Registeraccountants in het openbaar beroep. Verwacht kan worden dat beide wetten hebben geleid tot een grotere vraag naar accountantsdiensten. De twee variabelen die in de studie gebruikt zijn om de omvang van de markt te meten, het aantal gepubliceerde en gecontroleerde jaarverslagen en het aantal werknemers in het openbaar beroep, bevestigen dat deze groei heeft plaatsgevonden. De economische effecten van deze groei voor accountants in het openbaar beroep is afhankelijk van een eventuele aanpassing aan de aanbodzijde. De resultaten voor de aanbodzijde zijn verschillend voor accountants in dienst van een accountantsfirma en accountants die partner zijn van een accountantsfirma. De grootte van de eerste groep heeft zich aangepast aan de groei van de markt terwijl er voor de laatste groep geen sprake is van een aanpassing.

In hoofdstuk vijf worden de resultaten gepresenteerd van het onderzoek naar de effecten van de regelgeving voor ondernemingen. De twee wetten hebben het aantal ondernemingen en rechtsvormen dat publikatieplichtig is sterk vergroot. Ondernemingen die voorheen een grote mate van vrijheid hadden wat betreft de publikatie van financiële informatie, werden gecon- 
fronteerd met een grote hoeveelheid detailregels. Verwacht kan worden dat de twee wetten de keuze van rechtsvorm door ondernemingen hebben beïnvloed. De gegevens die in de studie worden gebruikt zijn het aantal ondernemingen in de diverse categorieën rechtsvormen en het aantal ondernemingen die hun rechtsvorm hebben gewijzigd. De resultaten van de studie wijzen erop dat beide wetten de keuze van rechtsvorm door ondernemingen hebben gewijzigd. Echter, in het geval van 1970 was het effect veel sterker dan in 1983. Dit verschil kan worden verklaard door de hogere directe en indirecte kosten van een wijziging van de rechtsvorm in 1983 in vergelijking met 1970 .

Hoofdstuk zes sluit af met een overzicht van de analytische en empirische bevindingen waarbij tevens de sterke en zwakke kanten van het onderzoek aan bod komen. Tenslotte worden er suggesties gedaan voor verder onderzoek en voor de regelgeving op het gebied van de externe verslaggeving. 



\section{Curriculum Vitae}

Steven (Jacobus) Maijoor is op 3 februari 1964 geboren te Hong Kong. In 1982 slaagde hij voor het eindexamen ongedeeld VWO. Gedurende de periode september 1982 - januari 1987 studeerde hij Economie aan de Rijksuniversiteit Groningen, met als specialisatie Bedrijfseconomie. $\mathrm{Na}$ het behalen van het doctoraaldiploma in januari $1987 \mathrm{trad}$ hij als assistent in opleiding in dienst bij de sectie Berichtgeving en Accountancy van de Rijksuniversiteit Limburg. Van augustus tot december 1987 was hij verbonden aan het Accounting and Finance Department van de London School of Economics and Political Science. Voor dit bezoek ontving hij een beurs van de Nederlandse Organisatie voor Wetenschappelijk Onderzoek. In 1989 was hij Fellow van het Doctoral Consortium van de American Accounting Association. Sinds 1 februari 1991 werkt hij als universitair docent "Externe Berichtgeving" bij de sectie Berichtgeving en Accountancy van de Rijksuniversiteit Limburg. Voor de periode van een jaar is hij treasurer van de European Accounting Association ('91-'92). 